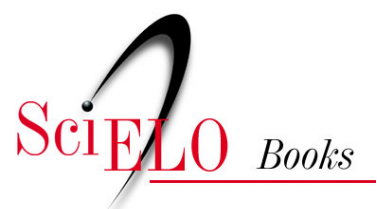

\title{
Design e ergonomia
}

aspectos tecnológicos

\section{Luis Carlos Paschoarelli}

Marizilda dos Santos Menezes

(orgs.)

PASCHOARELLI, LC., and MENEZES, MS., orgs. Design e ergonomia: aspectos tecnológicos [online]. São Paulo: Editora UNESP; São Paulo: Cultura Acadêmica, 2009. 279 p. ISBN 978-857983-001-3. Available from SciELO Books <http://books.scielo.org>.

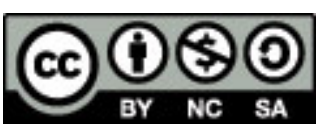

All the contents of this chapter, except where otherwise noted, is licensed under a Creative Commons Attribution-Non Commercial-ShareAlike 3.0 Unported.

Todo o conteúdo deste capítulo, exceto quando houver ressalva, é publicado sob a licença Creative Commons Atribuição Uso Não Comercial - Partilha nos Mesmos Termos 3.0 Não adaptada.

Todo el contenido de este capítulo, excepto donde se indique lo contrario, está bajo licencia de la licencia Creative Commons Reconocimento-NoComercial-CompartirIgual 3.0 Unported. 


\section{DESICN \\ E ERGONOMIA \\ ASPECTOS TECNOLÓGICOS}

LUIS CARLOS PASCHOARELLI

MARIZILDA DOS SANTOS MENEZES

(ORGS.) 


\section{Design E ERGONOMIA}





\section{LUIS CARLOS PASCHOARELLI MARIZILDA DOS SANTOS MENEZES (Orgs.)}

\section{DESIGN E ERGONOMIA Aspectos techológicos}


(C) 2009 Editora UNESP

\section{Cultura Acadêmica}

Praça da Sé, 108

01001-900 - São Paulo - SP

Tel.: (0xx11) 3242-7171

Fax: (0xx11) 3242-7172

www.editoraunesp.com.br

feu@editora.unesp.br

CIP - Brasil. Catalogação na fonte

Sindicato Nacional dos Editores de Livros, RJ

D487

Design e ergonomia : aspectos tecnológicos / Luis Carlos Paschoarelli, Marizilda dos Santos Menezes (org.). - São Paulo : Cultura Acadêmica, 2009.

il.

Inclui bibliografia

ISBN 978-85-7983-001-3

1. Ergonomia. 2. Desenho industrial. I. Paschoarelli, Luis Carlos. II. Menezes, Marizilda dos Santos.

09-6043.

CDD: 620.82

CDU: 60

Este livro é publicado pelo Programa de Publicações Digitais da Pró-Reitoria de Pós-Graduação da Universidade Estadual Paulista "Júlio de Mesquita Filho" (UNESP)

Editora afiliada:

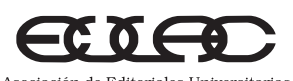

Asociación de Editoriales Universitarias de América Latina y el Caribe

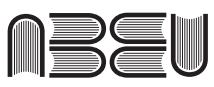

Associação Brasileira de Editoras Universitárias 


\section{SUMÁRIO}

Apresentação 7

1 Usabilidade e acessibilidade de equipamentos médicohospitalares: um estudo de caso com pacientes obesos 11 Cristina do Carmo Lucio e Luis Carlos Paschoarelli

2 Design ergonômico de cadeira de rodas para idosos 33 Ivan Ricardo Rodrigues Carriel e Luis Carlos Paschoarelli

3 Antropometria estática de indivíduos da terceira idade 55 Adelton Napoleão Franco e José Carlos Plácido da Silva

4 Avaliação de forças de preensão digital: parâmetros para o design ergonômico de produtos 73 Bruno Montanari Razza e Luis Carlos Paschoarelli

5 Estudo ergonômico ambiental de escolas das cidades de Bauru e Lençóis Paulista 97

Mariana Falcão Bormio e José Carlos Plácido da Silva

6 Condições ambientais em escolas municipais de ensino infantil da cidade de Marília (São Paulo): estudo de caso 119 Eiji Hayashi e João Roberto Gomes de Faria 
7 Revisão de metodologias de avaliação ergonômica aplicadas à carteira escolar: uma abordagem analítica e comparativa 147

Sileide Aparecida de Oliveira Paccola e José Carlos Plácido da Silva

8 Rótulos de embalagem de agrotóxico: uma abordagem ergonômica 169

Caroline Zanardo Gomes dos Santos e João Eduardo Guarnetti dos Santos

9 Rótulos e bulas de agrotóxicos: parâmetros de legibilidade tipográfica 197

Maria Gabriela Nunes Yamashita e João Eduardo Guarnetti dos Santos

10 Análise ergonômica do colete à prova de balas para atividades policiais 223 Iracilde Clara Vasconcelos e Luiz Gonzaga Campos Porto

11 Design ergonômico: análise do conforto e desconforto dos calçados com salto alto 241

Eunice Lopez Valente e Luis Carlos Paschoarelli

12 Insatisfação e desconforto: o caso da poltrona do motorista de ônibus urbano 269 Roberto Carlos Barduco e Abílio Garcia dos Santos Filho 


\section{ApresentaÇão}

A evolução tecnológica observada nas últimas décadas representa a materialização da criatividade humana no desenvolvimento de ambientes, produtos e sistemas, os quais trouxeram muitos benefícios, com destaque para o aumento na economia global, o aumento na expectativa de vida das pessoas, as possibilidades de comércio, interações e comunicações, entre outros.

Mas essa mesma evolução também vem resultando em alguns problemas, os quais preocupam tecnólogos, pesquisadores e entidades de proteção aos consumidores sob, pelo menos, dois aspectos bastante pragmáticos: o impacto negativo de muitas dessas tecnologias sobre o meio ambiente e os problemas das interfaces tecnológicas, as quais geram constrangimentos, acidentes e frustração aos consumidores e usuários.

Este segundo aspecto está em discussão desde o final do século passado, quando os termos ergonomia, usabilidade, acessibilidade e design universal tomaram conta das questões científicas em torno do design de produtos e sistemas. A discussão em torno desses temas, por vezes, parece antiquada para os dias atuais, mas de fato envolve questões ainda não respondidas pela comunidade científica. Ao design, ainda resta a questão: como a ergonomia pode contribuir para minimizar os impactos negativos da evolução tecnológica de produtos, sistemas e ambientes? 
Nesta coletânea, dividida em doze capítulos, são apresentadas diferentes questões, métodos de abordagem e expressivas demandas para a aplicação da ergonomia no design. O primeiro capítulo apresenta os problemas de usabilidade e acessibilidade enfrentados por indivíduos obesos quando eles necessitam de auxílio médico hospitalar, uma vez que mobiliários e equipamentos são oferecidos para o denominado "homem médio", o que exclui as pessoas com sobrepeso ou obesas.

Também sob as justificativas da acessibilidade, o segundo capítulo trata das particularidades da população de idosos (que está em crescimento no Brasil) e o reflexo destes no design de cadeira de rodas. Ainda considerando a população de idosos, o terceiro capítulo aborda um levantamento antropométrico de indivíduos da terceira idade que contribui expressivamente para a definição de parâmetros antropométricos destinados ao correto dimensionamento de produtos e ambientes.

O quarto capítulo aborda uma avaliação de forças de preensão digital, considerando as diferenças entre os gêneros (masculino e feminino) e reafirma, com parâmetros estatísticos, a influência dessas variáveis no design de instrumentos manuais que devem considerar a elevada capacidade física dos homens, e as limitações de força do público feminino.

Os três capítulos seguintes tratam de aspectos relacionados ao espaço e ao equipamento escolar, cuja demanda é elevada, especialmente no Brasil, onde a educação ainda não foi bem tratada. $\mathrm{O}$ quinto capítulo realiza uma comparação das condições ambientais entre escolas públicas e particulares em duas cidades paulistas. $\mathrm{O}$ sexto capítulo aborda um tema semelhante, as condições ambientais de escolas de ensino infantil de outra cidade do interior paulista, mas com outros processos metodológicos, e o sétimo capítulo discute as metodologias de avaliação ergonômica de equipamentos escolares.

Problemas informacionais em rótulos e bulas de embalagens também são objeto de estudo da ergonomia. Dois capítulos tratam desse assunto, abordando embalagens de agrotóxicos e legibilidade tipográfica das informações. 
Os três últimos capítulos destacam outros problemas com o uso de produtos: uma análise do colete de proteção para atividades policiais, uma avaliação perceptiva dos calçados com salto alto utilizados pelo público feminino e avaliação da poltrona do motorista de ônibus urbano.

É importante destacar que todos os capítulos relatam estudos e projetos de pesquisa desenvolvidos no Programa de Pós-graduação em Design da Unesp (Campus de Bauru), particularmente na linha de pesquisa Ergonomia. Estes estudos ressaltam a importância da aplicação da ergonomia no design de produtos e sistemas, com a finalidade de desenvolver tecnologias para a qualidade de vida humana. 



\title{
1 \\ USABILIDADE E ACESSIBILIDADE DE EQUIPAMENTOS MÉDICO-HOSPITALARES: UM ESTUDO DE CASO COM PACIENTES OBESOS
}

\author{
Cristina do Carmo Lucio ${ }^{1}$ \\ Luis Carlos Paschoarelli ${ }^{2}$
}

\section{Introdução}

A obesidade é uma doença que já pode ser considerada uma pandemia, pois atinge inúmeros países no mundo, com predominância em países desenvolvidos e em desenvolvimento. Com fatores desencadeantes tanto metabólicos quanto psicossociais, vem apresentando crescimento alarmante devido, principalmente, à adoção recente de hábitos ocidentais, como ingestão de alimentos constituídos de grande quantidade de açúcares e gorduras e o sedentarismo.

Estima-se que haja 1,7 bilhão de pessoas acima do peso em todo o mundo (Deitel, 2003) e a última pesquisa divulgada pela National Center for Health Statistics nos Estados Unidos mostra que $30 \%$ dos adultos norte-americanos acima de vinte anos são obesos (IOTF, 2006). Galvão (2006) relata, a partir de estudo do Centro de Controle e Prevenção de Doenças (CDC), que 71\% dos homens, $61 \%$ das mulheres e $33 \%$ das crianças estão acima do peso naquele país.

1 Mestre em design, Universidade Estadual de Maringá.

2 Pós-doutor em ergonomia, Universidade Estadual Paulista. 
Na Europa, o número de obesos está aumentando de modo preocupante; um em cada quatro homens é obeso e uma em cada três mulheres tem excesso de peso (Folha Online, 2006). No Brasil a situação não é diferente. Segundo o Instituto Brasileiro de Geografia e Estatística (IBGE, 2004), em 2002 havia 40,6\% de indivíduos com idade superior a vinte anos acima do peso e destes $11 \%$ eram obesos (cerca de 10,5 milhões de pessoas).

A obesidade pode facilitar o surgimento de graves problemas de saúde e psicológicos e, além desses problemas, frequentemente o indivíduo obeso enfrenta dificuldades na acessibilidade e usabilidade de produtos e equipamentos desenvolvidos para a considerada faixa média da população.

Menin et al. (2005), em seus estudos sobre antropometria de indivíduos obesos, comentam que os problemas de acessibilidade enfrentados por esses indivíduos têm levado empresários a investirem no aperfeiçoamento de serviços e produtos e na geração de novas tecnologias.

Apesar dessas iniciativas, Feeney (2002) alerta que as empresas não têm conhecimento sobre as características físicas e cognitivas desse público, como suas preferências, circunstâncias em que vivem e dados de seu estilo de vida, e desconhece os métodos para adquirir tais dados, o que impossibilita a produção de equipamentos adequados.

Nesse contexto, os equipamentos médico-hospitalares merecem atenção especial, pois têm a finalidade de reabilitar o paciente. Cardoso (2001) alerta que a difusão da ergonomia hospitalar é ainda pequena e muito restrita à atividade do profissional que trabalha em hospitais. A autora ainda expõe que ambientes e equipamentos inadequados podem gerar custos humanos, causando desconforto e até acidentes.

Desse modo, o presente capítulo pretende reunir informações sobre os problemas da obesidade e sua relação com a acessibilidade e usabilidade de produtos, procurando apresentar e discutir os problemas de interface entre usuários obesos e os produtos médico-hospitalares. 


\section{Revisão bibliográfica}

Ulijaszek (2007) enuncia que a obesidade emergiu como um importante fenômeno biológico humano construído pelas nações industrializadas durante os últimos sessenta anos e tem sido disseminada pelo mundo com a modernização e a industrialização. $\mathrm{O}$ autor completa que o rápido crescimento da doença indica que a tendência de tornar-se obeso é universal, justamente pela criação de ambientes "obesogênicos", ou seja, que favorecem o acúmulo de tecido adiposo por hábitos de vida pouco salutares.

Em seu estudo de revisão sobre uma possível relação entre obesidade e incapacidade, Ells et al. (2006) expõem que indivíduos com IMC acima de $40 \mathrm{~kg} / \mathrm{m}^{2}$ possuem elevados (e significativos) índices de dor na coluna, quando comparados com indivíduos com peso normal. Os autores acrescentam que os distúrbios mentais relacionados à obesidade são a segunda maior causa de incapacidade nesses indivíduos. Segundo estudo de Duval et al. (2006), os indivíduos obesos ainda aumentam seu risco de morte de 50 a $100 \%$, se comparado com o de indivíduos de peso normal.

Além dos graves problemas de saúde, os obesos sofrem preconceito, discriminação e muitos problemas relacionados à usabilidade de produtos, normalmente inadequados à sua condição física. Esses indivíduos, principalmente os obesos mórbidos, apresentam dificuldades na utilização de mobiliários, vestimentas, passagens e equipamentos médico-hospitalares, entre outros.

Segundo Pastore (2003), a obesidade é uma realidade sem previsão para ser resolvida e, por esse motivo, os obesos esperam a revisão dos padrões e normas atuais para confecção de produtos, de forma a tornarem-se adequados à sua condição de vida.

\section{A importância da multidisciplinaridade}

A correta aplicação dos conceitos multidisciplinares é de grande importância para a definição de parâmetros projetuais para a pro- 
dução de produtos e equipamentos voltados a públicos específicos, garantindo-lhes o bem-estar, devido à possibilidade de abranger diversos fatores, que seriam facilmente mascarados por apenas uma área do conhecimento.

Verifica-se por meio da integração entre acessibilidade, antropometria, design ergonômico, design universal, ergonomia e usabilidade, que é possível empregar soluções mais condizentes com as reais necessidades dos usuários, permitindo contemplar diversas potencialidades, que não seriam adequadamente atendidas pela ótica de uma única área do conhecimento. Martins et al. (2001) acrescentam que o papel dos profissionais é, antes de tudo, ouvir o usuário, visando tornar o ambiente construído acessível ao maior número de indivíduos possível.

No que se refere ao ambiente hospitalar, deve haver uma maior preocupação ao considerar a situação na qual os indivíduos se encontram quando internados. Nessa situação, muitas vezes atividades básicas são transformadas em tarefas de difícil execução, podendo gerar quadros de depressão, prejudicando a recuperação do paciente ou até mesmo agravando sua situação (Cardoso, 2001).

Segundo Paschoarelli et al. (2004), o principal problema de usabilidade e acessibilidade dos obesos está relacionado às questões dimensionais dos equipamentos e produtos disponíveis, normalmente produzidos para a faixa média da população, desconsiderando consequentemente grupos específicos.

Se considerarmos apenas o número de leitos para internação em estabelecimentos de saúde no Brasil em 2002 (IBGE, 2003), mais de 470 mil unidades, e a porcentagem da população obesa no Brasil, $11 \%$, quase 52 mil leitos deveriam ser direcionados a esse público, sem considerar, entretanto, que essa doença causa maiores prejuízos à saúde e, portanto, aumenta as chances de hospitalização e utilização dos serviços médicos e ambulatoriais.

Esses dados percentuais justificam propostas de projetos nesse campo, por entender-se a necessidade de adequação de uma série de produtos a uma parcela de mercado substancial, gerando sua confecção em escala industrial. 
É importante considerar que os produtos e equipamentos destinados aos obesos não devem apenas ter resistência ao peso e possuir dimensões maiores, mas devem ser também confortáveis e eficientes, permitindo alternância de posições do corpo, de forma a não exercer compressões prejudiciais da circulação sanguínea, além de oferecerem design seguro e compatível às necessidades dessas pessoas (Bucich \& Negrini, 2002).

Com relação à legislação e normas técnicas de acessibilidade no Brasil, há algumas leis e decretos vigorando em algumas cidades brasileiras, com o objetivo de melhorar a acessibilidade dos obesos. Muitas envolvem o aperfeiçoamento na prestação de serviço pelas empresas de transporte coletivo urbano ou reserva de assentos em espaços culturais e salas de projeção, ou ainda adaptação de camas de uso hospitalar a esse público específico, e outras obrigam todos os hospitais a possuírem macas dimensionadas para esses indivíduos.

Mas, apesar da existência dessas leis e decretos, não há na Associação Brasileira de Normas Técnicas (ABNT) uma norma específica com parâmetros de diferenciação quanto à forma, dimensões e requisitos de resistência para confecção de produtos e equipamentos destinados aos obesos; ou seja, há leis tangentes aos produtos e equipamentos destinados a esses indivíduos, mas não há base técnica específica de referência que valide sua usabilidade.

Consta na NBR 9050 de 2004 (Acessibilidade a edificações, mobiliário, espaços e equipamentos urbanos) que espaços em locais de reunião pública (cinemas, teatros) e locais de esporte, lazer e turismo devem ter assentos destinados a P.O., com especificação de onde devem estar instalados e referências quanto à largura, resistência e espaço livre frontal (item 8.2.1.3.3 - largura equivalente à de dois assentos, espaço livre frontal de no mínimo 0,60 m e devem suportar carga de no mínimo $250 \mathrm{~kg}$ ).

Entretanto, as especificações quanto ao tamanho e resistência são adequadas a pessoas com obesidade nível III (mórbida), acima de IMC 40, enquanto que a grande quantidade de obesos se enquadra entre os níveis I e II, com IMC até 40, ou seja, até cerca de $130 \mathrm{~kg}$ (para pessoas com 1,80 m). 
O que se pretende apontar é que poderiam ser disponibilizados esses assentos dispostos na norma em quantidades menores e os demais assentos com dimensionamento menor e menos resistentes do que especificado em norma, dispensando grandes espaços e gastos desnecessários com materiais, possibilitando fornecer, dessa forma, mais assentos, mais conforto e, consequentemente, maior acessibilidade. Essas providências reduziriam, também, o constrangimento de pessoas com obesidade graus I e II de terem que ser deslocadas a um assento duplo por questão de poucos centímetros, segregando-as.

Para que todos tenham direitos iguais (de fato), é necessário que todos tenham também oportunidades iguais de realização das mais diversas atividades cotidianas, independentemente de sua situação físico-motora.

Fica evidente a necessidade de uma análise tão ou mais criteriosa para os equipamentos médico-hospitalares. Esses produtos devem proporcionar o máximo de conforto e segurança aos seus usuários, por serem utilizados em situações de muito incômodo, dor e estresse, não devendo causar ainda mais transtornos do que o problema de saúde do indivíduo.

Cabe ao designer a valorização da capacidade funcional do usuário, identificando os problemas de interface e adequando os produtos às necessidades humanas, por meio de metodologias ajustáveis ao público específico (Baptista \& Martins, 2004).

Para Girardi (2006), outra questão muito importante que deve ser considerada no projeto refere-se ao aspecto estético, que na área médica envolve a humanização do ambiente, o respeito ao paciente e a racionalização do trabalho do profissional de saúde.

A função do designer nesse aspecto é justamente vencer o desafio de propor soluções inclusivas, visando extinguir a segregação causada por barreiras físicas e sociais. A integração social nas ações cotidianas possibilita ao portador de necessidades especiais uma rotina que pode ser considerada saudável no que se refere aos aspectos relacionados à autoestima e valorização do indivíduo (Emmel et al., 2002).

Lebovich (1993) relata que desde a antiguidade as pessoas têm tentado remediar deficiências ou habilidades reduzidas, e descreve 
de forma clara que as principais ferramentas para inclusão social são a flexibilidade, a criatividade e a imaginação. Completa que o bom design em termos de acessibilidade inicia com o acesso igualitário; não basta adicionar uma entrada acessível nos fundos de um ambiente, enquanto a entrada da frente permanece inacessível. Esse acesso igualitário, segundo o autor, deve contemplar todas as pessoas com a mesma informação e experiência.

Vem se tornando senso comum compatibilizar o design para indivíduos com necessidades especiais às demais pessoas, e segundo os propósitos do design universal, colocar-se no lugar do outro facilitaria a compreensão de suas necessidades e anseios. É de fundamental importância projetar objetos seguros, inteligíveis e agradáveis por meio de um design consciente em termos sociais, econômicos e ambientais, visando reduzir o preconceito a que esses indivíduos são submetidos por sua condição física.

\section{Conceitos de design universal e a usabilidade na avaliação de projetos}

Story et al. (1998) relatam que encontrar soluções universais é fácil na teoria, mas muito complicado na prática. O Centro de Design Universal da Universidade Estadual da Carolina do Norte (Estados Unidos) reuniu um grupo de arquitetos, designers de produto, engenheiros e pesquisadores de design ambiental com o objetivo de desenvolver princípios de design universal que englobem o conhecimento atual. Esses princípios visam avaliar projetos existentes, guiar processos de produção e educar designers e consumidores sobre características de produtos e ambientes com melhor usabilidade. Foram desenvolvidos sete princípios para determinar usabilidade e acessibilidade de produtos, ambientes e sistemas:

- Uso equitativo: o projeto deveatender apessoas com diferentes habilidades.

- Flexibilidade no uso: o projeto atendea uma gama deindivíduos com diferentes preferências e habilidades. 
- Uso simples eintuitivo: uso fácil einteligível, independentemente de experiência, conhecimento, forma de comunicação ou nível de entendimento dos usuários.

- Informação perceptível: o projeto devetransmitir informações de forma efetiva ao usuário, independentemente das condições ambientais ou das habilidades sensoriais dos usuários.

- Tolerância ao erro: o projeto deveminimizar erros eas conse quências adversas de ações acidentais.

- Baixo esforço físico: o projeto deveser utilizado comeficiência, conforto e fadiga mínima.

- Tamanho eespaço adequados para acesso euso: o projeto deve apresentar tamanho e espaços adequados para acesso, uso e manipulação de objetos, independentemente da antropometria, postura ou mobilidade do indivíduo.

Outros autores também apresentam princípios de design universal e usabilidade para serem aplicados na avaliação de produtos, equipamentos e sistemas. Para Jordan (1998), os princípios para melhorar a usabilidade dos produtos são:

- Consistência: operações semel hantes devem ser real izadas de forma semelhante.

- Compatibilidade há compatibilidadequando são atendidas as expectativas do usuário baseadas em suas experiências anteriores.

- Capacidade devemser respeitadas as capacidades individuais do usuário para cada função.

- Feedback: os produtos devem dar um feedback aos usuários quanto aos resultados de sua ação.

- Prevenção ecorreção deerros: os produtos devem impedir procedimentos errados e, caso ocorram, devem permitir correção fácil e rápida.

- Controle ampliar o controle queo usuário tem sobreas ações desempenhadas por determinado produto.

- Evidência: o produto deve indicar claramente sua função e modo de operação.

- Funcional idade e informação: o produto deveser acessível e de uso fácil. 
- Transferênciadetecnologia: deveser feito o uso apropriado de tecnologias desenvolvidas em outros contextos para realçar a usabilidade do produto.

- Clareza: funcional idade e método de operação devem ser explícitos.

Já Norman (1998) define quatro princípios de design para a inteligibilidade e usabilidade de produtos:

- Prover um bom modelo conceitual: sem um bom modelo, opera-se às cegas.

- Visibilidade éimportantemanter informaçõesvisíveisao maior número de indivíduos possível, incluindo deficientes visuais, sem que se precise recorrer a outras fontes para conhecer determinada informação.

- M apeamento: os produtos devem utilizar model os mentais conhecidos, sejam naturais ou culturais, facilitando a compreensão e uso.

- Feedback: é o retorno ao usuário sobre alguma ação que tenha sido executada.

\section{Objetivos}

Este capítulo teve como objetivo analisar a interface entre alguns tipos de equipamentos médico-hospitalares e os indivíduos obesos, verificando a ocorrência de problemas e restrições nessa interface e discutindo tais problemas observados entre usuários obesos e esses produtos.

\section{Materiais e métodos}

A pesquisa de campo foi desenvolvida pela observação do ambiente de estudo e da abordagem com pacientes obesos, conforme descrito a seguir. 


\section{Aspectos éticos}

O estudo em questão contemplou os procedimentos descritos pelo Conselho Nacional de Saúde, sob resolução 196-1996 (Brasil, 1996) e pela norma ERG-BR 1002 do Código de Deontologia do Ergonomista Certificado (Abergo, 2002), atendendo às exigências éticas e científicas fundamentais. Para tanto, ele foi analisado e aprovado pelo Comitê de Ética em Pesquisa da Faculdade de Medicina de Botucatu (OF.356/2006-CEP). Foi aplicado um Termo de Consentimento Livre e Esclarecido (TCLE), no qual o sujeito tomou ciência da espécie de pesquisa para a qual foi voluntário (não-remunerado).

\section{Casuística}

Foram abordados 51 pacientes obesos, dos quais vinte em clínicas e 31 internados em um hospital da cidade de Bauru (SP). Com relação ao gênero, foram 27 homens e 24 mulheres, entre 18 e 60 anos, com média de idade de 44 anos (d.p.11,1 anos) e IMC de 40,1 kg/m² (d.p. $9,8 \mathrm{~kg} / \mathrm{m}^{2}$ ).

\section{Procedimentos metodológicos: observação do ambiente de estudo}

Iniciou-se a pesquisa de campo por observação assistemática do Hospital de Base de Bauru, visando compreender o ambiente hospitalar para posterior realização da observação sistemática direta, cujos resultados possibilitaram a coleta de dados dos equipamentos médico-hospitalares e entrevistas com os indivíduos obesos e profissionais envolvidos no trato dos pacientes.

Para a observação assistemática, foram anotadas a quantidade e as condições de uso e manutenção dos equipamentos médicohospitalares disponíveis e a rotina hospitalar referente a banhos, alimentação dos pacientes, visita de médicos, medicação, horário 
regular para realização de cirurgias, higienização das dependências do hospital e horário de visitas.

Após essa observação, foi possível desenvolver um mapa simplificado do Hospital de Base de Bauru (figura 1), dividido por setores, visando codificar os dados e facilitar as medições de equipamentos.
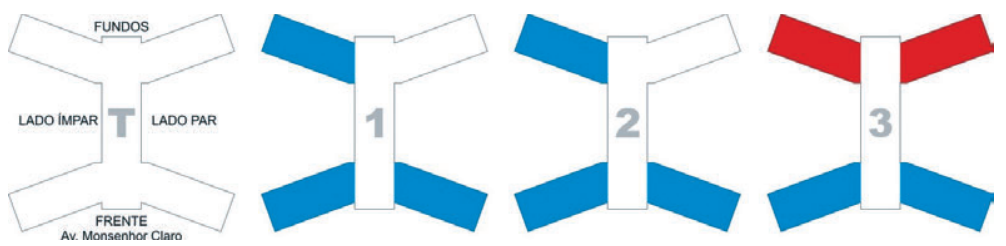

Figura 1. Mapa simplificado do Hospital de Base de Bauru - três andares e o térreo. As áreas azuis correspondem aos setores de internação e as áreas em vermelho correspondem ao centro cirúrgico. As demais áreas referem-se a setores de análises clínicas, exames gerais, UTI, farmácia, setores administrativos e outros.

Para a observação sistemática relatada neste capítulo, foram anotadas as condições de uso e manutenção dos equipamentos médicohospitalares definidas por meio da adaptação de princípios de acessibilidade, usabilidade e design universal de Jordan (1998), Norman (1998) e Story et al. (1998), já apresentados no referencial teórico. A partir do estudo de todos esses autores, foram adaptados os princípios que melhor se aplicavam à pesquisa e inseridos nos protocolos:

- Flexibilidade: deveatender ao maior número deindivíduos e com diferentes habilidades.

- Evidência: inteligibilidadedatarefa; uso simpleseintuitivo.

- Visi bilidade: informações devem estar visíveis ao usuário, incluindo deficientes sensoriais.

- Capacidade: equi pamento deveprever capacidadesindividuais diversas.

- Compatibilidade: com aspectos fisiológicos, culturais e de experiências anteriores; similaridade. 
- Tolerância: prevenção deacidentesecorreção deerros, por meio de pouca sensibilidade.

- Esforço: equi pamentos devem reduzir o gasto energético.

- Espaço: deveser apropriado ao maior número de indivíduos, incluindo obesos.

- Feedback: retorno ao usuário de que a operação está sendo realizada da forma correta ou incorreta.

Optou-se por realizar a observação sistemática juntamente com a abordagem aos usuários diretos (pacientes obesos internados) no Hospital de Base de Bauru, visando obter dados dos equipamentos e poder confrontar esses dados com as respostas dos indivíduos. Os equipamentos eram previamente observados sistematicamente e, após o término da análise, realizava-se então a entrevista com o paciente.

\section{Procedimentos metodológicos: abordagem com pacientes}

A abordagem iniciava-se pela apresentação do entrevistador e da pesquisa e, após a aceitação do sujeito, era realizada a análise sistemática dos equipamentos constantes no protocolo. Após a finalização dessa análise, o sujeito assinava o TCLE e seus dados pessoais eram anotados no protocolo de recrutamento. Ele era, então, interpelado sobre sua percepção de conforto no uso dos equipamentos médicohospitalares constantes no protocolo.

\section{Análise dos dados}

Para a análise dos dados, estes foram tabulados e submetidos à estatística descritiva e analítica por meio do teste estatístico de MannWhitney, visando comparar os grupos de dados e descobrir se havia diferenças estatisticamente significativas entre os mesmos $(p \leq 0,05)$. 


\section{Resultados e discussão}

\section{Resultados da observação sistemática}

A tabela 1 apresenta a avaliação sistemática dos equipamentos médico-hospitalares. Visando facilitar a compreensão, os princípios de usabilidade e design universal foram codificados e dispostos na tabela da seguinte maneira: flexibilidade (A), evidência (B), visibilidade (C), capacidade (D), compatibilidade (E), tolerância $(F)$, esforço $(G)$, espaço (H), feedback (I). As notas são distribuídas como ótimo (5), bom (4), regular (3), ruim (2) e péssimo (1).

Os resultados demonstram algumas inadequações dos equipamentos analisados. A figura 2 apresenta a média das notas atribuídas aos equipamentos médico-hospitalares de acordo com todos os princípios de acessibilidade, usabilidade e design universal.

Tabela 1. Resultados da observação sistemática dos equipamentos.

\begin{tabular}{|c|c|c|c|c|c|c|c|c|c|c|}
\hline \multicolumn{11}{|c|}{ Sistema de descanso e alimentação } \\
\hline Equipamento & & A & B & $\mathrm{C}$ & $\mathrm{D}$ & $\mathrm{E}$ & $\mathrm{F}$ & $\mathrm{G}$ & $\mathrm{H}$ & $\mathrm{I}$ \\
\hline \multirow{2}{*}{ Cama } & Média & 3,4 & 4,1 & 4,1 & 3,3 & 3,9 & 3,8 & 3,3 & 2,2 & 3,9 \\
\hline & D.P. & 0,6 & 0,7 & 0,6 & 0,5 & 0,6 & 0,5 & 0,6 & 0,7 & 0,5 \\
\hline \multirow{2}{*}{ Colchão } & Média & 3,2 & 4,5 & 4,4 & 3,3 & 4,3 & 3,5 & 2,7 & 1,9 & 4,0 \\
\hline & D.P. & 0,7 & 0,5 & 0,5 & 0,5 & 0,8 & 0,7 & 0,6 & 0,7 & 0,3 \\
\hline \multirow{2}{*}{ Escada } & Média & 2,8 & 4,3 & 3,8 & 2,6 & 4,1 & 1,8 & 2,7 & 2,2 & 3,8 \\
\hline & D.P. & 0,8 & 0,5 & 0,6 & 0,6 & 0,7 & 0,9 & 0,7 & 0,6 & 0,6 \\
\hline \multirow{2}{*}{$\begin{array}{l}\text { Suporte para } \\
\text { soro }\end{array}$} & Média & 3,2 & 3,9 & 3,1 & 2,8 & 3,4 & 3,4 & 2,6 & 3,0 & 3,9 \\
\hline & D.P. & 0,7 & 0,6 & 0,6 & 0,6 & 0,7 & 0,7 & 0,9 & 0,9 & 0,4 \\
\hline \multirow{2}{*}{$\begin{array}{l}\text { Suporte } \\
\text { alimentar }\end{array}$} & Média & 2,7 & 4,0 & 3,3 & 2,8 & 3,9 & 2,3 & 2,7 & 2,2 & 4,0 \\
\hline & D.P. & 0,5 & 0,5 & 0,5 & 0,4 & 0,6 & 0,5 & 0,9 & 0,7 & 0,0 \\
\hline \multirow{2}{*}{ Campainha } & Média & 3,6 & 4,1 & 3,5 & 3,2 & 4,0 & 3,1 & 3,3 & 3,3 & 3,9 \\
\hline & D.P. & 1,2 & 0,4 & 0,8 & 0,9 & 0,6 & 0,9 & 1,1 & 1,1 & 0,8 \\
\hline \multicolumn{11}{|c|}{ Sistema de banho } \\
\hline Equipamento & & A & $\mathrm{B}$ & $\mathrm{C}$ & $\mathrm{D}$ & $\mathrm{E}$ & $\mathrm{F}$ & $\mathrm{G}$ & $\mathrm{H}$ & $\mathrm{I}$ \\
\hline \multirow{2}{*}{$\begin{array}{l}\text { Cadeira de } \\
\text { banho }\end{array}$} & Média & 2,8 & 4,0 & 3,8 & 2,8 & 3,5 & 2,8 & 2,5 & 1,0 & 3,5 \\
\hline & D.P. & 0,5 & 0,8 & 0,5 & 0,5 & 0,6 & 0,5 & 1,0 & 0,0 & 0,6 \\
\hline
\end{tabular}


Tabela 1. Continuação.

\begin{tabular}{l|c|c|c|c|c|c|c|c|c|c}
\hline \multicolumn{10}{c}{ Sistema de locomoção } \\
\hline Equipamento & & $\mathrm{A}$ & $\mathrm{B}$ & $\mathrm{C}$ & $\mathrm{D}$ & $\mathrm{E}$ & $\mathrm{F}$ & $\mathrm{G}$ & $\mathrm{H}$ & $\mathrm{I}$ \\
\hline $\begin{array}{l}\text { Maca de } \\
\text { transporte }\end{array}$ & Média & $\mathbf{3 , 5}$ & $\mathbf{3 , 5}$ & $\mathbf{4 , 0}$ & $\mathbf{3 , 0}$ & $\mathbf{3 , 5}$ & $\mathbf{2 , 5}$ & $\mathbf{3 , 0}$ & $\mathbf{2 , 0}$ & $\mathbf{4 , 0}$ \\
\cline { 2 - 12 } & D.P. & 0,7 & 0,7 & 0,0 & 0,0 & 0,7 & 0,7 & 1,4 & 1,4 & 0,0 \\
\hline $\begin{array}{l}\text { Cadeira de } \\
\text { rodas }\end{array}$ & Média & $\mathbf{2 , 0}$ & $\mathbf{2 , 5}$ & $\mathbf{2 , 5}$ & $\mathbf{1 , 5}$ & $\mathbf{3 , 0}$ & $\mathbf{2 , 0}$ & $\mathbf{1 , 5}$ & $\mathbf{1 , 0}$ & $\mathbf{3 , 5}$ \\
\cline { 2 - 10 } & D.P. & 0,0 & 0,7 & 0,7 & 0,7 & 0,0 & 1,4 & 0,7 & 0,0 & 0,7 \\
\hline Andador & $\begin{array}{l}\text { Ohospital não possui andadores ou muletas; os pacientes os levam } \\
\text { Muletas }\end{array}$ \\
\hline
\end{tabular}

\section{CLASSIFICAÇÃO PELOS CRITÉRIOS DE USABILIDADE E DESIGN UNIVERSAL}

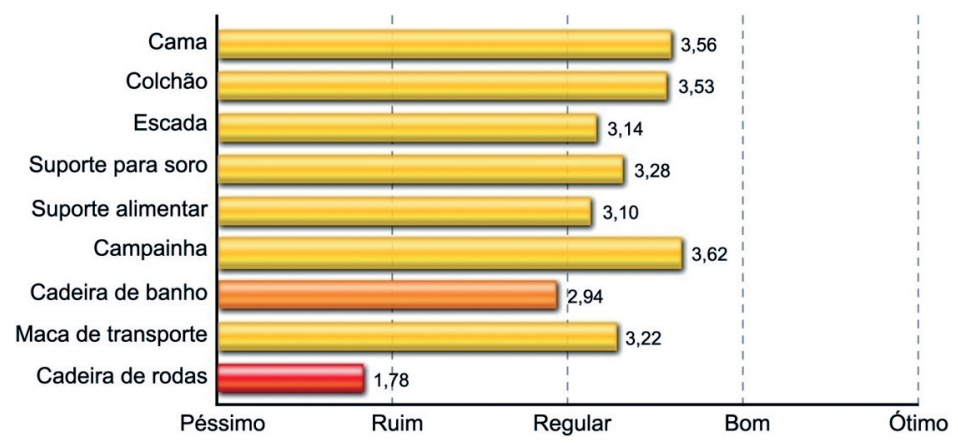

Figura 2. Classificação dos equipamentos pela média dos conceitos de usabilidade e design universal.

De todos os equipamentos, os que se mostram em situação mais preocupante são as cadeiras de rodas e as cadeiras de banho, pois possuem notas de regular a péssimo em grande parte dos princípios de usabilidade e design universal. De forma geral, pode-se dizer que esses dois equipamentos:

- Não atendem satiffatoriamentea grande partedos usuários;

- não são inteligíveiseas informações não semostram visíveisa indivíduos com diferentes habilidades;

- não aproveitam capacidades individuais; 
- possibilitama ocorrência deacidentes devido ao seu estado de conservação;

- não possuem espaço adequado para indivíduos acima do considerado "padrão", com nota péssima nesse quesito.

Apresentando problemas isolados com nota de ruim a péssimo encontram-se a escada, com grande risco de acidentes devido à falta de borrachas nos degraus e pés, e o colchão e a maca de transporte, com espaço inadequado a indivíduos de tamanho acima do considerado "padrão” (figura 3).
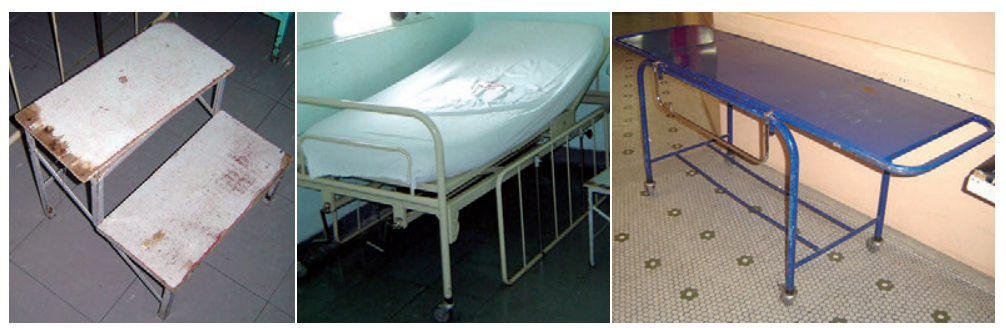

Figura 3. Escada, à esquerda. Colchão, ao centro. Maca de transporte, à direita.

A partir dessa primeira análise, fica evidente que o design, associado aos conhecimentos da pesquisa em ergonomia, tem papel importante na identificação desses problemas e apresentação de recomendações de melhoria ou do próprio desenvolvimento de projetos mais adequados aos seus usuários.

\section{Resultados da abordagem com os pacientes obesos}

No protocolo dos usuários diretos, havia apenas questões para atribuir nota (de ótimo a péssimo). Desse modo, será apresentada na figura 4 a classificação dos equipamentos sob a percepção dos pacientes obesos entrevistados. 


\section{CLASSIFICAÇÃO DOS EQUIPAMENTOS}

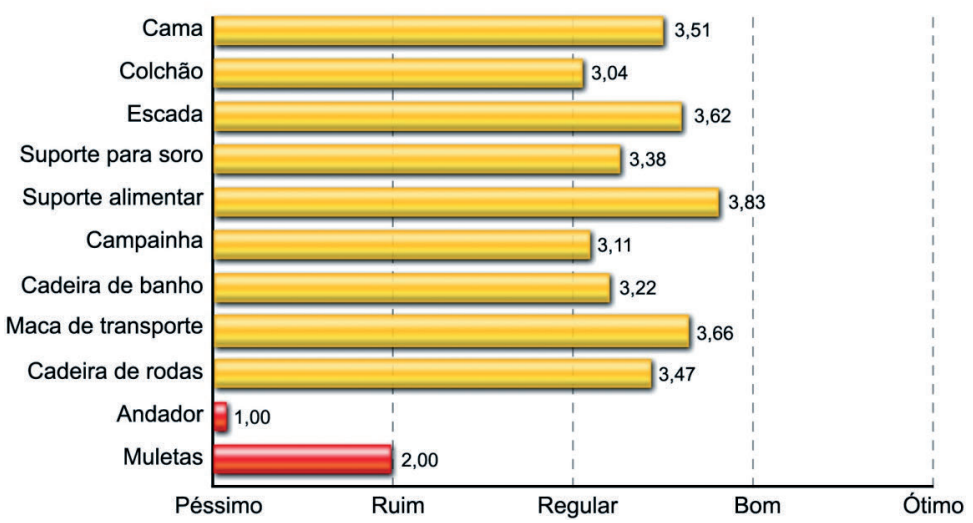

Figura 4. Classificação dos equipamentos por notas de ótimo (5) a péssimo (1).

De forma a comparar dados de públicos distintos, optou-se por dividir a amostra em duas partes: pacientes obesos internados no Hospital de Base de Bauru (31 sujeitos) e pacientes aguardando consulta em duas clínicas de problemas da obesidade (vinte sujeitos).

É importante salientar que a maioria dos pacientes abordados nas clínicas respondeu ter sido internada em hospitais particulares, ao passo que o Hospital de Base de Bauru é mantido pelo SUS, portanto, com características de hospital público. A figura 5 apresenta os conceitos atribuídos aos equipamentos pelos pacientes do hospital e das clínicas.

Observando a figura 5, verifica-se que não há grande variação nas respostas; apenas o item cadeira de banho apresentou diferença mais expressiva, entretanto não significativa $(\mathrm{p}=0,2228)$. A teoria estatística explica que tal diferença se deve, entre outros fatores, à quantidade reduzida de respostas obtidas nessa variável.

O suporte para soro apresentou diferença estatisticamente significativa ( $\mathrm{p}=0,0321)$. Os pacientes internados em hospitais particulares atribuíram notas inferiores a esse equipamento, ainda que se saiba que geralmente há suportes para soro com rodas e de material mais leve e fácil de transportar. Desse modo, não foram encontrados motivos concretos para justificar tal diferença nas respostas. 


\section{COMPARAÇÃO ENTRE PACIENTES OBESOS}

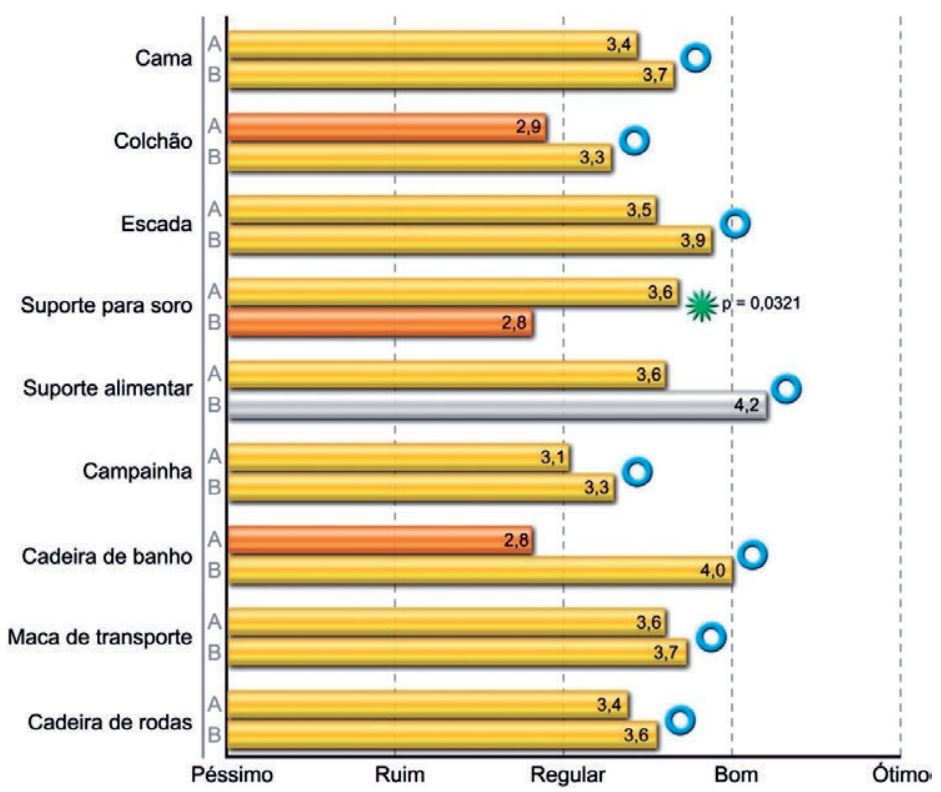

Figura 5. Comparação entre as respostas dos pacientes internados no Hospital de Base de Bauru (A) e entrevistados em clínicas (B), onde 米 indica que houve diferenças estatisticamente significativas $(\mathrm{p} \leq 0,05) \mathrm{e}$ indica que não houve diferenças significativas ( $\mathrm{p}>0,05)$, segundo teste de Mann-Whitney.

De modo geral, observa-se que houve pequena diferença nas opiniões, demonstrando consistência nos resultados.

\section{Análise sistemática $x$ abordagem com os pacientes obesos}

Comparando os dados obtidos nas abordagens (figura 5) com os dados obtidos na análise sistemática (figura 3), observa-se uma consistência nos resultados que evidencia que as condições de instalação e acomodação de obesos em diferentes hospitais necessitam de uma intervenção urgente do design, oferecendo melhores condições de acesso e uso por esses pacientes. 


\section{Considerações finais}

Este capítulo encontrou algumas dificuldades em sua formulação e desenvolvimento. A primeira dificuldade encontrada esteve relacionada ao pequeno e limitado número de referências antropométricas da população de obesos, além da falta de normas ou parâmetros técnicos brasileiros que regulamentem o dimensionamento de equipamentos médico-hospitalares. Esse fator acaba evidenciando a ausência de critérios para a produção desses produtos e a total despreocupação com sua adequação ergonômica.

Do ponto de vista metodológico, houve algumas limitações quanto aos resultados das abordagens junto ao público direto, pois as abordagens tratam de opiniões subjetivas, que podem ser influenciadas por fatores sobre os quais não há possibilidade de um controle rigoroso. A partir dos procedimentos metodológicos adotados e dos resultados apresentados e discutidos aqui, podemos considerar que a análise sistemática dos critérios de usabilidade, design universal e design ergonômico, associada às abordagens com usuários, possibilita identificar de forma mais objetiva os problemas mais críticos enfrentados por pacientes obesos.

Quanto aos métodos de abordagem, pode-se considerar que seria importante realizar uma ampla revisão metodológica de meios de abordagem por entrevista e questionários mais eficientes que possam não eliminar, mas conduzir a subjetividade de modo a apontar com maior clareza as opiniões e reclamações dos sujeitos, visando aproveitar com mais segurança a resposta dos entrevistados.

Apesar de os resultados obtidos com o estudo serem considerados preliminares, configuram-se como importantes parâmetros para o projeto de equipamentos mais seguros, eficientes e confortáveis para esses indivíduos, ressaltando que atualmente não há quaisquer padrões referentes a essa temática.

Pela observação e reflexão sobre esses problemas, e empregando-se os conhecimentos de design e ergonomia, é possível apresentar alguns parâmetros projetuais. É importante que o espaço ocupado por um obeso permita ou facilite o desenvolvimento de 
suas habilidades e capacidades individuais, não acentuando suas limitações.

Também são de fundamental importância vencer o preconceito e a segregação atuais e começar a desenvolver produtos com um design que inclua esses indivíduos, considerando que ninguém está livre de desenvolver esse problema ou ter um membro de sua família acometido pelo mesmo, e que ninguém se encontra nessa condição porque quer ou porque não se importa.

O desenvolvimento de produtos plenamente acessíveis a obesos também não deve ser encarado como um estímulo à doença, mas uma garantia de melhor qualidade de vida e conforto psíquico para que esse cidadão desenvolva plenamente suas atividades pessoais e de reabilitação.

De modo geral, o estudo apresentado neste capítulo contribui para destacar a importância da multidisciplinaridade no projeto e também a importância de se pensar nos percentis extremos da população que, embora isoladamente não sejam a maioria, se considerados em grupo tornam-se uma fatia considerável na economia e devem ser pensados em qualquer projeto que seja desenvolvido, pois são usuários e têm direitos e deveres como todo e qualquer cidadão, merecendo, portanto, dignidade no uso de bens e serviços e qualidade de vida.

\section{Referências bibliográficas}

ABERGO. Código de Deontologia do Ergonomista Certificado. Norma ERG BR 1002, 2002. Disponível em: <http://www.abergo.org.br>. Acesso em: 20 dez. 2004.

BAPTISTA, A. H. N., MARTINS, L. B. Ergonomia e a classificação internacional de funcionalidade, incapacidade e saúde. In: Congresso Brasileiro de Ergonomia, 13, 2004, Fortaleza. Anais do XIII Congresso Brasileiro de Ergonomia. Fortaleza, 2004. 1 CD-ROM.

BUCICH, C., NEGRINI, V. Cadeiras operacionais adequadas a pessoas obesas. In: Congresso Brasileiro de Ergonomia, 12, 2002, Recife. Anais do XII Congresso Brasileiro de Ergonomia. Recife, 2002. 1 CD-ROM. 
CARDOSO, V. M. B. Intervenção ergonômica. In: MORAES, A., FRISONI, B. C. (Org.) Ergodesign: produtos e processos. Rio de Janeiro: 2AB Editora, 2001. p.51-84.

DEITEL, M. Overweight and obesity worldwide now estimated to involve 1.7 billion people. Obesity Surgery, 13: 329-330, 2003.

DUVAL, K. et al. An overview of obesity-specific quality of life questionnaires. Obesity reviews, 7: 347-60, 2006.

ELLS, L. J. et al. Obesity and disability: a short review. Obesity reviews, 7:341-345. 2006.

EMMEL, M. L. G. et al. Identificação das áreas e postos de trabalho com potencial para receber pessoas portadoras de necessidades especiais. In: Congresso Brasileiro de Ergonomia, 12., 2002, Recife. Anais do XII Congresso Brasileiro de Ergonomia. Recife, 2002. 1 CD-ROM.

FEENEY, R. The ergonomics approach to inclusive design - are the needs of disabled and no disabled people different? In: Congresso Brasileiro de Ergonomia, 12, 2002, Recife. Anais do XII Congresso Brasileiro de Ergonomia (Conferência Internacional). Recife, 2002. 1 CD-ROM.

FOLHA ONLINE. Obesidade aumenta em "velocidade alarmante" na Europa, alerta estudo da France Presse, em Bruxelas, 2006. Disponível em: <http://www1.folha.uol.com.br/folha/ciencia/ult306u15173. shtml>. Acesso em: 13 set. 2006.

GALVÃO, V. Q. Mercado para obeso gira um Chile nos Estados Unidos. Folha de São Paulo Nova York. Folha Online, 2006. Disponível em: <http://www1.folha.uol.com.br/folha/dinheiro/ult91u110886. shtml>. Acesso em: 14 set. 2006.

GIRARDI, L. Design de produtos na área médica. In: Associação dos Designers de Produto. Disponível em: <http://www.adp.org.br $>$. Acesso em: 23 jun. 2006.

INSTITUTO BRASILEIRO DE GEOGRAFIA E ESTATÍSTICA (IBGE). Pesquisa de Assistência Médico-Sanitária 1976/200, 2003. Disponível em: <http://www.ibge.gov.br>. Acesso em: 1 mar. 2006.

. Pesquisa de Orçamentos Familiares, 2004. Disponível em: <http:// www.ibge.gov.br>. Acesso em: 22 mar. 2005.

INTERNATIONAL OBESITYTASK FORCE (IOTF). Departament of Health and Human Services. Centers for Disease Control and Prevention. Overweight and Obesity: Home. Disponível em: <http://www. iotf.org/popout.asp?linkto=http://www.cdc.gov/nccdphp/dnpa/ obesity/>. Acesso em: 13 set. 2006. 
JORDAN, P. An introduction to usability. Londres: Taylor \& Francis, 1998, $120 \mathrm{p}$.

LEBOVICH, W. L. Design for dignity. Nova Iorque: John Wiley \& Sons, 1993.

MARTINS, L. B. et al. Sistema de Informação e Design Universal - Garantia de Acessibilidade. In: Seminário Acessibilidade, Tecnologia da Informação e Inclusão Digital, 1., 2001, São Paulo. Anais eletrônicos do I Seminário Acessibilidade, Tecnologia da Informação e Inclusão Digital. São Paulo: USP, 2001. Disponível em: < http://www.fsp.usp.br/acessibilidade $>$. Acesso em: 21 jun. 2006.

MENIN, M. et al. Antropometria de obesos: uma análise das variáveis dimensionais entre os diferentes biótipos para definição de parâmetros ergonômicos. In: Congresso Internacional de Ergonomia e Usabilidade de Interfaces Humano-Tecnologia, 5., 2005, Rio de Janeiro. Anais do $5^{\circ}$ Congresso Internacional de Ergonomia e Usabilidade de Interfaces Humano-Tecnologia. Rio de Janeiro, 2005. 1 CD-ROM.

NORMAN, D. A. The design of everyday things. Londres: The MIT Press, 1998. 257p.

PASCHOARELLI, L. C. et al. Análise Dimensional de pessoas com diferentes biótipos: definindo parâmetros para a antropometria de obesos. In: Congresso Brasileiro de Ergonomia, 13, 2004, Fortaleza. Anais do XIII Congresso Brasileiro de Ergonomia. Fortaleza, 2004. 1 CD-ROM.

PASTORE, K. Guindaste para os gordões. Veja. São Paulo: Abril; ano 36, n. 5: p. 86-7, fev. 2003

STORY, M. F., MUELLER, J. L., MACE, R. L. The universal design file: Designing for people of all ages and abilities. Edição revisada. Washington: North Carolina State University - Center for Universal Design, 1998. 170p.

ULIJASZEK, S. J. Obesity: a disorder of convenience. Obesity reviews, 8 (1): 183-7, 2007. 



\title{
2 \\ DESIGN ERGONÔMICO DE CADEIRA DE RODAS PARA IDOSOS
}

\author{
Ivan Ricardo Rodrigues Carriel ${ }^{1}$ \\ Luis Carlos Paschoarelli ${ }^{2}$
}

\section{Introdução}

No último censo realizado pelo IBGE (2002), 8,6\% da população brasileira eram pessoas acima de sessenta anos, e este índice cresce a cada ano a um nível sem precedentes. Segundo relatório da ONU (2007), uma previsão para 2050 é que um quarto da população mundial será de idosos, ou seja, teremos cerca de 2 bilhões de pessoas com idade acima de sessenta anos.

Diante deste quadro demográfico crítico, pesquisas vêm questionando quais seriam os requisitos de qualidade que o idoso almeja para viver melhor o período senil. Resgatando os resultados apresentados por Villas Boas (2005), o idoso deseja ter alegria, família, condições de vida, saúde, bem-estar e independência.

Considerando os três últimos itens e a parcela de idosos que necessitam de tecnologias assistivas para locomoção, especialmente as cadeiras de rodas, definiu-se a questão da pesquisa e o problema a

1 Mestre em design, Universidade Federal de São Carlos.

2 Pós-doutor em ergonomia, Universidade Estadual Paulista. 
ser solucionado perguntando-se se as cadeiras de rodas atualmente comercializadas atendem às necessidades psicofisiológicas dos idosos.

\section{As bases científicas: ergonomia e design}

De caráter interdisciplinar, a ergonomia agrega-se a várias disciplinas que sustentam a sua base científica e tecnológica. O design, por exemplo, é uma dessas disciplinas que trazem de forma correlata um elo para que os objetivos da ergonomia sejam amplamente alcançados e estabelecidos. Dul \& Weerdmeester definem esse elo da seguinte forma: "A ergonomia é a ciência aplicada ao projeto de máquinas, equipamentos, sistemas e tarefas, com o objetivo de melhorar a segurança, saúde, conforto e a eficiência no trabalho" (2004).

Considerando as propostas de Bürdek (2006), o design tem um papel importante nesse elo, pois o design deve atender a problemas específicos, como, por exemplo, visualizar progressos tecnológicos, priorizar a utilização e o fácil manejo de problemas (não importa se hardware ou software), tornar transparente o contexto da produção, do consumo e da reutilização do produto e promover serviços e a comunicação, mas também, quando necessário, exercer com energia a tarefa de evitar produtos sem sentido. Portanto, diante das premissas da ergonomia e das metas para solucionar os problemas de design, a pesquisa aqui relatada objetiva encurtar os passos da tarefa de projetar, sugerindo recomendação para o projeto do produto cadeira de rodas para idosos.

\section{Fundamentação}

Por meio da observação da Interface Tecnológica (IT) caracterizada pelo idoso e a cadeira de rodas e também pelo enfermeiro e 
cuidador, conforme apresentado pela figura 6, percebeu-se que as cadeiras de rodas apresentavam problemas de interface, caracterizados principalmente pelas queixas de desconforto dos idosos usuários dessas cadeiras.

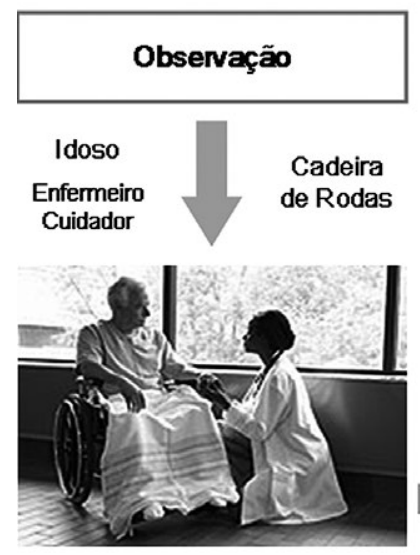

T=Interface Tecnológica

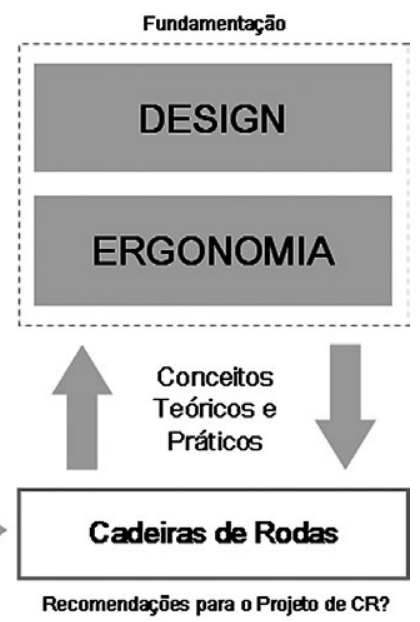

Figura 6. Fluxograma da fundamentação da pesquisa.

Diante desses problemas observados, buscou-se por meio dos conceitos teóricos e práticos da ergonomia e do design descobrir quais seriam as recomendações para o projeto de cadeira de rodas para idosos.

\section{Objetivos}

O objetivo geral da pesquisa foi sugerir recomendações para o projeto de cadeiras de rodas para idosos e que essas recomendações estivessem baseadas nos princípios do design ergonômico. Já os objetivos específicos foram conhecer a realidade das cadeiras de rodas e descobrir suas verdades; verificar a viabilidade de um método específico para a coleta e análise dos dados, e provocar um pensamento reflexivo da importância da aplicação do design ergonômico. 


\section{Revisão da literatura}

\section{Tecnologia assistiva}

Para criar um fluxo de entendimento para a pesquisa, começouse definindo a tecnologia assistiva, termo criado em 1988, segundo Bersch (2005), para dar suporte jurídico à legislação norte-americana. Mais tarde esse termo foi normalizado pela Internacional Organizacional for Standardization (ISO): “( ...) qualquer produto, instrumento, equipamento ou sistema técnico usado por uma pessoa deficiente, especialmente produzido ou disponível que previne, compensa, atenua ou neutraliza a incapacidade".

A norma regulamentada pela ISO 9999 apresenta definições e classificações do que seriam as tecnologias assistivas. Para exemplificar as tecnologias assistivas são necessários os seguintes artefatos:

auxiliares de treinamento e treino; próteses e órteses; auxílios para cuidados pessoais e higiene; auxílios para mobilidade; auxílios para cuidados domésticos; mobiliários e adaptações para habitações e outros locais; auxílios para comunicação, informação e sinalização; auxílios para manuseio de produtos e mercadorias; auxílios para melhorar o ambiente, ferramentas e máquinas e auxílios para recreação.

No Brasil, o termo tecnologia assistiva ainda é pouco utilizado, porém o sinônimo ajudas técnicas é utilizado. Por se tratar de um termo regulamentado por Lei é válido ressaltar o que diz o Artigo 61 do Decreto 5296, que aponta uma definição para o termo Ajudas Técnicas: "são produtos, instrumentos, equipamentos ou tecnologias adaptados ou projetadas para melhorar a funcionalidade da pessoa com deficiência ou com mobilidade reduzida, favorecendo a autonomia pessoal, total ou assistida".

Este capítulo não tem a pretensão de esgotar o assunto, mas sim de contribuir para o desenvolvimento de novos produtos, especialmente considerando as características psicológicas e fisiológicas dos idosos, buscando uma melhoria para a qualidade de vida dessas pessoas, proporcionando, a partir do conceito do design ergonômico, conforto, se- 
gurança e eficiência na realização das atividades da vida diária (AVDs), principalmente daqueles indivíduos que fazem uso de cadeira de rodas.

\section{As cadeiras de rodas}

Falando especificamente das cadeiras de rodas, esse objeto foi o primeiro a ser patenteado no Brasil. Segundo Rodrigues (1973), em 1830, D. Pedro I sancionou a Lei de Propriedade Industrial vigente até os dias de hoje - e por meio dessa lei o então inventor Joaquim Marques de Oliveira e Souza recebeu exclusividade por um período de dez anos pelo seu invento que denominava cadeira de rodas para aleijados. Diante desse fato marcante da História do Brasil, acreditou-se que seria fundamental fazer um levantamento do histórico da cadeira de rodas, pois, conforme sugeriu Ono (2006), fazer a relação da cultura e do design é essencial para entender a identidade dos indivíduos e de grupos sociais, já que Norman e Draper afirmaram que um produto é ao mesmo tempo "um reflexo da história cultural, política e econômica, o qual ajuda a moldar a sociedade e afeta a qualidade de vida das pessoas" (1986).

Portanto, buscou-se entender um pouco mais sobre as questões do design por meio do histórico iconográfico das cadeiras de rodas, ou seja, do estilo, do conceito, da forma do objeto e de suas diversas aplicações. Por meio da iconografia histórica dos mais de quarenta modelos de cadeiras de rodas catalogados, percebeu-se que há um descompasso no design das cadeiras de rodas se o compararmos com outros setores mais dinâmicos da indústria, como, por exemplo, o automobilístico. Em menos de cem anos a forma e o conceito do carro mudou completamente. Comparando o Ford T (1908) com o protótipo desenvolvido pela Toyota para o carro do futuro (2005), percebemos que em trezentos anos o design das cadeiras de rodas nada mudou no conceito e na sua forma. Porém, o protótipo para o carro do futuro desenvolvido pela Toyota deixa uma incógnita que descobriremos somente no seu tempo: será que a configuração do $I$ Unit representa o futuro dos carros ou será que representa o futuro das cadeiras de rodas? 


\section{Idoso}

Voltando à linha de fluxo das definições, para compreendermos o que é ser idoso, temos que entender o fator envelhecimento. $\mathrm{O}$ envelhecimento no Brasil tem um respaldo legal cumprido por leis e estatutos. Segundo Sanchez (2000), a classificação do envelhecimento pode ser feita em dois níveis, a saber, o envelhecimento normal que está relacionado com os fatores biológicos, cronológicos e sociais, e o envelhecimento patológico que corresponde às incapacidades psíquica, fenomenológica e funcional do indivíduo que caracterizam as enfermidades. Portanto, a compreensão dessas enfermidades sugere e direciona algumas demandas para o design de cadeira de rodas.

\section{Enfermidades da senescência}

Para Caldas (2004), o conceito de fragilidade é um importante parâmetro na área do envelhecimento, pois estabelece critérios para determinar quando e em que situações um idoso necessita de apoio. A fragilidade é definida por Hazzard et al. (2003) como a vulnerabilidade que o indivíduo apresenta aos desafios do próprio ambiente. Essa condição é observada em pessoas com mais de oitenta anos, ou naqueles mais jovens, que apresentam uma combinação de doenças ou limitações funcionais que reduzem sua capacidade de se adaptarem ao estresse causado por doenças agudas, hospitalizações ou outras situações de risco.

As principais características de fragilidade do ser humano são a idade avançada, a perda de autonomia e a presença de doenças crônicas ou síndromes geriátricas. São consideradas síndromes geriátricas: a instabilidade e quedas, imobilidade, deterioração cognitiva, déficit sensorial, incontinência e iatrogia. Com o intuito de minimizar risco acidentário, em consequência da fragilidade do idoso cadeirante, busca-se, a partir do estudo das enfermidades, uma relação com as necessidades de usabilidade das cadeiras de rodas e objetiva-se apresentar contribuições que possam ser adequadas às tecnologias 
assistivas, visando estabelecer um produto com características preventivas às complicações dessas doenças, além da manutenção ou reabilitação plena do estado de saúde do idoso.

Embora as intervenções do design ergonômico ainda sejam arbitrárias na área da saúde, percebeu-se que as enfermidades mais frequentes na senescência, como a diabetes mellitus, distúrbios músculo-esqueléticos e infecções urinárias, entre outras, exigem tanto o desenho específico quanto o desenvolvimento de acessórios.

Paschoarelli et al. (2005) sugerem propostas e conceitos metodológicos básicos para o design ergonômico, especialmente para a concepção de produtos que visam à prevenção e ou à reabilitação. Os autores afirmam que esses conceitos metodológicos mostram-se essenciais e significativos, tanto para o desenvolvimento de produtos seguros, confortáveis e eficientes, quanto para disponibilizar recursos para que a reintegração de incapacitados à sociedade ocorra de forma digna e humana. Portanto, a especificidade patológica demanda recomendações projetuais próprias para a cadeira de rodas poder oferecer maior segurança, conforto e eficiência e para o objetivo ser melhor alcançado deve-se associar a essas recomendações uma metodologia de desenvolvimento específica para o design de tecnologias assistivas. Se essas recomendações não forem bem resolvidas pelo design do produto, os fatores prevenção, manutenção e reabilitação do estado de saúde do idoso podem ficar comprometidos.

\section{Antropometria e biomecânica}

Outra recomendação projetual é considerar a antropometria, que se trata do estudo da forma e do tamanho do corpo. Rodriguez-Añez (2000) concluiu, baseando-se na definição de Roebuck (1975):

[A antropometria é a] ciência da mensuração e a arte da aplicação que estabelece a geometria física, as propriedades da massa e a capacidade física do corpo humano. O nome deriva de "anthropos", que significa homem, e "metrikos", que significa ou se relaciona com a mensuração. 
Para este capítulo foi revisada a antropometria estática de cinco grupos de idosos, dos quais se considerou para a referência dimensional os percentis 5 e 95 . Vinte e uma variáveis antropométricas expressivas para o design de cadeira de rodas foram corrigidas em consequência das roupas para que a antropometria pudesse ser aplicada de forma prática no design ergonômico de cadeira de rodas (CR) e atendesse à norma NBR 9050 da ABNT (figura 7).
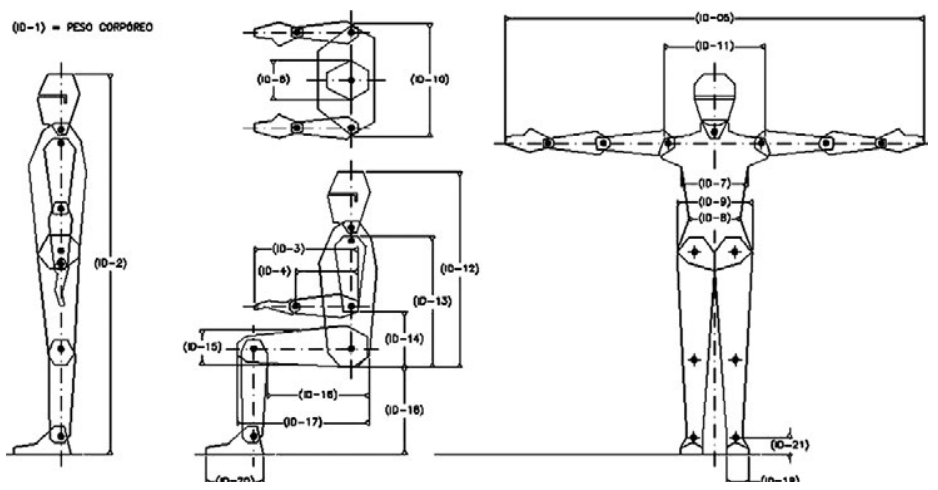

Figura 7. Variáveis antropométricas.

Outro critério projetual importante é a biomecânica: para diminuir a sobrecarga biomecânica do sentado deve-se trabalhar a postura, oferecendo ao produto ajustes dentro dos limites aceitáveis e seguros, pois a correta configuração das partes do corpo vai permitir o aperfeiçoamento da tarefa.

As formas do assento e os materiais empregados podem proporcionar uma postura do sentado mais adequada, e a maneira de propulsionar a cadeira de rodas também influencia na sobrecarga biomecânica. Conhecer e aplicar as amplitudes seguras e as técnicas de propulsão pode favorecer a eficiência da interface tecnológica e principalmente o estado de saúde do usuário.

Das formas de propulsão, segundo Bonninger et al. (2002), por exemplo, a semicircular é a mais adequada por provocar menos lesões nos ombros e braços. Já a propulsão em forma de arco é a mais inadequada (figura 8). 

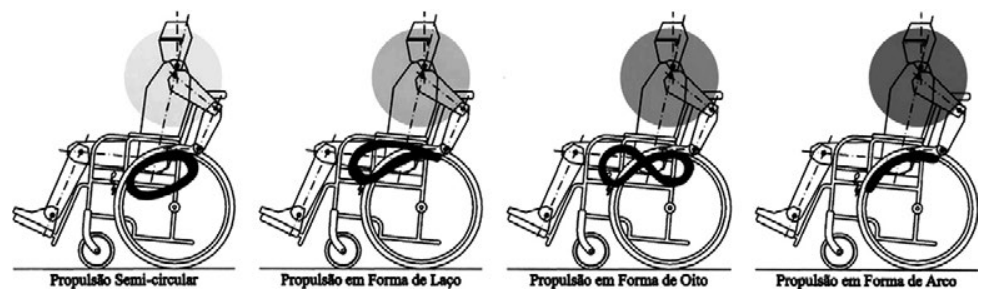

Figura 8. Grau de adequação das técnicas de propulsão da cadeira de rodas.

\section{Usabilidade}

Partindo do princípio de que a interface tecnológica deva ser flexível mesmo se existirem barreiras para essa flexibilidade (figura 9) e de que a usabilidade não é um critério pós-projeto, criou-se um modelo para o entendimento da usabilidade da cadeira de rodas.

Então, por meio de um teste de usabilidade, verificou-se como a especificidade patológica, as características físicas, de propulsão e morfológicas das cadeiras de rodas interferem nessa flexibilidade e quais seriam as recomendações para serem aplicadas nas etapas iniciais do desenvolvimento do produto.

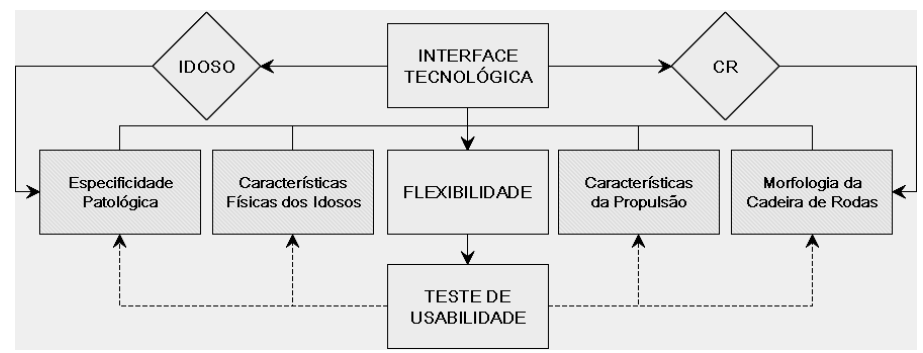

Figura 9. Fluxograma da flexibilidade.

Jordan (1998), Moraes (2001) e Iida (2005) alertam que a usabilidade deve ser considerada no desenvolvimento do design de produtos, e, especialmente quando os indivíduos são idosos, o design deve levar em consideração as características particulares desses indivíduos. 


\section{Metodologia}

\section{Estrutura metodológica da pesquisa}

A estrutura metodológica da pesquisa para este capítulo foi retratada numa pirâmide (figura 10), na qual os módulos da base contemplam a abordagem teórica e a pesquisa de opinião.

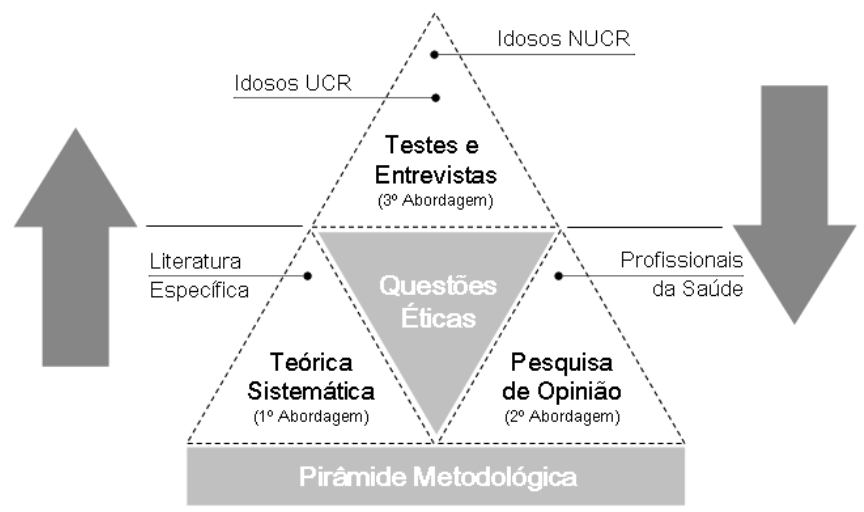

Figura 10. Pirâmide metodológica.

O módulo referente às questões éticas é responsável pela conexão entre os módulos, inclusive com a terceira abordagem, cujos testes e as entrevistas foram realizados com os idosos usuários e não-usuários de cadeira de rodas.

\section{Questões éticas}

Dos 11 critérios de eticidade adotados aqui vale ressaltar:

- Encaminhamento do projeto ao ComitêdeÉtica em Pesquisa da Faculdade de Medicina de Botucatu, que recebeu aprovação e liberação. 
- Utilização de umTermo de Consentimento LivreeEsclare cido (TCLE), regulamentado pelo Ministério da Saúde e pela Associação Brasileira de Ergonomia (Abergo).

- Utilização de uma ficha de anamnese que antecede os testes de usabilidade.

\section{Primeira abordagem: teórica sistemática}

Na primeira abordagem a cadeia temática do estudo teórico estava conectada com os termos idoso, ergonomia, cadeira de rodas e design, conforme apresentado pelo quadro da figura 11 .

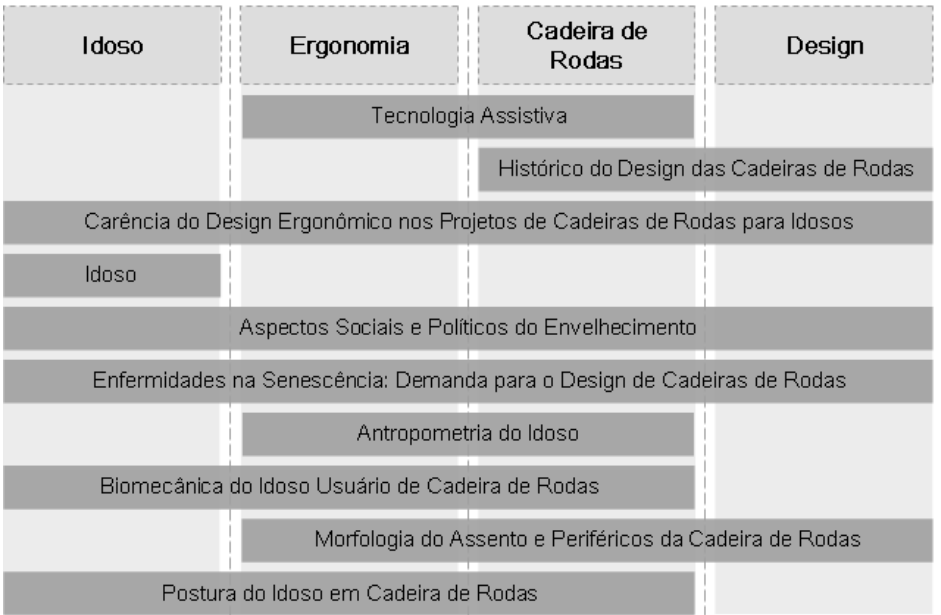

Figura 11. Cadeia temática da abordagem teórica.

\section{Segunda abordagem: pesquisa de opinião}

Na segunda abordagem, buscou-se entender a problemática da pesquisa ouvindo a opinião dos cuidadores, acompanhantes de idosos, enfermeiros e os profissionais das áreas clínicas, os quais estão diretamente ligados à interface tecnológica. 


\section{Materiais}

Os materiais utilizados na pesquisa de opinião foram:

- 315 cartas deapresentação;

- 315 protocolos depesquisa (entende-sepor protocol os a ficha de identificação do sujeito, o TCLE e o questionário propriamente dito).

Desses, 183 foram envelopados e enviados via Correios.

\section{Terceira abordagem: teste de usabilidade e entrevistas}

Para a terceira abordagem foi desenvolvido e montado um teste com base na NBR 9050 (figura 12), ou seja, desenvolveu-se uma pista de teste com dimensionais de acessibilidade normalizados e regulamentados.
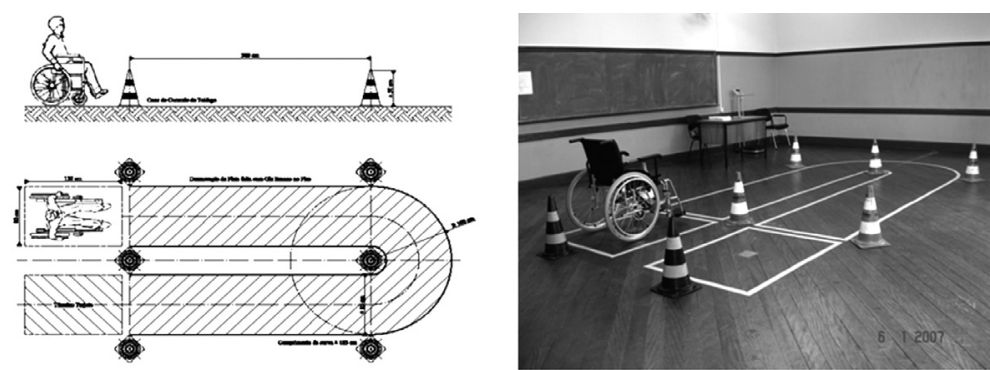

Figura 12. Desenho esquemático da pista de teste (esquerda) e pista de teste montada (direita).

Antes de o sujeito iniciar o teste, ele era orientado sobre como fazer o percurso. $\mathrm{O}$ enfermeiro realizava os procedimentos clínicos de pesagem, medição de altura e massa corpórea, e, se estivesse tudo em ordem, o sujeito estava apto a realizar os testes. Vale ressaltar que não tivemos nenhum sujeito inapto para realizar os testes. 


\section{Materiais e equipamentos}

Os materiais utilizados para os testes e entrevistas com idosos foram o protocolo de pesquisa, o diagrama de Corllet \& Manenica (1980) construído em madeira e jogos de cartões, o que deixou o procedimento mais dinâmico e interessante para o participante (figura 13).
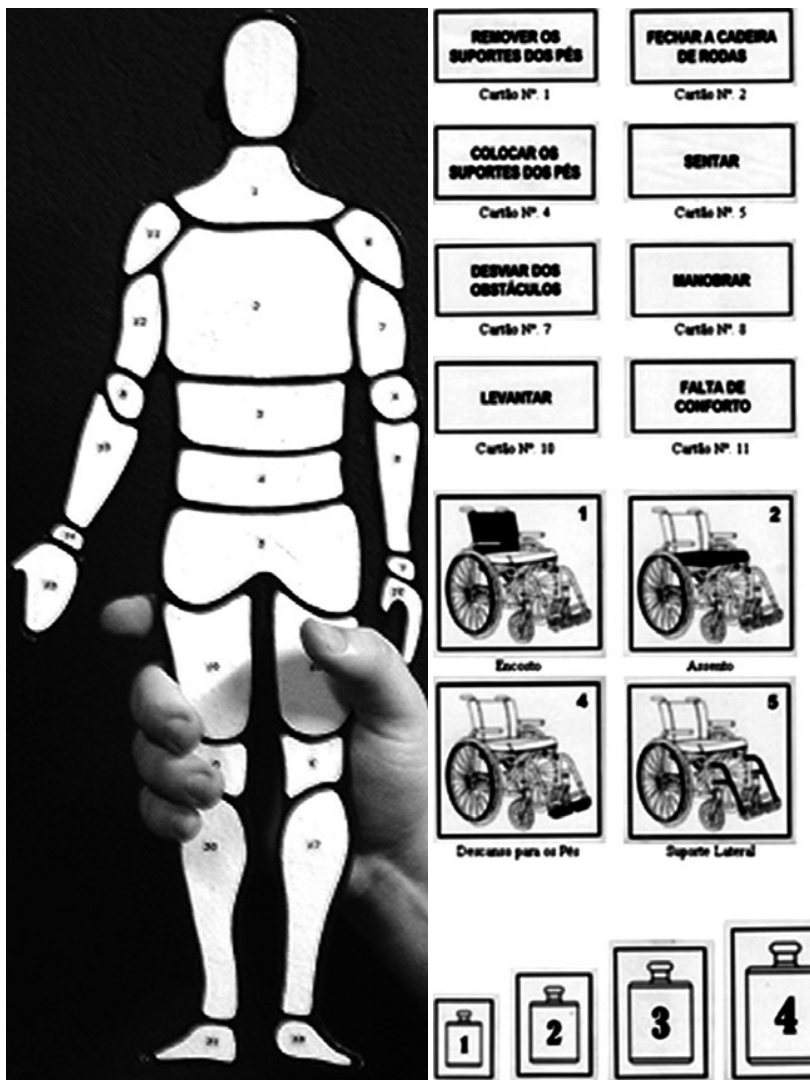

Cortion 2
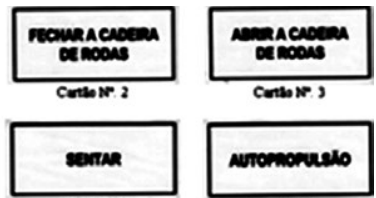

Conto in: 5

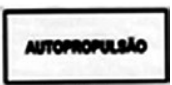

Cants No 6

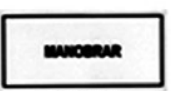

Corth in: 8
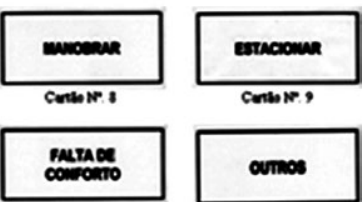

Cents No II

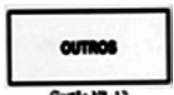

Contos 10
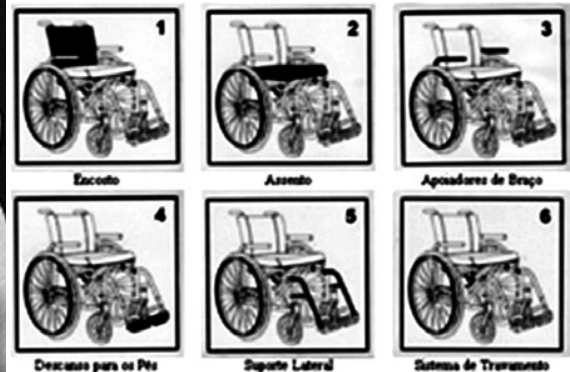

Deximas pore on No

somenterer

artome be treremots
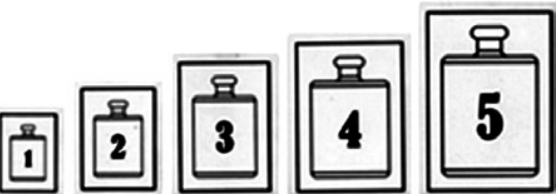

Figura 13. À esquerda, diagrama de Corllet \& Manenica (1980). À direita, jogos de cartões plastificados. 
Os equipamentos utilizados foram balança digital, com capacidade de 180 kg; cone de tráfego; esfigmomanômetro e estetoscópio; câmera/filmadora digital com tripé; e uma cadeira de rodas de propulsão manual, conforme apresentado pela figura 14 .
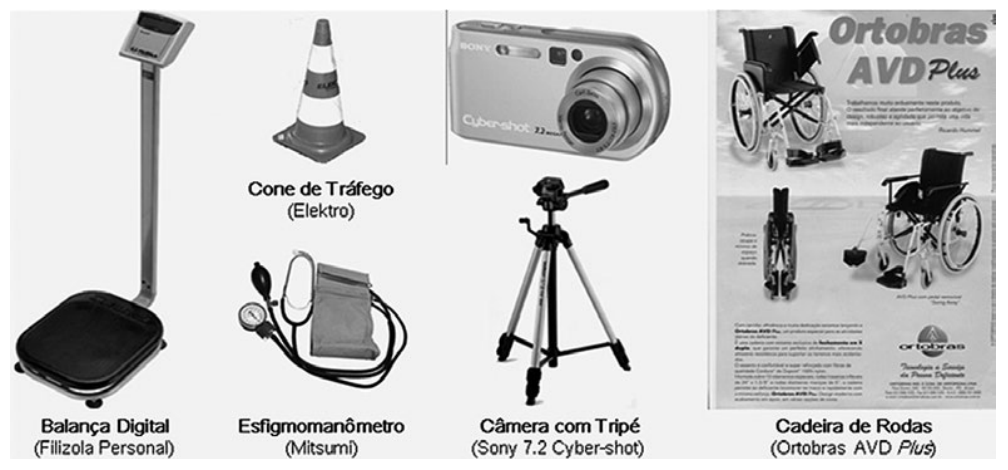

Figura 14. Equipamentos utilizados no teste de usabilidade.

A cadeira de rodas foi utilizada única e exclusivamente como referencial tecnológico, pois o objetivo dessa abordagem foi conhecer o desempenho do idoso na realização da tarefa. A cadeira de rodas modelo AVD Plus da Ortobrás também foi escolhida por apresentar uma proximidade técnica e estética com as cadeiras de rodas mais comumente utilizadas pelos idosos, por não existir um modelo de cadeira de rodas específico para idoso e por haver colaboração da Ortobrás, que doou a cadeira de rodas para a pesquisa. Vale ressaltar que seis empresas de cadeiras de rodas foram contatadas.

\section{Resultados}

\section{Resultados da pesquisa de opinião}

\section{Enfermeiros e cuidadores}

Os resultados obtidos na pesquisa de opinião com os enfermeiros retratam um quadro panorâmico entre as queixas de desconforto 
corporal e morfologia da cadeira de rodas, crítico e sistêmico: 13\% dos sujeitos apontaram que idosos, quando usuários de cadeiras de rodas, se queixam muito de dores no pescoço e costas-médias; 7,35\% apontaram as costas-inferiores; já para a região das costas-inferiores e bacia esse índice sobe para cerca de 30\%, e 20\% para a região das coxas e pernas.

Fazendo a associação com a morfologia da cadeira de rodas, temos o assento e os apoiadores de braços, sendo os itens mais críticos, por manterem uma relação direta com as regiões corporais das quais os idosos mais se queixam de desconforto.

\section{Profissionais das áreas clínicas}

Quando se perguntou aos profissionais das áreas clínicas qual era a região corporal em que o idoso usuário de cadeira de rodas apresentava maiores dificuldades de reabilitação, novamente, costas-inferiores e bacia aparecem no topo com quase 30\% das opiniões. Perguntou-se qual era a dificuldade que os profissionais encontravam para o sucesso da reabilitação do indivíduo e as respostas foram que assento/encosto, a falta de acessórios, a dificuldade de propulsão e o custo elevado da CR dificultavam a prescrição, comprometendo, portanto, todo o processo de reabilitação e muitas vezes levando o idoso a quadros clínicos mais críticos e irreversíveis.

\section{Resultados do teste de usabilidade e entrevistas}

Os resultados obtidos pelo teste de usabilidade e nas entrevistas, os quais podem ser observados pelo gráfico da figura 15, apontaram graus de dificuldade para diversas tarefas realizadas com cadeira de rodas. 


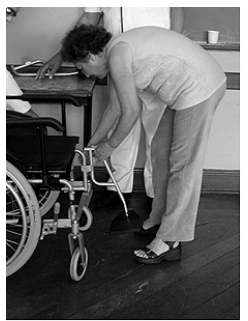

A - Sujeito Removendo os Suportes Laterais

C - Manobrar a Cadeira de Rodas

D - Autopropulsionar a Cadeira de Rodas

E - Desviar de Obstáculos

F - Falta de Conforto

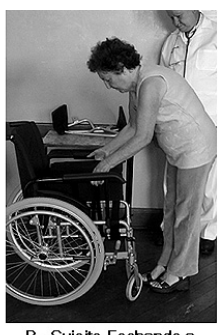

B - Sujeito Fechando a

Cadeira de Rodas

Figura 15. Resultados do teste de usabilidade.

Fazendo a análise do gráfico da figura 15, têm-se as seguintes conclusões: cerca de $60 \%$ dos idosos não-usuários de cadeira de rodas (INUCR) apontaram dificuldades para remover os suportes laterais. Vale ressaltar que o pino trava da cadeira utilizada no teste desgastou, tornando essa tarefa mais difícil. Mais de 15\% disse ser muito difícil fechar a cadeira de rodas. Comparando os resultados, a manobra da cadeira de rodas para 36\% dos INUCR é uma tarefa que demanda certa habilidade, o que se pode comprovar pelo índice dos idosos usuários de cadeira de rodas (IUCR) que cai para cerca de 15\%. Já para a tarefa de autopropulsão os índices invertem, ou seja, para os IUCR é mais difícil propulsionar a CR do que para os INUCR. Outras tarefas apontadas pelos IUCR foram a dificuldade de desviar de obstáculos e a falta de conforto do objeto.

\section{Resultados gerais da relação de desconforto entre homem e tecnologia}

Fazendo uma compararão genérica das abordagens realizadas, o grau de desconforto apontado pelos sujeitos no diagrama de Corllet \& Manenica (1980) está diretamente relacionado com a ineficiência 
ou inadequações da morfologia da cadeira de rodas. Para citar alguns dos exemplos apresentados pela figura 16 , temos a queixa de desconforto no pescoço por consequência da falta de apoio para a cabeça, e o desconforto nas costas-inferiores e bacia pela inadequação ou ineficiência do assento que interfere na manutenção da postura correta.

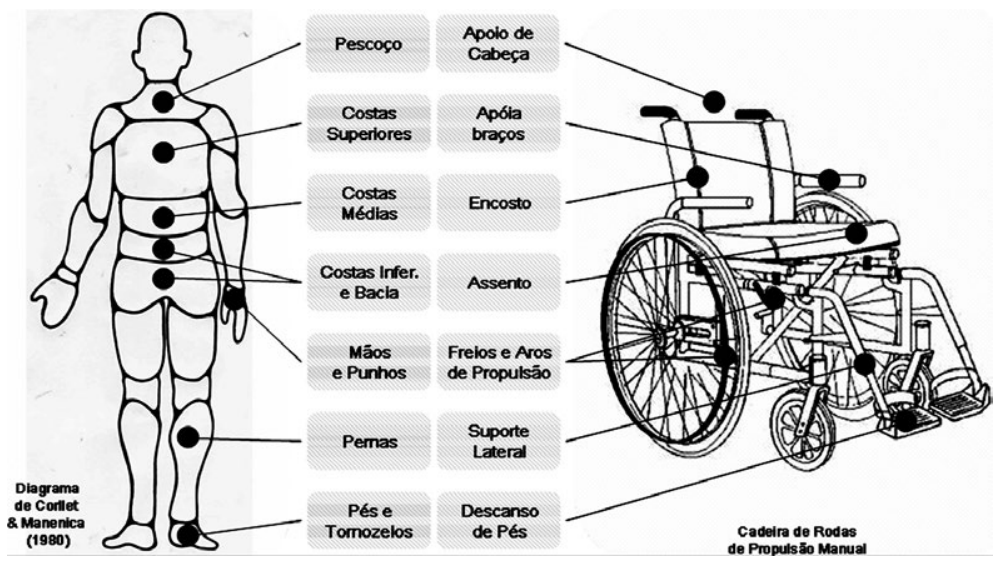

Figura 16. Relação do desconforto com a morfologia da cadeira de rodas.

\section{Considerações finais}

Embora as recomendações projetuais estejam detalhadas ao longo do capítulo, algumas reflexões para a prática projetual de cadeira de rodas para idosos podem ser apontadas. Não podemos esquecer que fatores como os aspectos sociais e econômicos, as enfermidades da senescência, os aspectos antropométricos e biomecânicos, e ainda a usabilidade e a postura do sentado devem ser considerados.

Também de grande importância é atrelar o padrão estético desejado pelo idoso ao design do produto, mudar o paradigma da forma e provocar mudanças para um novo conceito de rodas em cadeiras, desenvolver produtos de fácil higienização e manutenção e que possuam formatos anatômicos e ajustáveis. Pois, se considerarmos esses fatores, estaremos valorizando a vida do idoso cadeirante e 
consequentemente assumindo a responsabilidade de prevenção, manutenção e reabilitação do estado de saúde. As cadeiras de rodas também devem oferecer facilidade no seu transporte, e um manual ilustrado ou cartilha que seja de fácil entendimento. Também é importante criar uma família de cadeiras de rodas e acessórios com base na especificidade patológica e que cada objeto dessa família tenha um custo reduzido para atender a grande parte da população brasileira.

Por fim, este capítulo buscou apontar um equilíbrio entre o desenvolvimento científico e o desenvolvimento tecnológico, criando um elo de responsabilidade entre os desenvolvedores de cadeira de rodas, pois descobriu-se com a pesquisa, a partir da metodologia aplicada, que as cadeiras de rodas para idosos são específicas e se diferem dos parâmetros atuais utilizados, principalmente se a base projetual for o design ergonômico.

\section{Referências bibliográficas}

ASSOCIAÇÃO BRASILEIRA DE NORMAS TÉCNICAS (ABNT).

NBR9050: Acessibilidade e edificações, mobiliário, espaços e equipamentos urbanos. 2.ed. Rio de Janeiro: ABNT, 2004. 97p.

BALTAR, X. A. L. et al. Diseño y validación de una familia de sillas de ruedas: innovación y ergonomía para la integración social. In: Anais do $6^{\circ}$ Congresso Internacional de Ergonomia e Usabilidade de Interfaces Humano-Tecnologia: produtos, informação, ambiente construído, transporte $-6^{\circ}$ Ergodesign. Bauru, SP: LEI - DDI - PPGDI - Faac Universidade Estadual Paulista - Unesp, 2006. 6p.1 CD-ROM

BERSCH, R. Introdução à tecnologia assistiva. Centro Especializado em Desenvolvimento Infantil (Cedi). Porto Alegre, 2005. Disponível em: <http://www.cedionline.com.br/artigo_ta.html> Acessado em: 27 jan. 2006. 20p.

BONINGER, M. et al. Manual wheelchair pushrim biomechanics and axle position. Arch phys med rehabilitation. 2000; 81: p.608-13.

BRASIL. Decreto n.3.298, 20 de Dezembro de 1999. Regulamenta a Lei n. 7.853, de 24 de outubro de 1989. Diário Oficial da República Federativa do Brasil. Brasília, DF, 3 dez. 2004. Disponível em: <https://www. planalto.gov.br/ccivil/decreto/d3298.htm>. Acesso em: 20 dez. 2005. 
Decreto n.5.296, de 2 dezembro de 2004. Diário Oficial da República Federativa do Brasil. Brasília, DF, 3 dez. 2004. Disponível em: < http://www.mc.gov.br/rtv/lei/d_5296_02122004.pdf>. Acesso em: 20 dez. 2005.

Lei n.8.842, sancionada em 4 de janeiro de 1994, a qual "dispõem sobre a Política Nacional do Idoso, cria o Conselho Nacional do Idoso e dá outras providências". Diário Oficial da República Federativa do Brasil. Poder Executivo: Brasília, DF, 5 jan. 1996.

Política Nacional de Saúde do Idoso. Portaria n.1.395, de 9 de dezembro de 1999. Oficial da República Federativa do Brasil. Poder Executivo, Ministério da Saúde: Brasília, DF. 13 dez. 1999. N. 237 -E, seção 1, p.20-24

Estatuto do Idoso. Lei ${ }^{\circ} 10.741,1^{\circ}$ de Outubro de 2003. Oficial da República Federativa do Brasil. Brasília, DF, 3 out. 2003. Disponível em: <http://www010.dataprev.gov.br/sislex/paginas/42/2003/10741. htm>. Acessado em: 20 dez 2005.

BÜRDEK, B. E. Design: história, teoria e prática do design de produtos. Tradução de Freddy Vam Camp. São Paulo: Edgard Blücher, 2006, 496p.

CARRIEL, I. R. R. Recomendações ergonômicas para o projeto de cadeira de rodas: considerando os aspectos fisiológicos e cognitivos dos idosos. Bauru, 2007. Dissertação (Mestrado em Desenho Industrial)-Faculdade de Arquitetura, Artes e Comunicação, Universidade Estadual Paulista.

CARRIEL, I. R. R., PASCHOARELLI, L. C. A relação entre desconforto e problemas de usabilidade em cadeiras de rodas utilizadas pelos idosos: uma abordagem com os enfermeiros. In: Anais do $6^{\circ}$ Congresso Internacional de Ergonomia e Usabilidade de Interfaces Humano-Tecnologia: produtos, informação, ambiente construído, transporte $-6^{\circ}$ Ergodesign. Bauru, SP: LEI - DDI - PPGDI - FAAC - Universidade Estadual Paulista - Unesp, 2006. 6p.1 CD-ROM.

CARRIEL, I. R. R., et al. Aspectos ergonômicos e de usabilidade das cadeiras de rodas para idosos: uma revisão. Revista Assentamentos Humanos, Marilia, v.7, n.1, p.29-37, 2005.

CORLLET, E. N., MANENICA, I. The effects and measurement of working postures. Applied Ergonomics. 11 (01): p.7-16, 1980.

DUL, J., WEERDMEESTER, B. Ergonomia prática. 2.ed. São Paulo: Edgard Blücher, 2004.

FELISBERTO, L. C., PASCHOARELLI, L. C. Modelos humanos em escala para projeto ergonômico preliminar de postos de trabalho e pro- 
dutos. AEND-Br. Anais do PESD Design 2000. Rio de Janeiro, 2000. v.2, p.583-9.

FINLEY, M.A. et al. The biomechanics of wheelchair propulsion in individuals with and without upper-limb impairment. Journal of rehabilitation research $\mathcal{E}$ development - JRRD, v.41, n.3B, 2004. p.385-94.

FRANCO, A. N. Estudo da antropometria estática em indivíduos da terceira idade: verificação da viabilidade de um banco de dados antropométrico. Bauru, 2005. Dissertação (Mestrado) - Faculdade de Arquitetura, Artes e Comunicação, Universidade Estadual Paulista.

HAZZARD, W. R. et al. Principles of geriatric medicine and gerontology. 5.ed. Nova Iorque: McGraw Hill, 2003.

IIDA, I. Ergonomia: projeto e produção. 2.ed. revista \& ampliada. São Paulo: Edgard Blücher, 2005.

INSTITUTO BRASILEIRO DE GEOGRAFIA E ESTATÍSTICA (IBGE). Estudos \& pesquisas informação demográfica n.9: perfil dos idosos responsáveis pelos domicílios no Brasil 2002. Ministério do Planejamento, Orçamento e Gestão. Rio de Janeiro: IBGE, 2002. Disponível em: <http://www.ibge.gov.br/> Acessado em: 10 jan. 2006.

INTERNATIONAL ORGANIZATION FOR STANDARDIZATION. Norma UNE-EN ISO 9999: Ayudas técnicas para personas con discapacidad. Clasificación y terminologia. AEN/CTN 153. Madri: Asociación Española de Normalización y Certificación, 2003. 151p. (Versión oficial, en español, de la Norma Europea EN ISO 9999, de octubre de 2002, anula y sustituye a UNE-EN ISO 9999, de febrero de 1999. Biblioteca del Ceapat).

JORDAN, P. W. An introduction to usability. Londres: Taylor \& Francis, 1998.

KOTHIYAL, K., TETTEY, S. Anthropometry for design for the elderly. International Journal of occupational safety and ergonomics, v.7, n.1, p.15-34, 2001.

MOLENBROEK, J. F. M. Anthropometry of elderly people in the Netherlands: research and applications. Applied ergonomics, v.18, n.3, p.18799, 1987.

MORAES, A. de. Ergonomia e usabilidade de produtos, programas, informação. In: MORAES, A. de., FRISONI, B. C. Ergodesign: produtos e processos. Rio de Janeiro: 2AB, 2001, p.9-51.

ONO, M. M. Design e cultura: sintonia essencial. Curitiba: Edição da Autora, 2006.132p. 
PASCHOARELLI, L. C., CARRIEL, I. R. R., GANANÇA, A. da S. Prevenção e reabilitação: conceitos para uma discussão sob o ponto de vista do design ergonômico. In: Anais do $5^{\circ}$ Congresso Internacional de Ergonomia e Usabilidade de Interfaces Humano-Tecnologia: produtos, informação, ambiente construído, transporte $-5^{\circ}$ Ergodesign. Rio de Janeiro: PUC-Rio, 2005. 6p.1 CD-ROM.

RAMOS, C. M. da C., RIPPER, J. L. M., NOJIMA, V. L M. dos S. Avaliação da venda de cadeiras de rodas. In: Anais do II Congresso Internacional de Pesquisa em Design - Brasil. Rio de Janeiro: Anped, 2003. 8p.

REBELATO, J. R. Os profissionais da saúde e os conceitos de prevenção e terapia [texto digitado]. São Carlos: UFSCar. 2004.

RODRIGUEZ-AÑEZ, C. R. A antropometria na ergonomia. Cadernos de ensaios de ergonomia. Florianópolis, 2000.

ROEBUCK, J. A., KROEMER, K. H. E., THOMSON, W. G. Engineering anthropometry methods. Nova Iorque: Wiley-Intersciencie, J. Wiley, 1975.

RODRIGUES, C. da C. A inventiva brasileira. 2v. Brasília: Instituto Nacional do Livro, 1973. 527p. (Consulta Científica).

SALDANHA, L. A., CALDAS, C. P. Saúde do idoso: a arte de cuidar. 2.ed. Rio de Janeiro: Interciência, 2004.

SANCHEZ, M. A. S. A dependência e suas implicações para a perda de autonomia: estudo das representações para idosos de uma unidade ambulatorial geriátrica. Textos Envelhecimento. v.3 n.3 Rio de Janeiro: Unati. fev. 2000. Disponível em: <http://www.unati.uerj.br/tse/ scielo>. Acessado em: 4. ago. 2006.

SCHMELER, M. R., BUNING, M. E. Properties of Seat Cushions [2000]. Slides. Center for Assistive Technology and Department of Rehabilitation Science \& Technology - University of Pittsburgh. Disponível em: $<$ www.wheelchairnet.org/wcn_wcu/SlideLectures/MS/2Cushions. pdf> Acesso em: 10 dez. 2004.

SMITH, S., NORRIS, B., PEEBLES, L. Older Adultdata. The handbook of measurements and capabilities of the older adult - Date for design safety. Nottingham: University of Nottingham, 2000.

STOUDT, H. W. The anthropometry of the elderly. Human Factors, v.23, n.1, p.29-37, 1981.

TILLEY, A. R., HENRY DREYFUSS ASSOCIATES. As medidas do homem e da mulher. Tradução de Alexandre Salvaterra. Porto Alegre: Bookman, 2005. 
UNITED STATES OF AMERICA. Code of federal regulations. 28 CFR Part 36, revised as of July, 1, 1994. ADA - Standards for accessible design. Departament of Justice: Whashington D. C. p.489-580. Disponível em: <http://www.usdoj.gov/crt/ada/stdspdf.htm > Acesso em: 15 jan. 2005.

VILLAS BOAS, P. J. F. Qualidade de vida na terceira idade. In: XIII Encontro Nacional da Associação Brasil-Japão de Pesquisadores, 9. Botucatu, 2005. Resumos... Botucatu-SP: IB-Unesp, 2005. p22-3. 


\title{
3 \\ ANTROPOMETRIA ESTÁTICA DE INDIVÍDUOS DA TERCEIRA IDADE
}

\author{
Adelton Napoleão Franco ${ }^{1}$ \\ José Carlos Plácido da Silva
}

\section{Introdução}

Para muitos, os trabalhos envolvendo pessoas idosas não trazem benefícios práticos, são de difícil condução e necessitam maior dedicação. Há várias razões para trabalhar com idosos: dentre elas, o que nos motiva é oferecer condições de igualdade para as atividades da vida, aumentar as possibilidades para a utilização de produtos e serviços, contribuindo e melhorando a qualidade de vida dos idosos, incorporando a ergonomia, a antropometria e o envelhecimento humano como objeto de estudo.

O presente estudo foi estruturado e desenvolvido tendo como base trabalhos relacionados à antropometria (Silva,1995; Paschoarelli, 1997; Queiroz, 2000; Villa, 2001) que tiveram como amostra indivíduos de faixas etárias bem inferiores aos voluntários da presente pesquisa. Sabendo-se da importância da continuidade sistemática nas pesquisas, definiram-se as 27 variáveis antropométricas, mais o Índice de Massa Corpórea (IMC), a faixa etária e os locais de recrutamento dos participantes voluntários.

1 Mestre em design, Universidade do Sagrado Coração.

2 Professor titular, Universidade Estadual Paulista. 
O envelhecimento é, em grande parte, um desafio do mundo contemporâneo, afetando tanto os países ricos quanto os países pobres, ainda que de forma diferente e específica em cada sociedade, cultura e contexto socioeconômico. As estimativas sobre populações no mundo preveem para daqui a vinte anos um aumento de até $88 \%$ de idosos com mais de 65 anos de idade, o que representa quase um milhão de pessoas por mês.

Para a Organização Mundial da Saúde (OMS), em 2025, a expectativa de vida para mais de oitenta anos de idade será a idade média em pelo menos 26 países. Quatro deles - Itália, Japão, Islândia e Suécia - já cumprem essa expectativa (IBGE, 2000). O contingente de idosos no Brasil enfrenta um crescimento grandioso, como no resto do mundo. A estimativa da população geral no país é de 177.620.328 pessoas segundo o censo demográfico de 2000 do Instituto Brasileiro de Geografia e Estatística (IBGE).

Um panorama geral sobre os idosos no Brasil estima que 14.536.029 pessoas são idosos. No estado de São Paulo, são 3.316.957. Na cidade de Bauru, a população geral é de 316.064 pessoas, enquanto a de 60 anos ou mais chega a 32.841. Estatísticas mostram que a população idosa no Brasil em meados de 2020 chegará à casa dos $20 \%$ da população geral. Eles estarão em todas as partes das cidades, desenvolvendo o comércio, o turismo, o lazer e até disputando vagas no mercado de trabalho.

Seguindo essa premissa, Charness e Bosman (1992) destacam que uma simples extensão tradicional de acesso dos fatores humanos, de acordo com a idade, traria benefícios gerais à sociedade. Os primeiros fatores do centro de atenção para indivíduos na faixa de 40 a 64 anos são a eficiência e a segurança de produtos. Já o grupo da idade de 65 a 74 anos está mais relacionado com a segurança, conforto e tranquilidade de uso. Para o grupo de 75 anos ou mais, além desses, incluem-se os instrumentos e dispositivos de auxílio para AVDs, levando-se em conta as características do processo de envelhecimento.

O processo de envelhecimento humano é assunto atual nos meios de comunicação; a televisão dedica parte de seus preciosos minutos 
a apresentar em programas de entretenimento, e principalmente em telejornais, séries que tentam de alguma forma mostrar ao público que ficar velho não significa adoecer, mas, sim, entregar-se a esse estágio da vida com saúde, vivacidade, independência e apresentar-se funcional. Exemplos dessa natureza são mostrados na revista Veja de 15 de novembro de 2004, sob o título de capa: A ciência da vida longa e saudável. As jornalistas Thereza Venturoli, Isabela Boscov e Lucila Soares dedicam 11 páginas ao assunto, destacando que "a promessa é de uma velhice saudável e prazerosa”.

Para Erbolato (apud Neri \& Freire, 2000), algumas teorias foram baseadas em aspectos biológicos do ser humano citadas em estudos realizados por cientistas europeus no século passado, quando observaram uma série de alterações nos órgãos e no corpo humano, incluindo a diminuição de seu tamanho e deficiências em seu funcionamento. Durante o envelhecimento, todas as pessoas sofrem mudanças físicas.

Estudos de Ribas \& Ely (2002) demonstraram que os problemas encontrados frente às necessidades físicas, informativas e sociais da pessoa da terceira idade podem ser resolvidos desde que se tome conhecimento e consciência de suas limitações e potencialidades com a chegada da velhice. Além disso, há que se considerar que o espaço deve acompanhar as mudanças ocorridas no corpo humano frente ao envelhecimento, propiciando aos idosos, sobretudo aos de menor renda, mecanismos que lhes garantam igualdade de cidadania e mais independência para uma vida normal na utilização de edificações, espaços, mobiliários e equipamentos urbanos, apesar das limitações impostas pela velhice. Compartilham desse pensamento antropométrico Cavalcanti \& Ely (2002).

Frente a esse contexto, Bomm et al. (2003) e Barros (2000) discorrem: quando o ambiente não oferece condições de conforto, segurança e acessibilidade, ele não garante a seus usuários autonomia e independência.

A antropometria tem sua função multivariada na ergonomia, desde a concepção de produtos, racionalização de ambientes e espaços, elaboração e intervenção em postos de trabalho, aos estudos que 
tentam decifrar as variações e diferenças físicas, tanto individuais quanto em grupos e populações distintas.

No Brasil, a discussão sobre as variáveis antropométricas começa a ganhar corpo. No entanto, há tendência para pesquisar a população infantil, juvenil e adulta, enquanto para os idosos os estudos nessa área são insuficientes. Países como Canadá, China, França, Itália, Japão, Inglaterra e Estados Unidos acompanham substancialmente os parâmetros antropométricos de suas populações (Smith et al. 2000). Um documento exemplo dessa natureza (Older Adultdata da Inglaterra) é uma coleção de informações antropométricas de adultos de mais de cinquenta anos de idade de diversos países e inclui 155 medidas.

A antropometria trata de medidas físicas do corpo humano. Para Iida (1997), medir as pessoas seria uma tarefa fácil, bastando para isso ter uma régua, trena e balança, mas isso não é assim tão simples quando se deseja obter medidas confiáveis de uma população que contém indivíduos dos mais variados tipos. As condições em que essas medidas são realizadas (com ou sem roupas, com ou sem calçados, ereto ou na postura relaxada) influem nos resultados. É importante definir quem usa e quem usará, realmente, o produto para a escolha do melhor levantamento antropométrico a ser adotado no projeto (Quaresma \& Moraes, 2000).

O levantamento do IBGE de 1977 constituiu em avaliar o peso e a altura de indivíduos a partir de 18 anos e rotulou-se como representativo de toda população. O estudo procurou mostrar, por meio de comparações de dados, o quanto os valores da norma técnica PB 472 de 1979 estão diferentes dos reais. Na época, sugeriu a revisão da PB 472, incluindo em seu texto a necessidade de um levantamento antropométrico de outras variáveis, bem como de populações com idades distintas, para assim representar bem a população.

Com toda essa motivação, e diante de componentes considerados importantes por diversos pesquisadores e aqui explicitados, a proposta do presente capítulo foi verificar as características antropométricas e o IMC em indivíduos com 50 anos ou mais de idade, frequentadores de grupos da terceira idade da cidade de Bauru, reunindo 29 variáveis. 


\section{Materiais e métodos}

A amostra constitui-se de 190 pessoas de ambos os gêneros (masculino e feminino), com idade igual ou superior a cinquenta anos, frequentadoras das atividades físicas de grupos da terceira idade da cidade de Bauru (SP), nos anos de 2004 e 2005.

Para ser participante voluntário, o presente levantamento atevese aos idosos que não fossem dependentes de auxílio ou dispositivos de ajuda, como andadores, muletas, próteses de membros superiores ou inferiores, ou ainda acometidos por patologias determinantes que influenciem a postura em pé ou sentada, de forma a gerar diferenças significativas na padronização das medidas e nos parâmetros morfológicos identificados pelo pesquisador.

Trata-se de uma pesquisa transversal descritiva, desenvolvida por meio do raciocínio dedutivo, em que os sujeitos foram recrutados por conveniência, ou seja, o pesquisador solicitava a participação voluntária de acordo com a presença dos idosos nas atividades desenvolvidas.

Houve nas atividades físicas um total de 384 participantes, 304 mulheres e oitenta homens, e determinou-se o tamanho amostral com nível de 95\% de confiança e 10\% de erro de estimativa, estabelecendose, aproximadamente, 190 sujeitos voluntários, com proporcionalidade ao gênero (Cochran, 1977), constituindo a amostra de 50 homens e 140 mulheres (tabela 2).

Foram utilizadas tabelas preestabelecidas para o IMC (índice de Quetelet) que variam de acordo com a fonte consultada. As referências exemplificadas para a pesquisa foram da OMS (1995), Hirsh (2003), e da Iaso (2005) (tabela 3).

As técnicas estatísticas aplicadas para a apresentação e interpretação dos dados foram baseadas em tabelas de levantamentos antropométricos do Instituto Nacional de Tecnologia (INT) e recomendadas em Padovani (1995): medidas de posição ou tendência central: média simples, percentis $(1 ; 2,5 ; 5 ; 10 ; 25 ; 50 ; 75 ; 95$ e 99), valores máximo e mínimo, e medidas de dispersão ou variabilidade (desvio-padrão, coeficiente de variação e coeficiente de correlação). 


\section{Materiais e equipamentos métricos}

Foram empregados o parecer do Comitê de Ética em Pesquisa, protocolo 073/2005; termo de consentimento e protocolo de anotações, intitulado levantamento de dados antropométricos de indivíduos da terceira idade; uma balança de precisão com barra antropométrica, da marca Welmy, patrimônio número 04293, do Departamento de Desenho Industrial da Faac, Unesp de Bauru; uma cadeira antropométrica, com três escalas $(100 \mathrm{~cm}, 55 \mathrm{~cm}$ e $50 \mathrm{~cm}$ ), todas da marca Filling, construção própria; um paquímetro ou antropômetro, com escala de $100 \mathrm{~cm}$ da marca Filling, construção própria; e uma fita métrica (trena) flexível de $10 \mathrm{~m}$ da marca Western.

\section{Resultados}

Os resultados estão inseridos como dados quantitativos em quatro tabelas distintas: duas para amostra masculina (tabelas 2 e 3 ) e duas para amostra feminina (tabelas 4 e 5), com valores numéricos e suas unidades.

Tabela 2. Dados quantitativos da amostragem masculina.

\begin{tabular}{l|c|c|c|c|c}
\hline \multirow{2}{*}{$\begin{array}{c}\text { Variáveis } \\
\text { Antropométricas }\end{array}$} & \multicolumn{5}{|c}{ Valores Amostra Masculina - Estatística de N=50 } \\
\cline { 2 - 7 } & Média & $\begin{array}{c}\text { Desvio } \\
\text { padrão }\end{array}$ & $\begin{array}{c}\text { Coef. } \\
\text { Variação }\end{array}$ & $\begin{array}{c}\text { Valor } \\
\text { mínimo }\end{array}$ & $\begin{array}{c}\text { Valor } \\
\text { máximo }\end{array}$ \\
\hline Idade & 66,28 anos & 9,06 & $13,67 \%$ & 50 anos & 88 anos \\
\hline Peso Corpóreo & $75,32 \mathrm{~kg}$ & 11,53 & $11,53 \%$ & $48 \mathrm{~kg}$ & $101 \mathrm{~kg}$ \\
\hline Estatura & $166,87 \mathrm{~cm}$ & 6,43 & $3,85 \%$ & $157,00 \mathrm{~cm}$ & $183,00 \mathrm{~cm}$ \\
\hline Olhos-chão & $156,46 \mathrm{~cm}$ & 6,21 & $3,97 \%$ & $147,00 \mathrm{~cm}$ & $172,00 \mathrm{~cm}$ \\
\hline Acrômio-chão & $139,83 \mathrm{~cm}$ & 6,64 & $4,75 \%$ & $130,00 \mathrm{~cm}$ & $159,00 \mathrm{~cm}$ \\
\hline Cotovelo-chão & $102,96 \mathrm{~cm}$ & 4,44 & $4,31 \%$ & $95,00 \mathrm{~cm}$ & $115,00 \mathrm{~cm}$ \\
\hline Cotovelo-mão aberta & $46,38 \mathrm{~cm}$ & 2,43 & $5,25 \%$ & $41,00 \mathrm{~cm}$ & $53,00 \mathrm{~cm}$ \\
\hline Cotovelo-punho & $27,84 \mathrm{~cm}$ & 1,36 & $4,90 \%$ & $25,00 \mathrm{~cm}$ & $33,00 \mathrm{~cm}$ \\
\hline Axila-chão & $130,48 \mathrm{~cm}$ & 6,42 & $4,92 \%$ & $117,00 \mathrm{~cm}$ & $145,00 \mathrm{~cm}$ \\
\hline Acrômio-mão aberta & $74,05 \mathrm{~cm}$ & 3,56 & $4,81 \%$ & $67,00 \mathrm{~cm}$ & $85,00 \mathrm{~cm}$ \\
\hline
\end{tabular}


Tabela 2. Continnuação.

\begin{tabular}{l|c|c|c|c|c}
\hline \multirow{2}{*}{$\begin{array}{c}\text { Variáveis } \\
\text { Antropométricas }\end{array}$} & \multicolumn{4}{|c}{ Valores Amostra Masculina - Estatística de N=50 } \\
\cline { 2 - 6 } & $\begin{array}{c}\text { Desvio } \\
\text { padrão }\end{array}$ & $\begin{array}{c}\text { Coef. } \\
\text { Variação }\end{array}$ & $\begin{array}{c}\text { Valor } \\
\text { mínimo }\end{array}$ & $\begin{array}{c}\text { Valor } \\
\text { máximo }\end{array}$ \\
\hline $\begin{array}{l}\text { Circunferência } \\
\text { craniana }\end{array}$ & $57,16 \mathrm{~cm}$ & 1,40 & $2,45 \%$ & $54,00 \mathrm{~cm}$ & $61,00 \mathrm{~cm}$ \\
\hline $\begin{array}{l}\text { Circunferência } \\
\text { torácica }\end{array}$ & $97,24 \mathrm{~cm}$ & 8,01 & $8,24 \%$ & $82,00 \mathrm{~cm}$ & $117,00 \mathrm{~cm}$ \\
\hline $\begin{array}{l}\text { Circunferência } \\
\text { abdominal }\end{array}$ & $98,26 \mathrm{~cm}$ & 10,62 & $10,81 \%$ & $68,00 \mathrm{~cm}$ & $120,00 \mathrm{~cm}$ \\
\hline Largura quadril & $34,57 \mathrm{~cm}$ & 2,27 & $6,55 \%$ & $30,00 \mathrm{~cm}$ & $40,00 \mathrm{~cm}$ \\
\hline Largura acrômios & $29,09 \mathrm{~cm}$ & 2,19 & $7,33 \%$ & $25,00 \mathrm{~cm}$ & $36,00 \mathrm{~cm}$ \\
\hline Largura ombros & $45,60 \mathrm{~cm}$ & 3,20 & $7,02 \%$ & $38,00 \mathrm{~cm}$ & $53,00 \mathrm{~cm}$ \\
\hline Assento-cabeça & $85,03 \mathrm{~cm}$ & 4,29 & $5,04 \%$ & $78,00 \mathrm{~cm}$ & $97,00 \mathrm{~cm}$ \\
\hline Assento-olhos & $74,77 \mathrm{~cm}$ & 4,28 & $5,72 \%$ & $68,00 \mathrm{~cm}$ & $86,00 \mathrm{~cm}$ \\
\hline Assento-acrômio & $58,22 \mathrm{~cm}$ & 3,63 & $6,23 \%$ & $52,00 \mathrm{~cm}$ & $65,00 \mathrm{~cm}$ \\
\hline Assento-cotovelo & $21,60 \mathrm{~cm}$ & 2,87 & $13,29 \%$ & $15,00 \mathrm{~cm}$ & $27,00 \mathrm{~cm}$ \\
\hline Altura das coxas & $13,79 \mathrm{~cm}$ & 1,62 & $11,77 \%$ & $8,00 \mathrm{~cm}$ & $17,00 \mathrm{~cm}$ \\
\hline Sacro-poplítea & $48,77 \mathrm{~cm}$ & 2,41 & $4,93 \%$ & $43,00 \mathrm{~cm}$ & $55,00 \mathrm{~cm}$ \\
\hline Sacro-joelho & $59,66 \mathrm{~cm}$ & 2,39 & $4,01 \%$ & $55,00 \mathrm{~cm}$ & $66,00 \mathrm{~cm}$ \\
\hline Altura poplítea & $44,37 \mathrm{~cm}$ & 2,74 & $6,18 \%$ & $40,00 \mathrm{~cm}$ & $52,00 \mathrm{~cm}$ \\
\hline Largura do pé & $9,12 \mathrm{~cm}$ & 0,60 & $6,61 \%$ & $8,00 \mathrm{~cm}$ & $11,00 \mathrm{~cm}$ \\
\hline Comprimento do pé & $24,62 \mathrm{~cm}$ & 1,27 & $5,15 \%$ & $21,00 \mathrm{~cm}$ & $27,00 \mathrm{~cm}$ \\
\hline Altura calcânea & $7,66 \mathrm{~cm}$ & 0,88 & $11,45 \%$ & $6,00 \mathrm{~cm}$ & $10,00 \mathrm{~cm}$ \\
\hline IMC em cm ${ }^{2}$ & $26,52 \mathrm{~cm}{ }^{2}$ & 3,76 & $14,20 \%$ & $18,00 \mathrm{~cm}$ & $35,00 \mathrm{~cm}$ \\
\hline
\end{tabular}

Tabela 3. Dados quantitativos da amostragem masculina.

\begin{tabular}{l|c|c|c|c|c|c|c|c|c}
\hline \multirow{2}{*}{$\begin{array}{l}\text { Variáveis } \\
\text { Antropométricas }\end{array}$} & \multicolumn{7}{|c}{ Percentis Amostra Masculina de N= 50 } \\
\cline { 2 - 11 } & P01 & P2,5 & P05 & P10 & P25 & P50 & P75 & P95 & P99 \\
\hline Idade & 50,98 & 52,00 & 52,90 & 54,00 & 60,00 & 65,50 & 72,75 & 80,65 & 86,04 \\
\hline Peso Corpóreo & 49,72 & 53,41 & 60,45 & 61,09 & 67,25 & 76,25 & 82,00 & 95,00 & 98,55 \\
\hline Estatura cm & 157,49 & 158,23 & 159,00 & 159,00 & 161,00 & 166,00 & 169,00 & 179,01 & 182,51 \\
\hline Olhos-chão & 147,49 & 148,00 & 148,00 & 149,00 & 151,00 & 156,00 & 159,75 & 168,01 & 171,02 \\
\hline Acrômio-chão & 130,00 & 130,00 & 130,45 & 132,09 & 135,00 & 139,00 & 142,88 & 152,00 & 157,53 \\
\hline Cotovelo-chão & 95,49 & 96,00 & 96,00 & 97,09 & 100,00 & 102,00 & 105,75 & 110,55 & 113,53 \\
\hline $\begin{array}{l}\text { Cotovelo-mão } \\
\text { aberta }\end{array}$ & 41,00 & 41,23 & 42,00 & 43,00 & 45,00 & 47,00 & 48,00 & 49,55 & 52,51 \\
\hline
\end{tabular}


Tabela 3. Continuação.

\begin{tabular}{l|r|r|r|r|r|r|r|r|r}
\hline \multicolumn{1}{c|}{$\begin{array}{l}\text { Variáveis } \\
\text { Antropométricas }\end{array}$} & \multicolumn{7}{|c|}{ Percentis Amostra Masculina de N= 50 } \\
\cline { 2 - 10 } & $\mathbf{P 2 , 5}$ & P05 & P10 & P25 & P50 & P75 & P95 & P99 \\
\hline Axila-chão & 117,98 & 119,23 & 120,09 & 123,09 & 126,00 & 130,00 & 135,00 & 143,65 & 145,00 \\
\hline $\begin{array}{l}\text { Acrômio-mão } \\
\text { aberta }\end{array}$ & 67,00 & 67,23 & 68,45 & 69,09 & 72,00 & 74,00 & 76,00 & 79,55 & 83,04 \\
\hline Envergadura & 161,49 & 162,23 & 163,45 & 164,00 & 167,25 & 173,05 & 176,00 & 186,65 & 190,02 \\
\hline $\begin{array}{l}\text { Circunferência } \\
\text { craniana }\end{array}$ & 54,49 & 55,00 & 55,00 & 55,09 & 56,00 & 57,00 & 58,00 & 59,00 & 60,51 \\
\hline $\begin{array}{l}\text { Circunferência } \\
\text { torácica }\end{array}$ & 82,49 & 83,23 & 84,45 & 87,00 & 91,25 & 97,05 & 102,00 & 108,55 & 114,06 \\
\hline $\begin{array}{l}\text { Circunferência } \\
\text { abdominal }\end{array}$ & 69,96 & 74,48 & 83,09 & 85,09 & 90,25 & 99,05 & 105,00 & 114,55 & 117,55 \\
\hline Largura quadril & 30,49 & 31,00 & 31,45 & 32,00 & 33,00 & 34,00 & 36,00 & 38,55 & 39,51 \\
\hline Largura acrômios & 25,98 & 27,00 & 27,00 & 27,00 & 28,00 & 30,00 & 31,00 & 33,55 & 35,02 \\
\hline Largura ombros & 38,49 & 39,23 & 40,45 & 41,09 & 44,00 & 45,50 & 47,75 & 51,00 & 52,51 \\
\hline Assento-cabeça & 78,49 & 79,00 & 79,45 & 80,00 & 82,00 & 84,00 & 88,00 & 92,10 & 96,02 \\
\hline Assento-olhos & 68,49 & 69,00 & 69,00 & 69,09 & 72,00 & 74,00 & 77,00 & 81,55 & 85,02 \\
\hline Assento-acrômio & 52,00 & 52,23 & 53,45 & 54,00 & 55,25 & 57,50 & 61,00 & 64,55 & 65,00 \\
\hline Assento-cotovelo & 15,98 & 17,00 & 17,45 & 18,00 & 19,00 & 21,00 & 24,00 & 26,55 & 27,00 \\
\hline Altura das coxas & 9,47 & 11,00 & 11,45 & 12,00 & 13,00 & 14,00 & 15,00 & 16,00 & 17,00 \\
\hline Sacro-poplítea & 43,25 & 43,61 & 44,45 & 46,00 & 48,00 & 49,00 & 50,00 & 53,00 & 54,02 \\
\hline Sacro-joelho & 55,00 & 55,45 & 57,00 & 57,00 & 58,00 & 59,25 & 61,00 & 64,00 & 65,02 \\
\hline Altura poplítea & 40,00 & 40,00 & 40,23 & 41,00 & 43,00 & 44,00 & 45,88 & 49,55 & 51,76 \\
\hline Largura do pé & 8,00 & 8,00 & 8,00 & 8,50 & 9,00 & 9,00 & 9,50 & 10,00 & 10,76 \\
\hline Comprimentodopé & 21,49 & 22,11 & 22,33 & 23,00 & 24,00 & 24,50 & 25,50 & 26,38 & 27,00 \\
\hline Altura calcânea & 6,00 & 6,00 & 6,23 & 6,50 & 7,00 & 7,50 & 8,00 & 9,00 & 9,80 \\
\hline \begin{tabular}{l} 
IMCem cm ${ }^{2}$ \\
\hline
\end{tabular} & 18,00 & 18,45 & 20,00 & 22,00 & 24,00 & 27,00 & 29,00 & 32,00 & 34,02 \\
\hline
\end{tabular}

Tabela 4. Dados quantitativos da amostragem feminina.

\begin{tabular}{l|r|r|r|r|r}
\hline \multirow{2}{*}{$\begin{array}{c}\text { Variáveis } \\
\text { Antropométricas }\end{array}$} & \multicolumn{5}{|c}{ Valores Amostra Feminina - Estatística de N=140 } \\
\cline { 2 - 6 } & Média & $\begin{array}{c}\text { Desvio } \\
\text { padrão }\end{array}$ & $\begin{array}{c}\text { Coef. } \\
\text { Variação }\end{array}$ & $\begin{array}{c}\text { Valor } \\
\text { mínimo }\end{array}$ & $\begin{array}{c}\text { Valor } \\
\text { máximo }\end{array}$ \\
\hline Idade & 66,01 anos & 7,66 anos & $11,60 \%$ & 50 anos & 88 anos \\
\hline Peso Corpóreo & $64,30 \mathrm{~kg}$ & $10,84 \mathrm{~kg}$ & $16,85 \%$ & $40,00 \mathrm{~kg}$ & $105,05 \mathrm{~kg}$ \\
\hline Estatura & $154,27 \mathrm{~cm}$ & $5,87 \mathrm{~cm}$ & $3,81 \%$ & $136,00 \mathrm{~cm}$ & $169,00 \mathrm{~cm}$ \\
\hline Olhos-chão & $144,05 \mathrm{~cm}$ & $5,82 \mathrm{~cm}$ & $4,04 \%$ & $126,00 \mathrm{~cm}$ & $160,00 \mathrm{~cm}$ \\
\hline
\end{tabular}


Tabela 4. Continuação.

\begin{tabular}{|c|c|c|c|c|c|}
\hline \multirow{2}{*}{$\begin{array}{l}\text { Variáveis } \\
\text { Antropométricas }\end{array}$} & \multicolumn{5}{|c|}{ Valores Amostra Feminina - Estatística de N=140 } \\
\hline & Média & $\begin{array}{l}\text { Desvio } \\
\text { padrão }\end{array}$ & $\begin{array}{c}\text { Coef. } \\
\text { Variação }\end{array}$ & $\begin{array}{c}\text { Valor } \\
\text { mínimo }\end{array}$ & $\begin{array}{c}\text { Valor } \\
\text { máximo }\end{array}$ \\
\hline Coto & $\mathrm{m}$ & & & $80,00 \mathrm{~cm}$ & $104,00 \mathrm{~cm}$ \\
\hline Cotor & $42,75 \mathrm{~cm}$ & $2,12 \mathrm{~cm}$ & & & $49,00 \mathrm{~cm}$ \\
\hline Coto & $26,11 \mathrm{~cm}$ & $1,70 \mathrm{~cm}$ & & $22,00 \mathrm{~cm}$ & $32,00 \mathrm{~cm}$ \\
\hline Axila & $119,65 \mathrm{~cm}$ & 5,27 & & $105,00 \mathrm{~cm}$ & $134,00 \mathrm{~cm}$ \\
\hline Acrômio-mã & $67,90 \mathrm{~cm}$ & $3,20 \mathrm{~cm}$ & & $59,00 \mathrm{~cm}$ & $75,00 \mathrm{~cm}$ \\
\hline Enve & $158,50 \mathrm{~cm}$ & & & $137,00 \mathrm{~cm}$ & $177,00 \mathrm{~cm}$ \\
\hline & $5,28 \mathrm{~cm}$ & $1,50 \mathrm{~cm}$ & $270 \%$ & $51,00 \mathrm{~cm}$ & $6000 \mathrm{~cm}$ \\
\hline $\begin{array}{l}\mathrm{C} \\
\text { to }\end{array}$ & $92,18 \mathrm{~cm}$ & $7,65 \mathrm{~cm}$ & $8,30 \%$ & $72,00 \mathrm{~cm}$ & $113,00 \mathrm{~cm}$ \\
\hline $\begin{array}{l}\mathrm{C} \\
\mathrm{ab}\end{array}$ & $\mathrm{cm}$ & 9,46 & & $\mathrm{~m}$ & 122 \\
\hline uadril & $\mathrm{m}$ & $\mathrm{m}$ & 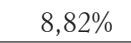 & $\mathrm{m}$ & $0 \mathrm{~cm}$ \\
\hline & & & & & $32,00 \mathrm{~cm}$ \\
\hline & $42,20 \mathrm{~cm}$ & & & $35,00 \mathrm{~cm}$ & $57,00 \mathrm{~cm}$ \\
\hline & & & & & $0 \mathrm{~cm}$ \\
\hline Asse & $69,92 \mathrm{~cm}$ & & $4,98 \%$ & $\mathrm{~cm}$ & $0 \mathrm{~cm}$ \\
\hline Assento- & $54,47 \mathrm{~cm}$ & $2,79 \mathrm{~cm}$ & $5,13 \%$ & $47,00 \mathrm{~cm}$ & $62,00 \mathrm{~cm}$ \\
\hline Assento-cotovelo & $20,44 \mathrm{~cm}$ & & & & $26,00 \mathrm{~cm}$ \\
\hline & & & & & $0,00 \mathrm{~cm}$ \\
\hline Sacro-poplítea & $46,45 \mathrm{~cm}$ & $2,79 \mathrm{~cm}$ & & $37,05 \mathrm{~cm}$ & $55,00 \mathrm{~cm}$ \\
\hline Sacro-joelho & $56,24 \mathrm{~cm}$ & $3,72 \mathrm{~cm}$ & & $45,00 \mathrm{~cm}$ & $79,00 \mathrm{~cm}$ \\
\hline Altura poplítea & $40,39 \mathrm{~cm}$ & $2,88 \mathrm{~cm}$ & $7,14 \%$ & $33,00 \mathrm{~cm}$ & $52,00 \mathrm{~cm}$ \\
\hline & & & & & $10,50 \mathrm{~cm}$ \\
\hline Comprimento do $\mathrm{p}$ & $22,31 \mathrm{~cm}$ & $1,16 \mathrm{~cm}$ & & $19,00 \mathrm{~cm}$ & $25,00 \mathrm{~cm}$ \\
\hline & & $0,74 \mathrm{~cm}$ & & $5,50 \mathrm{~cm}$ & $9,50 \mathrm{~cm}$ \\
\hline $\mathrm{IMC} \mathrm{em} \mathrm{cm}^{2}$ & $27,01 \mathrm{~cm}^{2}$ & $5,05 \mathrm{~cm}^{2}$ & $18,69 \%$ & $19,00 \mathrm{~cm}^{2}$ & $49,00 \mathrm{~cm}^{2}$ \\
\hline
\end{tabular}

Tabela 5. Dados quantitativos da amostragem feminina.

\begin{tabular}{l|r|r|r|r|r|r|r|r|c}
\hline \multicolumn{1}{c|}{$\begin{array}{c}\text { Variáveis } \\
\text { Antropométricas }\end{array}$} & \multicolumn{10}{c}{ Percentis Amostra Feminina de N=140 } \\
\hline & P01 & P2,5 & P05 & \multicolumn{1}{c}{ P10 } & P25 & P50 & P75 & P95 & P99 \\
\hline Idade & 50,39 & 52,48 & 54,00 & 57,00 & 60,00 & 66,00 & 71,00 & 78,00 & 84,22 \\
\hline Peso corpóreo & 43,70 & 46,74 & 49,45 & 52,90 & 58,00 & 62,00 & 69,13 & 83,01 & 98,03 \\
\hline Estatura & 139,95 & 143,00 & 144,00 & 146,00 & 151,00 & 154,00 & 158,00 & 162,53 & 167,4 \\
\hline
\end{tabular}


Tabela 5. Continuação.

\begin{tabular}{|c|c|c|c|c|c|c|c|c|c|}
\hline $\begin{array}{c}\text { Variáveis } \\
\text { Antropométricas }\end{array}$ & \multicolumn{9}{|c|}{ Percentis Amostra Feminina de N=140 } \\
\hline Olhos-chão & 129,56 & 133,00 & 134,00 & 136,00 & 140,75 & 144,00 & 148,00 & 152,05 & 156,6 \\
\hline Acrômio-chão & 115,17 & 117,48 & 119,00 & 122,00 & 126,00 & 129,05 & 133,00 & 137,00 & 139,6 \\
\hline Cotovelo-chão & 85,39 & 87,00 & 88,00 & 89,00 & 91,00 & 95,00 & 97,00 & 100,00 & 102,0 \\
\hline Cotovelo-mão aberta & 38,00 & 38,00 & 39,00 & 40,00 & 41,00 & 43,00 & 44,00 & 46,00 & 46,61 \\
\hline Cotovelo-punho & 22,39 & 23,00 & 23,00 & 24,00 & 25,00 & 26,00 & 27,00 & 29,00 & 30,00 \\
\hline Axila-chão & 107,39 & 109,48 & 111,00 & 112,00 & 116,00 & 120,00 & 123,00 & 127,05 & 132,4 \\
\hline Acrômio-mão aberta & 60,00 & 61,00 & 62,00 & 64,00 & 66,00 & 68,00 & 70,00 & 73,05 & 74,81 \\
\hline Envergadura & 140,78 & 144,24 & 145,00 & 150,00 & 154,00 & 158,00 & 163,00 & 170,00 & 173,8 \\
\hline $\begin{array}{l}\text { Circunferência } \\
\text { craniana }\end{array}$ & 52,00 & 52,00 & 53,00 & 53,00 & 54,00 & 55,00 & 56,00 & 58,00 & 59,00 \\
\hline $\begin{array}{l}\text { Circunferência } \\
\text { torácica }\end{array}$ & 80,00 & 80,00 & 81,00 & 83,00 & 87,00 & 91,00 & 97,00 & 106,05 & 110,2 \\
\hline $\begin{array}{l}\text { Circunferência } \\
\text { abdominal }\end{array}$ & 75,00 & 76,00 & 80,00 & 83,00 & 89,00 & 93,00 & 100,00 & 110,01 & 120,4 \\
\hline Largura quadril & 30,00 & 31,00 & 00 & 32,00 & 3,00 & 5,00 & 7,00 & 40,01 & 44,00 \\
\hline Largura acrômios & 22,00 & 22,00 & 23,00 & 24,00 & 26,00 & 27,00 & 28,00 & 30,00 & 31,00 \\
\hline Largura ombros & 36,00 & 36,48 & 37,00 & 38,00 & 40,00 & 41,25 & 45,00 & 48,05 & 51,61 \\
\hline Assento-cabeça & 71,00 & 71,95 & 73,00 & 75,00 & 78,00 & 80,00 & 83,00 & 85,00 & 86,00 \\
\hline Assento-olhos & 60,39 & 61,95 & 64,00 & 65,00 & 68,00 & 70,00 & 72,00 & 75,00 & 75,61 \\
\hline Assento-acrômio & 47,39 & 49,00 & 50,00 & 51,00 & 52,88 & 55,00 & 56,63 & 58,03 & 60,00 \\
\hline Assento-cotovelo & 15,20 & 15,74 & 16,00 & 17,00 & 19,00 & 20,00 & 22,00 & 24,53 & 25,81 \\
\hline Altura das coxas & 10,00 & 10,00 & 11,00 & 11,00 & 13,00 & 14,00 & 14,50 & 16,00 & 19,31 \\
\hline Sacro-poplítea & 39,09 & 40,48 & 42,00 & 43,00 & 45,00 & 46,05 & 48,00 & 51,00 & 52,61 \\
\hline Sacro-joelho & 48,09 & 49,24 & 51,00 & 53,00 & 54,00 & 56,00 & 58,00 & 61,00 & 64,81 \\
\hline Altura poplítea & 33,59 & 35,00 & 36,00 & 37,00 & 38,88 & 41,00 & 42,00 & 45,00 & 46,61 \\
\hline Largura do pé & 7,50 & 8,00 & 8,00 & 8,00 & 8,00 & 8,50 & 9,00 & 9,50 & 10,00 \\
\hline Comprimento do pé & 20,00 & 20,00 & 21,00 & 21,00 & 21,50 & 22,50 & 23,00 & 24,00 & 25,00 \\
\hline Altura calcânea & 6,00 & 6,00 & 6,00 & 7,00 & 7,00 & 7,50 & 8,00 & 8,50 & 9,00 \\
\hline $\mathrm{IMC} \mathrm{em} \mathrm{cm}^{2}$ & 19,39 & 20,00 & 21,00 & 22,00 & 24,00 & 26,00 & 29,00 & 358,00 & 44,88 \\
\hline
\end{tabular}

\section{Discussão}

Com o objetivo de verificar as características físicas antropométricas de idosos que subsidiem procedimentos metodológicos utilizados por pesquisadores e profissionais que investigam e concentram seus trabalhos em projetos, produtos e serviços para a população estudada, 
a pesquisa direcionou os resultados de forma quantitativa. Visando abranger a faixa etária mais ampla possível, ateve-se aos cinquenta anos em diante, alcançado a marca dos 88 anos de idade em ambos os gêneros.

No presente estudo, as mulheres representaram $73,7 \%$ da amostra, e os homens 26,3\%, num total de 190 sujeitos. Em estudos também transversais, Kubena et al. (1991) coletaram dados antropométricos em 424 idosos. As mulheres representaram 63\% da amostra e os homens 37\%. Falciglia et al. (1988) depararam com essa variabilidade entre os gêneros: do total de 746 indivíduos, $66 \%$ eram mulheres e 34\% homens. Em Menezes e Marucci (2005), que estudaram a antropometria de 305 idosos, 69,2\% eram mulheres e $30,8 \%$ eram homens.

Na variável idade cronológica, observou-se uma variabilidade de participação dos diferentes grupos etários. Os sujeitos homens de cinquenta a 59 anos de idade representam 22\% desse grupo, enquanto 44\% estão entre sessenta e 69 anos, representando a maioria; 28\% têm entre setenta e 79 anos e 6\% do grupo têm oitenta ou mais anos de idade, atingindo-se uma média de 66,28 \pm 9,06 anos.

No caso das mulheres, a média ficou em 66,01 \pm 7,66 anos de idade. Os valores assemelham-se quando observamos as porcentagens participativas de faixas etárias: 20\% desse grupo apresentou idade entre cinquenta e 59 anos; as mulheres com sessenta a 69 anos também foram maioria com 46,4\%; já as de idade entre setenta a 79 anos representaram 29,3\%, e as mais velhas (oitenta a 88 anos) participaram com 4,3\%, sugerindo uma participação mais efetiva dos grupos etários entre sessenta a 79 anos em ambos os gêneros.

Quanto à variável peso corpóreo (E01 - kg), os sujeitos masculinos marcaram a média de 75,32 $\pm 11,53 \mathrm{~kg}$, enquanto entre os do sexo feminino a média foi de $64,30 \pm 10,84 \mathrm{~kg}$. Se confrontarmos esses resultados com os dados do projeto piloto de Franco et al. (2003), observaremos uma aproximação, mesmo sendo estudos realizados com equipamentos e grupos diferentes. Vejamos: nos homens o peso médio foi de $68,07 \pm 15,59 \mathrm{~kg}$, nas mulheres a média foi $64,91 \pm$ $12,75 \mathrm{~kg}$. No presente estudo o valor máximo aferido dessa variável 
foi $101 \mathrm{~kg}$ para homens e 105,5 kg para mulheres, o valor mínimo foi $48 \mathrm{~kg}$ nos homens e $40 \mathrm{~kg}$ nas mulheres. Os resultados do projeto piloto ficaram assim distribuídos: nos homens o valor máximo alcançado foi $93 \mathrm{~kg}$, e nas mulheres $96 \mathrm{~kg}$, já os valores mínimos para homens e mulheres foram $46 \mathrm{~kg}$ e $44 \mathrm{~kg}$ respectivamente. Em Zuchetto e Trevisan (1993), o peso corporal foi uma das preocupações em relação ao estilo de vida dos idosos.

A variável estatura $(\mathrm{E} 02-\mathrm{cm})$ sugere observações quanto ao declínio do controle do equilíbrio estático e no momento em que se procediam as leituras das medidas em pé. A variável envergadura $(\mathrm{E} 10-\mathrm{cm})$ na maioria das vezes registrou medidas superiores em relação à estatura. Características físicas determinadas pelas mudanças corporais do processo de envelhecimento, que atingem a coluna vertebral e suas estruturas adjacentes, mudam a configuração corporal que antes era mais ereta e agora se mostra com as curvaturas mais acentuadas (Venturoli et al., 2004; Yuaso \& Squizzatto, 1996).

Dentre outros aspectos, esses são visíveis, podem se transformar em possíveis itens de auxílio a estudos sobre o assunto atual, integrando-os com prováveis perdas da capacidade cardiorrespiratória, das funções neuromusculares, das degenerações músculo-esqueléticas (ossos, articulações, ligamentos e tendões), talvez partindo-se para estudos longitudinais, acompanhando e correlacionando essas variáveis enquanto os indivíduos envelhecem (Franco et al., 2003; Ribas \& Ely, 2002; Mochizuki et al., 1997; DeVitta \& Rebelato, 2000).

Com essas estruturas perturbadas, um dos aspectos pertinentes comprometido pelo processo de envelhecimento são os alcances, que diminuem em decorrência das perdas de amplitude de movimentos articulares, gerando consequências para realizações de tarefas às vezes comuns, como caminhar, sentar, deitar e levantar, controle do equilíbrio, segurar objetos e manter-se numa determinada postura em amplitudes articulares acentuadas por longos períodos, levando, muitas vezes, à ideia de que a velhice está ligada a pessoas com incapacidades gerais. Não basta apenas agregar mais tempo à vida: é preciso aliar a capacidade funcional à qualidade de vida do idoso (Bomm et al., 2003; Cavalcanti \& Ely, 2002; Veras, 2001). 
Como os dados coletados de peso e altura e registrados sistematicamente possibilitaram-se os cálculos do IMC. Trata-se do índice de Quetelet, um parâmetro muito difundido nas áreas da saúde e de relativamente fácil compreensão por parte das pessoas. Para o indivíduo, o interessante é estar dentro dos parâmetros numéricos chamados "normais", ou pelo menos próximo deles. Sugestivamente é difundido que estando o indivíduo dentro das faixas tidas como "normais", ele estaria menos suscetível a futuros problemas de saúde, principalmente os cardiovasculares (diabetes e AVCs - acidentes vasculares cerebrais) ficando, portanto, distante ou fora do grupo de risco.

Os idosos aqui estudados apresentaram resultados equivalentes aos tidos como normais, com variações para mais e para menos, mas também tendências e aproximações nas faixas denominadas de risco para o desenvolvimento da obesidade. Eles estiveram assim distribuídos: o IMC nos homens foi na média $26,52 \pm 3,77 \mathrm{~kg} / \mathrm{m}^{2}$; nas mulheres $27,01 \pm 5,05 \mathrm{~kg} / \mathrm{m}^{2}$ em média. O grupo feminino foi o que mais chamou a atenção pelas marcas alcançadas, que ultrapassaram os valores denominados pela literatura como de obesidade.

A pesquisa deste capítulo foi direcionada a idosos praticantes de atividades físicas, não se verificando a frequência ou intensidade das aulas. Mesmo assim, evidências quantitativas sugerem uma melhor e mais aprofundada pesquisa na área. Uma das características do envelhecimento humano é o aumento de peso corpóreo, pelo acúmulo de gordura subcutânea, diminuição das excreções fisiológicas, pela baixa perda calórica e ingestão de alimentos hipercalóricos. Todos esses fatores aliados à inatividade ou atividades de proporções inadequadas podem colaborar com um desequilíbrio metabólico e traduzir-se em resultados insatisfatórios quanto ao IMC. Pesquisas na área mostram uma compreensível tendência na diminuição desses índices a partir dos setenta anos de idade, já que nessa faixa etária pode-se verificar uma perda de massa muscular e diminuição de gordura corporal (Nagahama et al., 2003; Gillies et al., 1999; Hafner et al., 1992).

Para complementar essas evidências, outro índice pode ser aplicado na avaliação e verificação das condições de saúde, bem como na apuração para saber o estágio físico em que a pessoa se encontra. É 
a circunferência abdominal, que é o grande marcador do excesso de gordura visceral que tem relação muito forte com o risco de cardiopatias como o enfarte. No presente estudo, os homens registraram média de 98,26 $\pm 10,62 \mathrm{~cm}$ para essa variável, enquanto as mulheres, média de 94,14 $\pm 9,46 \mathrm{~cm}$. Segundo a Sociedade Brasileira de Cardiologia (SBC), nos homens a circunferência abdominal não deve ser superior a $94 \mathrm{~cm}$, e nas mulheres deve estar abaixo de $80 \mathrm{~cm}$. Os dados apresentados sugerem melhores estudos. Também já sabe que a obesidade abdominal central é um importante fator hipertensogênico: em estudos clínicos, já foi demonstrado que indivíduos com medidas excessivas da circunferência abdominal agregam vários fatores de risco cardiovascular (Lopes et al., 2003).

Um dos principais aspectos da pesquisa foi a precisão dos equipamentos e escalas métricas utilizadas, bem como a padronização dos "parâmetros morfológicos", dando confiabilidade aos dados coletados. Quando averiguamos as médias e desvios-padrão de quatro variáveis distintas (estatura, olhos-chão, assento-cabeça e assento-olhos), verificamos que as diferenças entre as quatro variáveis são extremamente próximas, por exemplo: estatura (E02) - a média dos homens foi de 166,87 $\pm 6,43 \mathrm{~cm}$; a distância olhos-chão (E03) obteve média de 156,46 \pm 6,21 cm: a diferença entre essas medidas foi de 9 a 11 centímetros. A diferença entre assento-cabeça (S01) e assento-olhos (S02) também é muito próxima, entre 9 e 11 centímetros. As médias foram respectivamente 85,03 4,29 cm e $74,77 \pm 4,28 \mathrm{~cm}$. Observando-se os valores, nota-se uma rigorosa aproximação nos mesmos moldes acima. Para o grupo feminino, observa-se semelhança entre essas diferenças. A estatura (E02) feminina marcou média de 154,27 $\pm 5,87 \mathrm{~cm}$; a distância olhos-chão (E03) marcou média de 144,05 $\pm 5,82 \mathrm{~cm}$. Recorrendo aos dados na postura sentada, observou-se média para assento-cabeça (S01) de 79,87 \pm 3,53 cm, e assento-olhos (S02) com média de 69,62 \pm $3,47 \mathrm{~cm}$, apresentando uma diferença de médias de 9 a $11 \mathrm{~cm}$.

Aplicando o teste estatístico de coeficiente de correlação para os valores apresentados acima, observam-se as aproximações bem perto do valor 1,0: 0,98 e 0,96 para as mulheres e 0,99 e 0,94 para 
homens, demonstrando serem insignificantes as diferenças. Assim, a afirmação sobre a precisão nas medidas pode ser entendida da seguinte forma: logo após a leitura da medida da estatura, procedese à leitura da variável olhos-chão. $\mathrm{O}$ mesmo acontece na postura sentada, verifica-se a altura assento-cabeça e na sequência assento-olhos. Entre uma variável e outra não se encontra uma estrutura morfológica que está presente nas demais variáveis - uma articulação móvel que interfira diretamente nas medidas. Portanto, quando se aferem medidas de variáveis antropométricas obedecendo a padrões metodológicos, diminuem-se as chances de erros nas leituras. $\mathrm{O}$ mesmo ocorre quando estão presentes as articulações: se a amplitude de movimento ou o ângulo articular não for sempre mantido, possivelmente haverá incorreções e imprecisões nas medidas. Essa característica não ocorre nas variáveis aqui analisadas.

Todas as medidas definitivas tomadas e apresentadas no atual levantamento obedeceram aos critérios básicos da antropometria: definição da população alvo, escolha das posturas (bípede, sentada, na forma estática), utilização de equipamentos métricos precisos. Todas as medidas foram realizadas pelo mesmo pesquisador e houve padronização dos "pontos fixos", aqui denominados parâmetros morfológicos. A partir dessas características científicas, obtiveram-se dados quantitativos da antropometria de idosos, que, se utilizados adequadamente, possivelmente contribuirão com profissionais em seus projetos, produtos e serviços destinados aos mais velhos.

\section{Conclusão}

Mesmo sendo um estudo transversal, em que os sujeitos foram observados uma única vez dentro dos grupos, e tratando-se de um levantamento antropométrico com equipamentos e ferramentas relativamente simples, as análises indicaram que diante dos resultados quantitativos apresentados e das observações qualitativas descritas acerca do envelhecimento humano, o estudo em questão proporcionou uma experiência prática de aquisição de conhecimento 
científico, corroborando com a inferência quanto à exequibilidade na elaboração do Banco de Dados Antropométricos, sendo parte representativa do referido projeto informativo. Possivelmente, ele poderá estar inserido na literatura especializada, evidentemente como auxílio para estudos complementares ou aprofundados na área, de forma a aplicá-los integralmente na sociedade, visando ao bem-estar e melhora na qualidade de vida da população.

O processo de envelhecimento humano demonstra cada vez mais que as diferenças individuais determinam a continuidade sistemática de trabalhos alternativos, como apresentou o presente capítulo, implementando o acompanhamento integral, beneficiando o idoso e tornando-o participativo no aspecto da cidadania.

As considerações finais deste capítulo levam-nos a refletir quanto às contribuições diretas e indiretas para o conhecimento e para os futuros projetos antropométricos, de forma a possibilitar pesquisas, comparações e intercâmbios disponibilizando subsídios ao setor produtivo, ambientes de trabalho e AVDs.

\section{Referências bibliográficas}

BARROS, C. F. M. Casa segura: uma arquitetura para a maturidade. Rio de Janeiro: Papel e Virtual, 2000. 116p.

BOMM, R. T., ELY, V. H. M., SZÜCS, C. P. Adequação dos espaços mínimos da habitação social à circulação da cadeira de rodas - necessidade frequente da população idosa. In III Ergodesign. Anais..., PUC, Rio de Janeiro, 2003.

CAVALCANTI, P. B., ELY, V. H. B. Avaliação de instituições para a terceira idade em Florianópolis (SC): In Abergo: XII Congresso Brasileiro de Ergonomia, Anais... Recife (PE), 2002.

CHARNESS, N., BOSMAN, E. A. Human factors and age. Estados Unidos, 1992, p.495 -551.

COCHRAN, W. Sampling techniques. 3.ed. Nova Iorque: John Wiley, 1997. 555p.

DEVITTA, A., REBELLATO, J. R. Tipo de ocupação, idade e sexo como fatores de risco da osteoartrose. Revista Salusvita. Universidade do Sagrado Coração, Bauru (SP), v.19, n.1, p.133-42. 2000. 
FALCIGLIA, G., O'CONNOR, M. J., GEDLING, M. A. Upper arm anthropometric norms in elderly white subjetcs: Journal of the American Dietetic Association. v.88, n.5. University of Cincinnati, 1988, p.569-74.

FRANCO, A. N.; PASCHOARELLI, L. C.; SILVA, J. C. P. Antropometria estática de um grupo de idosos de Bauru. In: I Jornada de Ergonomia da UFJF: Anais... Juiz de Fora: Universidade Federal de Juiz de Fora, 2003.

Avaliação de equipamento antropométrico, para antropometria estática em idosos: In: III Ergodesign: Anais... Rio de Janeiro: PUC, 2003.

Investigação das condições de segurança, acessibilidade e usabilidade dos banheiros em sete instituições de idosos (asilos). In: IV Ergodesign: Anais.... Rio de Janeiro: PUC, 2004.

FRANCO, A. N. et al.Verificação da adequação entre as Normas 9050/94 da ABNT e parâmetros antropométricos de idosos da cidade de Bauru. In: Abergo: XIV Congresso Brasileiro de Ergonomia: Anais... Fortaleza (CE), 2004.

HAFNER, S. M. et al. Clustering of cardiovascular risk factors in confirmed prehypertensive individuals. Hypertension, 1992. p.38-45.

IIDA, I. Ergonomia: projeto e produção. São Paulo: Edgard Blücher, 1990. 465p.

INTERNATIONAL ASSOCIATION FOR THE STUDY OF OBESITY (IASO). International journal. In: Obesity online (NAASO).

Disponível em $<\mathrm{http} / /$ : www.iaso.org/images/ijo/2005>. Acesso em: 10 jun. de 2005.

IRSH, I. B. Doze coisas que você precisa saber para tratar a diabetes. São Paulo: American Diabetes Association (ADA), Anima, 2003. 176p.

KUBENA, K. S. et al. Anthropometry and health in the elderly. Journal of the American Dietetic Association, v.91, n.11. Texas: A e M University, 1991. p.1402-7.

LOPES, H. F., BARRETO FILHO, J. A. S., RICCIO, G. M. Tratamento não-medicamentoso da hipertensão arterial. Revista da Sociedade de Cardiologia do estado de São Paulo, v.13, n.1, jan.-fev. 2003. p.148-55.

MENEZES, T. N; MARUCCI, M. F. N. Antropometria de idosos residentes em instituições geriátricas em Fortaleza (CE). Revista saúde pública, n.39 (2), USP, 2005. p.169-75.

MINISTÉRIO DO PLANEJAMENTO. Instituto Brasileiro de Geografia e Estatística (IBGE). In: Perfil dos Municípios Brasileiros, 2000.

Disponível em: <http//: www.ibge.gov.br/home/estatísticas/2005/ default.shtm>. Acesso em: 10 jun. de 2005. 
NERI, A. L., FREIRE, S. A. (Orgs.) E por falar em boa velhice. Campinas: Papirus, 2000. 135p.

ORGANIZAÇÃO MUNDIAL DA SAÚDE (OMS). El estado físico: uso e interpretación de la antropometria. Informe de um Comitê de Expertos de la OMS; n 854; 1995.

PADOVANI, C. R. Estatística na metodologia da investigação científica. Botucatu: Instituto de Biociências, Departamento de Bioestatística da Unesp,1995. 22p.

PASCHOARELLI, L. C. O posto de trabalho: carteira escolar como objeto de desenvolvimento da educação infantil - uma contribuição do design e da ergonomia. Bauru, 1997. 121p. Dissertação (Mestrado em Desenho Industrial) - Faculdade de Arquitetura, Artes e Comunicação da Universidade Estadual Paulista.

QUARESMA, M., MORAES, A. Aplicando a antropometria ao design de produto - estações de trabalho e mobiliários. Revista estudos em Design, PUC, v.8, n.3. Rio de Janeiro, 2000, p.27-51.

QUEIROZ, H. F. M. Levantamento de dados antropométricos de alunos universitários da Unesp, Bauru. 2000. 77p. Relatório apresentado à Fapesp, Bolsa de Iniciação Científica - Universidade Estadual Paulista.

RIBAS, V. G., ELY, V. H. M. Parâmetros para moradia da terceira idade. In: II Ergodesign. Anais... Rio de Janeiro: PUC, 2002.

SILVA, J. C. P. Levantamento de dados antropométricos da pré-escola ao primeiro grau na rede escolar de Bauru (SP). Bauru, 1997. Tese (Livre Docência) - Faculdade de Arquitetura, Artes e Comunicação da Unesp.

SMITH, S., NORRIS, B., PEEBLES, L. Older adultdata: the handbook of measurements and capabilities of older adult. Institute for Occupational Ergonomics, University of Nottingham, NG7 2RD, 2000. 217p.

VENTUROLI, T., BOSCOV, I., SOARES, L. A ciência da vida longa-viver mais e melhor. Veja: Ed.1871, ano 37, n.37. Abr.-set. de 2004, p.96-108.

VILLA, L. C. Levantamento de dados antropométricos dos estudantes do ensino médio na rede escolar da cidade de Bauru (SP). Bauru, 2001. 73p. Relatório apresentado à Fapesp, Bolsa de Iniciação Científica Universidade Estadual Paulista.

YUASO, D. R., SGUIZZATTO, G. T.. In: PAPALÉO NETO, M. Gerontologia - Fisioterapia em pacientes idosos. São Paulo: Atheneu, 1996. p.331-47.

ZUCHETTO, A. T., TREVISAN, C. M. Estudo descritivo das variáveis relacionadas à saúde e estilo de vida na terceira idade. Revista Saúde. v.19 (3-4), Universidade Federal de Santa Maria (SC), 1993. p.61-6. 


\title{
4 \\ AvaliaÇÃo de FORÇAS DE PREENSÃo DIGITAL: PARÂMETROS PARA O DESIGN ERGONÔMICO DE PRODUTOS
}

\author{
Bruno Montanari Razza \\ Luis Carlos Paschoarelli ${ }^{2}$
}

\section{Introdução}

Para desempenhar muitas atividades da vida diária, a preensão é aliada à aplicação de força muscular, permitindo a manipulação de objetos e a realização de tarefas cotidianas. No trabalho, a maior parte das atividades é realizada por meio da intervenção humana, e a realização dessas operações é determinada pela habilidade do trabalhador em realizar o trabalho mecânico, diretamente dependente de sua capacidade muscular (Mital \& Kumar, 1998a).

Entretanto, são comuns atividades que ultrapassam os limites da versatilidade dos membros superiores, fazendo com que as mãos excedam suas capacidades. Apesar da crescente automação no ambiente industrial, muitas tarefas ainda apresentam grande demanda de esforços manuais, como, por exemplo, certas atividades de manutenção, carregamento de cargas, transporte de pacientes em hospitais e operação de algumas máquinas e equipamentos, dentre outras (Imrhan, 1991; Kim \& Kim, 2000).

1 Mestre em design, Universidade Estadual de Maringá.

2 Pós-doutorado em ergonomia, Universidade Estadual Paulista. 
O dimensionamento incorreto dessa variável (força) pode gerar limitações nas tarefas, tanto para os usuários mais fortes (de mãos menos sensíveis), podendo provocar acionamentos acidentais, quanto para os mais fracos, que trabalharão com sobrecarga de seus sistemas ósteo-musculares, sob risco de lesão, ou simplesmente de não conseguir realizar a atividade (Pheasant, 1996; Mital \& Kumar, 1998a).

Essas exigências inadequadas de força, além de outras variáveis como repetitividade, desvios extremos e frequentes do punho, concentração de pressão, vibração e exposição ao frio, têm levado a um aumento nos diagnósticos de doenças ocupacionais em membros superiores, como síndrome do túnel do carpo, tenossinovites e tendinites (Kattel et al., 1996). Nos Estados Unidos, 45\% do total de lesões na indústria estão relacionadas à aplicação de forças com as mãos, transporte manual de cargas e uso de ferramentas manuais, apresentando um custo anual de mais de 150 bilhões de dólares (Aghazadeh \& Mital, 1987).

As preensões digitais, particularmente, têm sido associadas a altos índices de Distúrbio Ósteo-muscular Relacionado ao Trabalho (DORT). Armstrong e Chaffin (1979) propuseram essa associação quando estudaram a incidência de síndrome do túnel do carpo em costureiras. Dos dois grupos de costureiras avaliados, um sadio e o outro com a doença previamente diagnosticada, observaram que o grupo com a patologia fez uso de preensões digitais mais frequentemente que o grupo sadio. Chao et al. (1976) também haviam indicado que as preensões digitais provocam, no segundo e terceiro tendões do músculo flexor digital profundo, cargas três a quatro vezes maiores que a força real efetuada, enquanto a preensão palmar provoca tensões de apenas duas a três vezes. Essa tensão decorrente da preensão digital pode ser ainda mais intensificada se houver associação com desvios de punho (Eksioglu et al., 1996). Por esses motivos, Keyserling et al. (1993) incluíram o uso de preensões digitais como um fator de risco em seu método de avaliação ergonômica de tarefas manuais.

Dessa forma, é notável a importância da compreensão correta do funcionamento biomecânico dos membros superiores e dos órgãos preênseis, particularmente com relação a tarefas que exigem aplicação de força. Segundo Lowe \& Freivalds (1999), dentre todos 
os fatores de risco de desenvolvimento de DORT, a aplicação de força é a variável mais complexa de avaliar, por envolver influências de inúmeras condições. Essas condições podem estar relacionadas a características dos indivíduos (gênero, idade, antropometria), da postura (desvios de punho, posição do antebraço), da tarefa e do ambiente (repetitividade, localização do objeto, ruído) e do objeto (forma, tamanho, acabamento superficial). Essas variáveis serão discutidas mais detalhadamente no referencial teórico.

Além das doenças ocupacionais, são relatados também muitos problemas relacionados a demandas inadequadas de força em embalagens, principalmente em produtos fechados a vácuo ou que possuem lacres de segurança contra crianças. O processo de fechamento dessas embalagens, além do objetivo de preservar alimentos perecíveis, tem o intuito de prevenir aberturas acidentais e evitar que os consumidores experimentem os produtos antes de comprálos (Voorbij \& Steenbekkers, 2002). A solução ideal seria projetar embalagens e produtos que possam ser utilizados pela maioria da população, incluindo todos os indivíduos adultos que vivem independentemente. Entretanto, por diversos motivos (dentre eles a falta de normas reguladoras), esses produtos chegam ao consumidor com as mais variadas demandas de força (idem).

Ilustrando esses argumentos, Crawford et al. (2002) relatam que no Reino Unido, em 1994, houve 550 acidentes com a abertura de frascos de vidro e 610 acidentes com a abertura de frascos de plástico, sendo essas ocorrências atribuídas ao uso de ferramentas cortantes, empregadas para auxiliar na abertura de tampas duras e lacres difíceis de serem retirados apenas com as mãos. Imrhan (1994) acrescenta que esses índices poderiam ser ainda mais graves, pois muitos produtos nos quais é notória a dificuldade de uso são evitados pelos consumidores, e o simples fato de terem um consumo mais restrito por determinado grupo de pessoas já deveria ser considerado um índice relevante.

Essas ocorrências de doenças ocupacionais, acidentes e lesões poderiam ser minimizadas com o projeto adequado de produtos e tarefas, mas isso somente será possível quando já se houver estabelecido parâmetros seguros das variáveis envolvidas na atividade em 
questão. Para suprir parte dessa necessidade, torna-se necessária a realização de levantamentos da capacidade biomecânica das mãos ao desempenharem tarefas cotidianas, principalmente aquelas nas quais há exigência de força muscular. Tendo em vista a quantidade de produtos manipuláveis disponíveis em nosso entorno material, essa necessidade fica cada vez mais evidente, exigindo esforços conjuntos das áreas do design, da ergonomia, da fisioterapia e da engenharia de produção, dentre outras. É possível reconhecer esse perfil multidisciplinar ao observar os enfoques específicos dados a cada pesquisa na área, proporcionando, a partir de contribuições especializadas, a formação de conhecimento na área do conhecimento biomecânico, que ainda está em processo de formação.

\section{Revisão bibliográfica}

Muitos estudos estão sendo realizados com o objetivo de avaliar a capacidade manipulativa das mãos, principalmente com relação à aplicação de força. Napier (1956), uma das primeiras referências nesse campo, estudou os movimentos da mão e classificou as preensões em dois grupos: as preensões de força (preensões palmares) e as preensões de precisão (preensões digitais). Outra referência importante nesse campo é o estudo de Kapandji (1987), que ampliou a gama das preensões para: preensões puras (palmares, digitais e centradas), preensões com peso (auxiliadas pela gravidade) e preensões-ações (associadas a movimentos) (figura 17).

Existem também outras classificações (Cutkosky \& Wright, 1986 apud Kinoshita et al. 1996), mas neste capítulo será adotada a nomenclatura definida por Kapandji (1987). Alguns pesquisadores propuseram-se a realizar estudos com o objetivo de gerar dados normativos de força, formando uma base de dados de normalidade para tratamentos clínicos e de parâmetros para o projeto de produtos e equipamentos (Hanten et al., 1999; Mathiowetz et al., 1985a; Crosby et al., 1994; Thorngren \& Werner, 1979). Um dos primeiros estudos nesse sentido foi realizado por Kellor et al. (1971) e, apesar 


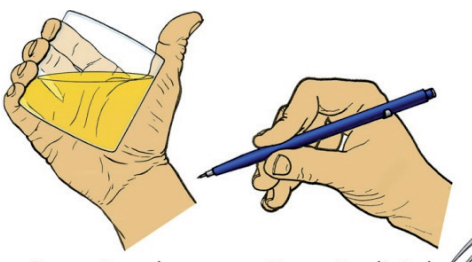

Preensão palmar

Preensão digital

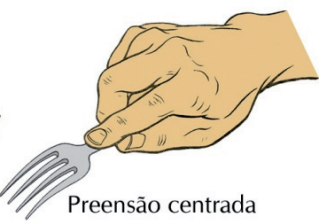

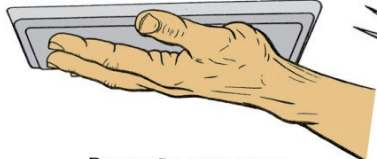

Preensão com peso

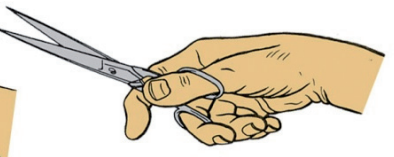

Preensão-ação

Figura 17. Tipos de preensão definidos por Kapandji (1987). Fonte: adaptado de Kapandji (1987, p.267, 273, 277, 279 e 281).

de apresentar alguns problemas metodológicos, gerou dados de força e destreza para diagnósticos mais seguros de lesões na fisioterapia.

Alguns estudos também se preocupam em explorar padrões de comportamento da força com o intuito de propor modelos biomecânicos capazes de estimar a capacidade muscular de um indivíduo com base em dados preexistentes (idade, gênero, antropometria, lateralidade etc.) mais fáceis de serem obtidos (Hanten et al., 1999; Voorbij \& Steenbekkers, 2001; Roman-Liu \& Tokarski, 2005; Eksioglu et al., 1996; Niosh, 1981; Waters et al., 1993). Entretanto, Peebles e Norris (2000, 2003) e Pheasant (1996), ao afirmarem que as variáveis da tarefa influenciam mais acentuadamente a força manual que as características individuais, ressaltam as dificuldades que esses modelos teriam para estimar com precisão e confiabilidade a força de um indivíduo.

O estudo das capacidades biomecânicas do homem, principalmente quanto aos limites de força e resistência, é muito amplo e complexo, e a maior parte dos esforços está ainda concentrada na avaliação das forças de preensão, tanto palmares quanto digitais. Entretanto, alguns autores têm proposto novas abordagens nesse campo, buscando reproduzir em laboratório algumas interfaces comumente encontradas nas tarefas ocupacionais ou em atividades 
da vida diária. Com o objetivo principal de gerar parâmetros ergonômicos para o design de produtos e tarefas (e não necessariamente uma base de dados para avaliação clínica), esses estudos vêm abordando forças de tração, compressão e torque aliadas a preensões digitais e palmares sob diversas interfaces.

No campo do design, a principal referência até o presente momento é o trabalho desenvolvido pelo Departamento de Comércio e Indústria do Reino Unido em conjunto com a Universidade de Nottingham, que teve por objetivo gerar parâmetros de forças manuais para o design de produtos mais seguros e adequados ao uso (Peebles \& Norris, 2003). De acordo com os autores, a maior parte dos dados de força disponíveis não pode ser aplicada diretamente para o design de produtos, pois seguiram posicionamentos padronizados não relacionados com tarefas cotidianas que não correspondem com a real interação entre indivíduos e produtos.

\section{Variáveis de influência nas forças manuais}

Conforme mencionado anteriormente, uma das características mais marcantes nos estudos que avaliam forças manuais é a presença de inúmeras variáveis interferindo nos resultados. Para uma melhor compreensão do comportamento dos principais fatores de influência na força manual, foi proposta uma divisão dessas variáveis entre as características individuais (variáveis relacionadas aos sujeitos das pesquisas, como gênero, idade, lateralidade, antropometria etc.) e as características anatômicas e biomecânicas (relacionadas à atividade e ao organismo humano, como postura corporal e das diversas articulações etc.).

\section{Características individuais}

De acordo com Sanders \& McCormick (1993), das muitas características individuais que podem afetar a força, o gênero apresenta as 
maiores diferenças em valores médios - o gênero feminino gera forças de aproximadamente dois terços (67\%) da força do gênero masculino, podendo ainda variar de 35\% a 89\% dependendo do grupo muscular avaliado. Nas forças de preensão digital, alguns autores relatam que a força do gênero feminino pode ser de $57 \%$ a $63 \%$ da força do gênero masculino (Dempsey \& Ayoub, 1996; Hefferman; Freivalds, 2000; Shih \& Ou, 2005), enquanto outros apresentam valores em torno de 70\% a 73\% (Araújo et al., 2002; Crosby et al., 1994). A variação da força ao longo da vida foi o objetivo de estudo de várias pesquisas sobre forças manuais. A maioria dos autores apresenta uma tendência comum de variação da força manual relacionada à idade do indivíduo, havendo um pico de força no início da fase adulta (25-29 anos), um período de estabilidade até o início da velhice ( 55 anos) e um declínio gradual com o avanço da idade (Mathiowetz et al., 1985a; Montoye \& Lamphiear, 1977; Voorbij \& Steenbekkers, 2001; Mathiowetz et al., 1986, entre outros).

A força potencial de um músculo pode ser estimada pela medição de sua seção circular em repouso, tendo-se em vista que o número de elementos contráteis é proporcional ao volume desse músculo (Kozin et al., 1999). Essa premissa leva a crer em uma relação entre variáveis antropométricas, principalmente não-lineares, e a força muscular de um indivíduo. Assim, vários estudos vêm propondo correlações entre a antropometria e a força manual. Entretanto, Chaffin et al. (2001) comentam que, em geral, medidas antropométricas (peso, tamanho e forma) de um indivíduo não são suficientes para determinar sua capacidade de realização de força. Acrescentam ainda que esse critério (antropometria) não deve ser utilizado para estimar a capacidade de trabalho de um indivíduo, fator bastante utilizado para a seleção de pessoal em tarefas que exigem maior aplicação de força. Para as forças de preensão digital, as correlações encontradas eram em geral fracas ou inexpressivas e apenas relacionadas a algumas variáveis muito particulares.

A lateralidade, isto é, a assimetria entre os hemisférios cerebrais no controle de certas funções, tem sido muito avaliada nas atividades 
manuais. Assim como a fala, predominantemente dominada pelo hemisfério esquerdo, existe uma relação entre a preferência manual (destro ou canhoto) e a lateralidade cerebral. Entretanto, essa relação entre a mão preferencial e o hemisfério cerebral predominante não é tão clara - o cérebro dos canhotos não é simplesmente uma versão espelhada da organização cerebral dos destros (Coren, 1992 apud Agtmael et al., 2001). A maioria dos estudos aponta que a mão dominante dos destros é mais forte em $6 \%$ a $14 \%$ que a não-dominante (Petersen et al., 1989; Imrhan \& Loo, 1989; Crosby et al., 1994; Imrhan \& Jenkins, 1999; Lindahl et al., 1994; O'Driscoll et al., 1992). Para os canhotos, os estudos apontam que a mão dominante é igualmente ou apenas ligeiramente mais forte (1-2\%) que a mão não-dominante (Crosby et al., 1994; Petersen et al., 1989; Schmauder et al., 1992).

\section{Variáveis anatômicas, biomecânicas e da tarefa}

A localização e o tamanho dos objetos, ferramentas e equipamentos alteram a postura do punho e dos dedos, modificando a posição e comprimento da musculatura em relação às articulações dos membros superiores (Shih; \& Ou, 2005; Roman-Liu \& Tokarski, 2005). Sob diferentes posicionamentos a força manual certamente sofrerá alterações, pois há mudanças na relação de comprimento-tensão dos músculos (Richards, 1997; Dempsey \& Ayoub, 1996).

Os desvios de punho causam compressão dos tendões flexores dos dedos contra as paredes do túnel do carpo e outras estruturas internas. Nas posições estendida e flexionada, a compressão das membranas sinoviais (que envolvem os tendões) também leva a um aumento de tensão no nervo médio que, aliada a ações repetitivas, pode resultar na síndrome do túnel do carpo (Imrhan, 1991; Armstrong \& Chaffin, 1979). Por esses motivos, a influência de posições não-neutras do punho sobre a força de preensão digital tem sido bastante estudada recentemente (figura 18). De acordo com Kapandji (1990) a posição do punho que proporciona a máxima eficiência dos músculos que 
controlam os dedos (especialmente os flexores) para a realização das preensões é com uma pequena extensão do punho (40-45 ) e ligeiro desvio ulnar $\left(15^{\circ}\right)$. Esses resultados são respaldados pelo conhecimento anatômico dos membros superiores, no qual se afirma que os tendões flexores do punho ficam relativamente encurtados quando o punho está na posição neutra; esse encurtamento é agravado com a flexão do punho (Kraft \& Detels, 1972).
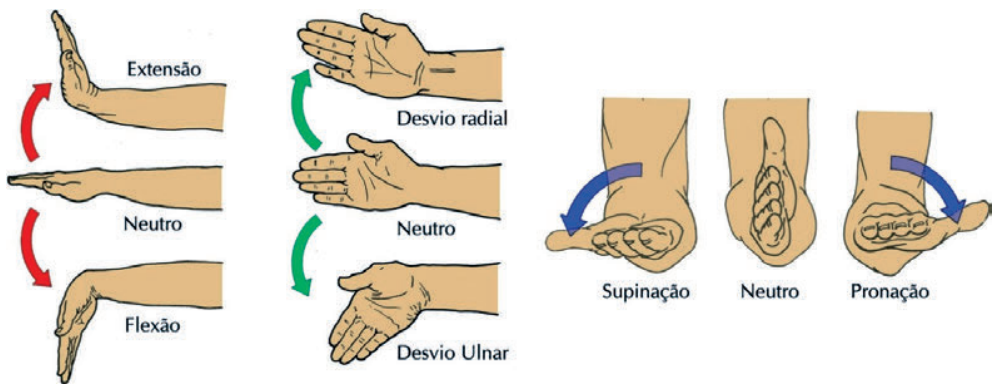

Figura 18. Desvios de punho (flexo-extensão e radio-ulnar) e desvios de antebraço (pronosupinação). Fonte: adaptado de Kapandji (1987, p.109 e 143).

\section{Avaliações da preensão digital}

As preensões digitais desempenham um papel crucial na manipulação de pequenos objetos, tanto no ambiente ocupacional (fabricação de objetos e na montagem de componentes) quanto em ações da vida cotidiana (escrever, segurar objetos, virar chaves, preparação de alimentos, abertura de embalagens, manipulações finas etc.) (Mital \& Kumar, 1998b; Imrhan, 1994). Apesar de constituírem movimentos mais delicados e precisos, em muitos trabalhos industriais as preensões digitais são também empregadas para a aplicação de grandes forças, principalmente em objetos que são pequenos demais para a preensão palmar ser empregada, ou onde há restrições de espaço, posturas corporais inadequadas ou uma orientação peculiar do objeto a ser manipulado (Imrhan, 1991). 
O tipo de preensão influencia muito a aplicação de força por parte do indivíduo, devido às diferentes configurações assumidas pelos ossos, tendões, músculos e ligamentos (figura 19). Pela análise dos vários estudos realizados é possível verificar certo padrão de variação da força entre os tipos de preensão digital. Tomando-se da mais forte para a mais fraca, as preensões podem ser ordenadas da seguinte maneira: preensão pulpo-lateral, preensão tridigital, preensão bidigital polegar/indicador (terminal e subterminal) e preensão bidigital polegar/médio (Dempsey \& Ayoub, 1996; Imrhan, 1991; Araújo et al., 2002). Entretanto, essa ordenação é ainda questionável, principalmente com relação às preensões tridigital e pulpo-lateral.

Ager et al. (1984), Imrhan \& Jenkins (1999) e Imrhan \& Rahman (1995) apresentaram valores significativamente maiores para a preensão tridigital, em detrimento da pulpo-lateral. Outros estudos não encontraram diferenças significativas entre essas duas preensões (Mathiowetz et al., 1985a).

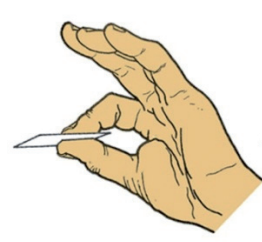

A - Bidigital 2

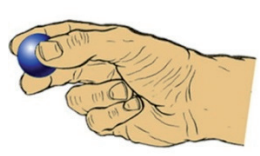

D - Tridigital

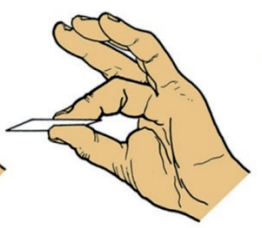

B - Bidigital 3

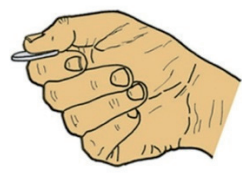

E - Pulpo-lateral

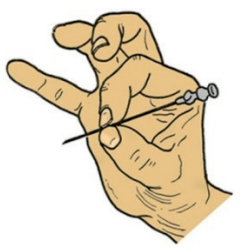

C - Bidigital 2

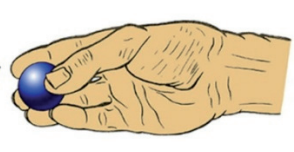

F - Pentadigital

Figura 19. Preensões digitais mais comuns: A) preensão bidigital subterminal de oposição do polegar ao indicador; B) preensão bidigital subterminal de oposição do polegar ao médio; C) preensão bidigital terminal de oposição do polegar ao indicador; D) preensão tridigital de oposição do polegar aos dedos indicador e médio; E) preensão de oposição do polegar à face lateral do indicador; e F) preensão pentadigital. Fonte: Adaptado de Kapandji (1987, p.265, 267 e 271). 
Como o tamanho, a forma e a localização dos objetos alteram a FPD, é muito importante o conhecimento dessas variáveis nessa atividade (Mital \& Kumar, 1998b). Estudos que analisaram a influência de pegas de diferentes tamanhos na força de preensão digital observaram que para as preensões bidigital e tridigital há maiores resultados de força em pegas de 44 a $50 \mathrm{~mm}$; no entanto, para a preensão pulpo-lateral os estudos são discordantes (Imrhan \& Rahman, 1995; Dempsey \& Ayoub, 1996; Shivers et al., 2002).

\section{Objetivos}

O objetivo da pesquisa foi desenvolver um estudo biomecânico paramétrico, envolvendo indivíduos de uma amostra populacional adulta, categorizados de acordo com os diferentes gêneros, objetivando especificar as forças de manipulação empregadas nas atividades da vida diária (AVD), por meio de ações funcionais simuladas (particularmente a tração associada a preensões digitais) possibilitando apresentar parâmetros para o design ergonômico de produtos industriais seguros e confiáveis e testar a hipótese da pesquisa.

\section{Materiais e métodos}

\section{Aspectos éticos}

Os procedimentos da pesquisa foram aprovados pelo Comitê de Ética em Pesquisa da Faculdade de Medicina de Botucatu (Universidade Estadual Paulista) e foram atendidas as recomendações do Conselho Nacional de Saúde (Resolução 196-1996) e da Associação Brasileira de Ergonomia (ERG BR 1002) para pesquisas que envolvem seres humanos. O consentimento por escrito dos sujeitos para participar do estudo como voluntários não-remunerados foi obtido e todos os procedimentos foram amplamente explicados aos sujeitos. 


\section{Sujeitos}

Participaram do experimento sessenta indivíduos selecionados da população de estudantes da Universidade Estadual Paulista, sendo trinta do gênero masculino e trinta do gênero feminino, todos adultos e destros. A idade média do gênero feminino foi de 21,60 anos (D. P. 3,05), em um intervalo de 18 a 30 anos; para o gênero masculino, a idade média foi de 21,83 anos (D. P. 2,46), em um intervalo de 18 a 28 anos. Nenhum dos sujeitos apresentou qualquer sintoma de doença músculo-esquelética nos membros superiores ou qualquer histórico de lesão nas mãos e punhos no último ano. Para garantir que a amostra fosse integralmente destra foi empregado o Inventário de Edimburgo (Oldfield, 1971), que avalia por meio de questões subjetivas o grau de lateralização do indivíduo.

\section{Materiais}

A medição da força da contração isométrica voluntária máxima foi coletada com um dinamômetro digital AFG500 (Mecmesin Ltd., Inglaterra), com capacidade máxima de $500 \mathrm{~N}$, exatidão de $0,1 \%$ de fundo de escala, interface de comunicação analógica $+4 \ldots 0 \ldots-4 \mathrm{~V}$ de fundo de escala, interface de comunicação digital RS-232 e taxa de amostragem máxima de $5000 \mathrm{~Hz}$. Os dados foram aquisitados por um computador pessoal com sistema operacional Windows XP $\left(\right.$ Microsoft $^{\circledR}$, versão 2002) e foi desenvolvido um software (SAD$\mathrm{BIO}$ - Sistema de Aquisição de Dados Biomecânicos, Labview 7.0, National Instruments ${ }^{\circledR}$, Inglaterra) específico para o estudo.

Os sujeitos realizaram as medições em três pegas representando objetos de três alturas diferentes, sendo uma apresentando uma altura de $40 \mathrm{~mm}$ ( 40 x 40 x $40 \mathrm{~mm}$ ), outra de $20 \mathrm{~mm}(20 \times 40 \times 40 \mathrm{~mm})$ e outra apresentando uma extensão em tecido de aproximadamente $1 \mathrm{~mm}$ de espessura $(1 \times 40 \times 40 \mathrm{~mm})$. Nas pegas de $20 \mathrm{~mm}$ e $40 \mathrm{~mm}$ foi aplicado tecido em toda a superfície de contato com as mãos para a padronização da textura na interface mão-objeto, além de ter sido 
aplicado um arredondamento nos cantos para evitar concentração de tensão nas mãos dos sujeitos (figura 20).

Também foram empregados equipamentos para a coleta das variáveis antropométricas e protocolos impressos para a coleta de dados pessoais dos sujeitos, o consentimento em participar do estudo e o nível de lateralidade (Edinburgh Inventory, Oldfield, 1971).
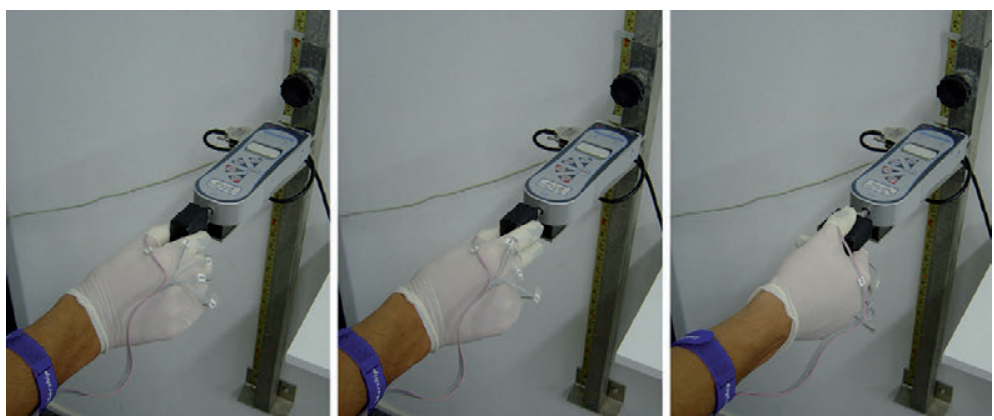

Figura 20. Equipamentos de avaliação e os tipos de preensão digital avaliados (da esquerda para a direita: bidigital, tridigital e pulpo-lateral).

\section{Procedimentos}

Os sujeitos nesse experimento exerceram a força máxima de puxar (contração isométrica voluntária máxima) com preensões digitais, sendo avaliada a combinação de três variáveis do experimento: 1) tamanho da pega: as pegas avaliadas apresentavam três variações de altura $(40,0 \mathrm{~mm}, 20,0 \mathrm{~mm}$ e 2,0 $\mathrm{mm})$ que possibilitaram avaliar três diferentes aberturas de preensão; 2) tipo de preensão: foram realizadas forças de puxar com as preensões bidigital pulpo-lateral (lateral-pinch - key-pinch), tridigital (three-jaw chuck-pinch) e bidigital polegar-indicador ( $p u l p-2) ; 3$ ) lateralidade: as medições foram realizadas com as mãos esquerda e direita.

Isso constituiu um total de 18 diferentes variáveis ( $3 \times 3 \times 2)$. Atributos pessoais dos sujeitos (idade, gênero), variáveis antropométricas (estatura, peso, comprimento da mão, largura da mão, largura meta- 
carpal, comprimento palmar, comprimento de cada dedo e distância cotovelo-chão) e a percepção subjetiva do esforço executado pelos voluntários também foram coletados.

Para a avaliação da contração isométrica voluntária máxima no ato de puxar, foi pedido ao indivíduo para permanecer na postura em pé, de frente ao equipamento, o cotovelo do membro superior avaliado flexionado em $90^{\circ}$, o antebraço na posição neutra alinhado horizontalmente e o punho posicionado livremente de acordo com a preferência do sujeito. O equipamento foi posicionado na altura do cotovelo do indivíduo. Esse posicionamento segue os procedimentos adotados por Peebles \& Norris (2003) e as diretrizes de Daams (1993). Foi pedido aos sujeitos para manterem os dedos não-atuantes na preensão flexionados junto à palma da mão, pois essa medida foi indicada pela literatura por apresentar uma grande influência na força realizada (Hook \& Stanley, 1986). Na medição da tração com as preensões bidigital e tridigital, o punho permaneceu em extensão e ligeiro desvio ulnar. Essa condição já havia sido advertida por Mathiowetz et al. (1984) e não deve implicar prejuízos para os resultados finais. Em todas as medições os sujeitos utilizaram luvas de borracha nas mãos.

A força resultante da contração isométrica voluntária máxima foi coletada num intervalo de cinco segundos, descartado-se o primeiro e o último segundo. Foi tomada como resultado a média de força obtida no intervalo de três segundos. Essas medidas foram empregadas previamente em outras abordagens e mostraram-se eficazes para garantir resultados mais homogêneos.

Para a comprovação da validade da coleta foi realizada uma segunda medição e observou-se se a diferença entre os valores obtidos nas duas medições não variou mais de 10\%. Quando essa variação era inferior a $10 \%$, foi considerada como resultado a coleta que obteve o valor médio mais alto, e, se a variação fosse superior a 10\%, uma terceira medição era realizada; nesse caso eram observadas as duas medições que apresentassem menos de 10\% de diferença entre si e adotava-se como resultado a maior. Quando as três medições variaram mais de $10 \%$ entre si, tomou-se como resultado a coleta de maior valor. 
Os sujeitos foram instruídos a exercerem sua força máxima, assim que ouvissem o sinal sonoro, sem movimentos súbitos, num intervalo de aproximadamente um segundo, e manterem essa contração até ouvirem novamente o sinal sonoro (cinco segundos de medição), de acordo com as recomendações de Caldwell et al. (1974).

Foi oferecido um feedback positivo e geral para os sujeitos, informando-os se os procedimentos estavam correndo da maneira adequada e se suas ações estavam corretas. Não foi fornecida informação sobre o desempenho dos indivíduos e também não havia a presença de expectadores no ambiente de estudo. A ordem de mensuração das variáveis era aleatória de modo a evitar influências de variáveis externas desconhecidas no estudo. Foi oferecido um intervalo de trinta segundos a um minuto entre as medições. Os sujeitos eram encorajados a pedirem intervalos maiores caso sentissem necessidade, atendendo às recomendações de Caldwell et al. (1974), Chaffin \& Andersson (1990) e Mital \& Kumar (1998). Quando o pesquisador notava que o voluntário poderia estar fatigado, esses intervalos para descanso eram conferidos mesmo sem a solicitação expressa do sujeito.

\section{Análise dos dados}

Em todos os resultados da pesquisa foi empregada análise estatística descritiva. A análise de variância (ANOVA) foi empregada para determinar influências significativas das variáveis do teste (tipo de preensão digital, tamanho da pega, mão empregada e gênero dos sujeitos) na força de puxar. O nível de significância do teste ANOVA foi determinado em $5 \%(\mathrm{p} \leq 0,05)$.

\section{Resultados}

Com relação às medidas antropométricas, o gênero masculino foi significativamente $(\mathrm{p} \leq 0,05)$ maior que o gênero feminino, com 
exceção do IMC. A diferença antropométrica existente entre as mãos esquerda e direita não foi significativa estatisticamente. Os resultados da força de puxar com as preensões digitais estão apresentados na tabela 6 . Pode-se observar que o gênero masculino apresentou maiores forças que o gênero feminino em todas as variáveis analisadas e essas diferenças foram, em sua maioria, significativas estatisticamente, com apenas algumas exceções nas variáveis que apresentaram menor magnitude de força (algumas preensões bidigitais, especialmente com a mão esquerda). O gênero feminino realizou em média 76,96\% da força do gênero masculino. Para as preensões bidigital e tridigital, é aparente uma tendência de aumento da força com o aumento da abertura da preensão (figura 21).

Da pega de $1 \mathrm{~mm}$ para a pega de $20 \mathrm{~mm}$, essas preensões apresentaram um aumento de força de aproximadamente $5 \%$ a $12 \%$; da pega de $20 \mathrm{~mm}$ para $40 \mathrm{~mm}$ o aumento foi um pouco menor, $1,7 \%$ a $7 \%$; e da pega de $1 \mathrm{~mm}$ para a de $40 \mathrm{~mm}$ o aumento foi maior, de $13 \%$ a $21 \%$, sendo que para a preensão tridigital essas diferenças foram significativas para o gênero masculino. Para a preensão pulpo-lateral, no entanto, o comportamento da força foi diferente: a abertura da preensão que apresentou os maiores valores de força foi a de $20 \mathrm{~mm}$, sendo que o aumento da abertura da preensão de $20 \mathrm{~mm}$ para $40 \mathrm{~mm}$ gerou uma redução na força de aproximadamente 2,5 a 4\%.

A análise estatística (ANOVA) apontou que a preensão pulpolateral é significativamente mais forte que a preensão bidigital, em todas as situações avaliadas. Para o gênero masculino, a preensão pulpo-lateral também é significativamente mais forte que a preensão tridigital em todas as pegas, mas, para o gênero feminino, essa diferença é apenas significativa na pega de $1 \mathrm{~mm}$. A preensão tridigital também se mostra mais forte que a bidigital, mas a diferença é apenas significativa na pega grande, para ambos os gêneros. Também foi observada uma diferença significativa entre essas preensões na pega pequena com a mão direita para o gênero masculino. As preensões bidigital e tridigital representam, em média, $66 \%$ e $81 \%$ da força da preensão pulpo-lateral, respectivamente. 
Tabela 6: Tração manual com preensões digitais (dados em kgf).

\begin{tabular}{l|c|c|c|c|c|c}
\hline & \multicolumn{2}{|c|}{ Total } & \multicolumn{2}{c|}{$\begin{array}{c}\text { Gênero } \\
\text { feminino }\end{array}$} & \multicolumn{2}{c}{$\begin{array}{c}\text { Gênero } \\
\text { masculino }\end{array}$} \\
\hline Pegas mãos preensões & Média & D.P. & Média & D.P. & Média & D.P. \\
\hline $40 \mathrm{~mm}$ direita bidigital & 4,01 & 1,39 & 3,59 & 0,96 & 4,44 & 1,63 \\
\hline $40 \mathrm{~mm}$ direita pulpo-lateral & 5,60 & 2,05 & 4,58 & 1,43 & 6,63 & 2,09 \\
\hline $40 \mathrm{~mm}$ direita tridigital & 5,01 & 1,53 & 4,40 & 1,37 & 5,63 & 1,44 \\
\hline $40 \mathrm{~mm}$ esquerda bidigital & 3,63 & 1,17 & 3,32 & 0,89 & 3,95 & 1,33 \\
\hline $40 \mathrm{~mm}$ esquerda pulpo-lateral & 5,28 & 1,96 & 4,32 & 1,30 & 6,25 & 2,05 \\
\hline $40 \mathrm{~mm}$ esquerda tridigital & 4,65 & 1,47 & 4,15 & 1,35 & 5,15 & 1,43 \\
\hline $20 \mathrm{~mm}$ direita bidigital & 3,88 & 1,04 & 3,54 & 0,84 & 4,22 & 1,11 \\
\hline $20 \mathrm{~mm}$ direita pulpo-lateral & 5,75 & 1,84 & 4,74 & 1,32 & 6,77 & 1,74 \\
\hline $20 \mathrm{~mm}$ direita tridigital & 4,67 & 1,32 & 4,09 & 1,17 & 5,25 & 1,23 \\
\hline $20 \mathrm{~mm}$ esquerda bidigital & 3,57 & 1,11 & 3,26 & 0,86 & 3,88 & 1,26 \\
\hline $20 \mathrm{~mm}$ esquerda pulpo-lateral & 5,51 & 1,73 & 4,44 & 1,27 & 6,57 & 1,46 \\
\hline $20 \mathrm{~mm}$ esquerda tridigital & 4,29 & 1,17 & 3,90 & 1,06 & 4,69 & 1,16 \\
\hline $1 \mathrm{~mm}$ direita bidigital & 3,54 & 1,21 & 3,18 & 0,97 & 3,89 & 1,32 \\
\hline $1 \mathrm{~mm}$ direita pulpo-lateral & 5,46 & 1,76 & 4,75 & 1,46 & 6,17 & 1,77 \\
\hline $1 \mathrm{~mm}$ direita tridigital & 4,24 & 1,19 & 3,81 & 1,06 & 4,66 & 1,17 \\
\hline $1 \mathrm{~mm}$ esquerda bidigital & 3,12 & 1,10 & 2,73 & 0,81 & 3,51 & 1,22 \\
\hline $1 \mathrm{~mm}$ esquerda pulpo-lateral & 5,09 & 1,52 & 4,43 & 1,29 & 5,75 & 1,46 \\
\hline $1 \mathrm{~mm}$ esquerda tridigital & 3,83 & 1,17 & 3,37 & 0,96 & 4,30 & 1,19 \\
\hline & & & & &
\end{tabular}

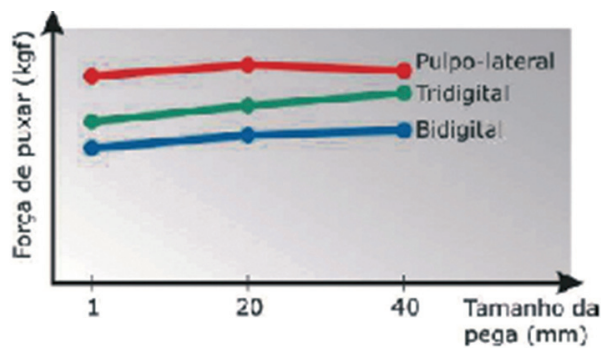

Figura 21. Variação da força de puxar de acordo com o tipo de preensão e o tamanho da pega.

Foi obtida uma maior magnitude de força na mão direita em detrimento da mão esquerda para ambos os gêneros; a diferença média foi de 8,1\%. Esse comportamento já era esperado devido à amostra ser destra. 
Entretanto, essas diferenças não foram estatisticamente significativas para nenhuma variável estudada. Entre as aberturas de preensão, a pega de $40 \mathrm{~mm}$ foi a que gerou maiores forças, seguida da de $20 \mathrm{~mm}$ e da $1 \mathrm{~mm}$, com exceção da preensão pulpo-lateral, na qual a pega de $20 \mathrm{~mm}$ foi maior. Entretanto, na maioria das variáveis analisadas essas diferenças não foram estatisticamente significativas.

Foi realizada também uma análise para identificar a presença de correlação entre as dimensões antropométricas e a força aplicada, em cada variável analisada. A correlação existente entre a antropometria e a força foi baixa e não significativa, em todos os cruzamentos realizados.

\section{Discussão}

Em avaliações de atividades manuais, o tamanho do objeto manipulado tem sido bastante estudado e, em muitos trabalhos, mostrouse como uma variável determinante da facilidade de realização da tarefa. Em nosso estudo, foi observada uma influência da altura da preensão na força manual, mas essa variável, em geral, não foi significativa e foi subjugada pela influência do tipo de preensão digital empregada.

Fica, no entanto, aparente uma tendência de aumento da força com o aumento do tamanho da pega para as preensões bidigital e tridigital. Outros autores também observaram esse comportamento para essas preensões (Imrhan \& Rahman, 1995; Dempsey \& Ayoub, 1996; Shih \& Ou, 2005; Peebles \& Norris, 2003). Já para a preensão pulpo-lateral, os valores maiores de força foram obtidos na abertura de preensão de $20 \mathrm{~mm}$, apresentando um comportamento de aumento e declínio da força conforme a altura da pega empregada. Imrhan \& Rahman (1995) e Dempsey \& Ayoub (1996) também observaram esse mesmo comportamento para a preensão pulpo-lateral, embora Imrhan \& Rahman tenham obtido a força máxima na pega de $20 \mathrm{~mm}$, e Dempsey \& Ayoub tenham observado maiores forças na pega de $50 \mathrm{~mm}$. Entretanto, Shivers et al. (2002) apresentam resultados to- 
talmente discordantes para essa variável, relatando forças de maior magnitude para as maiores aberturas de preensão.

Segundo Imrhan \& Rahman (1995), a razão para esse comportamento da preensão pulpo-lateral pode ser explicada por possíveis prejuízos impostos pelo distanciamento entre os dedos indicador e polegar na relação comprimento-tensão dos músculos que controlam o polegar e também uma possível perda do movimento de alavanca para essas articulações.

O tipo de preensão digital empregado foi identificado como um dos fatores de maior influência nas forças manuais. Em nosso estudo, observou-se que a preensão mais forte é a pulpo-lateral, seguida da tridigital e, por último, da bidigital. Os mesmos resultados também foram encontrados em outros estudos (Dempsey \& Ayoub, 1996; Imrhan, 1991; Peebles \& Norris, 2003), ao passo que alguns autores obtiveram resultados de maior magnitude de força na preensão tridigital em detrimento da pulpo-lateral (Ager et al., 1984; Imrhan \& Rahman, 1995). Entretanto, no estudo de Ager et al. (1984) essa variação pode ser decorrente das condições do equipamento empregado e da amostra selecionada. Os autores empregaram o dinamômetro de pinça Preston ${ }^{\circledR}$, que apresenta uma abertura de preensão de aproximadamente $25 \mathrm{~mm}$. Como a amostra estudada era de crianças de 5 a 12 anos de idade, isso pode ter prejudicado a realização da preensão pulpo-lateral, pois alturas de pega maiores podem comprometer essa preensão.

As preensões também variaram quanto à proporção da magnitude de força. No estudo de Imrhan \& Sundararajan (1992) as preensões tridigital e bidigital apresentaram em média 60,3\% e 39,6\% da força da preensão pulpo-lateral, respectivamente. Em nosso estudo, considerando apenas a pega de tecido, as preensões tridigital e bidigital realizaram, em média, $77,7 \%$ e 59,3\% da força da preensão pulpolateral, respectivamente.

Imrhan \& Sundararajan (1992) afirmam que os músculos do ombro podem contribuir com $45-56 \%$ da força aplicada para a tração manual associada a preensões digitais, especialmente com a preensão pulpo-lateral, o que pode ter influenciado os resultados de maior 
magnitude para essa preensão. Em nosso trabalho foi observado que a mão esquerda realiza em média $92,5 \%$ da força da mão direita. Esses resultados são condizentes com vários estudos que procuraram estudar a relação da dominância na força manual (Petersen et al., 1989; Imrhan \& Loo, 1989; Crosby et al., 1994; Lindahl et al., 1994; O’Driscoll et al., 1992; Imrhan \& Sundararajan, 1992).

A correlação não-significativa entre antropometria e força encontrada neste estudo indica que essas variáveis são independentes para a força de puxar com preensão digital. Isso ocorre porque, para realizar a força de puxar, são empregados diversos grupos musculares, especialmente os músculos do braço, costas e membros inferiores, uma vez que o corpo todo deve ser acionado para realizar o esforço de reação (sentido oposto) ao de puxar, procurando manter o equilíbrio corporal (Chaffin et al., 2001).

A mesma baixa correlação entre força e antropometria foi obtida por Peebles \& Norris (2003), o que já era esperado tendo em vista que a mesma metodologia foi empregada. No estudo de Imrhan \& Sundararajan (1992) foram observadas correlações entre algumas variáveis antropométricas (estatura, peso corporal e largura da mão) e a força de puxar, mas somente com a preensão pulpo-lateral. Entretanto, as condições de avaliação e o tipo de ação muscular empregada neste estudo diferem muito dos de Imrhan \& Sundararajan (1992).

\section{Considerações finais}

Dentre todos os fatores que podem afetar a força de puxar com preensão digital, certamente o tipo de preensão digital empregada é um dos mais influentes. A redução imposta à capacidade de geração de força, quando utilizada a preensão bidigital, por exemplo, apresenta uma maior magnitude que variáveis da tarefa, como o tamanho do objeto manipulado, ou características individuais, como dominância. O uso da preensão bidigital pode implicar uma redução média de 33,5\% na força em comparação com a melhor condição (preensão pulpo-lateral). O gênero é outro fator que apresenta grande influên- 
cia nas forças manuais, fator que deve ser considerado ao projetar produtos e tarefas nas quais há a participação do gênero feminino.

Uma recomendação de aplicação dos parâmetros disponibilizados aqui para o projeto de produtos e tarefas em que se utilizem preensões digitais é que devem ser priorizadas as preensões pulpo-laterais em detrimento da bidigital e tridigital. Isso tornará a atividade mais fácil e confortável para o usuário já que essa preensão permite a aplicação de maior força. A adoção dessa condição gera implicações no desenho dos produtos: a área disponível para os dedos deve ser um pouco maior, pois essa preensão exige maior espaço para ser executada que outras preensões digitais, e a espessura do objeto (distância entre os dedos opositores da preensão) devem ser de aproximadamente $20 \mathrm{~mm}$, condição na qual a força gerada foi maior.

Portanto, a principal relevância desta pesquisa é a geração de parâmetros de forças manuais que poderão contribuir, conforme explicitado, para diversas áreas do conhecimento científico-tecnológico, sempre buscando ampliar o conforto, a usabilidade e a segurança nas mais diversas atividades humanas. Alguns exemplos seriam postos de trabalho e tarefas na indústria, projetos de produtos de uso cotidiano (embalagens, ferramentas manuais etc) e ajudar a compor uma base de dados de normalidade para diagnósticos mais precisos de doenças musculoesqueléticas, dentre outros.

\section{Agradecimentos}

Esta pesquisa foi financiada pela Fundação de Amparo à Pesquisa do Estado de São Paulo (Fapesp) (Proc. 05/58600-7).

\section{Referências bibliográficas}

AGER, C. L., OLIVETT, B. L., JOHNSON, C. L. Grasp and pinch strength in children 5 to 12 years old. The American Journal of Occupational Therapy, 38 (2): 107-113, 1984. 
AGHAZADEH, F., MITAL, A. Injuries due to hand tools: results of a questionnaire. Applied Ergonomics, 18: 273-278, 1987.

ARMSTRONG, C. A., CHAFFIN, D. B. Carpal tunnel syndrome and selected personal attributes. Journal of Occupational Therapy, 21 (7): 481-486, 1979.

CALDWELL, L. S. et al. A proposed standard procedure for static muscle strength testing. American Industrial Hygiene Association Journal, 35 : 201-206, 1974.

CHAO, E. Y., OPGRANDE, J. D., AXMEAR, F. E. Three dimensional force analysis of finger joints in selected isometric hand functions. Journal of Biomechanics, 9: 387-396, 1976.

CRAWFORD, J. O., WANIBE, E., LAXMAN, N. The interaction between lid diameter, height and shape on wrist torque exertion in younger and older adults. Ergonomics, 45(13): 922-923, 2002.

CROSBY, C. A., WEHBÉ, M. A., MAWR, B. Hand strength: normative values. The Journal of Hand Surgery, 19A (4): 665-670, 1994.

DAAMS, B. J. Static force exertion in postures with different degrees of freedom. Ergonomics, 36 (4): 397-406, 1993.

DEMPSEY, P. G., AYOUB, M. M. The influence of gender, grasp type, pinch width and wrist position on sustained pinch strength. International Journal of Industrial Ergonomics, 17: 259-273, 1996.

EKSIOGLU, M., FERNANDEZ, J. E., TWOMEY, J. M. Predicting peak pinch strength: Artificial neural network vs. regression. International Journal of Industrial Ergonomics, 18: 431-441, 1996.

HOOK, W. E., STANLEY, J. K. Assessment of thumb to index pulp to pulp pinch grip strengths. Journal of Hand Surgery (Br), 11 (1): 91-92, 1986.

IMRHAN, S. N. The influence of wrist position on different types of pinch strength. Applied Ergonomics, 22 (6): 379-384, 1991.

Muscular strength in the elderly - Implications for ergonomic design. International Journal of Industrial Ergonomics, 13: 125-138, 1994.

IMRHAN, S. N., LOO, C. H. Modeling wrist-twisting strength of the elderly. Ergonomics, 31(12): 1807-1819, 1988.

Trends in finger pinch strength in children, adults, and the elderly. Human Factors, 31 (6): 689-701, 1989.

IMRHAN, S. N., RAHMAN, R. The effect of pinch width on pinch strengths of adult males using realistic pinch-handle coupling. International Journal of Industrial Ergonomics, 16: 123-134, 1995. 
IMRHAN, S. N., SUNDARARAJAN, K. An investigation of finger pull strengths. Ergonomics, 35 (3): 289-299, 1992.

KATTEL, B. P., FREDERICKS, T. K., FERNANDEZ, J. E., LEE, D. C. The effect of upper-extremity posture on maximum grip strength. International Journal of Industrial Ergonomics, 18: 423-429, 1996.

KELLOR, M. et al. Hand strength and dexterity. The American Journal of Occupational Therapy, 25(2): 77-83, 1971.

KEYSERLING, W. M. et al. A checklist for evaluating ergonomic risk factors associated with upper extremity cumulative trauma disorders. Ergonomics, 36 (7): 807-831, 1993.

KIM, C., KIM, T. Maximum torque exertion capabilities of Korean at varying body postures with common hand tools. In: International Ergonomics Association, 14., 2000, San Diego. Proceedings of the International Ergonomics Association. San Diego: IEA, 2000, 4p.1 CD-ROM.

KRAFT, G. H., DETELS, P. E. Position of function of the wrist. Archives of Physical Medicine and Rehabilitation, 52: 272-275, 1972.

LINDAHL, O. A. et al. Grip strength of the human hand - measurements on normal subjects with a new hand strength analysis system (Hastras). Journal of Medical Engineering E Technology, 18 (3): 101-103, 1994.

MATHIOWETZ, V., RENNELLS, C., DONAHOC, L. Effect of elbow position on grip and key pinch strength. The Journal of Hand Surgery, 10A (5): 694-697, 1985b.

MATHIOWETZ, V., WIEMER, D. M., FEDERMAN, S. M. Grip and pinch strength: norms for 6 to 19-year-olds. The American Journal of Occupational Therapy, 40 (10): 705-711, 1986.

MATHIOWETZ, V. et al. Reliability and validity of grip and pinch strength evaluations. The Journal of Hand Surgery, 9A (2): 222-226, 1984.

MATHIOWETZ, V. et al. Grip and pinch strength: normative data for adults. Archives of Physical Medicine and Rehabilitation, 66: 69-74, 1985a.

MITAL, A., KUMAR, S. Human muscle strength definitions, measurement, and usage: Part I - Guidelines for the practitioner. International Journal of Industrial Ergonomics, 22: 101-121, 1998a.

. Human muscle strength definitions, measurement, and usage: Part II - The scientific basis (knowledge base) for the guide. International Journal of Industrial Ergonomics, 22: 123-144, 1998b.

O'DRISCOLL. S. W. et al. The relationship between wrist position, grasp size, and grip strength. Journal of Hand Surgery, 17A (1): 169-177, 1992. 
OLDFIELD, R. C. The assessment and analysis of handedness: The Edinburgh inventory. Neuropsychologia, 9: 97-113, 1971.

PEEBLES, L., NORRIS, B. Filling "gaps" in strength data for design. Applied Ergonomics, 34: 73-88, 2003.

PETERSEN, P. et al. Grip strength and hand dominance: challenging the 10\% Rule. American Journal of Occupational Therapy, 43 (7): 444-447, 1989.

SHIH, Y.C., OU, Y.C. Influences of span and wrist posture on peak chuck pinch strength and time needed to reach peak strength. International Journal of Industrial Ergonomics, 35: 527-536, 2005.

SHIVERS, C. L., MIRKA, G .A., KABER, D. B. Effect of grip on lateral pinch grip strength. Human Factors, 44 (4): 569-577, 2002. 


\title{
5 \\ ESTUDO ERGONÔMICO AMBIENTAL DE ESCOLAS DAS CIDADES DE BAURU e Lençóis Paulista
}

\author{
Mariana Falcão Bormio ${ }^{1}$ \\ José Carlos Plácido da Silva
}

\section{Introdução}

Atualmente, sabe-se que uma configuração ambiental deve ser estabelecida visando ao atendimento das necessidades e características apresentadas pelo tipo de atividade e do trabalhador que a desenvolverá, pois a importância dessa relação atribui-se ao fato de que todos os componentes desse sistema influenciam-se mutuamente, resultando no condicionamento físico-psicológico do usuário, seja positivamente, despertando sensações de conforto, segurança e bemestar, que favorecem um bom desempenho e o aumento da produtividade, seja negativamente, gerando constrangimentos e insatisfações.

Nesse contexto, utilizando a metodologia Ergonomic Workplace Analysis (EWA - Análise Ergonômica do Local de Trabalho), o presente capítulo desenvolveu uma Avaliação Pós-Ocupação (APO) de instituições de ensino públicas e particulares das cidades de Bauru(SP)e Lençóis Paulista (SP), tendo por objetivo identificar a maneira como os fatores físico-ambientais lumínicos, térmicos e acústicos apresentamse nesses ambientes, especificamente nas salas de aula, onde é desen-

1 Mestre em design, Universidade Estadual Paulista.

2 Professor titular, Universidade Estadual Paulista. 
volvida a atividade de aprendizado; seguindo-se uma comparação entre os resultados das condições encontradas nos dois tipos de instituição.

\section{A interface: ambiente construído e o homem}

Ao longo da história, vários foram os ambientes construídos que acabaram por refletir épocas, pensamentos, estilos, marcar conquistas, soberanias, revoluções e ideais políticos e sociais. Entretanto, nota-se que esses ambientes foram - ou em muitos casos ainda são - pensados enfocando seus usos, aspectos e materiais construtivos, dimensões e significados estéticos, não direcionando as devidas preocupações com o homem/usuário que, por não ser entendido como componente do projeto, acabava sofrendo ao utilizá-los as consequências de problemas humano-ambientais, com frequentes ocorrências de constrangimentos e insatisfações.

A respeito do que constituem esses ambientes, Rapoport (1978) considera-os como extensões tridimensionais do mundo que rodeia o ser (intervalos, relações e distância entre pessoas, entre pessoas e coisas, e entre coisas), organizados espacialmente de maneira a expressar significados ao utilizar símbolos, materiais, cores e formas. E Santos (2001) complementa atribuindo-lhes, além do caráter físico, o estético, o informativo e o psicológico, que dentro do contexto de projeto devem direcionar-se a agradar, servir, proteger e unir as pessoas no exercício de suas atividades.

Para Ornestein \& Romero (1995) e Löbach (2001), a importância dos ambientes deve-se ao fato de que a partir das condições que neles são geradas, pode-se alterar o modo de vida das pessoas pois, segundo Gifford (1976 apud Kowaltowski et. al. 2001), esses possuem atrativos e configurações próprias que podem ser manipuladas, visando à percepção do usuário para seu funcionamento. Não se deve, portanto, segundo Pigossi (2004), ignorar ou desprezar a força de atuação que o ambiente exerce sobre as pessoas, mas, sim, reconhecê-la e utilizá-la como um recurso a mais, pois "nós modelamos a arquitetura e por ela somos modelados” (Hall, 1981 p.99). 
Direcionando-se à satisfação que o usuário usufrui em relação aos espaços, Atlas \& Özsoy (1998) consideram que tal sentimento resulta de um processo de cognições, reações e percepções que se tem do conjunto de condições e do relacionamento dos elementos que o constituem, ou seja, das características do usuário, dos atributos físicos dos espaços e das crenças do usuário sobre a vivência ou uso desses espaços. Verdussen (1978) classifica esses fatores em dois grupos, considerando o imediatismo de sua influência: primários (temperatura, iluminação, ruído, vibrações, odores, cores) e secundários (arquitetura, relações humanas, remuneração, estabilidade, apoio social).

Considera-se, portanto, que para que se possam projetar ambientes eficientes e eficazes, que satisfaçam seus usuários, enquanto qualidade de vida, estética, funcionalidade, conforto, salubridade e segurança, arquitetos e designers devem entender a maneira como ocorre a relação ambiente construído/homem/atividade, considerando a importância de cada um dos componentes e a maneira como eles se apresentam no sistema ao estabelecer influências diretas uns sobre os outros, devendo ser respeitadas as características, necessidades e restrições particulares de cada um.

Esse fato é corroborado por Bormio (2007), ao entender que situações nas quais são identificados altos índices de concentração ou longos períodos de exposição a um ou mais fatores ambientais, métodos inseguros de trabalho (falta de controle e proteção, desorganização do trabalho e ambiente hostil, com má configuração, má sinalização e presença de barreiras arquitetônicas) podem causar desarmonia no sistema, propiciando condições inadequadas para a realização de atividades, podendo vir a acarretar riscos e/ou perigos ao usuário, assim como despertar sensações de desconforto físico ou psíquico, sentimentos de estresse, monotonia, fadiga e problemas de saúde.

Para Ely et al. (2000) a percepção é um ato consciente pela busca de informações do meio ambiente (já o ato inconsciente são atividades permanentes e complexas asseguradas pelos seguintes sistemas sensoriais: audição, visão, paladar, olfato, háptico e equilíbrio). Quando essa ocorre de forma positiva desperta qualidade de vida, bem-estar e conforto, sendo a definição desses sentimentos algo subjetivo, pois 
depende da pessoa que está experimentando a situação. Esses fatores estão relacionados entre si, sendo um consequência do outro.

Diante dos conceitos expostos, o presente capítulo direcionou-se especificamente ao seu objeto de enfoque, ou seja, a abordagem dessa relação na qual se estipula o ambiente construído (sala de aula), o homem/usuário (aluno) e a atividade/trabalho (aprendizagem). O objetivo principal foi entender e caracterizar a maneira como ocorre a relação entre esses componentes, destacando principalmente o papel do ambiente construído dentro desse contexto.

\section{Ambiente escolar/aluno}

Conforme observado anteriormente, todo ambiente exerce influências sobre o indivíduo que o ocupa, sendo tal fato ressaltado ao se falar em ambiente escolar, pois considera-se que os primeiros anos de vida de uma pessoa são decisivos, sendo nesse período que ocorre um processo intenso do desenvolvimento natural da criança (maturação e crescimento) em seus aspectos físicos, afetivos, cognitivos e sociais. Além disso, as crianças estão indo para a escola cada vez mais cedo, devido ao contexto vivido pela sociedade atual, regido por um ritmo intenso de trabalho, que não deixa alternativa às mães (Elali, 2002).

Lima (1989) destaca que nesse ambiente a criança se desenvolve, estabelecendo sua relação com o mundo e com as pessoas a partir de um relacionamento, e seus esquemas de aquisição de conhecimento são construídos, num processo permanente, em que novos níveis de conhecimentos são indefinidamente elaborados a partir das interações com o meio. Os ambientes acabam por transcenderem suas dimensões físicas e transformam-se em entes e locais de alegria, de medo, de segurança, de curiosidade, de descoberta.

Nesse contexto, o ambiente escolar, segundo Leucz (2001), pode ser um facilitador do processo de ensino-aprendizagem, ou fornecer obstáculos para a ocorrência normal desse processo, interferindo na produtividade e no rendimento do aluno. Para Sodré (2005), tanto na perspectiva dos teóricos e legisladores quanto na prática, a escola 
afirma-se cada vez mais como um ambiente físico e social que proporciona conhecimento, participação e interação com seus usuários, num processo permanente na relação sujeito-objeto-ambiente.

\section{Sala de aula}

Entre os diversos espaços que compõem o ambiente escolar, a sala de aula apresenta um papel de destaque, pois é onde o aluno permanece a maior parte do tempo em que se encontra nessa instituição, por essa configurar-se como seu posto de trabalho. Dessa maneira, assim como qualquer outro ambiente construído, esse necessita da harmonia e o devido controle entre as variáveis que a compõem, ou seja, seus agentes ambientais, os mobiliários, o layout, os aspectos arquitetônicos, os usuários, os métodos pedagógicos e metodológicos, de maneira a tornar-se funcional e atender às necessidades das atividades que ali serão desenvolvidas.

Segundo Azevedo (2002), o projeto arquitetônico do ambiente escolar deve oferecer boas condições construtivas, que sejam capazes de fortalecer as relações existentes entre pessoas e ambientes. Para Sodré (2005), esses ambientes devem ser planejados de maneira a atender às necessidades e experiências particulares de cada turma de forma inclusiva, em função dos interesses manifestados pelas crianças, facilitando o agrupamento dos alunos, a dinamização das ações pedagógicas, o convívio com a comunidade e a reflexão dos professores, e proporcionando interações, desenvolvimento da autonomia e condições de afetividade entre adultos e crianças (realização de atividades e disponibilidade para interagir e brincar, tornando o ambiente educativo e construtivo).

Bernardi (2001) cita que na literatura técnica, os fatores ambientais apresentam-se divididos relacionando-se ao conforto ambiental térmico, lumínico, acústico e funcional, e que conhecer o ambiente e suas influências possibilita ao professor predizer o comportamento em certas circunstâncias e transformá-lo harmonicamente aos propósitos e expectativas comportamentais esperados, visando o 
aumento da eficiência e, consequentemente, elevando o nível de aprendizagem dos alunos.

Atentando-se a todos os fatos apresentados, mas principalmente levando em consideração que o ambiente é responsável por fornecer estímulos sensoriais, que, de acordo com a maneira como se apresenta configurado, determinadas percepções despertam nos indivíduos que o ocupam, influenciando, condicionando e determinando o grau de conforto, satisfação e produção do usuário, assim como seu comportamento e conduta, seja de maneira positiva ou negativa. $\mathrm{O}$ presente trabalho avalia a relação aluno, ambiente escolar/sala de aula e o processo de aprendizagem, enfocando especificamente os aspectos físico-ambientais lumínicos, térmicos e acústicos.

\section{Método}

O presente trabalho adota a metodologia Ergonomic Workplace Analysis (EWA - Análise Ergonômica do Local de Trabalho), desenvolvida por Ahonem et al. (1989), que se destaca pela importância histórica, no contexto de análise ergonômica do local de trabalho, caracterizada por abordagens subjetivas e objetivas. Essa metodologia consiste em uma APO, desenvolvida por meio da aplicação de um protocolo que avalia o local de trabalho, com uma abordagem ampla, que possibilita diferentes enfoques, seja de forma geral, abordando o ambiente, ou mesmo pontual, enfocando, por exemplo, o mobiliário, de maneira a não somente caracterizar fisicamente o local de trabalho, mas também a percepção do usuário e do avaliador em relação ao processo de trabalho.

Tal fato direcionou a aplicação do protocolo de forma conjunta, resultando em dois trabalhos distintos. No que se refere à análise do ambiente, foi desenvolvida por Bormio (2007) a dissertação intitulada Avaliação pós-ocupação ambiental de escolas das cidades de Bauru (SP) e Lençóis Paulista (SP); quanto à do mobiliário, Paccola (2007) elaborou a Revisão de metodologias de avaliação ergonômica aplicadas à carteira escolar. 


\section{Ambiente e sujeitos}

No estudo de caso, a análise foi desenvolvida no ambiente escolar, em salas de aula, onde se desenvolve predominantemente o trabalho de aprendizado pelos usuários-alunos. A amostragem de escolas foi definida objetivando diversidade de realidades sociais dos alunos e de configuração ambiental e aspectos construtivos dos edifícios, optando-se, portanto, pelo trabalho em instituições particulares e públicas das cidades de Bauru e Lençóis Paulista, por apresentarem investimentos financeiros que variam consideravelmente e, consequentemente, o contexto em questão.

As instituições escolhidas para o estudo foram:

- Particulares: Cursos e Colégio Fênix (Bauru/ SP); Serviço Nacional de Aprendizagem Industrial (Senai) - João Martins Coube (Bauru/SP); Colégio São José (Lençóis Paulista/SP); Senai Lençóis Paulista (Lençóis Paulista/SP).

- Estaduais: Escola Estadual Professor Ernesto M onte(Bauru/ SP); Escola Estadual Professor Morais Pacheco (Bauru/SP); Escola Estadual Dr. Paulo Zillo (Lençóis Paulista/SP); Escola Estadual Professor Rubens Pietraroia (Lençóis Paulista/SP).

A população constituiu-se de 213 alunos do ensino médio, com idade entre 15 e 17 anos, sendo os participantes escolhidos entre os presentes no momento da realização da coleta dos dados, dispostos a participar da pesquisa, tendo em vista a capacidade de compreensão e inquirição satisfatórias.

\section{Procedimentos para aplicação da pesquisa}

A primeira etapa para a aplicação da pesquisa consistiu na realização de uma visita a cada instituição, sendo explicado nesse momento o conteúdo e a forma como a investigação se desenvolveria e os objetivos esperados e sendo solicitada autorização da direção para a aplicação do trabalho com os alunos. Nessa oportunidade 
também foram registradas as primeiras impressões locais das instituições, com relação às características físico-ambientais, mobiliários e usuários.

A definição da sala de aula a ser trabalhada foi feita pelo diretor ou responsável pela instituição, mediante os critérios estabelecidos e solicitados pelos avaliadores, ou seja, alunos capazes de compreender e responder as questões e que tivessem idade entre 15 e 17 anos. Tendo em vista o grande número de alunos e o pouco tempo para a aplicação do protocolo, optou-se por uma entrevista coletiva, com preenchimento individual e simultâneo. Dessa maneira, cada voluntário-aluno recebeu um termo de consentimento, que esclarecia o objetivo da pesquisa, assim como a forma como ela seria desenvolvida, e que foi devidamente assinado pelo aluno e por seu responsável legal, e arquivado pelos avaliadores. Para a aplicação do protocolo, foi entregue a cada aluno uma ficha impressa contendo 14 questões objetivas e campos para respostas diretas e possíveis observações.

Desenvolveu-se a pesquisa da seguinte maneira:

- Aval iaçõesdosal unos: ocorreu por meio deentrevistacol etiva, sendo o preenchimento individual e simultâneo. Nessa fase, um dos avaliadores conduzia a entrevista, lendo cada item em voz alta, mostrando as alternativas de respostas e esclarecendo possíveis dúvidas referentes às perguntas que enfocavam as percepções em relação ao local de trabalho. As respostas dessa análise subjetiva deveriam ser expressas por uma classificação variável de bom ++; regular +; ruim -; a muito ruim --.

\section{- M edições técnicas e registros fotográficos: as medições re} ferentes aos fatores físico-ambientais (ruído, iluminação e temperatura) foram realizadas pelo outro avaliador, arquiteto e especialista em Engenharia de Segurança do Trabalho, apto a tal tarefa. Essas medições foram realizadas utilizando-se aparelhos adequados, que se apresentavam devidamente calibrados e certificados por órgão responsável. Os valores obtidos foram devidamente anotados no campo preestabelecido no protocolo. 
Durante essa etapa registrou-se por meio de fotografias digitais o usuário utilizando o local, no contexto geral da sala de aula, e pontual (carteira escolar), identificado por numeração.

\section{- A nálises do avaliador: a partir desse ponto, cada avaliador} direcionou suas abordagens para o foco de seu trabalho. Essas análises foram desenvolvidas de maneira objetiva e consistiram nas percepções do avaliador em relação aos usuários desenvolvendo suas atividades, confrontando os valores resultantes das medições técnicas com os valores indicados pelas normas brasileiras, objetivando assim determinar o desvio entre as condições de trabalho constatadas no ambiente em relação às recomendações da literatura. Para tanto, obedeceu-se a uma escala na qual os índices de classificação variam de 1 a 5 , sendo 1 -ideal, 2 - bom, 3 - regular, 4 - ruim, e 5 - péssimo.

Lembramos que conforme citado ao longo do presente capítulo, uma configuração ambiental possui vários aspectos de conforto que devem ser avaliados, de forma a atingir o objetivo de bem estar, produtividade e segurança de seus usuários. Entretanto, optamos aqui por analisar especificamente os itens de avaliação que dizem respeito aos aspectos físicos-ambientais preestabelecidos por essa metodologia, ou seja, iluminação, temperatura e ruído.

Os materiais utilizados para preenchimento do protocolo foram câmera digital, decibelímetro (medidor de nível de pressão sonora digital), luxímetro (medidor de intensidade de lux digital), termohigrômetro digital.

\section{Caracterização e análises por escola}

\section{Colégio Fênix}

Instituição particular, que oferece cursos de ensino da educação infantil ao pré-vestibular, nos períodos matutino e vespertino. Seu edifício possui traços da arquitetura contemporânea, que mistura 
elementos aparentes da estrutura de concreto armado com acabamentos em metal. O local avaliado nessa escola possui capacidade para acomodar até cinquenta alunos, dos quais vinte são utilizados pela turma analisada. No que se refere aos aspectos construtivos, essa sala de aula acompanha o padrão utilizado em todo o restante da edificação, ou seja, estrutura erguida em concreto armado, fechamento em paredes de alvenaria (bloco de cimento), piso em ladrilho cerâmico, forro em laje de concreto armado e grandes aberturas de vidro. A caracterização e análise dos fatores físico-ambientais podem ser observadas na tabela 7 .

Tabela 7. Caracterização e análise dos fatores físico-ambientais.

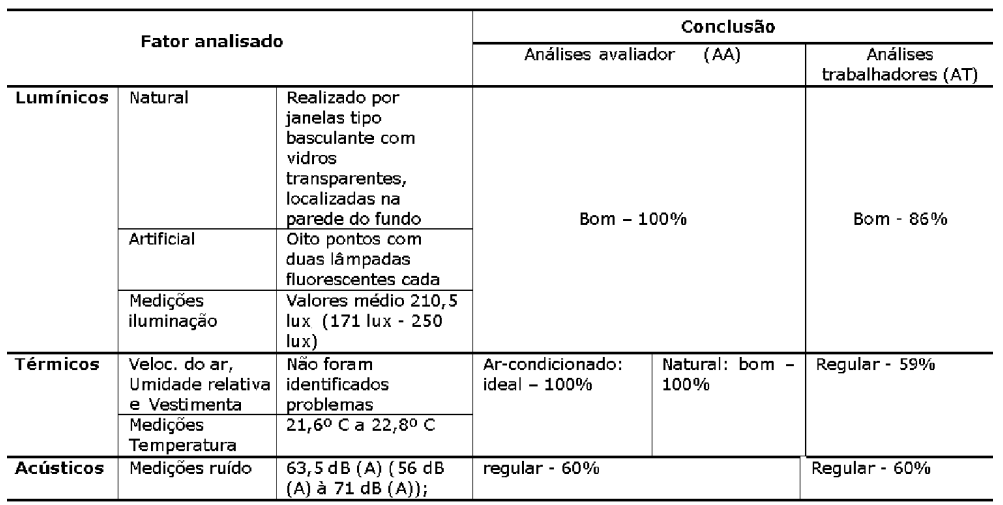

Ao desenvolver uma análise geral das condições dos fatores físicoambientais dessa sala de aula, os resultados obtidos pelas análises do avaliador mostraram duas situações: uma primeira que totalizou os resultados considerando enquanto condições térmicas o sistema de ar condicionado, de maneira que se entendeu $46 \%$ como predominantemente boas, e a segunda com as condições naturais do ambiente, obtendo-se o resultado dessas como boas em 79\%. Observou-se segundo as análises desenvolvidas pelos alunos o predomínio da classificação das condições dos fatores físico-ambientais como boas em $44 \%$. 


\section{Escola Estadual Professor Ernesto Monte}

A Escola Estadual Professor Ernesto Monte localiza-se na cidade de Bauru e atende atualmente alunos do ensino fundamental do $6^{\circ}$ ao $9^{\circ}$ ano e ensino médio do $1^{\circ}$ ao $3^{\circ}$ ano, nos períodos matutino, vespertino e noturno. Fundada em 1930, é considerada uma das escolas estaduais mais tradicionais do município. Seu prédio é tombado pelo patrimônio histórico municipal, e apresenta características que revelam marcas da transição dos primeiros anos da República para o início do modernismo na arquitetura escolar brasileira. No que se refere aos aspectos construtivos, observa-se que essa escola foi edificada em alvenaria, com espessas paredes de tijolos de barro, piso cimentado e teto em laje de concreto armado. A sala de aula onde foram realizadas as análises possui uma capacidade máxima de acomodação para 41 alunos, dos quais 29 lugares são utilizados. A caracterização e análise dos fatores físico-ambientais podem ser observadas na tabela 8 .

Tabela 8. Caracterização e análise dos fatores físico-ambientais.

\begin{tabular}{|c|c|c|c|c|}
\hline \multirow{2}{*}{\multicolumn{3}{|c|}{ Fator analisado }} & \multirow{2}{*}{\multicolumn{2}{|c|}{ Conclusão }} \\
\hline & & & & \\
\hline \multirow[t]{3}{*}{ Lumínicos } & Natural & $\begin{array}{l}\text { aproveita o partido } \\
\text { arquitetônico da edificação, que } \\
\text { apresenta grandes aberturas } \\
\text { que permitem a ocorrência de } \\
\text { grande incidência de raios } \\
\text { solares, favorecendo a } \\
\text { iluminação do local. Nessa sala } \\
\text { de aula eppecificamente, as } \\
\text { janelas são do tipo basculante } \\
\text { com caixilhos de ferro e vidros } \\
\text { transparentes, localizadas em } \\
\text { uma parede lateral }\end{array}$ & \multirow[t]{3}{*}{ Ideal - $100 \%$} & \multirow[t]{3}{*}{ Bom - 55\% } \\
\hline & Artificial & $\begin{array}{l}\text { Quatro pontos com duas } \\
\text { lâmpadas fluorescentes cada }\end{array}$ & & \\
\hline & $\begin{array}{l}\text { Mediçōes } \\
\text { iluminaçäo }\end{array}$ & $\begin{array}{l}\text { Valor médio } 958,5 \text { lux ( } 920 \text { lux } \\
-997 \text { lux) }\end{array}$ & & \\
\hline \multirow[t]{2}{*}{ Térmicos } & $\begin{array}{l}\text { Veloc, do ar } \\
\text { Umidade relativa } \\
\text { e Vestimenta }\end{array}$ & $\begin{array}{l}\text { Não foram identificados } \\
\text { problemas }\end{array}$ & \multirow[t]{2}{*}{ Ruim - 100\% } & \multirow[t]{2}{*}{ Regular - 52\% } \\
\hline & $\begin{array}{l}\text { Mediçóes } \\
\text { Temperatura }\end{array}$ & $\begin{array}{l}\text { Valor médio } 28,35^{\circ} \mathrm{C}\left(28,2^{\circ} \mathrm{C}-\right. \\
\left.28,5^{\circ} \mathrm{C}\right)\end{array}$ & & \\
\hline Acústicos & Medições ruido & $\begin{array}{l}\text { Valor médio - } 60 \mathrm{~dB}(\mathrm{~A})(69 \\
\mathrm{dB}(\mathrm{A})-50 \mathrm{~dB}(\mathrm{~A}))\end{array}$ & Regular - $67 \%$ & Regular - $45 \%$ \\
\hline
\end{tabular}

Ao totalizar de uma maneira geral a análise das condições dos fatores físico-ambientais dessa sala de aula, observou-se a classifi- 
cação segundo o avaliador como ideias em 34\%, enquanto nas análises desenvolvidas pelos alunos predominou a classificação regular em $38 \%$.

\section{Escola Estadual Professor Morais Pacheco}

A Escola Estadual Professor Morais Pacheco localiza-se na periferia da cidade de Bauru e atende alunos do ensino fundamental do $6^{\circ}$ ao $9^{\circ}$ ano e ensino médio do $1^{\circ}$ ao $3^{\circ}$ ano, nos períodos matutino, vespertino e noturno. Fundada em 1959, seu edifício é marcado por traços modernistas, com amplas aberturas, áreas livres e pé direito alto, sendo a construção executada em alvenaria: tijolo cerâmico, piso em granilite e forro em laje de concreto armado. O local de estudo dessa escola possui capacidade de acomodação para 38 alunos, dos quais trinta são utilizados atualmente.

Concluiu-se, portanto, que as condições dos fatores físico-ambientais dessa sala de aula, segundo as análises técnicas do avaliador, apresentaram-se predominantemente como ideais em 55\%,enquanto o enfoque subjetivo das análises desenvolvidas pelos alunos consideraram-nas regulares em $46 \%$.

\section{Escola Senai João Martins Coube}

A escola Senai João Martins Coube, localizada na cidade de Bauru, é uma instituição particular que oferece ensino técnico profissionalizante em diversos cursos, nos períodos matutino, vespertino e noturno. Sua edificação segue traços modernistas, com alto padrão de construção, que passa regularmente por reformas, para estar sempre adequada a proporcionar condições plenas de trabalho a seus alunos e funcionários. O local analisado nessa escola possui capacidade de acomodação para 32 alunos, dos quais 27 são utilizados pela turma participante da pesquisa. Toda a edificação foi construída em alvenaria, sendo que o piso e o forro são definidos de acordo com 
a necessidade das tarefas a serem realizadas no local. Nesse caso, especificamente, o piso é em taco de madeira e o teto em forro de PVC, pois trata-se de uma sala de aula de uso exclusivo para aulas expositivas. A caracterização e análise dos fatores físico-ambientais podem ser observadas na tabela 9 .

Tabela 9. Caracterização e análise dos fatores físico-ambientais.

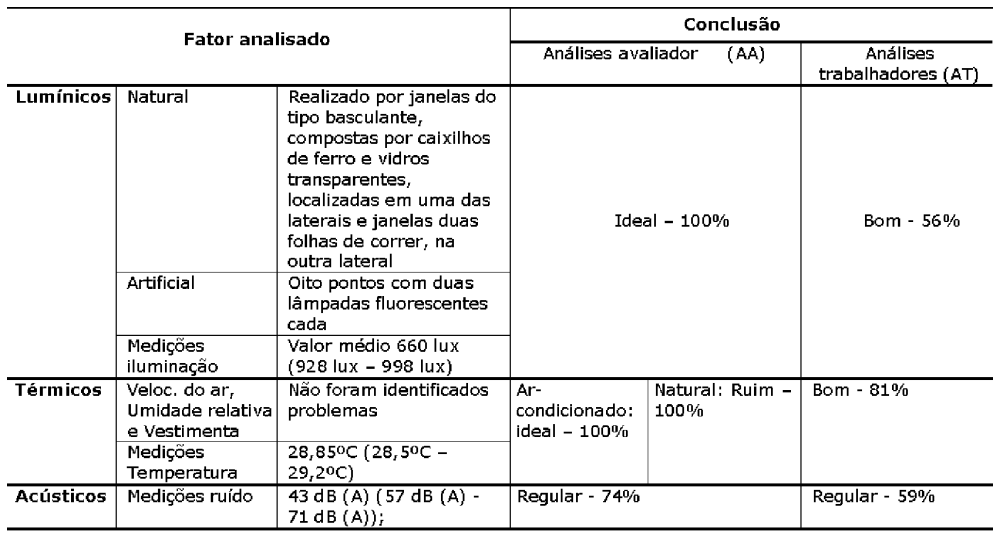

Diante do contexto apresentado pelas análises desenvolvidas, observaram-se duas classificações para as condições físico-ambientais dessa sala de aula segundo as análises desenvolvidas pelo avaliador, a primeira obtida a partir dos resultados da avaliação térmica considerando a presença de sistema de ar-condicionado, 67\% ideal, e a segunda das condições naturais do ambiente, 33\% ideal. As análises desenvolvidas pelos alunos classificaram o ambiente como tendo condições predominantemente boas em $61 \%$.

\section{Colégio São José}

O Colégio São José, localizado na cidade de Lençóis Paulista, trata-se de uma instituição particular, que oferece ensino para educação 
infantil, fundamental e médio, nos períodos matutino e vespertino. Fundado em 1997, o edifício do Colégio é uma construção recente executada em alvenaria: tijolos cerâmicos, com estrutura de concreto armado e piso em ladrilho cerâmico. Apresenta um programa que contém salas de aula, pátios, biblioteca e parques. O local de estudo dessa escola possui capacidade para acomodar trinta alunos, dos quais 29 são utilizados pela turma analisada. A caracterização e análise dos fatores físico-ambientais podem ser observadas na tabela 10 .

Tabela 10. Caracterização e análise dos fatores físico-ambientais.

\begin{tabular}{|c|c|c|c|c|}
\hline \multicolumn{3}{|c|}{ Fator analisado } & \multicolumn{2}{|c|}{ Conclusão } \\
\hline \multirow[t]{3}{*}{ Lumínicos } & Natural & $\begin{array}{l}\text { Realizado por três janelas do } \\
\text { tipo basculante, composta por } \\
\text { caixilhos de ferro e vidros } \\
\text { transparentes, localizadas em } \\
\text { uma das paredes laterais }\end{array}$ & \multirow{3}{*}{ Bom - 59\% } & \multirow{3}{*}{ Bom - $52 \%$} \\
\hline & Artificial & $\begin{array}{l}\text { Quatro pontos com três } \\
\text { lâmpadas fluorescentes cada }\end{array}$ & & \\
\hline & $\begin{array}{l}\text { Medições } \\
\text { iluminação }\end{array}$ & $\begin{array}{l}\text { Valor médio } 368 \text { lux (226 lux } \\
-510 \text { lux) }\end{array}$ & & \\
\hline \multirow[t]{2}{*}{ Térmicos } & $\begin{array}{l}\text { Veloc. do ar, } \\
\text { Umidade relativa } \\
\text { e Vestimenta }\end{array}$ & $\begin{array}{l}\text { Nã̃o foram identificados } \\
\text { problemas }\end{array}$ & \multirow[t]{2}{*}{ Regular - 89\% } & \multirow[t]{2}{*}{ Regular - 41\% } \\
\hline & $\begin{array}{l}\text { Medições } \\
\text { Temperatura }\end{array}$ & $\begin{array}{l}\text { Valor médio } 16,95^{\circ} \mathrm{C}\left(16,1^{\circ} \mathrm{C}\right. \\
\left.-17,8^{\circ} \mathrm{C}\right)\end{array}$ & & \\
\hline Acústicos & Mediçôes ruído & $\begin{array}{l}\text { Valor médio- } 45 \mathrm{~dB}(\mathrm{~A})(30 \\
d B(A)-60 d B(A))\end{array}$ & Bom-83\% & Regular - 40\% \\
\hline
\end{tabular}

Diante das análises desenvolvidas, pode-se concluir que as condições dos fatores físico-ambientais dessa sala de aula, segundo as análises do avaliador, foram predominantemente boas em $46 \%$, enquanto nas análises desenvolvidas pelos alunos predominou a classificação regular em 41\%.

\section{Escola Estadual Dr. Paulo Zillo}

A Escola Estadual Dr. Paulo Zillo localiza-se na cidade de Lençóis Paulista e atende alunos do ensino fundamental e médio do $1^{\circ}$ ao $3^{\circ}$ ano, nos períodos matutino, vespertino e noturno. Fundada em 1951, seu edifício apresenta traços clássicos das edificações dos primeiros anos da República, com planta simétrica, construída em 
alvenaria: tijolo cerâmico, pé-direito alto, forro e piso de madeira. O local de estudo dessa escola possui capacidade para acomodar trinta alunos. A caracterização e análise dos fatores físico-ambientais podem ser observadas na tabela 11 .

Tabela 11. Caracterização e análise dos fatores físico-ambientais.

\begin{tabular}{|c|c|c|c|c|}
\hline \multirow{2}{*}{\multicolumn{3}{|c|}{ Fator analisado }} & \multirow{2}{*}{\multicolumn{2}{|c|}{ Conclusão }} \\
\hline & & & & \\
\hline \multirow[t]{3}{*}{ Lumínicos } & Natural & $\begin{array}{l}\text { Realizado por três janelas do } \\
\text { tipo basculante, com caixilhos } \\
\text { de ferro e vidros } \\
\text { transparentes; localizadas em } \\
\text { uma das laterais da sala }\end{array}$ & \multirow[t]{3}{*}{ Bom - $100 \%$} & \multirow[t]{3}{*}{ Regular - $67 \%$} \\
\hline & Artificial & $\begin{array}{l}\text { Seis pontos com duas } \\
\text { lâmpadas fluorescentes cada }\end{array}$ & & \\
\hline & $\begin{array}{l}\text { Medições } \\
\text { iluminação }\end{array}$ & $\begin{array}{l}\text { Valor médio } 686,5 \text { lux ( } 415 \\
\text { lux }-958 \text { lux })\end{array}$ & & \\
\hline \multirow[t]{2}{*}{ Térmicos } & $\begin{array}{l}\text { Veloc. do ar, } \\
\text { Umidade relativa } \\
\text { e Vestimenta }\end{array}$ & $\begin{array}{l}\text { Năo foram identificados } \\
\text { problemas }\end{array}$ & \multirow[t]{2}{*}{ Bom - 76\% } & \multirow[t]{2}{*}{ Ruim - 63\% } \\
\hline & $\begin{array}{l}\text { Medições } \\
\text { Temperatura }\end{array}$ & $\begin{array}{l}\text { Valor médio } 17,8^{\circ} \mathrm{C}\left(18,7^{\circ} \mathrm{C}-\right. \\
\left.20,8^{\circ} \mathrm{C}\right)\end{array}$ & & \\
\hline Acústicos & Mediçốes ruído & $\begin{array}{l}\text { Valor médio - } 58 \mathrm{~dB}(\mathrm{~A})(51 \\
\mathrm{dB}(\mathrm{A})-65 \mathrm{~dB}(\mathrm{~A}))\end{array}$ & Bom - 86\% & Ruim - 53\% \\
\hline
\end{tabular}

O que se pôde concluir após a realização das análises foi que, de uma maneira geral, as condições dos fatores físico-ambientais dessa sala de aula foram predominantemente boas segundo o avaliador em $54 \%$. Entretanto, as análises desenvolvidas pelos alunos classificaram-nas como regulares em $46 \%$.

\section{Escola Estadual Professor Rubens Pietraroia}

A Escola Estadual Professor Rubens Pietraroia localiza-se na cidade de Lençóis Paulista e atende alunos do ensino fundamental do $6^{\circ}$ ao $9^{\circ}$ ano e o ensino médio, nos períodos matutino, vespertino e noturno. Seu edifício é um exemplo clássico da racionalização construtiva enfrentada pelas instituições públicas a partir de 1960, com o predomínio de técnicas simples: nesse caso paredes executadas em alvenaria, piso em cimentado e forro em placas de madeira compensada. O local estudado nessa escola possui capacidade de 
acomodação para 38 alunos, dos quais 36 são utilizados atualmente. A caracterização e análise dos fatores físico-ambientais podem ser observadas na Tabela 12.

Tabela 12. Caracterização e análise dos fatores físico-ambientais.

\begin{tabular}{|c|c|c|c|c|}
\hline \multirow{2}{*}{\multicolumn{3}{|c|}{ Fator analisado }} & \multirow{2}{*}{\multicolumn{2}{|c|}{ Conclusão }} \\
\hline & & & & \\
\hline \multirow[t]{3}{*}{ Lumínicos } & Natural & $\begin{array}{l}\text { Proveniente das janelas do tipo } \\
\text { basculante, compostas por } \\
\text { caixilhos de ferro e vidros } \\
\text { transparentes, que ocupam a } \\
\text { parede toda de uma das laterais }\end{array}$ & \multirow[t]{3}{*}{ Bom - 75\% } & \multirow[t]{3}{*}{ Ruim - 53\% } \\
\hline & Artificial & $\begin{array}{l}\text { Seis pontos com quatro } \\
\text { lâmpadas fluorescentes cada }\end{array}$ & & \\
\hline & $\begin{array}{l}\text { Medições } \\
\text { iluminação }\end{array}$ & $\begin{array}{l}\text { Valor médio } 264,5 \text { lux ( } 197 \text { lux } \\
-332 \text { lux) }\end{array}$ & & \\
\hline \multirow[t]{2}{*}{ Térmicos } & $\begin{array}{l}\text { Veloc. do ar, } \\
\text { Umidade relativa } \\
\text { e Vestimenta }\end{array}$ & $\begin{array}{l}\text { Não foram identificados } \\
\text { problemas }\end{array}$ & \multirow[t]{2}{*}{ Regular - 100\% } & \multirow[t]{2}{*}{ Ruim - 50\% } \\
\hline & $\begin{array}{l}\text { Medições } \\
\text { Temperatura }\end{array}$ & $\begin{array}{l}\text { Valor médio } 17,8^{\circ} \mathrm{C}\left(17,4^{\circ} \mathrm{C}-\right. \\
\left.18,2^{\circ} \mathrm{C}\right)\end{array}$ & & \\
\hline Acústicos & Medições ruído & $\begin{array}{l}\text { Valor médio - } 60 \mathrm{~dB}(\mathrm{~A})(62 \\
\mathrm{dB}(\mathrm{A})-59 \mathrm{~dB}(\mathrm{~A}))\end{array}$ & Bom - 75\% & Ruim - $42 \%$ \\
\hline
\end{tabular}

Por meio das análises das condições gerais dos fatores físico-ambientais pode-se concluir que nessa sala de aula, segundo o avaliador, essas condições foram predominantemente boas em $50 \%$, enquanto que para os alunos foram ruins em $48 \%$.

\section{Escola Senai Lençóis Paulista}

A unidade Lençóis Paulista do Serviço Nacional de Aprendizagem Industrial (Senai) foi inaugurada em 1987. Essa instituição oferece formação profissionalizante em diversos cursos nos períodos matutino, vespertino e noturno. Sua edificação segue traços modernos, com construção que passa regularmente por reformas de maneira a estar sempre adequada às exigências das disciplinas ministradas. O local de estudo nessa escola foi desenvolvido em uma sala de aula com capacidade de acomodação para trinta alunos, dos quais 12 são utilizados pela turma analisada. Assim como as outras salas de aula da edificação, essa é construída em alvenaria, o piso com 
revestimento em paviflex e laje em estrutura de concreto armado. A caracterização e análise dos fatores físico-ambientais podem ser observadas na tabela 13.

Tabela 13. Caracterização e análise dos fatores físico-ambientais.

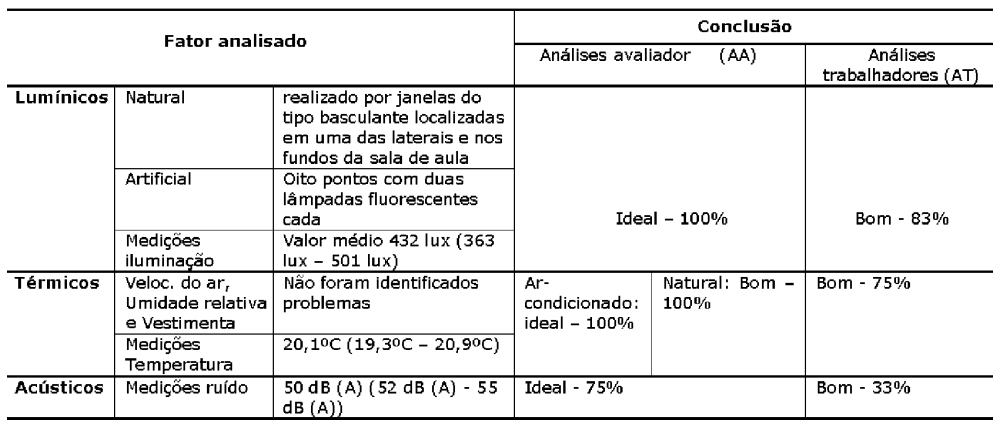

Ao fazer a análise geral das condições dos fatores físico-ambientais da sala de aula, observaram-se, segundo as análises desenvolvidas pelo avaliador, duas classificações, a primeira considerando a presença de sistema de ar-condicionado, fato esse que associado aos demais fatores observados classificaram o ambiente como possuindo condições térmicas 100\% ideais, e a segunda diante das condições térmicas naturais, que resultou na classificação do ambiente como predominantemente ideal em $58 \%$. O que foi observado a partir das análises desenvolvidas pelos alunos foi o predomínio da classificação das condições ambientais como sendo boas em 64\%.

\section{Análise comparativa ente as condições encontradas nas escolas estaduais e particulares}

A partir dos resultados obtidos com as análises individuais das condições dos fatores físico-ambientais das salas de aula, pode-se constituir um quadro comparativo entre as instituições estaduais e as particulares. Consequentemente pode-se identificar, e assim 
destacar, possíveis diferenças em relação aos aspectos avaliados, tanto pela abordagem do avaliador, como pela dos alunos. Primeiramente observando os resultados das análises técnicas desenvolvidas pelo avaliador, caracterizaram-se as condições encontradas nas escolas estaduais, onde houve a predominância igual dos percentuais de condições ideais e boas (32\%). Os maiores problemas identificados nesse tipo de instituição dizem respeito aos aspectos térmicos, que foram classificados como predominantemente regulares (56\%). A acústica ambiental apresentou-se em 57\% como boa, enquanto a iluminação classificou-se em $81 \%$ como ideal. O quadro encontrado nas instituições particulares apresentou dois enfoques de classificação das condições físico-ambientais, o primeiro desenvolvido considerando nas análises as condições térmicas com a presença do sistema de ar condicionado, que mostrou o predomínio de condições ideais (52\%). O item que apresentou as piores classificações foi a acústica ambiental, com predomínio de condições boas (40\%). O aspecto térmico do ambiente foi classificado como de condições ideais (75\%) e o lumínico teve classificação ideal (60\%).

O segundo enfoque foi desenvolvido considerando as condições naturais do ambiente em relação aos fatores térmicos. Dessa maneira a classificação das condições gerais dos fatores físico-ambientais das escolas particulares foi predominantemente boa (43\%). O item que apresentou as piores classificações foi a acústica ambiental, com predomínio de condições boas (40\%), seguido do aspecto térmico (bom em 50\%) e lumínico (ideal em 60\%).

A partir dos resultados obtidos com as análises técnicas do avaliador, nos dois tipos de instituições, constatou-se que as condições dos fatores físico-ambientais apresentaram-se em melhores condições nas escolas particulares do que nas estaduais em ambos os casos, ou seja, com ou sem o uso de sistema de ar-condicionado. Destaca-se, no entanto, que não houve grandes diferenças nas classificações, e que as condições encontradas nas escolas estaduais foram melhores do que o esperado. Ao enfocar as análises dos trabalhadores, que corresponderam às percepções que eles obtêm do ambiente ao ocupálo para desenvolver suas atividades, caracterizou-se um quadro no 
qual as escolas estaduais foram classificadas como apresentando a predominância de condições físico-ambientais ruins (42\%). Nessa avaliação o item que apresentou as piores classificações foi a acústica ambiental (50\% ruim), enquanto o aspecto térmico classificou-se predominantemente como ruim (46\%), e o lumínico regular (47\%). Destaca-se a alta classificação desses ambientes como tendo condições muito ruins.

Entretanto, as instituições particulares foram classificadas como possuindo condições predominantemente boas (50\%). As condições acústicas foram o item que apresentou as piores classificações (regulares em 45\%), seguido das térmicas ( $51 \%$ boas) e das condições lumínicas que foram definidas como predominantemente boas (69\%). Concluiu-se por meio da observação dos resultados das análises dos trabalhadores/alunos que a insatisfação dos alunos da rede pública em relação ao local onde desenvolvem o trabalho de aprendizagem foi clara e grande. Talvez se possa explicar esse fato pela falta de opções em mudanças ou cobrança por condições melhores, o que não se repete nas instituições particulares, que foram classificadas em 50\% como tendo condições boas.

\section{Considerações finais}

Como pôde ser constatado no decorrer deste capítulo, as sensações despertadas no usuário frente ao ambiente ocupado constituem-se em mais do que reações fisiológicas, visto que também o influenciam psicologicamente, e condicionam seu comportamento e o desempenho de suas atividades. No caso do ambiente escolar, entende-se que a configuração física que esse assume exerce influência direta na adaptação do estudante ao meio e, consequentemente, na evolução do processo de aprendizado. Pode-se concluir que a complexidade desse ambiente muitas vezes ultrapassa os aspectos estipulados por normas e indicações propostas, uma vez que segurança, acessibilidade, qualidade de vida, bem-estar e conforto são obtidos a partir de uma adequada conjugação de conhecimentos interdisciplinares. 


\section{Referências bibliograficas}

AHONEM, M. et al. Ergonomic Workplace Analysis. Helsinki: Finnish Institute of Occupational Health, 1989.

ALTAS, N.E., OZSOY, A. Spatial adaptability and flexibility as parameters of user satisfaction for quality housing. Building and Environment. Elsevier Sciense, v.33, n.5, p.315-23, 1998.

BERNARDI, N. Avaliação da interferência comportamental do usuário para a melhoria do conforto ambiental em espaços escolares: estudo de caso em Campinas-SP. Campinas,2001. Dissertação (Mestrado em Engenharia Civil) - Universidade Estadual de Campinas.

BORMIO, M. F. Sinalização visual de segurança - Estudo de caso Senai Lençóis Paulista. 2007. Monografia (Especialista em Engenharia de Segurança do Trabalho) - Faculdade de Engenharia, Universidade Estadual Paulista, Bauru, 2007.

ELALI, G. A. Ambientes para educação infantil: um quebra-cabeça? Contribuições metodológicas na avaliação pós-ocupação de edificações e na elaboração de diretrizes para projetos arquitetônicos na área. São Paulo, 2002. Tese (Doutorado em Estruturas Ambientais Urbanas) - Faculdade de Arquitetura e Urbanismo, Universidade de São Paulo.

ELY, V. H. M. B. et al. Espaço pessoal e relações interpessoais em abrigos de ônibus. In: Seminário Internacional de Psicologia e Projeto do Ambiente Construído, Rio de Janeiro, 2000.

HALL, E. A dimensão oculta. 2.ed. Rio de Janeiro: Francisco Alves, 1981.

KOWALTOWSKI, D. C. C. et al. Divulgação do conhecimento em conforto ambiental. In: VI Encontro Nacional e III Encontro Latino-Americano sobre Conforto no ambiente Construído. São Pedro: Antac, 2001.

LEUCZ, J. Ambiente de trabalho das salas de aula no ensino básico nas escolas de Curitiba. Florianópolis, 2001. Dissertação (Mestrado em Engenharia de Produção) - Universidade Federal de Santa Catarina.

LIMA, M. W. de S. A cidade e a criança. São Paulo: Nobel, 1989.

LÖBACH, B. Design industrial - bases para a configuração dos produtos industriais. Traduzição de Freddy Van Camp. São Paulo: Edgard Blücher, 2001.

ORSNTEIN, S., BRUNA, G., ROMÉRO, M. Ambiente construído e comportamento: a avaliação pós-ocupação e a qualidade ambiental. São Paulo: Nobel, Fauusp, 1995.

PIGOSSI, C. D. A importância das cores e natureza no ambiente interno. In: $4^{\circ}$ Congresso de Humanização Hospitalar em ação, 2004. 
RAPOPORT, A. Aspectos humanos de la forma urbana. Barcelona: Gustavo Gilli, 1978.

SANTOS, V. M. V. Modelo de avaliação de projetos - enfoque cognitivo e ergonômico. Florianópolis, 2001. Dissertação (Doutorado em Engenharia de Produção) - Universidade Federal de Santa Catarina.

VERDUSSEN, R. Ergonomia: a racionalização humanizada do trabalho. Rio de Janeiro: Livros Técnicos e Científicos, 1978. 



\title{
6 \\ CONDIÇÕES AMBIENTAIS EM ESCOLAS \\ MUNICIPAIS DE ENSINO INFANTIL DA \\ cidade de Marília (SÃo Paulo): \\ ESTUDO DE CASO
}

\author{
Eiji Hayashi ${ }^{1}$ \\ João Roberto Gomes de Faria ${ }^{2}$
}

\section{Introdução}

A cada ano que passa, o número de trabalhadores do setor de refeições coletivas de escolas adoece mais rapidamente, ainda que vivamos em um século no qual a tecnologia e a ciência cruzam dados incessantemente para o benefício da saúde.

No decorrer deste capítulo são mostrados dados de saúde correspondentes a fatores ligados tanto aos hábitos rotineiros de trabalho quanto aos hábitos de pós-jornada de trabalho e sua influência com a LER/DORT. A ergonomia trata de envolver diversas áreas, focando sempre no desenvolvimento do sistema produtivo e na saúde do trabalhador. No caso dos merendeiros das EMEIs da cidade de Marília, resume-se em desvendar os aspectos relacionados a tais incidências que constantemente causam precoces adoecimentos nesses trabalhadores.

O objetivo da pesquisa foi constatar fatos reais sobre as condições de trabalho, saúde e vida dos merendeiros das EMEIs da cidade de Marília, as razões dos afastamentos por doença e citar a forma como

1 Mestre em design, Universidade Estadual Paulista.

2 Livre-docente, Universidade Estadual Paulista. 
é realizada a tarefa em virtude de todos os problemas relatados. $\mathrm{O}$ estudo tende à compreensão das estratégias de ação da ergonomia, objetivando uma futura intervenção projetual no processo de trabalho, caso seja requisitada. Trata-se de uma pesquisa descritiva, desenvolvida pelo raciocínio dedutivo, na qual são analisadas e compreendidas as condições técnicas, ambientais e organizacionais de trabalho. Ela possui uma abordagem de caráter investigativo, contexto social e dialético com relacionamento de dados de outros pesquisadores.

\section{Referencial bibliográfico}

Cada Unidade de Alimentação e Nutrição (UAN) de EMEI possui características próprias e particularidades que a conformam singularmente. A formação do merendeiro é moldada de acordo com sua necessidade, característica, limite e possibilidade do posto de trabalho, levando em conta o objetivo produtivo. Entre as muitas questões que afligem os trabalhadores do setor está a batalha pelo reconhecimento de sua profissão em relação à sociedade, melhoria das condições de trabalho, saúde do trabalhador e a responsabilidade também no processo de formação e educação das crianças na escola.

\section{Ergonomia}

\section{Conceitos e definições}

Hendrick (1993 apud Moraes, 2000) afirma que a única e específica tecnologia da ergonomia é a tecnologia da interface homem-sistema. A ergonomia como ciência trata de desenvolver conhecimentos sobre as capacidades, limites e outras características do desempenho humano e que se relacionam com o projeto de interfaces entre indivíduos e outros componentes do sistema. Como prática, a ergonomia 
compreende a aplicação da tecnologia da interface homem-sistema a projeto ou modificações de sistemas para aumentar a segurança, o conforto e a eficiência do sistema e da qualidade de vida.

\section{Legislação - Norma regulamentadora 17 - Regulamento técnico - RDC216 da Anvisa - Doenças relacionadas ao trabalho}

\section{Conceitos e definições}

Conforme Couto (2004), no início dos anos 1990, com os Distúrbios Osteomusculares Relacionados ao Trabalho (DORT) sendo considerados um problema universal, um número incontável de artigos científicos foi escrito, muitos deles concordando com a abordagem da biomecânica, outros discordando. Em uma pesquisa para desenvolver uma teoria sobre esses distúrbios, foi confirmada a existência de diversos fatores envolvidos em sua origem, tais como fatores de natureza psicológica, social, biomecânica e também fatores organizacionais.

A prevalência de disfunções músculo-esqueléticas relacionados ao trabalho é supostamente maior em países em desenvolvimento, já que as condições de trabalho e os serviços de saúde tendem a ser mais precários do que os existentes nos países tradicionalmente desenvolvidos (Coury, 2005).

\section{Fatores de risco}

Os fatores para o surgimento das LER/DORT dependem de várias causas, direta ou indiretamente, e são dependentes de outros elementos no local de trabalho. Na caracterização da exposição aos fatores de risco, alguns elementos são importantes, dentre outros fatores etiológicos que influenciam ou causam ou agravam a LER/ DORT: 
- desrespeito aosfatoresergonômi coseantropométricos(equipamentos, acessórios, ferramentas, mobiliário, posicionamentos, distâncias etc.);

- anatômia (região exposta);

- intensidadeda atividade;

- organização (duração, pausas, horários, excesso dejornadas);

- postura no posto detrabal ho;

- ambiente (frio, vibração epressões locais sobre os tecidos);

- sobrecarga estática (manter um membro em posição contra a gravidade);

- sobrecarga dinâmica;

- monotoniafísica el ou psicológica (invariabilidadedatarefa);

- fatores organizacionais epsicossociais.

\section{Análise ergonômica do trabalho}

A ergonomia tem descoberto e aceitado a distinção entre o trabalho prescrito, comumente chamado "tarefa" (sendo que esta é elaborada e designada pela direção da empresa e apresentada aos trabalhadores em manuais de funções) e o trabalho real também chamado "atividade" (que é o trabalho desenvolvido efetivamente no dia a dia pelo trabalhador em seu posto de trabalho). Esse trabalhador não é somente um agente biológico que só existe como um corpo, mas tem também dimensões cognitivas, afetivas e relacionais que estão indissociavelmente ligadas durante o desenvolvimento de sua atividade laboral.

\section{Análise do posto de trabalho dos merendeiros}

Realizando uma AET de todos os fatores variáveis no local de trabalho, podemos detectar os pontos negativos que envolvem essa profissão. Dentre eles se destacam a temperatura elevada e a adoção de postura incorreta acarretando problemas de mal-estar, dores nos 
membros e na coluna. Entre os fatores que prejudicam a saúde dos merendeiros podemos citar alguns relacionados ao tipo de trabalho que executam e à forma organizacional do trabalho escolar, assim como outros referentes à sua vida pessoal. Destacamos algumas características da categoria: a maioria é composta de mulheres não muito jovens, entre 30 e 55 anos de idade, negras e pardas, pobres, com pouca escolaridade e sem formação profissional.

A Secretaria Municipal da Higiene e Saúde da cidade de Marília relata que no mês de julho de 2005, dos 195 merendeiros em exercício, 27 estavam em situação de readaptação nas funções diárias de seu local de trabalho. Esse número equivale a 13,8\% de profissionais que sofreram algum tipo de lesão que acarretou o afastamento e mudanças na rotina de seu trabalho diário.

\section{Objetivo da análise ergonômica do trabalho dos merendeiros}

O objetivo da análise ergonômica do trabalho dos merendeiros é avaliar a qualidade do trabalho em seu posto de trabalho. Essa qualidade refere-se ao conforto e segurança em sua jornada rotineira, tornando visíveis os aspectos positivos e negativos e suas possíveis correções, evitando danos ao corpo, principalmente no que se refere às doenças ocupacionais (LER/DORT). Neste capítulo, dados referentes $\mathrm{AET}$ dos merendeiros são mostrados em nível global, focando coleta de informações do design do posto de trabalho e considerando que fatores complexos como biomecânica são destinados aos profissionais habilitados na área da saúde, não sendo, portando, objeto de estudo e análise. Nos resultados cita-se a confrontação de dados técnicos referenciais com dados colhidos no decorrer da pesquisa. Dados referenciais da norma NR17 foram complementados com os de outras normas como a da RDC-16 da Anvisa (direcionada para setores de saúde), Abergo (ergonomia), Aberc (setor de refeição coletiva), NBR 5413 (iluminância de interiores), além de vários autores citados constantemente. 


\section{Metodologia da análise ergonômica da tarefa dos merendeiros}

Foi utilizada como instrumento a AET descrita anteriormente no referencial teórico.

O desenvolvimento da metodologia constituiu-se das seguintes etapas: análise documental e coleta de dados, pedido de autorização para investigação in loco nas EMEIs, entrevista com a direção da empresa terceirizada, entrevistas com profissionais da Secretaria Municipal da Higiene e Saúde, entrevista e aplicação de questionários com os merendeiros, observação do posto de trabalho, medidas antropométricas e análise dos dados obtidos.

A coleta de dados foi realizada em 21 UANs de EMEIs existentes e em funcionamento na cidade de Marília até novembro de 2005 por meio de entrevistas pautadas. Essas foram realizadas pela abordagem nas pausas e nos intervalos do horário previamente autorizado das $13 \mathrm{~h} 00$ às $16 \mathrm{~h} 00$.

\section{Materiais}

Usaram-se termos de consentimento livre e esclarecido e questionários para coleta de dados ergonômicos. Usaram-se os seguintes equipamentos: máquina fotográfica digital de 4.1 megapixels (Fuji), trena de 5 metros (First), termômetro-higrômetro-luximetro-decibelímetro (THDL-400 Instrutherm) e notebook Acer 3610 Celeron M 1.5.

\section{Análise dos dados}

A análise dos dados é o elemento essencial da ergonomia. Orienta a análise da demanda e o funcionamento produtivo, sintetiza resultados e compara dados referentes à ergonomia. Pode tratar-se de manter uma produção ou resolver determinado problema organizacional. 


\section{Resultados}

\section{Organização estrutural}

Cada EMEI possui na maioria das UANs três trabalhadores para o desempenho da função. A jornada de trabalho tem início às 7h00 e término às $17 \mathrm{~h} 00$. O horário do almoço é das $12 \mathrm{~h} 00$ às $13 \mathrm{~h} 30$. As tarefas são distribuídas conforme as necessidades do dia. Não existe uma atividade fixa para cada trabalhador. Dependendo do tipo de refeição a ser preparada, a cocção é adiantada para que as refeições sejam servidas em tempo hábil. A quantidade e o tempo de exposição do alimento pronto para servir são fatores que influenciam no dia a dia dos merendeiros. A preocupação com a higiene e com o estado nutricional dos alimentos em uma longa exposição demanda uma eficiência cautelosa no preparo e no servir. Nutricionistas da empresa SP Alimentação, empresa terceirizada fornecedora de alimentos pré-preparados, realizam semanalmente visitas nas EMEIs levando instruções aos merendeiros sobre métodos de preparo, higiene e práticas atuais que envolvem a profissão. O cuidado também com alunos alérgicos a certos tipos de alimentos faz parte da rotina do trabalho desses profissionais.

\section{Espaços físicos das cozinhas de EMEls}

A estrutura do espaço físico destinado ao preparo da merenda escolar assemelha-se ao layout das cozinhas residenciais. Possuem em um só espaço os equipamentos necessários para a realização da tarefa (bancada, pia, tanque, forno, fogão, geladeira e freezer, entre outros), equipamentos que dividem espaços com os próprios trabalhadores. Toda UAN possui espaço reservado para o setor de armazenamento. Somente em algumas unidades constatou-se uma construção padronizada na parte física, mas diferente entre si no modo da disposição dos móveis e equipamentos. A maioria foi projetada anos atrás e adaptada às condições atuais das necessidades da demanda. 


\section{Análise da tarefa}

Essa etapa da pesquisa consistiu-se em analisar as condições dos postos de trabalho dos merendeiros, levando em consideração as condições ambientais em que exercem e executam sua função.

\section{Considerações sobre a função}

O trabalho dos merendeiros caracteriza-se de um modo geral pela manipulação manual e intensa na preparação dos alimentos e posterior limpeza do local de trabalho. Todo o trabalho é acompanhado de movimentos repetitivos de membros superiores e coluna, levantamento de pesos excessivos, mantendo-se na postura em pé por longos períodos. A distribuição dos alimentos estocáveis é realizada nas quintas e sextas-feiras. Produtos perecíveis são comercializados diretamente com produtores que se encarregam da distribuição todas as sextas-feiras, diretamente nas EMEIs.

Em relação à hierarquia, os merendeiros ficam subordinados à direção de cada escola e supervisionados por nutricionistas e coordenadores da SP Alimentação. Dúvidas quanto à preparação de alguma refeição são repassadas diretamente à direção, que as repassa ao responsável pela elaboração do cardápio.

Muitas vezes eles são obrigados a serviços extras de limpeza ou mesmo de preparo do cardápio para o dia seguinte. Algumas indicações do cardápio exigem uma prévia organização no preparo. Descongelar alimentos ou picar legumes são tarefas extras que exigem a atenção desses trabalhadores. A pressão do tempo, movimentos repetitivos são alguns dos aspectos rotineiros desse posto de trabalho.

O cardápio mensal é fixado em local visível no painel dentro de cada cozinha, para que diariamente o merendeiro possa ter acesso às informações e com isso calcular o ritmo de trabalho do grupo. As normas e procedimentos de trabalho são seguidos geralmente pela vivência do trabalho rotineiro de preparo das refeições. 
As queixas sobre problemas de saúde são inúmeras e comuns a todos os merendeiros das EMEIs. A maioria cita a fadiga física ao final de cada jornada de trabalho como umas das principais. Utensílios e materiais utilizados em determinadas funções também são responsáveis por queixas. A maior reclamação entre utensílios fica por conta do aparelho para corte de legumes. Os movimentos repetitivos, o esforço para o funcionamento de tal dispositivo desencadeia dores frequentes que podem perdurar por um longo período durante a jornada de trabalho. Relatos de consultas médicas são constantes.

\section{Das pausas}

Pausas de dez a 15 minutos para o café são realizadas de acordo com a disponibilidade das tarefas. Geralmente ocorrem após as refeições servidas pela manhã ou tarde. Aos sábados não há expediente.

\section{Características do trabalhador}

Foram entrevistados trabalhadores que atuam na função de 2 meses a 31 anos de carreira. Trabalhadores que completaram até dez anos no cargo são a maioria. Foram tabulados dados de trabalhadores com mais de dez anos de serviço e funções menores. Os merendeiros das EMEIs da cidade de Marília constituem-se basicamente, em sua maioria, de mulheres, representando elas $95,2 \%$ e os homens, $4,8 \%$. O grau de escolaridade é no mínimo o ensino fundamental. A preocupação com a higiene da alimentação e saúde acarretou medidas de melhoria social e psicossocial. Aspectos positivos são descritos, quando comparados ao modelo anterior de sistema produtivo. Existem trabalhadores de todas as raças, de acordo com a classificação adotada do IBGE, que coleta como dado de identificação racial a cor da pele (quesito cor) por meio da autoclassificação em um dos cinco itens: preta, parda, branca, amarela, indígena. 
A estatura média dos merendeiros é de 1,61m. Abaixo dessa média foi encontrada a maior parte dos tipos raciais, exceto a raça/ cor preta que compõe 100\% dos entrevistados acima da média.

\section{Organização}

Todas as tarefas são realizadas em conjunto, não havendo uma divisão setorial para cada atividade. Conforme as necessidades, os trabalhadores desempenham determinada função de acordo com a produção das refeições a serem produzidas. Cada EMEI possui um determinado número de refeições a serem produzidas e são distribuídas de acordo com a demanda de cada turno. Os intervalos para as refeições são de 30 minutos em média, divididos sequencialmente por ordem de classe crescente em grau. Cada classe, dentro de uma norma de conduta, tem sua ordem de chegada determinada pelo ritmo de consumo. A quantidade de alunos no refeitório depende de cada unidade, pois o número de assentos disponíveis influencia na demanda das refeições.

\section{Acidentes de trabalho}

Dentre os entrevistados, $82,25 \%$ registraram terem sofrido acidente de trabalho em decorrência de alguma atividade realizada. Casos de queimaduras são os que lideram a maior parte dos relatos, com $59,6 \%$, seguidos por dores causadas pelo excesso de peso com $50 \%$, cortes superficiais e profundos nas mãos com $45,1 \%$, escorregões e choques elétricos com 19,3\%, batidas e esbarrões em decorrência da falta de espaço de circulação com 19,3\% e queda de objetos como panelas, alimentos e utensílios pesados sobre o trabalhador com $17,7 \%$. Sobre afastamento por acidentes de trabalho, 25,8\% responderam já terem sido medicados e afastados. Em relação à prevenção de acidentes, 48,3\% dos merendeiros relataram terem tido instrução ou treinamento no início de suas funções. 


\section{Características do ambiente e das ferramentas de trabalho}

\section{Área física}

Cozinha e depósito: as cozinhas das EMEIs são constituídas por duas áreas, uma destinada à produção e outra para armazenamento. Algumas unidades contêm uma terceira área anexa destinada aos serviços de higienização de utensílios. O layout das UANs baseia-se em três tipos, conforme posicionamento da bancada, pia, fogão e refrigerador: $45 \%$ das cozinhas são em L, 25\% em U e 30\% em paralelo.

Pé-direito: a altura do pé-direito das cozinhas situa-se entre 2,80m a 3,60m de altura, considerada ideal para seu porte (médio) conforme Silva Filho (1996, p.149) para as cozinhas da EMEIs.

Piso: quanto ao piso, na maioria das UANs estão devidamente adequados, nivelados, sem ressaltos e constituídos de material do tipo granilite (35\%), espécie de composto misto de partículas de granito e mármore em composição com cimento, dando aparência e forma regular em toda a sua extensão, ou cerâmica (65\%). Estes dois tipos de piso suportam tráfego intenso e a presença de materiais químicos para limpeza. Dentro da faixa de acidentes por escorregões, 47\% desses eventos ocorreram em piso do tipo granilite e $53 \%$ em piso do tipo cerâmico.

Portas e janelas: em todas as instalações das unidades de alimentação foram encontradas janelas do tipo metálica corrediça ou basculante. A inexistência de proteção por telas nas janelas em todas as unidades indica riscos de atração, abrigo, acesso ou proliferação de vetores ou pragas urbanas (RDC 216 Anvisa).

Ventilação e exaustão: Silva Filho (1996) sugere que o valor de vinte vezes por hora é o padrão mínimo adotado para um ambiente mais saudável. Já Kinton (1998) declara que a troca de ar mínima de trinta vezes por hora seja suficiente para ambiente de cozimento, podendo alcançar a medida de sessenta vezes para produtos que produzam intenso calor e fumaça. Das 21 EMEIs pesquisadas, somente 
duas apresentavam sistema de troca de ar por exaustão. Apenas um deles estava em funcionamento e era do tipo eólico. Em entrevista com os trabalhadores nessa unidade, verificamos que mesmo após a instalação do equipamento eles não sentiram melhoras nas condições ambientais. Declararam que o aparelho era ineficiente.

No caso da impossibilidade de conforto ambiental por meio natural, é indicado recorrer a meios artificiais como os já citados exaustores dimensionados tecnicamente. É banido o uso de ventiladores ou ar-condicionado nesses locais. São equipamentos que não atendem aos requisitos e não devem ser utilizados nas áreas de processamento e manipulação de alimentos. Foram encontrados instalados ventiladores de teto e de parede que não atendem aos requisitos das normas e associações.

Revestimento: quanto às paredes das cozinhas, a maioria é revestida de azulejos até o teto, lisos, impermeáveis e laváveis. Somente em algumas unidades, ou em setores de recebimento e lavagem de utensílios, o revestimento de azulejos vai até a altura de 1,5m.

Dimensões do posto de trabalho: segundo Kinton (1999, p.401) são necessários aproximadamente $4,2 \mathrm{~m}^{2}$ por pessoa; um espaço exíguo pode fazer com que o pessoal trabalhe muito perto de fogões, cadeiras, facas, liquidificador etc. É desejável uma distância de $137 \mathrm{~cm}$ dos equipamentos, e as cozinhas devem estar adequadas para o pessoal poder mover-se com segurança. O espaçamento ideal entre planos de trabalho é de 1,20 a 1,50m de distância. O manual da Aberc e da Anvisa sobre áreas de UANs destaca que elas devem seguir uma linha racional de produção, obedecer a um fluxo coerente e evitar cruzamentos entre as atividades. As áreas devem impedir a contaminação cruzada entre alimentos e/ou utensílios limpos e o retorno de utensílios sujos. Na circulação de pessoas, o corpo humano é referência básica para medidas de pessoas de maior e menor tamanho. Como já mencionado, a média da área construída das cozinhas é de $32,32 \mathrm{~m}^{2}$, enquanto as áreas destinadas ao depósito são em média de $10,75 \mathrm{~m}^{2}$. Em algumas unidades encontramos medidas inversas de espaço físico onde despensas excedem o tamanho em relação à área da cozinha. De uma forma geral, 45,1\% possuem espaço satisfatório, 
conforme dados da entrevista sobre a realização do trabalho rotineiro com suficiente área para circulação e transporte de carga.

\section{Do mobiliário, equipamento e utensílios}

O dimensionamento dos equipamentos e utensílios tem relação direta com a demanda das refeições, padrões e sistemas de distribuição. Todos devem ser compostos de materiais de fácil higienização, livre de superfícies que evitem a limpeza ou partes móveis que possam causar algum acidente. Móveis como mesas, bancada e prateleiras devem ser dimensionados de acordo com a exigência do serviço prestado.

Na maioria das cozinhas das EMEIs não é respeitado um espaço para os pés. Como mostra a figura 22, o trabalhador sente a necessidade de curvar o tronco para a realização da tarefa. Um espaço adequado permite a movimentação dos membros inferiores e a mudança frequente de postura, atenuando possível desconforto postural.
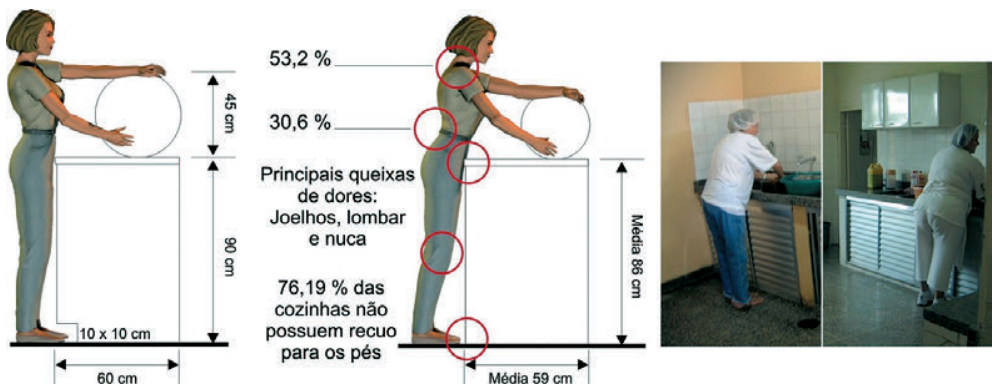

Figura 22. Posicionamento correto e incorreto do trabalhador.

Já para o alcance das prateleiras, o ideal é que elas estejam a no máximo $1,85 \mathrm{~m}$ de altura. Devem estar localizadas a uma distância de $25 \mathrm{~cm}$ do piso e com profundidade não superior a $45 \mathrm{~cm}$ (Aberc, 1998). Iida (2005) afirma que a faixa ideal de operação com mãos situa-se entre $65 \mathrm{~cm}$ e $150 \mathrm{~cm}$ acima do nível do piso. Fora dessa faixa, o corpo deverá realizar movimentos maiores, como inclinar o dorso. 
Na figura 23 podemos verificar que $88,7 \%$ dos merendeiros responderam que a altura média da prateleira de $195 \mathrm{~cm}$ acima do nível do solo encontra-se na faixa normal para uso. Essa situação confirma a relação de Thiberg que a altura máxima de alcance é de 1,24 vez a altura do indivíduo.

A figura 24 mostra aspectos relativos às alturas das bocas de distribuição encontradas em diferentes cozinhas.

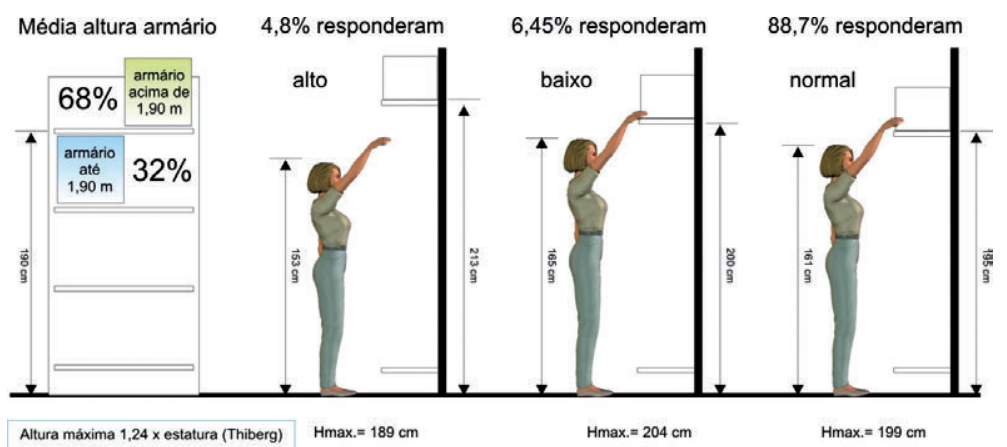

Figura 23. Posicionamento de prateleiras conforme pesquisa.

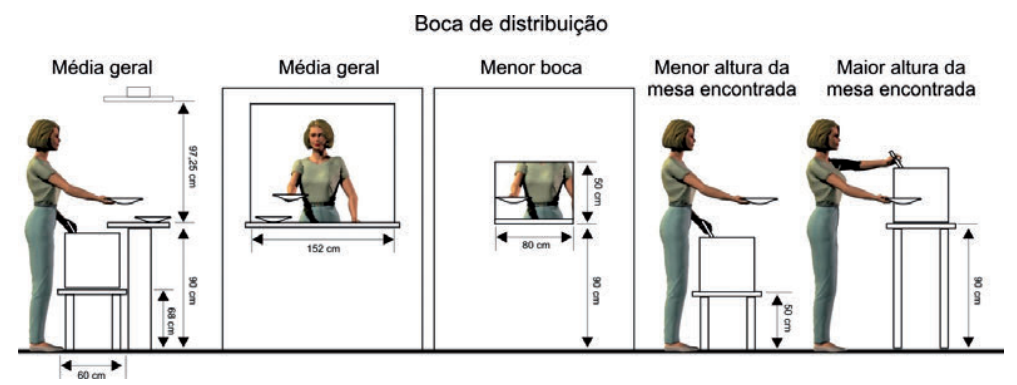

Figura 24. Altura do apoio para caldeirões e boca de distribuição.

\section{Da iluminação}

Conforme a Norma NBR 5413 (iluminância de interiores), a iluminação das cozinhas deve medir entre 300, 500 ou 750 lux e a 
iluminação geral 150, duzentos, ou trezentos lux. Essas três medidas adotadas para cada situação dependem de outros fatores que, quando calculados, mostram a relação ideal para o setor. Os três fatores determinantes da iluminância adequada são idade, velocidade de precisão e refletância do fundo da tarefa. Cada qual recebe um peso, indicando assim um valor algébrico para mais ou para menos na média das iluminâncias recomendadas.

Dul \& Weerdmeester (2004, p.78) expressam que para determinar a quantidade de luz é necessário fazer distinções entre a luz ambiental, iluminação no local de trabalho e iluminação especial. Recomenda-se de dez a duzentos lux para lugares onde não há tarefas exigentes, como é o caso de depósitos, e de duzentos a oitocentos lux para tarefas normais como leituras, montagens e operações de máquinas. Iida (1995, p.253) explica que o rendimento visual tende a crescer com o logaritmo da iluminância a partir de dez lux até cerca de mil lux, enquanto a fadiga visual se reduz nessa faixa.

A diversidade dos ambientes de trabalho retrata características individuais de cada EMEI. Encontram-se cozinhas das mais diversas configurações de arquitetura. Janelas venezianas, maxi-ar e basculantes, entre outras, diferem no grau de iluminação natural pelo posicionamento e tipo de material empregado.

Para a iluminação artificial, um dos pontos importantes é o Índice de Reprodução de Cores (IRC) da lâmpada. Quanto mais próximo o índice for ao IRC 100 (dado à luz solar), maior a fidelidade de cores no ambiente. A iluminação da área de preparação deve proporcionar a visualização de forma que as atividades sejam realizadas sem comprometer a higiene e as características sensoriais dos alimentos (RDC 216 Anvisa).

Conforme a Aberc (1998, p.38) a iluminação deve ser distribuída uniformemente no ambiente, garantindo boa visibilidade. A iluminação mais recomendada é a natural. A iluminação artificial, quando necessária, deve ser tal que não altere as características sensoriais (visuais) dos alimentos. Não é recomendado que fontes sejam instaladas sobre a linha de produção. As recomendações da Aberc são: 
para áreas de inspeção, 540 lux; para área de processamento, 220 lux, e nas outras áreas, 110 lux.

A fabricante Philips (1981, p.295) recomenda para áreas de trabalho geral trezentos lux, processos com duzentos lux e área de inspeção com quinhentos lux. A seguir as medidas de mínima e máxima iluminação encontradas nos locais de trabalho das escolas pesquisadas: lluminância sobre o tanque - máxima de 960 lux/mínima de 24 lux; iluminância sobre a pia - máxima de 756 lux/mínima de 25 lux; iluminância sobre fogão - máxima de 1.494 lux/mínima de 46 lux; iluminância sobre a bancada - máxima de 1.240 lux/mínima de 25 lux; iluminância sobre a boca de distribuição - máxima de 603 lux/mínima de 43 lux.

Em áreas de depósito, onde há pouca movimentação e exigência visual, foram coletadas medidas acima do esperado, atingindo a média de 223 lux. Das unidades avaliadas, apenas duas situavam-se abaixo do nível recomendado de cem lux. Outras alcançavam valores sete vezes mais altos. A mínima e máxima encontrada nesses setores foram 72 lux e setecentos lux. Das 21 cozinhas analisadas, apenas quatro estavam acima da medida de quinhentos lux recomendada por Dul, Grandjean, Iida e Philips, mostrando a ineficiência do sistema de iluminação da maioria das unidades de alimentação das EMEIs (figura 25).

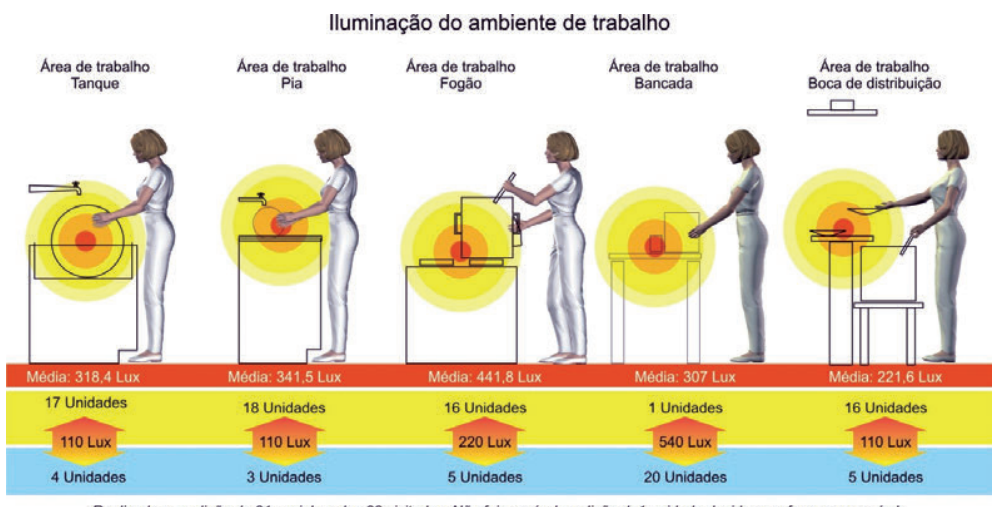

Realizada a mediçáo de 21 cozinhas das 22 visitadas. Náo fol possivel mediçấo de1 unidade devido as reformas no periodo

Figura 25. Medida da iluminação encontrada em determinada função. 


\section{Do ruído}

Ruídos intensos, acima de $90 \mathrm{~dB}$, dificultam a comunicação verbal e produzem aborrecimentos de desconcentração mental em certas tarefas. O nível de ruído é ocasionado constantemente pela soma de sons combinados de equipamentos como liquidificador, panela de pressão, higienização de pratos, copos, talheres e diálogo entre trabalhadores. A média de ruído nos horários normais e sem interferência de sons dos alunos no refeitório foi de 81,03 dB. A figura 26 mostra os resultados da pesquisa com trabalhadores sobre as condições sonoras do ambiente de trabalho.

É barulhento

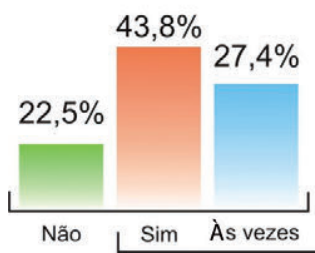

Em qual situação consideram ruidosa

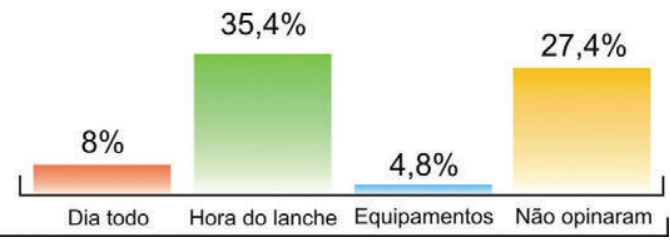

Figura 26. Resultado da medição de ruído.

Uma panela de pressão, sozinha, emite ruído constante de até 93,7 dB. Já nos horários das refeições dos alunos, com o ruído emitido pela voz deles chegou-se a picos de 98,2 dB, com média de 85,7 dB.

\section{Da temperatura e umidade}

O homem é um ser pertencente à classe dos animais homeotérmicos, que possuem mecanismos de regulação térmica para manter a temperatura corporal mais ou menos constante em torno de $37^{\circ} \mathrm{C}$. Ou seja, independentemente da temperatura externa, o homem tende a manter a temperatura estável. A temperatura e a umidade ambiental influem diretamente no desempenho do trabalho humano. Em ambientes acima de $35^{\circ} \mathrm{C}$ a evaporação torna-se o único mecanismo para o corpo manter seu equilíbrio térmico. A associação de trabalho físico pesado e as con- 
dições externas inadequadas podem provocar um desequilíbrio térmico corporal. A tolerância vai até $39,5^{\circ} \mathrm{C}$ por curtos períodos de tempo.

Segundo Iida (1995, p.237) quando o homem é obrigado a suportar altas temperaturas, o seu rendimento cai. A velocidade do trabalho diminui, as pausas tornam-se maiores e mais frequentes, o grau de concentração diminui e a frequência de erros e acidentes tende a aumentar significativamente, principalmente a partir de $30^{\circ} \mathrm{C}$. O suor faz com que o organismo perca sal provocando excitação e, se prolongada a situação, podem surgir sintomas de cãibras.

Os condicionantes para a elevação da temperatura nas cozinhas são causados pela grande maioria nos locais pesquisados pela soma de elementos que geram calor como forno, fogão, vapor das panelas, iluminação e equipamentos elétricos. Resultados da pesquisa apontam a temperatura elevada no posto de trabalho com um dos grandes condicionantes de irritabilidade e cansaço na jornada de trabalho (figura 27). A média da temperatura medida nas cozinhas foi de $28,5^{\circ} \mathrm{C}$ no horário da coleta de dados.

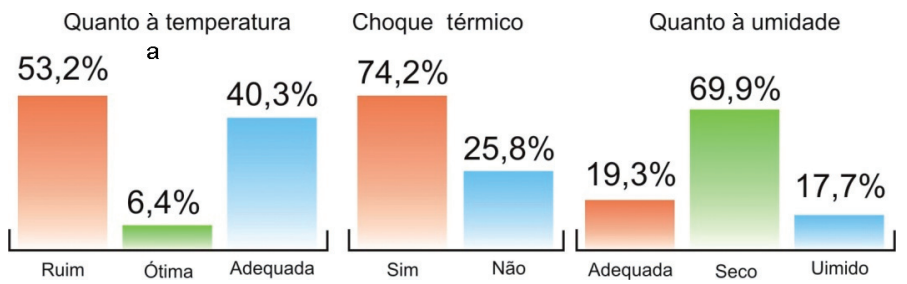

Figura 27. Fatores térmicos dentro da cozinha.

A norma regulamentadora NR17 determina índice de temperatura entre $20^{\circ} \mathrm{Ce} 23^{\circ} \mathrm{C}$ e umidade relativa do ar não inferior a $40 \%$. A Aberc determina temperatura ideal para as unidades de alimentação de $22^{\circ} \mathrm{C}$ a $26^{\circ} \mathrm{C}$ com umidade relativa do ar de $50 \%$ a $60 \%$. Kinton (1998) estipula para uma máxima eficiência e conforto uma temperatura não entre $20^{\circ} \mathrm{C}$ e $26^{\circ} \mathrm{C}$ com umidade máxima de $60 \%$ para não afetar a produtividade. Dentro da faixa ideal de temperatura e umidade proposta pela Aberc e pesquisadores, somente uma unidade obteve condições normais de trabalho (figura 28). 


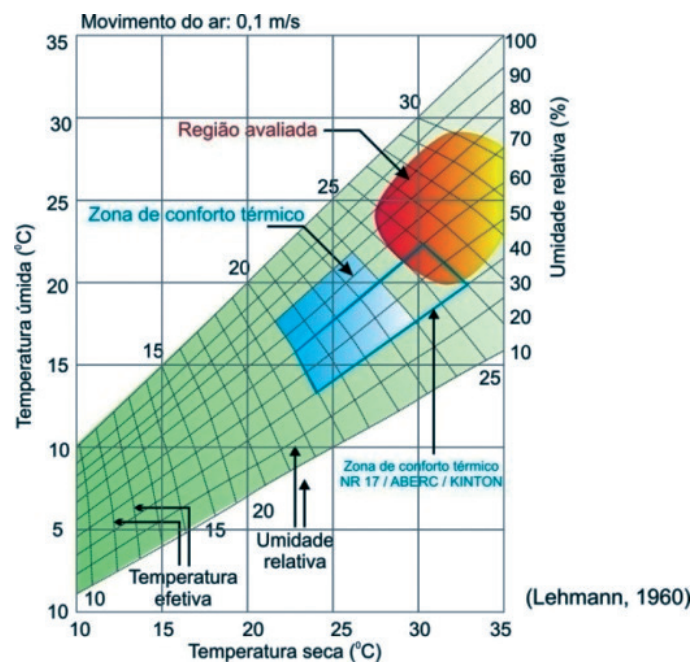

Figura 28. Gráfico da zona de conforto térmico (Iida, 2005, p.497).

\section{Análise da atividade}

Objetivando avaliar o nível de treinamento, aspectos sociais, posto de trabalho e saúde do trabalhador, foi elaborado questionário com base na lista de verificação ergonômica de Dul, do protocolo de investigação de LER/DORT do Ministério da Saúde e técnica de medição de desconforto postural de Corlett \& Manenica. Foram pesquisadas as seguintes atividades: recebimento, armazenamento, pré-preparo, cocção, distribuição e higienização.

\section{Saúde do trabalhador}

Durante uma jornada de trabalho intensa, os merendeiros vivem situações que podem desencadear vários fatores para seu adoecimento. A Anvisa determina que manipuladores de alimentos que apresentarem sintomas de lesões ou enfermidades que possam comprometer a qualidade higiênico-sanitária dos alimentos devem 
ser afastados das atividades de preparação de alimentos enquanto persistirem essas condições de saúde. Uma má postura oriunda de fatores externos provocados por mobiliário inadequado ou mesmo vícios de uma postura incorreta também são responsáveis pelo grande desgaste físico do trabalhador. Em relatos, o ruído excessivo é mais intenso em situações no período de cocção somadas aos das refeições, durante as quais a irritação dos merendeiros é visível nos momentos de gritaria, arrastar de móveis e conversa e agitação das crianças. A falta de equipamento adequado para determinada função é citada também no desconforto postural.

Os resultados de desconforto postural baseados no modelo de Corlett \& Manenica mostram com clareza pontos de desconforto citados durante a investigação. As regiões mais indicadas de desconforto após o final de cada jornada de trabalho foram a região do pescoço, com 51,6\%, com nível de desconforto grau sete em 15,6\% dos trabalhadores; ombros, com 51,6\%, com grau sete em $15 \%$; e pernas, com $53,2 \%$, com grau sete em $24 \%$ dos trabalhadores (figura 29). Nessas regiões inferiores, a principal causa de desconforto é pela postura em pé adotada durante a jornada de trabalho. Sabemos que a posição parada em pé é altamente fatigante devido à exigência estática do grupo muscular para mantê-la na posição. O coração encontra maior resistência para bombear sangue para os extremos do corpo.

Já nos membros superiores a tensão pelo ritmo de trabalho, movimentos repetitivos, excesso de força, movimentos inconvenientes, postura, mobiliário, excesso de peso, entre outros, são alguns dos fatores responsáveis pelas dores generalizadas ao longo desses membros que não suportam tamanha carga durante período prolongado.

O acúmulo de vários outros fatores ocasiona dores de longa duração que se tornam frequentes e irreversíveis em determinado momento. Braços, antebraços, punhos e mãos são indicados como membros que em determinadas posturas requerem uma parada na produção pelas dores insuportáveis. Falta de firmeza nas mãos, dores nas articulações, choques nos nervos são consequências diretas do excesso de trabalho. Movimentos repetitivos de lavagem de pratos e talheres são apontados como funções sacrificantes. 


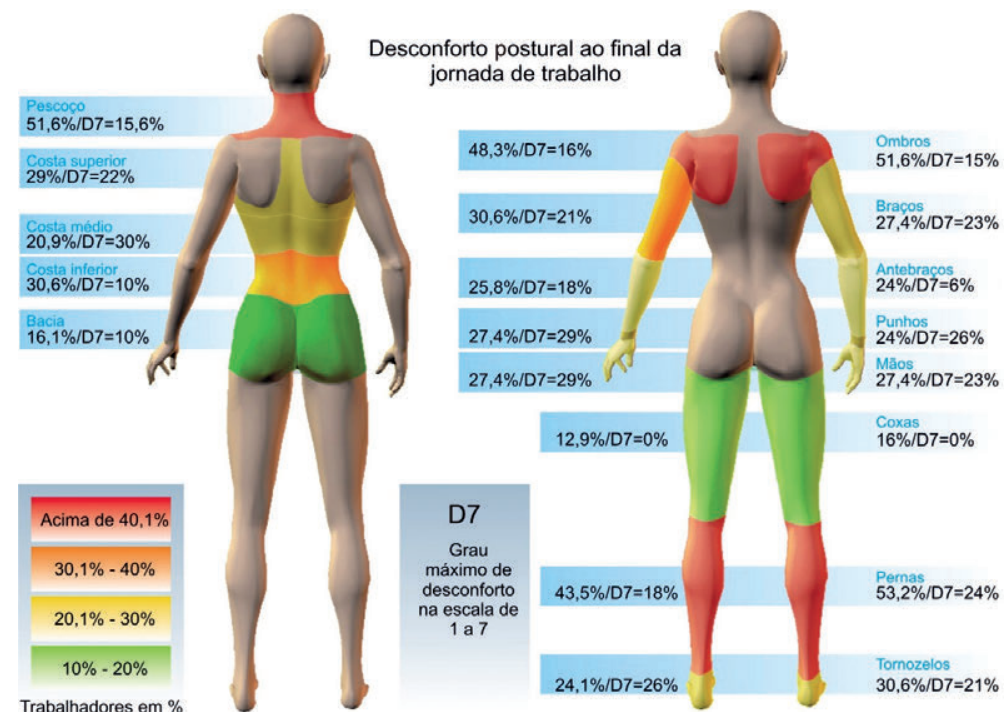

Figura 29. Gráfico de desconforto postural (baseado em Corlett \& Manenica, p.175-92).

Ainda sobre desconforto postural sentido por causa de equipamentos, $30 \%$ dos merendeiros responderam que a limpeza do piso com rodos e vassouras impróprias são os responsáveis. Algumas adaptações foram mostradas nesses equipamentos, como o alongamento de cabo para facilitar seu manuseio e consequentemente minimizar dores na coluna.

Podemos associar aos resultados obtidos sobre dores pelo corpo como originados em posturas e movimentos inadequados nos quais são acionados diversos músculos, ligamentos e articulações para realização de certos movimentos. Para $80,6 \%$ dos merendeiros, as dores pelo corpo são sentidas em determinadas posturas, o que nos dá a certeza de que certos movimentos são responsáveis por dores localizadas. Esses trabalhadores $(83,8 \%)$ relatam que a jornada de trabalho se torna mais sacrificante se sujeitados intermitentemente a dores em determinadas regiões ou mesmo pelo corpo todo.

Como os músculos são responsáveis pela força direta necessária para a realização de determinado movimento, é natural que seja ele o 
responsável pela maior quantidade de queixas das dores. Para 72,5\% dos merendeiros, dores nos músculos são sentidas constantemente, enquanto dores nos tendões e nas articulações são queixas de 48,3\% dos trabalhadores.

A elevada temperatura provocada pelo intenso funcionamento de fornos, fogões, refrigeradores e outros meios de irradiação de calor, somada ao pouco espaço físico e exaustão de ar inexistente na maioria das cozinhas são condicionantes para ocasionar o excesso de suor, fazendo com que o organismo perca sal, provocando excitação prolongada e surgindo sintomas de cãibras. Em 32,2\% dos casos a cãibra surge como consequência direta da temperatura. Não foi constatada que a cãibra fosse associada aos indivíduos portadores de hipertensão, menopausa ou qualquer outro tipo de situação que possa ter influenciado nos resultados de trabalhadores com excesso de sudorese.

A falta de firmeza das mãos (32,2\% dos casos), choques (20,7\%) e formigamentos $(46,7 \%)$ são sintomas de indivíduos portadores de síndrome do túnel do carpo devido a movimentos repetitivos de flexão como lavar louça, mas também de extensão com o punho, principalmente acompanhada por realização de força como cortar carnes e picar rotineiramente grande quantidade de legumes.

No total, 40,5\% dos merendeiros estão sob medicação constante de várias substâncias químicas que vão desde anti-inflamatórios, relaxantes musculares e até antibióticos ou fototerápicos, todos relacionados ao tratamento de doenças músculo-esqueléticas. Notamos que muitos indivíduos que praticam atividade física (52,3\%) estão sob medicação constante (figura 30).
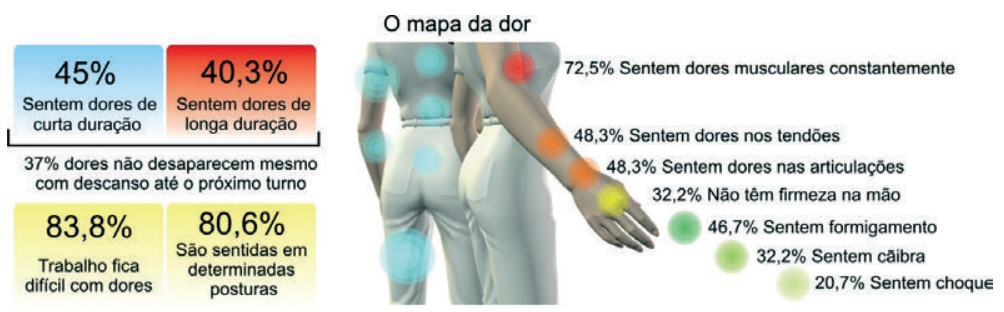

Figura 30. Porcentagem de dor sentida pelo merendeiro rotineiramente. 
Conforme dados da pesquisa, 30,2\% dos merendeiros dizem terem distúrbios de sono causando um déficit na qualidade de descanso noturno. Nota-se, entretanto, que quando é feita a relação de trabalhadores que dormem bem com a de trabalhadores que dormem mal, observamos que indivíduos com déficit na qualidade de sono têm varizes, são tabagistas, são hipertensos ou têm gastrite. Esses casos podem ter influência direta no sono ou vice-versa, mas podemos relacioná-los nitidamente (figura 31 ).

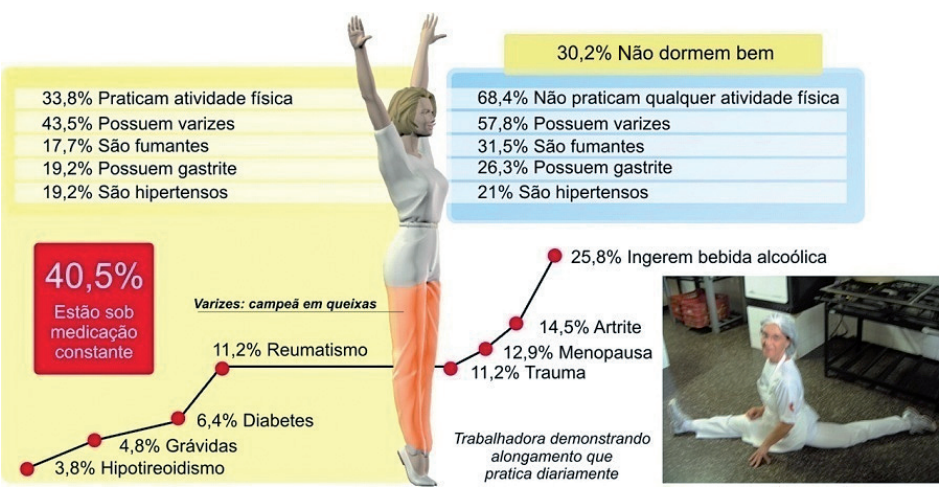

Figura 31. Tipos de doenças ou situações relacionados aos merendeiros.

Sintomas como fadiga constante, física e mental, acompanhados de distúrbios do sono, cansaço, irritabilidade, desânimo, sudorese e taquicardia, entre outros, são características também de síndromes neuróticas, que são situações difíceis de serem analisadas, pois dependem de um processo investigativo específico para cada indivíduo quanto ao ambiente, nível de organização e a percepção da influência do trabalho no processo de saúde/doença.

O estresse também é um sinal de fadiga fisiológica, ocasionando um maior consumo de energia e de oxigênio pela tensão muscular do indivíduo. Notamos que para 37\% dos merendeiros a chamada fadiga crônica não é reversível apenas com pausas ou sonos. Já faz parte de uma situação que tem efeito cumulativo e o tratamento médico faz-se necessário, pois trata-se de uma complexa situação que determina- 
do indivíduo passa não só no trabalho rotineiro, mas também por problemas pessoais ou familiares. Na fadiga psicológica dos merendeiros, falta de motivação pessoal ou questões de hierarquia criam um sentimento de cansaço, irritabilidade e desinteresse no trabalho.

\section{Diagnósticos e conclusão}

Todos os trabalhadores realizam esforço físico em determinadas funções no trabalho. As maiores exigências são nos momentos da locomoção de grandes caldeirões cheios, quando o peso supera sessenta quilos. A indicação de que $72,5 \%$ dos trabalhadores sentem dores constantes mostra a situação alarmante em que vivem os merendeiros. A forma como é imposto o sistema de trabalho dificulta uma melhoria na saúde individual e coletiva. A sobrecarga, movimentos repetitivos, mobiliários fora dos padrões, equipamentos inadequados e condições ambientais são alguns dos desencadeantes de doenças relacionadas ao trabalho. Quase todas as atividades são realizadas em pé, o que torna o trabalho desgastante em sua jornada. O índice de 52,2\% de queixas de desconforto nas pernas mostra o quão fatigante é trabalhar nessa posição. A temperatura elevada e o choque térmico foram alguns dos condicionantes pelo desgaste físico. O calor torna o trabalho mais árduo pela sensação de cansaço e irritabilidade que produz e, consequentemente, ocasiona dores pelo choque térmico na abertura dos freezers e refrigeradores ou pelo contato constante com a água fria. No pré-preparo de alimentos, como no corte de legumes, o picador para a tarefa é considerado por alguns merendeiros como um equipamento que exige esforço em regiões do corpo, gerando dores nos ombros, braços e pescoço. Mexedores (pás de material plástico) para cocção de alimentos também são indicados como instrumentos de difícil manuseio pelo peso excessivo, o que acaba dificultando o trabalho.

A maior exigência por movimentos repetitivos dá-se na tarefa de higienização de pratos e talheres. A grande quantidade de utensílios para limpeza condiciona um ritmo intenso para seu desempenho. Cozinhas com estrutura inadequada impedem que mais de um me- 
rendeiro realize a mesma tarefa pela falta de espaço e equipamentos. A sobrecarga gera desgaste que ao longo do tempo condiciona os trabalhadores ao surgimento de dores de longa duração, que mesmo após o descanso diário se prolonga durante a próxima jornada de trabalho.

Apesar da implantação do sistema terceirizado de distribuição de alimentos, a existência de elevados índices de doenças ocupacionais relacionados ao trabalho indica que o processo produtivo, equipamentos, mobiliário e ambiente ainda são deficientes, ocasionando problemas diretos e indiretos ao trabalhador. $\mathrm{O}$ acúmulo constante de vários fatores inapropriados gera doenças irreversíveis no trabalhador, levando posteriormente ao afastamento e, consequentemente, à sua readaptação, tornando-os improdutivos e incapazes de desempenhar atividades que exigem um mínimo de esforço.

O espaço físico da maioria das unidades de alimentação é em geral satisfatório pela declaração dos merendeiros. Em algumas unidades é necessário um melhor rearranjo de mobiliário e equipamentos para que haja eficiência na área de circulação de pessoas e materiais. A bancada da cozinha deveria ser o elemento principal. Os estudos revelam que a maior parte dos movimentos utiliza esse item com grande frequência, tornando-o assim responsável pelo melhor fluxo. Entretanto, há casos em que não existe nenhuma possibilidade de mudança mais efetiva, pelas características físicas que o local apresenta. A existência de várias UANs com estrutura adaptada para tal finalidade torna impossível um projeto para a melhoria de suas necessidades, causando transtorno permanente.

Locais inadequados e impossibilitados de quaisquer tipos de mudança são considerados desumanos. Pessoas são obrigadas a dividir o mesmo espaço com caixas, panelas e equipamentos, dificultando sua rotina de trabalho e restringindo condições para uma melhor qualidade de vida.

Quanto ao posicionamento do corpo junto à pia, a maioria das cozinhas não possui em seu projeto um espaço destinado para a acomodação dos pés. O trabalhador é obrigado a adotar uma posição inclinada e curvar seu tronco para realizar a tarefa, forçando a coluna e, consequentemente, causando desconforto postural. 
A iluminação na maioria das cozinhas é deficitária, não atingindo o mínimo estipulado pela norma regulamentadora NR 24 e pela Aberc.

Como já sabemos, crianças emitem sons de frequências altas, o que ocasiona uma propagação de ondas de longo alcance e que geram maior irritabilidade nos funcionários próximos ao local da fonte emissora. No período das refeições, as reclamações são maiores. Quanto aos ruídos de talheres, equipamentos elétricos etc., o som que esses emitem são aceitáveis e não produzem tanto efeito negativo. Constatou-se queixa de ruído intenso por causa do chiado das panelas de pressão, o que obriga os merendeiros a se comunicarem em uma intensidade mais elevada de voz.

O sistema de trabalho não padronizado, no que se refere à rotina de organização e distribuição de alimentos, gera uma particularidade de produção diferenciada em cada unidade. Cada EMEI adota um sistema que melhor se adapta à necessidade de funcionamento. $\mathrm{O}$ trabalho prescrito não é seguido corretamente: o que o determina é a experiência adotada por cada trabalhador durante anos de rotina. Existem cozinhas em que é necessário um maior percurso para o deslocamento de copos, pratos e talheres. Pilhas de pratos pesam em média de 4,5 quilos.

O deslocamento de caldeirões cheios ainda é realizado com o auxílio de dois funcionários. Encontramos alguns trabalhadores relatando que durante anos vêm praticando esses carregamentos sozinhos. Panelas com mais de sessenta quilos são levadas a uma distância de até oito metros, dependendo da unidade analisada. A periculosidade desse ato já levou trabalhadores a sofrerem queimaduras, escorregões e lesões na coluna. Os trabalhadores que sofreram esse tipo de acidente registraram dores localizadas nos braços, mãos, punhos e, alguns, falta de firmeza nas mãos. Em relação ao salário, o descontentamento é visível quando citam que ao longo do tempo veem seus ganhos depreciados, com o poder de compra cada vez mais irrisório.

Grande parte dos "novatos" que ingressam nessa profissão encontra nas cozinhas um meio temporário de subsistência. Ingressam no trabalho pensando em outras formas rentáveis e menos fatigantes que 
proporcionem uma qualidade de vida desejável. Calado et al. (2006) afirma que cozinhas industriais modernas devem ser concebidas dentro do conceito de cozinhas otimizadas ou design competitivo, no qual se destaca a preocupação projetual de ordem sistêmica. Esse conceito visa contemplar atributos de integração e flexibilidade dos seus postos e equipamentos, tendo em vista a adequação funcional e operacional, como também os fatores de climatização, níveis de iluminação, ruído e acabamento de superfícies.

A urgência de uma intervenção ergonômica nos locais de trabalho, um projeto social regulador financeiro e conscientização dos problemas que afligem o setor são de extrema importância, pois atualmente (2005), o índice constatado de $24 \%$ de merendeiros afastados e posteriormente readaptados mostra o nível alarmante de profissionais inseridos em um ciclo produtivo vicioso que transforma trabalhadores saudáveis em cidadãos doentes e incapacitados.

Uma intervenção ergonômica de urgência seria importante para minimizar a gravidade dos males para trabalhadores que sofrem com doenças músculos-esqueléticas e precaver os saudáveis do perigo iminente que a profissão condiciona. Outras áreas da medicina, saúde do trabalhador, fisioterapia, segurança do trabalho e ergonomia podem certamente atuar em conjunto para poderem juntas formular soluções coerentes e que satisfaçam o merendeiro com uma melhor qualidade de vida.

Recomendações de trabalhos futuros surgem da necessidade de pesquisar a vida cotidiana desses trabalhadores fora de seu posto de trabalho para ter uma visão mais ampla da qualidade de vida após o expediente.

\section{Referências bibliográficas}

ABERC. Manual Aberc de práticas de elaboração e serviço de refeições para coletividade. São Paulo, 1998.

AGÊNCIA NACIONAL DE VIGILÂNCIA SANITÁRIA. Resolução $R D C n^{\circ}$ 216. Disponível em: <http://e-legis.bvs.br/leisref/public/ showAct.ph>. Acesso em 10 ago. 2005 
COUTO, H. de A. Novas perspectivas na prevenção dos distúrbios dolorosos dos membros superiores. Revista brasileira de medicina do trabalho. V.1, n., jul./set., 2004.

GRANDJEAN, E. Manual de ergonomia: adaptando o trabalho ao homem. Porto Alegre: Artes Médicas, 1998.

IIDA, I. Ergonomia: projeto e produção. São Paulo: Edgar Blücher, 2005.

KINTON, R., CESERANI, V., FOSKET, D. Enciclopédia de serviços de alimentação. São Paulo: Varela, 1998.

MINISTÉRIO DA SAÚDE (Org.). LER / DORT - Protocolo de investigação, diagnóstico, tratamento e prevenção. Secretaria de Políticas de Saúde, 2002. Disponível em: <http://www.saudeemmovimento.com. br>. Acesso em 10 maio 2006.

Normas regulamentadoras de segurança do trabalho. NR 17 Ergonomia. http://www.mtb.gov.br/Empregador/segsau/Legislacao/ Normas/conteudo/nr17/default.asp >. Acesso em 10 jan 2005.

MORAES, A. de, FRISONI, B. C. Ergodesign: produtos e processos. Rio de Janeiro: 2AB, 2001.

MORAES, A. de, MONT'ALVÃO, C. Ergonomia: conceitos e aplicações. Rio de Janeiro: 2AB, 2000.

NUNES, B. de O. O sentido do trabalho para merendeiras e serventes em situação de readaptação nas escolas públicas do Rio de Janeiro. 161p.2000. (Mestrado) - Fundação Oswaldo Cruz, Escola Nacional de Saúde Pública.

PHILIPS. Manual de projetos de iluminação. Eindhoven: Centro de Projetos e Engenharia de Iluminação da Philips Lighting Division, 1981.

ROCHA, C. S. da. Qualidade de vida no trabalho e ergonomia: conceitos e práticas complementares. Serviço Social \& Sociedade. São Paulo: Cortez, 2002.

SERRANO, R. C. Novo equipamento de medições antropométricas. São Paulo: Fundacentro, 1996.

SILVA FILHO, A. R. A. Manual básico para planejamento e projeto de restaurantes e cozinha industrial. São Paulo: Livraria Varela, 1996. 


\title{
7 \\ REVISÃo de METOdOLOGIAS DE AVALIAÇÃO ERGONÔMICA APLICADAS À CARTEIRA ESCOLAR: UMA ABORDAGEM ANALÍTICA E COMPARATIVA
}

\author{
Sileide Aparecida de Oliveira Paccola ${ }^{1}$ \\ José Carlos Plácido da Silva²
}

\section{Introdução}

A história mostra que o homem promove a evolução do seu conhecimento na relação de aprendizagem estabelecida entre aqueles que possuem e transmitem informação e aqueles que procuram aprendê-la. Essa relação, que ocorre até os dias de hoje, configurou um espaço próprio chamado de ambiente de aprendizagem que, de acordo com a sociedade na qual se dá, desenvolve características peculiares, mas, de modo geral, sempre se estabelece de forma semelhante no que diz respeito à acomodação e posição corporal, tanto dos alunos quanto dos mestres. Portanto, a sala de aula, a carteira escolar e a cátedra - cadeira do mestre - constituem acomodações que se desenvolveram no ambiente escolar para favorecer a posição sentada e auxiliar na atividade de ensino e aprendizagem.

Por meio de um paralelo traçado com a história da educação, evidencia-se a história do mobiliário escolar, mais especificamente da carteira escolar, além dos primeiros sinais do design e da ergono-

1 Mestre em design, Universidade Estadual Paulista.

2 Professor titular, Universidade Estadual Paulista. 
mia nesse mobiliário. Dos aspectos que efetivam a configuração do mobiliário escolar como posto de trabalho, a sua relevância como conjunto de sistemas - ferramentas, máquinas e mobiliário - que auxilia especificamente no desenvolvimento da atividade humana oferece a sustentação necessária para tratar do mobiliário escolar como tal. Essa configuração faz-se necessária, já que justifica a abordagem do design sob a ótica da ergonomia neste capítulo. Atualmente existe uma disponibilidade importante de metodologias de avaliação ergonômica com aplicações cada vez mais específicas. Esse processo é visto como um andamento natural da evolução da área frente às demandas e exigências ocorridas. Por isso, Cuixart \& Pons (1997) observam que são muitos os métodos aplicáveis numa análise e avaliação do ônus postural, porém poucos têm abrangência ampla das situações e, sobretudo, não apresentam os mesmos resultados. Por essa razão existe a preocupação em dispor de ferramentas ou métodos capazes de evidenciar o ônus postural que indiquem o nível de gravidade ou de risco num posto específico. Portanto, um dos aspectos mais importantes na seleção de um determinado método é o nível de adequação do mesmo em função dos objetivos predeterminados.

Desse modo, a comparação entre metodologias realizada neste capítulo oferece instrumentos importantes para evidenciar as características de cada uma, em função da aplicação em mobiliário escolar, além de falhas e elementos evolutivos da área. Esse processo revela uma série de possibilidades, sobretudo no sentido de promover um aprimoramento constante das metodologias estudadas. A aplicação da metodologia de avaliação ergonômica oferece como resultado todos os elementos necessários e essenciais para identificar e destacar os reais problemas do local de trabalho. Uma intervenção adequada deve considerar todos os fatores do trabalho, de forma que seu efeito satisfaça às reais implicações locais.

Com base nesses princípios, a aplicação do método Ergonomic Workplace Analysis (EWA - Análise Ergonômica do Local de Trabalho) revelou sua estrutura abrangente, e uma correspondência em relação aos critérios destacados na comparação das metodolo- 
gias. O presente capítulo teve como objetivo identificar critérios de avaliação ergonômica para servir de base na comparação das metodologias dirigidas ao mobiliário escolar, e aplicá-los nesse contexto pelo método EWA, para analisar seu desempenho e resultados nessa realidade específica, contribuindo assim para a ampliação do conhecimento científico no campo da ergonomia relacionado à carteira escolar.

\section{A carteira escolar - design e ergonomia numa revisão histórica}

Os primeiros sinais de escola, marcada pela utilização da escrita, aparecem nas culturas escribas egípcias, mesopotâmicas e sírias, caracterizados pela utilização da tabuleta apoiada sobre as pernas do escriba. Estes acomodavam-se no chão, com as pernas cruzadas. Marrou (1971) mostra uma escola para formação de escribas, em Mari, cidade mesopotâmica sobre o rio Eufrates, onde existiram duas salas de aula, com fileiras paralelas de bancos com dois, três e quatro lugares, juntamente com o material escolar, composto por escrivaninhas de terracota, tabuletas e conchas.

Segundo Pinho (2004), é na escola medieval cristã que se inicia o uso de um mobiliário específico para a prática de aprendizagem. Esse mobiliário era composto de uma bancada com assento para ocupação coletiva. O modelo surgiu a partir do mobiliário utilizado pelos monges copistas no século XIII, que seguiu sendo utilizado durante o período medieval, nas escolas cristãs, e mais tarde pelas escolas tradicionais públicas e particulares, até o princípio do século XX.

O conjunto de bancada e banco coletivo segue como um modelo padrão até o início do século XX. Entretanto, a nova realidade industrial faz com que, antes mesmo do início deste século, apareçam alternativas de carteira escolar. Essas alternativas trazem, em sua estrutura e detalhes, a preocupação com conforto e praticidade não observados no mobiliário escolar dos séculos anteriores. 
Paschoarelli (1997) aponta que o surgimento da Bauhaus (1919) desperta novos conceitos sobre concepção de desenhos. Inovações como a proposta por Breuer (1930) apresentam um desenho estrutural contemporâneo inédito até então em carteiras escolares. A conformação diferenciada dos materiais para a construção das cadeiras apresenta curvas que acomodam perfeitamente e adequadamente seu usuário. Essas propostas marcam a preocupação com o conforto e bem-estar psicofísico, presente na estrutura limpa e bem finalizada nos detalhes, que reporta a uma estética agradável.

As propostas da Bauhaus refletiram no interesse pela adequação da carteira ao uso do aluno. Nessa década, esse interesse é consolidado a partir dos estudos de Perkins \& Cocking (1949), apoiados em dados antropométricos aplicados ao mobiliário escolar, no qual também apontam problemas ergonômicos nos mobiliários escolares que são classificados como antigos e insatisfatórios.

Esse estudo propõe soluções de adequação da carteira, para o uso escolar, semelhante às propostas da Bauhaus. Essa semelhança é percebida até as décadas atuais, o que confirma a importância da Bauhaus no processo de incorporação do design e da ergonomia nos projetos de carteira escolar.

Nas décadas seguintes, ocorreu um processo de desenvolvimento e amadurecimento de conceitos para o mobiliário escolar. Esse processo deu-se no âmbito do design, com atenção voltada não só à ergonomia, mas também para a utilização de materiais, funcionalidade, cor e viabilidade de produção. Esse é o caso do projeto de mobiliário proposto por Bonsiepe (1978), que mais tarde é adotado pela Unesco como solução de mobiliário escolar para os projetos de reconstrução e apoio aos países mais pobres.

No Brasil, o Estudo de Mobiliário Escolar/MEC-Cebrace, desenvolvido em 1978 pelo Instituto de Desenho Industrial do Museu de Arte Moderna do Rio de Janeiro-IDI/MAM/RJ (Mello Filho, 1998), foi o passo inicial dado pelo governo para definir padrões dimensionais aplicados ao mobiliário escolar. Esse estudo estabeleceu padrões de medidas para mesa e cadeira de aluno, critérios para 
licitação, aquisição e avaliação da qualidade do mobiliário escolar, além de métodos para ensaio de resistência desse mobiliário, baseados na norma francesa NFD 60-511. O estudo favoreceu o mobiliário escolar, estimulando alterações importantes na estrutura, no emprego de materiais e no design.

As pesquisas com aplicação de conceitos ergonômicos em mobiliário escolar deram início a uma geração de propostas e contribuições importantes para o desenvolvimento desse tema. É o que se observa na proposta de Paschoarelli (1997) para educação infantil, que apresenta condições de usabilidade integral pelas crianças por conta da boa aplicação dos conceitos de design e ergonomia.

Em 1998, o Ministério da Educação, juntamente com o Fundescola, lançou um caderno com parâmetros para a fabricação do mobiliário escolar e sua disposição na sala de aula, elaborado por Mello Filho. Esse caderno complementa e reforça as normas ABNT 14006 e 14007, datadas de 1997. Essas normas passaram por uma revisão em 2003, e a Norma 14007 foi incorporada na Norma 14006, formando uma única referência. Esses documentos são atualmente as referências para projetos de mobiliário escolar desenvolvidos no Brasil. Novas concepções de mobiliário escolar surgem refletidas em conceitos atuais de design, como o design ergonômico e design universal, ligados ao novo conceito de usabilidade. A linha ultraergonômica é um exemplo prático de design ergonômico na qual se observam vários aspectos que atendem às normas da $\mathrm{ABNT}$ e às recomendações de Mello Filho (1998). Nesse projeto é evidenciada a importância da usabilidade e do conforto, aplicados por meio das ferramentas do design e da ergonomia.

Já a Carteira Escolar Inclusiva (CEI) é o exemplo de design universal. Criada para atender à demanda existente de mobiliário escolar inclusivo, é destinada a usuários portadores ou não de necessidades especiais (PNE), com o objetivo de proporcionar bom posicionamento, estabilidade e segurança intelectual na prática de tarefas escolares, atribuindo ao aluno condições de acessibilidade, independência e autonomia. 


\section{Revisão de metodologias de avaliação ergonômica aplicadas à carteira escolar}

A ergonomia nas suas mais variadas definições está sempre relacionada ao contexto da interação do homem com o sistema, e o sistema, por sua vez, quase sempre remetido ao conceito de trabalho. Dessa forma, a aplicação prática ergonômica é justificada quando intervém na interface que intermedia o homem e a sua tarefa, e, segundo Moraes \& Mont’Alvão (2000), essa é a única e específica tecnologia da ergonomia, que confere aumento da segurança, conforto e eficiência do sistema e da qualidade de vida.

\section{Recomendações técnicas para o mobiliário escolar - Fundescola - avaliação ergonômica}

Bergmiller (1999) aponta que deve haver, entre outros, critérios ergonômicos para determinar a qualidade do mobiliário escolar e estabelece três considerações sobre isso:

- O al uno não sedesenvolvedemodo constanteao longo da infância e adolescência. O crescimento do corpo é desproporcional. Cabeça, tronco e membros desenvolvem-se gradualmente, variando suas proporções em relação às estaturas. Assim, o móvel também não pode manter as mesmas proporções nos diversos tamanhos.

- Os hábitos einfluências sociais, culturais e psicológicas dos usuários devem ser levados em conta, já que o uso do próprio corpo e dos objetos sofre o reflexo dessas condições. A regionalidade também é um fator a ser observado no momento da compra do mobiliário escolar.

- A idadeescolar éa faseinicial deum processo de socialização do indivíduo. $\mathrm{O}$ ambiente à sua volta deve favorecer o agrupamento, contribuindo para o processo de aprendizado. O móvel escolar adequado é o que permite tanto o trabalho individual como em grupo: 
Do equipamento mobiliário devem ser exigidos vários atributos, não só os técnicos, os financeiros ou os econômicos, cujas noções são mais ou menos familiares a todas as pessoas. Com razão, também devem ser exigidas qualidades ergonômicas, estéticas, funcionais e outras voltadas ao atendimento correto das crianças e dos adolescentes. Isto significa ter em conta as necessidades especiais destes usuários. Por conseguinte, sobretudo quando se tratar do suprimento de móveis para uso direto dos alunos e alunas, há uma série de problemas cujas soluções têm de ser encontradas mediante estudos. (Mello Filho, 1998, p.10)

Mello Filho aponta a ergonomia, no que se refere à antropometria e avaliação ergonômica, como um dos temas mais carentes de atenção para pesquisas e para criação de critérios. O equipamento mobiliário escolar deve sofrer avaliações sistemáticas, de modo que possa ser continuamente readequado. Para isso, a avaliação deve ocorrer mediante cooperação entre usuários, indústria e todos os envolvidos nos processos de decisão, para que uma série de questões seja respondida. Essa cooperação concretiza-se na aplicação de avaliação ergonômica nos móveis já existentes, realizada nas próprias escolas, na dinâmica real das atividades como pré-requisito para projetos de um novo mobiliário, e que sejam relevadas as opiniões de designers e pedagogos, apontando aspectos que devem ser mantidos e outros que devem ser revisados.

\section{Metodologias de avaliação ergonômica}

Atualmente existe uma oferta importante de metodologias de avaliação ergonômica, com tendência de aplicação específica. Esse processo é visto como um andamento natural de evolução da área, frente às demandas e exigências urgentes. Contudo, Cuixart \& Pons (1997) atentam para o fato de que são muitos os métodos que podem ser utilizados para a análise e avaliação do ônus postural, porém nem todos são aplicáveis a todas as situações, e também não apresentam os mesmos resultados. Por essa razão, existe a preocupação em dispor de ferra- 
mentas ou métodos capazes de evidenciar o ônus postural que nos indiquem o nível de gravidade ou de risco num posto específico. Portanto, um dos aspectos mais importantes na seleção de um determinado método é o nível de adequação do mesmo, em função de nossos objetivos. Seguindo esse pensamento, pode-se dizer então que a comparação entre métodos torna-se interessante, visto que oferece instrumentos para evidenciar as características de cada um, em função da aplicação que se pretende destinar, além de falhas e elementos evolutivos da área. Esse processo oferece uma série de possibilidades, sobretudo no sentido de promover um aprimoramento constante das metodologias estudadas.

\section{Metodologias de avaliação ergonômica com aplicação em mobiliário escolar - tabelas descritivo-analíticas}

Tabela 14. Paschoarelli \& Silva (1994) - Avaliação ergonômica da carteira pré-escolar.

\begin{tabular}{|c|c|}
\hline Etapas & Aspectos da etapa \\
\hline $\begin{array}{l}\text { Identificação das características } \\
\text { fisicas dos alunos em fase pré- } \\
\text { escolar. }\end{array}$ & $\begin{array}{l}\text { - Utilização de ficha para coleta e registro do levantamento } \\
\text { antropométrico, com campos para identificação dos dados } \\
\text { pessoais do aluno, e apontamento de medidas estáticas nas } \\
\text { posições ereta e sentada. }\end{array}$ \\
\hline $\begin{array}{l}\text { Caracterização do mobillário, } \\
\text { com base nas dimensões } \\
\text { funciona is do posto de trabalho } \\
\text { especificado. } \\
\text { Determinação das caracteristicas } \\
\text { e necessidades didático- } \\
\text { pedagógicas, específicas da pré- } \\
\text { escola, portanto, as solicitações } \\
\text { para utilização do equipamento. }\end{array}$ & $\begin{array}{l}\text { - Etapa realizada através de formulário, onde são } \\
\text { apontadas as medições a serem aferidas, identificadas por } \\
\text { código, foto da carteira e representação gráfica } \\
\text { bidimensional. } \\
\text { o Etapa realizada através de um questionário, com } \\
\text { perguntas de múltipla escolha, combinadas com perguntas } \\
\text { abertas, que tratam dos problemas relativos à carteira } \\
\text { escolar em questão, e as necessidades do usuário diante das } \\
\text { mesmas. }\end{array}$ \\
\hline $\begin{array}{l}\text { Caracterização das posturas } \\
\text { empregadas, avaliando as } \\
\text { características biofisicas } \\
\text { observadas nestas posturas. }\end{array}$ & $\begin{array}{l}\text { o Este momento da avaliação é realizado a partir de } \\
\text { observação direta e registro fotográfico. }\end{array}$ \\
\hline \multicolumn{2}{|c|}{$\begin{array}{l}\text { Análise interativa de todas as relações encontradas e determinadas, para apontamento das } \\
\text { condições oferecidas e problemas definidos. }\end{array}$} \\
\hline \multicolumn{2}{|l|}{ Resultados } \\
\hline \multicolumn{2}{|c|}{$\begin{array}{l}\text { Paschoarelli (1997), a partir da aplicação desta metodologia, constatou: } \\
\text { - Condições indesejáveis dos equipamentos analisados; } \\
\text { - Comprometimento biofísico do usuário; } \\
\text { - Aspectos fisicos deficientes; } \\
\text { - Atend imento deficiente às necessidades didático-pedagógicas. }\end{array}$} \\
\hline \multicolumn{2}{|l|}{ Estratégia de abordagem } \\
\hline \multicolumn{2}{|c|}{$\begin{array}{l}\text { - Identificação das dimensões físicas dos alunos em fase pré-escolar; Identificaçăo visual do } \\
\text { objeto em avaliação; Análise dimensional; Identificação da função do objeto em avaliação; } \\
\text { Identificação de fatores problemáticos do objeto em avaliação; Identificação das posturas } \\
\text { assumidas na utilização do objeto em avaliação; Análise dos dados, direcionada a apontar } \\
\text { condições oferecidas e problemas definidos. }\end{array}$} \\
\hline
\end{tabular}


Tabela 15. Carvalho (2005) - Estudo ergonômico do posto de atividade discente em instituição de ensino superior.

\begin{tabular}{|c|c|}
\hline Etapas & Aspectos da etapa \\
\hline $\begin{array}{l}\text { Determinar a freqüência } \\
\text { de permanência do aluno } \\
\text { na faculdade, e sua } \\
\text { localização na sala; }\end{array}$ & $\begin{array}{l}\text { - Questionário com } 2 \text { questões objetivas (sim e não), sobre tempo e frequêêcia de } \\
\text { permanência na sala e na carteira. } \\
\text { - Utilizacão de esquema qráfico da sala, para apontar localização da carteira ocupa } \\
\text { pelo aluno. }\end{array}$ \\
\hline \multirow{2}{*}{$\begin{array}{l}\text { P Avaliação geral, numa } \\
\text { valoração de péssimo. } \\
\text { ruim, regular, bom, } \\
\text { excelente e sem opinião; }\end{array}$} & - Utilização de uma tabela para apontamento do nível de satisfação referente a: \\
\hline & $\begin{array}{ll}\text { - Lay-out; } & \text { - Aspectos ambientais da sala; } \\
\text { - Disposição do equipamento áudio visual; } & \text { - Relação Postura X Mobiliário X Recursos } \\
\text { - Número de alunos e recursos necessários; } & \text { didáticos; } \\
\text { - Espaço X conteúdo proposto; } & \text { - Pausas; } \\
\text { - Aplicação das cores; } & \text { - Conforto; } \\
\text { - Desempenho do professor; } & \text { - Aspectos antropométricos e projetuais } \\
\text { - Relação professor X aluno; } & \text { da carteira; } \\
\end{array}$ \\
\hline $\begin{array}{l}\text { Dapeamento das dores } \\
\text { corporais e freqüência; }\end{array}$ & $\begin{array}{l}\text { - Utilização do diagrama de Corlett e Manenica complementado com indicaşões de } \\
\text { frequêencia. }\end{array}$ \\
\hline $\begin{array}{l}\text { Registro da postura com } \\
\text { o aluno em condição de } \\
\text { cansaço geral; }\end{array}$ & $\begin{array}{l}\text { - Utilização de } 05 \text { registros posturais, para apontamento da post } \\
\text { relaxamento do aluno. }\end{array}$ \\
\hline \multirow{2}{*}{$\begin{array}{l}\text { Cansaço geral; } \\
\text { pessontificação dos dados aluno: }\end{array}$} & - Utilização de 6 questões de múltipla-escolha referentes a: \\
\hline & $\begin{array}{l}\text { - Ano de curso: } \\
\text { - Idade/sexo/no de filhos; } \\
\text { - Renda familiar; } \\
\text { - No de moradores na casa; } \\
\text { - Trabalho/carga horária; } \\
\text { - Percentual do tempo de permanência nas posições: sentado, em pé e andando. }\end{array}$ \\
\hline \multirow{2}{*}{$\begin{array}{l}\text { Identificação das } \\
\text { condiçốes ambientais da } \\
\text { sala de aula; }\end{array}$} & - Utilização de tabela para apontamento dos valores de medição, referentes a: \\
\hline & $\begin{array}{ll}\text { - Ruido: } & \text { - No de ianelas; } \\
\text { - Iluminação; } & \text { - No de aparelhos } \\
\text { - Temperatura; } & \text { - No de alunos; } \\
\text { - Dimensão da área; } & \text { - Densidade espac } \\
\text { - Cores ambientais; } & \text { - Curso / Disciplin }\end{array}$ \\
\hline $\begin{array}{l}\text { ados por Análise } \\
\text { a; }\end{array}$ & $\begin{array}{l}\text { - Análise Descritiva - utilizada para determinar o qrau de importância da perce } \\
\text { conforto das condicionantes fisicas e erqonômicas do ambiente das salas de aula } \\
\text { o Análise de Cluster - utilizada para identificar aqrupamento de variáveis cateq } \\
\text { Dores nas partes do corpo; Trabalho; Horas de Trabalho; Posicão que Trabalha. } \\
\text { variáveis não categóricas: Postura e Mobiliário do posto de atividade discente. }\end{array}$ \\
\hline \multicolumn{2}{|l|}{ Resultados } \\
\hline \multicolumn{2}{|l|}{ Análise Descritiva } \\
\hline \multicolumn{2}{|c|}{$\begin{array}{l}\text { O layout das salas, a percep̧̧ão de conforto acústico, a postura dos alunos e o mobiliário das salas de aula } \\
\text { pesquisadas, apresentam-se abaixo do nível considerado bom, referente aos indicadores de percepsão de conforto } \\
\text { ergonômico do ambiente. }\end{array}$} \\
\hline \multicolumn{2}{|c|}{$\begin{array}{l}\text { Layout - Apontamento de adequação do espaço da sala de aula destinado ao professor e do espaço para o } \\
\text { conteúdo proposto pela disciplina. A localização da porta de entrada das salas de aula, a quantidade de alunos nas } \\
\text { salas de aula e a visualização da posição dos equipamentos didáticos foram apontados como inadequados. } \\
\text { Observou-se também que năo ocorre mudança de sala de aula durante a mudança de disciplina, e que ocorre o } \\
\text { hábito de permanência nas mesmas carteiras. }\end{array}$} \\
\hline \multicolumn{2}{|c|}{$\begin{array}{l}\text { Cores - Utilização inadequada das cores para a transmissão da informação com recursos didáticos. As demais } \\
\text { variáveis eraonômicas do empreao das cores no ambiente de sala de aula foram avaliadas positivamente em } \\
\text { relação a percep̧̧ão de conforto visual.. }\end{array}$} \\
\hline \multicolumn{2}{|c|}{$\begin{array}{l}\text { Ruido e acústica - Apontado nivel irregular de ruido provocado pelo equipamento de ar condicionado. As demais } \\
\text { variáveis referentes a acústica não obtiveram boas médias, exceto a influência do barulho externo dos corredores. } \\
\text { Luminosidade - iluminação verificada como deficiente na maioria das salas e excessiva em duas salas, sugerindo o } \\
\text { desperdicio de energia elétrica e a fadiga visual. Verificou-se incidencia de luz direta nos olhos, reflexos e } \\
\text { ofuscamento nas salas de aula. As demais variáveis destacaram-se positivamente. }\end{array}$} \\
\hline \multicolumn{2}{|c|}{ 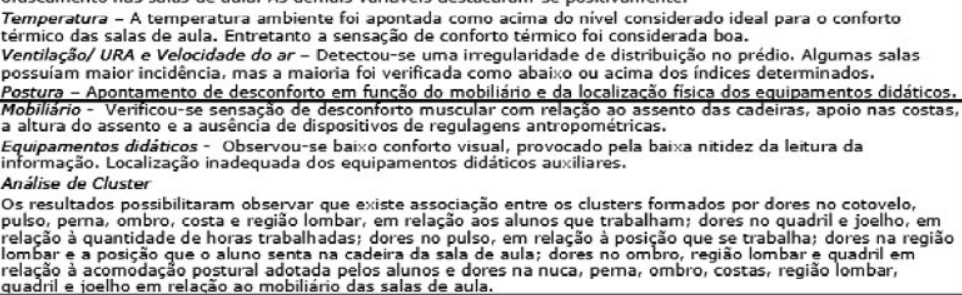 } \\
\hline
\end{tabular}


Tabela 16. Carvalho (2005) - Estudo ergonômico do posto de atividade discente em instituição de ensino superior.

Estratégia de abordagem

- Estimativa do tempo de utilização da carteira;

- Identificação da localizaçăo deste posto na sala

- Identificação da localizaçăo deste posto nas sala;

Mobiliário e Equipamentos didáticos : :

- Identificação das áreas do colpo onde ocorrem dores;

Identificação da postura sentada em sala de aula.

- Identificaçäo do perfil dos alunos pesquisados.

Tabela 17. Soares (2001) - Avaliação ergonômica da carteira universitária.

\begin{tabular}{|c|c|c|}
\hline \multicolumn{2}{|l|}{ Etapas } & \\
\hline \multicolumn{2}{|c|}{$\begin{array}{l}\text { PAnálise da Tarefa. } \\
\text { * Observaçäo do comportamento do usuário para identificar atividades e } \\
\text { posturas assumidas em consequêencia de cada uma. } \\
\text { * Análise das atividades identificadas, em funçäo dos comportamentos } \\
\text { observados nos usuários extremos. } \\
\text { * Apontamento de pontos negativos do mobiliário e conseqüências } \\
\text { posturais. }\end{array}$} & $\begin{array}{l}\text { stro } \\
\text { ante } \\
\text { base }\end{array}$ \\
\hline \multicolumn{2}{|c|}{$\begin{array}{l}\text { Análise dos registros de freqūência posturais } \\
\text { Observaçáo assistemática (OA): } \\
\text { Observação livre e sem planejamento, onde é registrada toda a rotina do } \\
\text { objeto de observação. Nesse instante é que são identificados os elementos } \\
\text { relevantes para a avaliação, seus mornentos e intensidade. } \\
\text { Observaçăo sistemática (OS): Esta observação é realizada a partir de } \\
\text { um planejamento criterioso de materiais, posicionamento, objeto de } \\
\text { observação e tempo. }\end{array}$} & los \\
\hline S Avaliaç̃̃o Dimensional & \multicolumn{2}{|c|}{$\begin{array}{l}\text { Coletado nas amostras referente ao determinado } \\
\text { na literatura para: } \\
\text { - Definição das áreas otimizadas de alcance; } \\
\text { - Reaistro aráfico das incompatibilidades entre as } \\
\text { carteiras analisadas e os usuários de percentis } \\
\text { extremos. }\end{array}$} \\
\hline \\
\hline \multicolumn{3}{|c|}{$\begin{array}{l}\text { Soares (2001), a partir da aplicação desta metodologia, constatou que: } \\
\text { - Para projetos de assento, é imprescindivel analisar a mobilidade exigida pelo corpo humano; } \\
\text { - É impossivel determinar uma situação de postura ótima, visto que cada pessoa intuitivamente se acomoda da } \\
\text { melhor maneira possivel. }\end{array}$} \\
\hline \multicolumn{3}{|c|}{$\begin{array}{l}\text { - A literatura fornece recomendações dispares, o que concorre para o questionamento desses dados. } \\
\text { - A análise da tarefa, como ferramenta de avaliação, foi vista como extremamente eficaz, no sentido de } \\
\text { favorecer a constataçōes de incompatibilidades entre a distância da superficie e os olhos dos usuários. Essa } \\
\text { técnica também contribui para a obtenção dos requisitos de conforto e funcionalidade, passiveis de serem } \\
\text { aplicadas a projetos de assentos para diversos postos de trabalho. }\end{array}$} \\
\hline \multicolumn{3}{|l|}{$\begin{array}{l}\text { - Para a obtenção de uma qua } \\
\text { ambientais e pedagógicos, nã }\end{array}$} \\
\hline \multicolumn{3}{|l|}{ Estratégia de abordagem } \\
\hline \multicolumn{3}{|l|}{ mensional. } \\
\hline
\end{tabular}

Tabela 18. Pinho (2004) - Avaliação do conforto em cadeiras escolares.

\begin{tabular}{|l|ll|}
\hline Etapas & \multicolumn{2}{|c|}{ Aspectos da etapa } \\
\hline An Análise do & Nesta etapa são identificados os seguintes aspectos: \\
Ambiente da sala & - Caracteristicas da sala; & - Frequência e periodo de utilização; \\
de aula. & - Dimensionamento; & - Equipamentos; \\
& - Material empreqado na construção; & - Recursos áudio-visuais; \\
& - Cores e tons da pintura; & - Recursos para condicionamento ambiental; \\
& - Janelas; & - Identificação do mobiliário; \\
& - Piso; & Identificação dos usuánios-alvo desta análise. \\
\hline
\end{tabular}


Tabela 19. Pinho (2004) - Avaliação do conforto em cadeiras escolares.

\begin{tabular}{|c|c|}
\hline $\begin{array}{l}\text { D Importåncia e } \\
\text { satisfação dos } \\
\text { usuários com a } \\
\text { classe. }\end{array}$ & $\begin{array}{l}\text { - } \quad 1^{\circ} \text { fase: Questionamento verbal, com relação a opinião sobre o ambiente da sala de aula, } \\
\text { anseios e descontentamentos. Respostas livres, registradas em folha de papel. } \\
\text { - } \quad 2^{\circ} \text { fase } \\
\text { Questionário: } \\
\text { - } 05 \text { questões abertas para identificar as caracteristicas do usuário; - } 10 \text { questões diretas, } \\
\text { com respostas apontadas numa escala que parte de "nada importante" até "muito } \\
\text { importante", sobre os aspectos relativos a conforto; } \\
\text { - } 01 \text { questão aberta para definição da palavra conforto. }\end{array}$ \\
\hline $\begin{array}{l}\text { Teste prático } \\
\text { de conforto em } \\
\text { cadeiras } \\
\text { escolares }\end{array}$ & $\begin{array}{l}\text { Questionário: } \\
\text { - } 03 \text { lacunas para identificação de altura, sexo e a carteira avaliada; } \\
\text { - } 01 \text { questão reguladora da escala que parte de "pouco significativo" até "muito } \\
\text { significativo"; } \\
\text { - } 03 \text { questões sobre o conforto da cadeira com escala que parte de "pouco confortável" até } \\
\text { "muito confortável". }\end{array}$ \\
\hline $\begin{array}{l}\text { Teste visual } \\
\text { de conforto em } \\
\text { cadeiras } \\
\text { escolares }\end{array}$ & 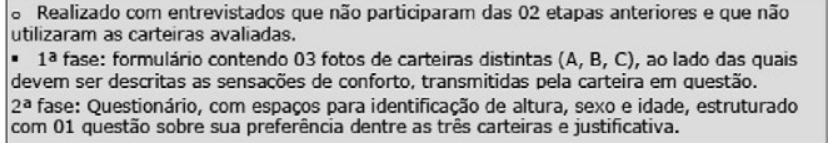 \\
\hline \multicolumn{2}{|l|}{ Resultados } \\
\hline \multicolumn{2}{|c|}{$\begin{array}{l}\text { - A cadeira e a mesa escolar não satisfazem as necessidades dos usuários e são apontados como os elementos } \\
\text { de maior relevância, com relação aos outros que compõem o ambiente de aprendizagem. } \\
\text { - Esta metodologia evidencia a ausência do aspecto conforto nas carteiras escolares avaliadas. } \\
\text { Dessa forma contribui com elementos concretos para novos estudos destinados à criação de soluços } \\
\text { provedoras de conforto para este mobiliário. }\end{array}$} \\
\hline \multicolumn{2}{|c|}{ Estratégia de abordagem } \\
\hline & \\
\hline
\end{tabular}

Tabela 20. Moro (2005) - Constrangimentos posturais impostos pelo mobiliário escolar.

\begin{tabular}{|c|c|}
\hline Etapas & Aspectos da etapa \\
\hline $\begin{array}{l}\text { Investigação da relaç̃̃o } \\
\text { aluno x carteira escolar. } \\
\text { - Aplicação de questionário, } \\
\text { para apurar de que forma } \\
\text { ocorre a relação do aluno com a } \\
\text { sua carteira escolar. }\end{array}$ & $\begin{array}{l}\text { O questionário é estruturado em: } \\
\text { - } 07 \text { questốes diretas; } \\
\text { - } 02 \text { questốes analíticas compostas por } 2 \text { fotos, com campos para indicação da } \\
\text { postura adotada e a que o entrevistado julgar correta; } \\
\text { - 01 questão baseada no diagrama de Corlett e Manenica (1986), para } \\
\text { indicação das reqiốes do corpo onde ocorrem sensação de dor e desconforto, } \\
\text { durante a interação com a carteira escolar. }\end{array}$ \\
\hline $\begin{array}{l}\text { Investigação prática } \\
\text { controlada. } \\
\text { - Aplicação de um experimento } \\
\text { controlado em laboratório, que } \\
\text { participam } 04 \text { crianças com } \\
\text { idade média de } 11 \text { anos, da } \\
\text { rede pública de ensino, as quais } \\
\text { não apresentam nenhum sinal } \\
\text { de distúrbio postural. }\end{array}$ & $\begin{array}{l}\text { Registro efetuado com uma câmera digital posicionada em relação ao plano } \\
\text { sagital do objeto. As fotos foram processadas no computador com o auxílio de } \\
\text { um software gráfico, a fim de se obter os ângulos posturais ocorridos, e que } \\
\text { representavam maior importância para um estudo de postura sentada. } \\
\text { Os alunos são fotocrafados em duas situacōes: } \\
\text { - Executando a tarefa de escrever, ocupando uma carteira convencional } \\
\text { encontrada nas escolas da rede pública. } \\
\text { - Executando a tarefa de escrever, ocupando uma carteira regulável projetada } \\
\text { segundo as recomendações ergonómicas. }\end{array}$ \\
\hline \multicolumn{2}{|l|}{ Resultados } \\
\hline \multicolumn{2}{|c|}{$\begin{array}{l}\text { Moro (2005), a partir da aplicação desta metodologia, constatou: } \\
\text { - o conjunto cadeira/mesa é inadequado às caracteristicas antropométricas e biomecânicas dos alunos, o que } \\
\text { provoca desde danos posturais até dificuldade de aprendizagem. } \\
\text { - A abordagem ergonômica é capaz de promover uma amenização, com relação aos problemas causados pela } \\
\text { interação do aluno com essa interface de sala de aula. }\end{array}$} \\
\hline \multicolumn{2}{|l|}{ Estratégia de abordagem } \\
\hline $\begin{array}{l}\text { - Ide } \\
\text { ativi }\end{array}$ & ; Identific \\
\hline
\end{tabular}




\section{Comparação metodológica}

Num processo comparativo, com resultados contemplativos ao objetivo da aplicação em mobiliário escolar, são necessários critérios que correspondam diretamente aos aspectos envolvidos no contexto desse mobiliário. Iida (1990), Dul \& Weedmeester (2004) e Grandjean (1998) abordam de forma semelhante os aspectos considerados de importante relevância na avaliação da interação do homem com o sistema utilizado para desenvolver suas atividades. $\mathrm{O}$ conjunto dos elementos apontados em cada aspecto de abordagem constitui os critérios estabelecidos por esses autores para tratar de avaliação ergonômica.

Tabela 21. Relação aspectos/critérios propostos por Iida (1990), Dul \& Weedmeester (2004) e Grandjean (1998).

\begin{tabular}{|c|c|c|c|}
\hline Aspectos & lida $(1090)$ & Dul e Weedmeester $(2004)$ & Grandjean (1998) \\
\hline Antropométricos & $\begin{array}{l}\text { - Trabalho estátiocoldinámico; } \\
\text { - Posturas assumidas; } \\
\text { - Aplicaços de forças; } \\
\text { - Levantam. e transp. de cargas: } \\
\text { - Espaço de trabalho; } \\
\text { - Antropometria estática; } \\
\text { - Antrop. dinăm ica/funcional. }\end{array}$ & $\begin{array}{l}\text { - Trabalho sentado; } \\
\text { - Trabalho em pé; } \\
\text { - Mudanças de postura; } \\
\text { - Posturas de máos e bracos; } \\
\text { - Levantam. e transp. de cargas; } \\
\text { - Puram. e empurram. de carga. }\end{array}$ & \multirow{2}{*}{$\begin{array}{l}\text { - Aplicaçăo de forças; } \\
\text { - Trabalho sentado; } \\
\text { - Trabalho em pé; } \\
\text { - Postura cabeça/ruce: } \\
\text { - Espaço de trabalho; } \\
\text { - O assento de } \\
\text { trabalho; } \\
\text { - Trabalhos de } \\
\text { precisão; }\end{array}$} \\
\hline $\begin{array}{l}\text { Projetuais do } \\
\text { posto de } \\
\text { trabalho } \\
\end{array}$ & $\begin{array}{l}\text { - Adequaçaso da tarefa; } \\
\text { - Arranja flsico do posto de } \\
\text { trabalho. }\end{array}$ & O cutor nato trata desse apeeto: & \\
\hline Ambientais & $\begin{array}{l}\text { - Temperatura; } \\
\text { - Ruido; } \\
\text { - Vibração; } \\
\text { - Tluminaçăo; } \\
\text { - Cores. }\end{array}$ & $\begin{array}{l}\text { - Ruído; } \\
\text { - Vibração; } \\
\text { - Iluminaçăo; } \\
\text { - Clima; }\end{array}$ & $\begin{array}{l}\text { - Ruido; } \\
\text { - Vibraçắ; } \\
\text { - Ilumn inaçă ; } \\
\text { - Clima; } \\
\text { - Cores; } \\
\text { - Música. }\end{array}$ \\
\hline $\begin{array}{l}\text { Humanos no } \\
\text { trahalho }\end{array}$ & $\begin{array}{l}\text { - Manotonia; } \\
\text { - Fadiga; } \\
\text { - Motivaçüo; } \\
\text { - IdadeisexoiPNE }\end{array}$ & O autor nolo trata desse aspecto; & $\begin{array}{l}\text { - Atividade mental; } \\
\text { - Fadiga; } \\
\text { - Monotonia; } \\
\text { - Estresse; }\end{array}$ \\
\hline $\begin{array}{l}\text { Organilaçătio do } \\
\text { trabalho }\end{array}$ & $\begin{array}{l}\text { - Carga de estresse; } \\
\text { - Carga horária; } \\
\text { - Relacionamento interpesscal. }\end{array}$ & $\begin{array}{l}\text { - Distribuição dos cargos em } \\
\text { funçâ das tarefas; } \\
\text { - Organiz flexivel do trabalho. }\end{array}$ & $\begin{array}{l}\text { - Jomada de trabalho; } \\
\text { - Turnos de trabalho. }\end{array}$ \\
\hline
\end{tabular}


Tabela 22. Elementos coincidentes entre os autores.

\begin{tabular}{|c|c|}
\hline Aspectos & Concordhincin \\
\hline & $\begin{array}{l}\text { - Trabalho estáticoldinâm ico (sentadolem pe), } \\
\text { - Posturas assumidas: }\end{array}$ \\
\hline Biomecânicos & $\begin{array}{l}\text { - Aplicações de forças (Puxamento e empurfumento de carga); } \\
\text { - Levantamento e transporte de cargas. }\end{array}$ \\
\hline Antropometricos & $\begin{array}{l}\text { - Antropometria estática: } \\
\text { - Antropometria dinâmica/funcional. }\end{array}$ \\
\hline Projetuais do posto de trabalho & $\begin{array}{l}\text { - Adequaçăo da tarefa; } \\
\text { - Arranjo fisico do posto de trabalho. }\end{array}$ \\
\hline Ambientais & $\begin{array}{l}\text { - Temperatura; } \\
\text { - Ruido: } \\
\text { - Vibraçăo; } \\
\text { - Ilumineçăo; } \\
\text { - Cores. }\end{array}$ \\
\hline Humanos no trabalho & $\begin{array}{l}\text { - Monotonia; } \\
\text { - Fadiga; } \\
\text { - Motivaçà; } \\
\text { - Estresse; }\end{array}$ \\
\hline Organtzaç & $\begin{array}{l}\text { - Distribuiçăo de turnos: } \\
\text { - Carga horária; } \\
\text { - Relacionamento interpessoal. }\end{array}$ \\
\hline
\end{tabular}

Tabela 23. Quadro comparativo (M1) - Paschoarelli \& Silva (1994) / (M2)-Carvalho (2005) / (M3)-Soares (2001) / (M4)-Pinho (2004) / (M5)-Moro (2005).

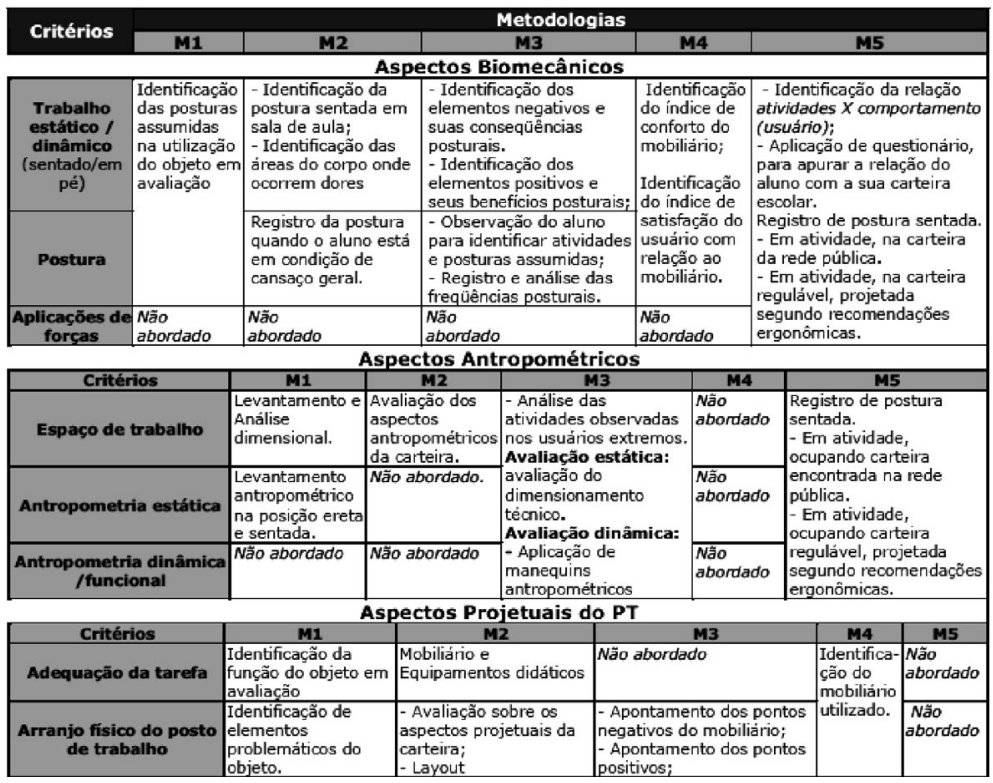


Tabela 23. Continuação.

\begin{tabular}{|c|c|c|c|c|c|c|}
\hline \multicolumn{7}{|c|}{ Aspectos Ambientais } \\
\hline Critérios & M1 & M2 & M3 & \multicolumn{2}{|c|}{ M4 } & M5 \\
\hline $\begin{array}{c}\text { Temperatura } \\
\text { Ruído } \\
\text { Vibração } \\
\text { Iluminação Cores }\end{array}$ & \multirow[t]{2}{*}{$\begin{array}{l}\text { Não } \\
\text { abordado }\end{array}$} & $\begin{array}{l}\text { Identificação das variáveis } \\
\text { ergonômicas - Temperatura, } \\
\text { Acústica, Vibraçäo, Iluminação, } \\
\text { Cores. }\end{array}$ & $\begin{array}{l}\text { Não } \\
\text { abordado }\end{array}$ & \multicolumn{2}{|c|}{$\begin{array}{l}\text { Identificaçăo das } \\
\text { caracteristicas } \\
\text { ambientais e do indice } \\
\text { de confolto ambiental. }\end{array}$} & $\begin{array}{l}\text { Não } \\
\text { abordado }\end{array}$ \\
\hline \multicolumn{6}{|c|}{ Aspectos Humanos no trabalho } & \\
\hline Critérios & M1 & M2 & M3 & M4 & \multicolumn{2}{|c|}{ M5 } \\
\hline Monotonia & \multirow{4}{*}{\begin{tabular}{l|} 
Não \\
abordado
\end{tabular}} & \multirow{4}{*}{$\begin{array}{l}\text { Avaliação referente à: Disposição dos } \\
\text { equipamentos de áudio visual; Número } \\
\text { de alunos e recursos necessários; } \\
\text { Espaço X conteúdo proposto; Aplicação } \\
\text { das cores; Desempenho do professor; } \\
\text { Pausas; Conforto. }\end{array}$} & \multirow{4}{*}{$\begin{array}{l}\text { Năo } \\
\text { abordado }\end{array}$} & \multirow{4}{*}{$\begin{array}{l}\text { Não } \\
\text { abordado }\end{array}$} & \multirow{2}{*}{\multicolumn{2}{|c|}{\begin{tabular}{|l|} 
Não abordado \\
Identificação dos \\
transtomos ocorridos \\
durante a atividade.
\end{tabular}}} \\
\hline Fadiga & & & & & & \\
\hline Motivação & & & & & \multirow{2}{*}{\multicolumn{2}{|c|}{ Não abordado }} \\
\hline Estresse & & & & & & \\
\hline \multicolumn{7}{|c|}{ Aspectos Organização do trabalho } \\
\hline Critérios & Mi & M2 & M3 & & $\overline{44}$ & M5 \\
\hline Distribuiçäo de turnos & \multirow[t]{3}{*}{$\begin{array}{l}\text { Nẵo } \\
\text { abordado }\end{array}$} & $\begin{array}{l}\text { Avaliação sobre a mudança de sala } \\
\text { entre as disciplinas. }\end{array}$ & \multirow[t]{3}{*}{$\begin{array}{l}\text { Nẫo } \\
\text { abordado }\end{array}$} & \multicolumn{2}{|c|}{ Năo abordado. } & \multirow[t]{3}{*}{$\begin{array}{l}\text { Não } \\
\text { abordado }\end{array}$} \\
\hline Carga horária & & $\begin{array}{l}\text { Estimativa do tempo de utilização da } \\
\text { carteira. }\end{array}$ & & \multicolumn{2}{|c|}{$\begin{array}{l}\text { Análise da freqüência } \\
\text { e periodo de utilização } \\
\text { da sala de aula. }\end{array}$} & \\
\hline $\begin{array}{l}\text { Relacionamento } \\
\text { interpessoal }\end{array}$ & & $\begin{array}{l}\text { Avaliação, na escala de péssimo, ruim, } \\
\text { regular, bom, excelente e sem opinião } \\
\text { sobre a relação Professor X Aluno. }\end{array}$ & & \multicolumn{2}{|c|}{ Nào abordado. } & \\
\hline
\end{tabular}

\section{Nível de atendimento dos critérios}

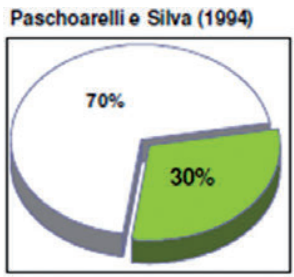

\section{Soares (2001)}

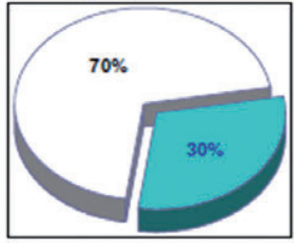

Moro (2005)

Pinho (2004)
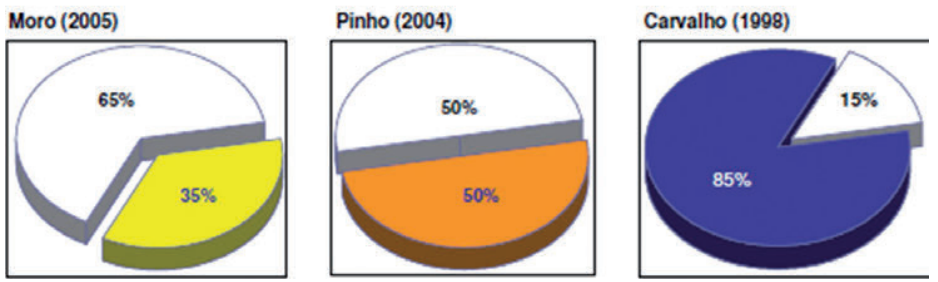

Figura 32. Gráficos - percentuais de critérios atendidos.

\section{Materiais e métodos}

Para a aplicação dos critérios considerados no processo de comparação das metodologias, será utilizado o citado método Ergonomic 
Workplace Analysis (EWA) por possuir uma estrutura bastante abrangente, que se assemelha ao estabelecido pelos critérios. $\mathrm{O}$ EWA é uma metodologia criada pelo Instituto Finlandês de Saúde Ocupacional (Finnish Institute of Occupational Health - FIOH), utilizada para identificar os riscos ergonômicos do local de trabalho - ambiente, posto, relações interpessoais e trabalho. Sua base teórica corresponde à fisiologia do trabalho, biomecânica ocupacional, aspectos psicológicos, higiene ocupacional e em um modelo participativo da organização do trabalho, fatores que constituem recomendações gerais e objetivas para o trabalho sadio e seguro. A estrutura de avaliação desse método é constituída pelos itens da tabela 24. A avaliação ocorre sob os focos do avaliador e do trabalhador. Essa medida permite ao avaliador contrapor seus resultados à opinião do usuário. A opinião do trabalhador tem um valor de importância elevado, visto que traz o peso da experiência prática de utilização de seu posto.

\section{Avaliação do avaliador}

A avaliação obedece a uma escala de 1 a 5 , na qual se comparam condições, arranjo do posto e o ambiente de trabalho com as recomendações da literatura, diferenciando o ocorrido do recomendável. Classificação de 4 ou 5 aponta condições, de trabalho ou ambientais, inadequadas ao trabalhador. Nessa ordem, as condições adequadas são classificadas em 1 ou 2.

\section{Avaliação do trabalhador (aluno)}

A avaliação do trabalhador é o fator comparativo e complementar para os resultados da análise, considerando a prática do mesmo, referente ao seu local de trabalho. Obedece à escala: "bom" (++), "regular" (+), "ruim" (-), "muito ruim" (--). Esse registro é realizado por meio de entrevista ao trabalhador, conduzida pelo avaliador. 
Tabela 24. Itens de avaliação do método EWA.

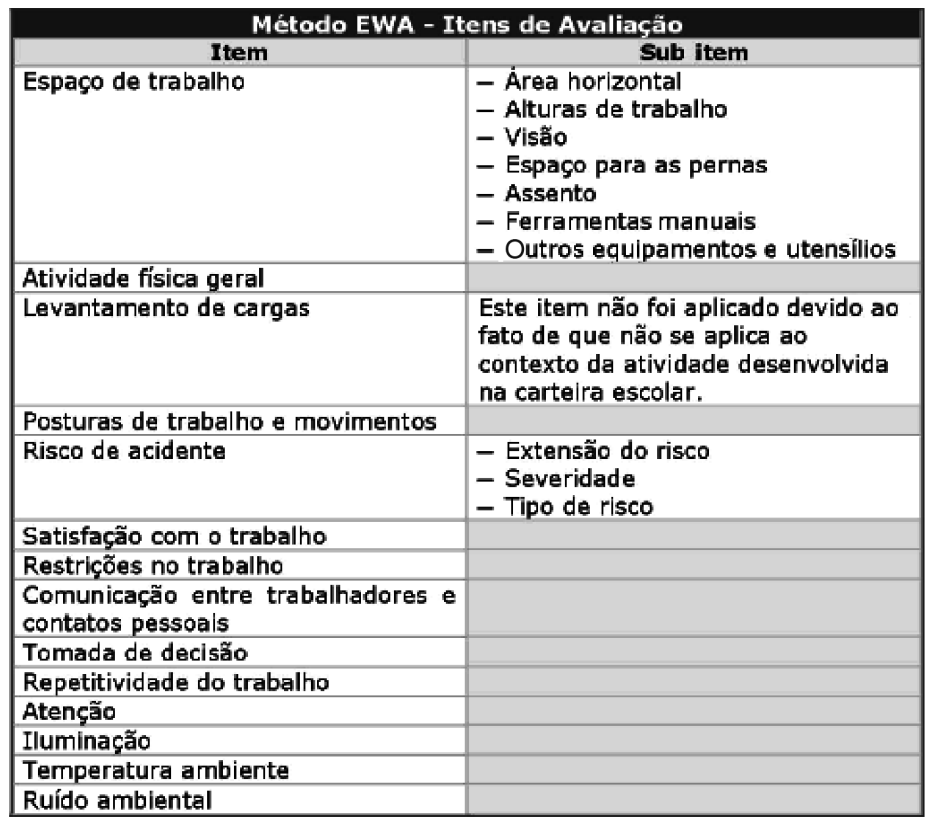

\section{Aplicação da metodologia}

Os locais de realização dessa aplicação foram definidos observando a diversidade social e pedagógica, possibilitando caracterizar condições e realidades diversas. Portanto, o estudo envolveu instituições particulares e públicas, implicando o total de 222 alunos entrevistados, conforme a tabela 25.

Tabela 25. Instituições participantes da pesquisa.

\begin{tabular}{|c|c|c|}
\hline Instituição & Endereço & Alunos \\
\hline E. E. Profo "Ernesto Monte" & Praça das Cerejeiras $4-44$ & 29 \\
\hline E. E. Profo "Moraes Pacheco" & R. Primeiro De Malo, $16-10$ & 30 \\
\hline Coléglo Fểnix & R. Anhanguera 9-19 & 29 \\
\hline SENAI "Joăo Martins Coube" & R. Virgillo Malta 11-22 & 27 \\
\hline E. E. Dr. "Paulo Zillo" & R. Treze de Maio 509, Centro & 30 \\
\hline E. E. Prof. "Rubens Pietraróia" & R. da Imprensa 431, Núcleo Luiz Zillo & 36 \\
\hline Colégio S马ao José & R. Joăo Carneiro Geraldes 600 , Jd. Ubirama & 29 \\
\hline SENAI - Lenç̧is Paulista & R. Aristeu Rodrigues Sampaio 271 & 12 \\
\hline Total & & 222 \\
\hline
\end{tabular}


O formulário foi respondido por meio de entrevista coletiva, com preenchimento individual e simultâneo. A aplicação ocorreu em três etapas:

- A val iação dos al unos: um dos aval iadores conduziu a entrevista, lendo cada item em voz alta e mostrando as alternativas de resposta, para, em seguida, os entrevistados registrarem sua resposta.

- A náli ise dos avaliadores: realizada com o auxílio de fotos da carteira e seu ocupante, registradas nos protocolos individuais. Essa análise obedeceu às indicações do protocolo para resposta, enquadrando-as nas normas brasileiras NRs e ABNT.

- Medições técnicas: ruído, iluminação e temperatura. Para as medições técnicas foram utilizados os aparelhos descritos adiante, de acordo com as seguintes aplicações: decibelímetro - ruído; luxímetro - iluminação; termo-higrômetro - temperatura.

As medições foram realizadas por um dos avaliadores, durante o horário de aula, simultaneamente à realização da avaliação. Os aparelhos foram posicionados sobre a carteira do aluno, seguindo a ordem de coleta de dados (iluminação, temperatura e ruído). As medições ocorreram durante os seguintes períodos de aula (EscolaPeríodo): Fênix - vespertino; E. E. Prof. Ernesto Monte-vespertino; E. E. Prof. Moraes Pacheco - matutino; Senai - Bauru - vespertino; Colégio São José - matutino; E. E. Dr. Paulo Zillo - matutino; E. E. Prof. Rubens Pietraroia - matutino; Senai - Lençóis Paulista vespertino.

\section{Instrumentos e materiais}

Nessa aplicação foram adotados os seguintes materiais: câmera digital Sony - CyberShot DSC W55 - 7,2 megapixels; decibelímetro - medidor de nível de pressão sonora digital - Datalogger - 
Instrutherm Instrumentos de Medição - DEC-5010 - código 03051; luxímetro - medidor de intensidade de lux digital - Instrutherm Instrumentos de Medição - Ld-209 - código 02034 Calibração: 06/05 - certificação: 11724-V-06.06; termo-higrômetro digital - Minipa Indústria Eletrônica- modelo MTH-1360; software de planilha eletrônica e gráficos - Microsoft Office Excel.

\section{Resultados}

A figura 33 mostra os gráficos com os níveis dos índices de avaliação das categorias avaliador $(1,2,3,4$ e 5) e aluno (+ +, +, - e - -), referentes a cada item abordado pelo método, podendo-se observar os percentuais de satisfação e adequação apontados pelas categorias.

\section{Perfil geral de adequação dos locais de trabalho avaliados}

Os gráficos da figura 34 mostram que ocorreu uma grande discordância de avaliação entre as categorias pesquisador e aluno, apesar de elas terem estabelecido uma avaliação positiva, em um nível superior a 50\%. Na categoria pesquisador esse nível foi de 53,9\%. Já na categoria aluno, a avaliação positiva foi bem superior, atingindo 94,3\%. Esses números indicam que, principalmente na opinião dos alunos, esse local de trabalho contribui para o bom desempenho de suas atividades. Contudo, a avaliação da categoria pesquisador é restritiva quanto aos itens espaço de trabalho, posturas e movimentos e risco de acidentes, o que pode ser observado nos gráficos de resultados das escolas. Esses elementos mostraram uma regularidade constante de índices negativos, que, segundo a literatura, não só impedem o bom desempenho no trabalho como também favorecem o surgimento de constrangimentos psicofísicos no usuário. 
Espaço de trabalho
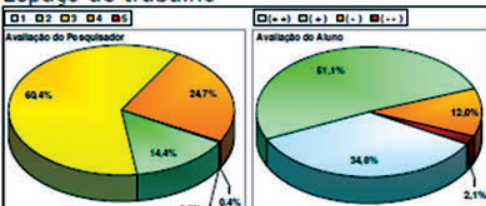

Atividade fisica em geral

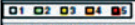
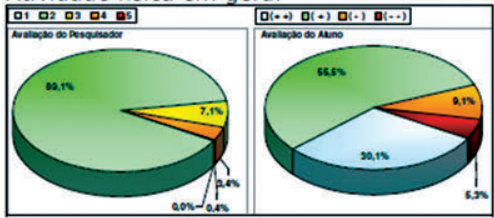

Posturas de trabalho e movimentos
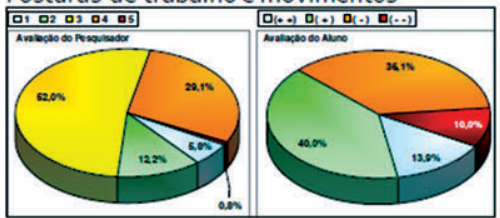

Risco de acidentes
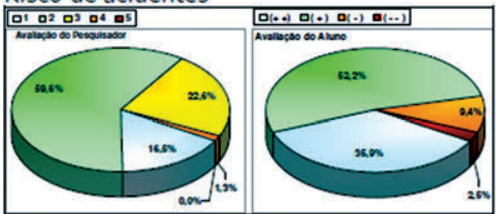

Restrições no trabalho

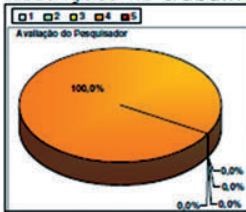

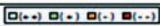
Nuilivato no Naino

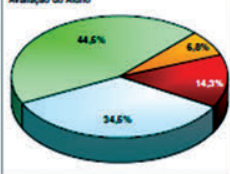

Satisfação com o trabalho

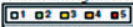

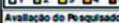
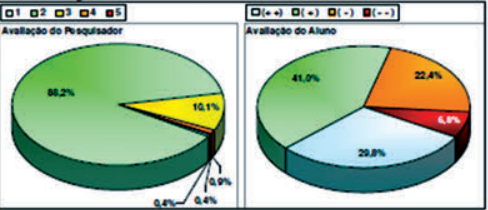

Ruido ambiental
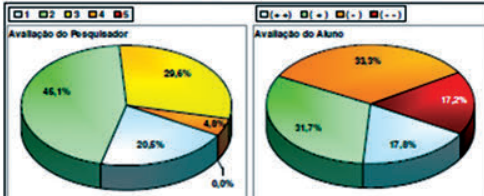

Comunicação e contatos pessoais

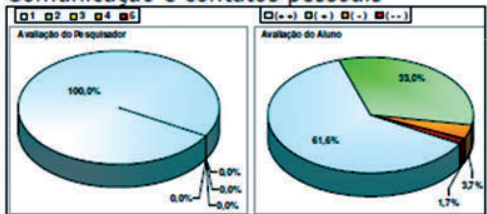

Tomada de decisão

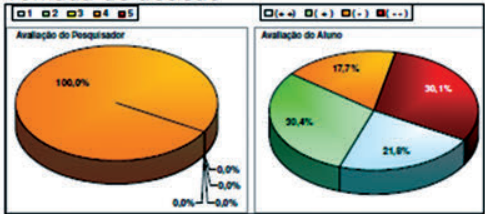

Repetitividade do trabalho
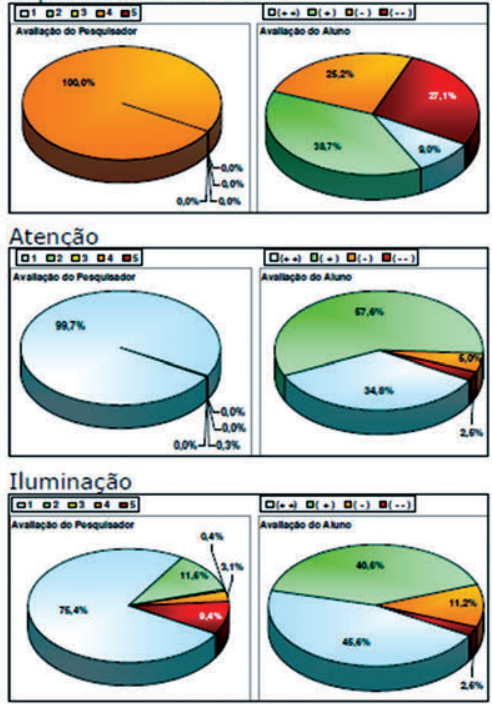

Temperatura ambiente

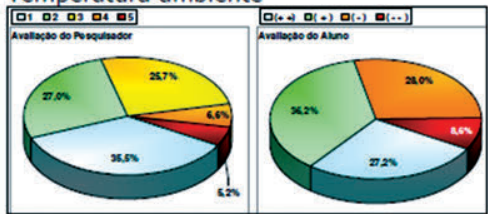

Figura 33. Resultados. 

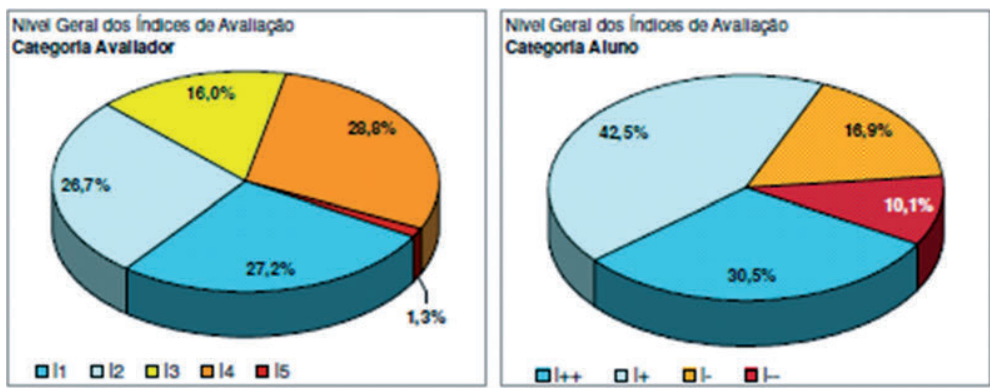

Figura 34. Perfil geral de adequação.

\section{Considerações finais}

A comparação entre as metodologias relacionadas nos quadros descritivos analíticos, realizada à luz dos critérios considerados pelos autores estudados nas tabelas, revelou nas metodologias grandes lacunas referentes ao atendimento da totalidade dos critérios destacados nas figuras. Observando-se a comparação, nota-se que os aspectos ambientais, humanos e de organização do trabalho ainda não despertam o mesmo nível de atenção para a pesquisa que os antropométricos e os biomecânicos.

Entretanto, é importante salientar que, apesar do fato de os critérios não terem sido tratados de forma conjunta em todas as metodologias, em duas delas mais de $50 \%$ dos aspectos foram atingidos. Esse fator sinaliza uma preocupação em considerar não só os aspectos biomecânicos e antropométricos, mas o conjunto de elementos que interferem direta e indiretamente no nível da relação entre o aluno e a carteira escolar. Ou seja, reconhecer a necessidade de ponderar de forma global esse contexto.

A partir dos critérios concordantes entre os autores citados, é possível observar que existe correspondência em relação aos itens de avaliação do método EWA. Entretanto, os aspectos biomecânicos, antropométricos e projetuais do posto de trabalho, que têm uma implicação profunda na interação do usuário com o seu posto, são abordados superficialmente, não dispondo de campos para a veri- 
ficação detalhada nem para identificação específica dos elementos que compõem esses aspectos na carteira. Esse fator impede que os problemas advindos desses elementos sejam evidenciados de forma eficiente, e impossibilita as eventuais correções necessárias para a real adequação do mobiliário. Essa constatação também se aplica às questões ambientais, visto que os riscos físicos observados pelos autores vão além daqueles contemplados no questionário do EWA, bem como a ausência de campos mais bem estruturados, necessários para registro dos dados coletados por meio dos aparelhos de medição.

Além disso, há de se observar que o caráter abrangente do EWA proporciona um panorama ergonômico quanto à situação em que se encontra o local estudado. Nesse sentido, o desempenho desse método demonstrou sua eficiência para identificar as áreas nas quais ocorrem focos de inadequação, disponibilizando um mapa dos pontos a serem tratados mais especificamente. Nessa situação, torna-se evidente que se deve utilizar um método apropriado associado ao EWA para avaliação do aspecto identificado como problemático, com a finalidade de conhecer os fatores geradores de constrangimento.

\section{Referências bibliográficas}

AHONEM, M., LAUNIS, M., KUORINKA, T. Ergonomic Workplace Analysis. Helsinki: Ergonomics Section - Finnish Institute of Occupational Health, 1989. 34p.

BERGMILlER, K. H., SOUZA, P. L. P., BRANDÃO, M. B. A. Ensino Fundamental: mobiliário escolar. Brasília: Fundescola, MEC, 1999. 70p. (Cadernos Técnicos I n.3).

CARVALHO, V. G. Estudo ergonômico do posto de atividade discente em instituição de ensino superior. 123p. Natal, 2005. Dissertação (Mestrado em Engenharia de Produção) - Universidade Federal do Rio Grande do Norte, Centro de Tecnologia.

CUIXART, S. N.e PONS, I. D. NTP 452: Avaliação das condições de trabalho: ônus postural. Centro Nacional de Condições de Trabalho. Instituo de Seguridade e Higiene no Trabalho - Ministério Espanhol do Trabalho e Assuntos Sociais. 1997. Disponível em: <www.estrucplan.com. ar/ articulos/imprimirss.asp? IDArticulo=340>. Acessado em 26 fev. 2007. 
DUL, J., WEERDMEESTER, B. Ergonomia prática. São Paulo: Edgard Blücher, 2004. 135p.

GRANDJEAN, E. Manual de ergonomia: adaptando o trabalho ao homem. Traduzido por João Pedro Stein. Porto Alegre: Bookmam, 1998.

IIDA, I. Ergonomia: projeto e produção. São Paulo: Edgard Blucher, 1992. MARROU, H. É. História da educação na Antiguidade. São Paulo: Herder, Edusp, 1971. 639p.

MELLO FILHO, J. H. Equipamentos e mobiliário: elaboração de projetos e desenvolvimento. Brasília: Fundescola-MEC, 1998. 36p. (Recomendações técnicas. Procedimentos n.8).

MORAES, A., MONT'ALVÃO, C. Ergonomia: conceitos e aplicações. 2.ed. Rio de Janeiro: 2AB, 2000. 136p.

MORO, A. R. P. Ergonomia da sala de aula: constrangimentos posturais impostos pelo mobiliário escolar. 2005. Revista Digital EF y Deportes. Disponível em: <http://www.efdeportes. com/efd85/ergon.htm>. Acessado em 15 out. 2006.

PASCHOARELLI, L. C., SILVA, J. C. P. Pesquisa com crianças na faixa escolar do pré-primário à quarta série do primário das E.M.E.I.s e E.M.P.G.s da cidade de Bauru: projeto de mobiliário escolar para o método Freinet. In: P\&D Design 94, 1994, São Paulo. Anais do PEDD Design 94 - Estudo em Design. Rio de Janeiro: AEnD, 1994. v.II. p.57- 72.

PERKINS, L. B., COCKING, W. D. Progressive architecture library. Nova Iorque: Reinhold, 1949. 264p.

PINHO, A. O. Avaliação de conforto em cadeiras escolares para usuários adultos trabalhadores. Porto Alegre, 2004. Dissertação (Mestrado em Engenharia de Produção). Universidade Federal do Rio Grande do Sul.

SOARES, M. M. Contribuições da ergonomia do produto ao design e avaliação de mobiliários escolares: carteira universitária, um estudo de caso. In: MORAES, A. de \& FRISONI, B. C. (Org.). Ergodesign: produtos e processos. Rio de Janeiro: 2AB, 2001. p.138-68. 


\title{
8 \\ RÓTULOS DE EMBALAGEM DE AGROTÓXICO: UMA ABORDAGEM ERGONÔMICA
}

\author{
Caroline Zanardo Gomes dos Santos ${ }^{1}$ \\ João Eduardo Guarnetti dos Santos ${ }^{2}$
}

\section{Introdução}

Os conceitos de design e ergonomia vêm sendo explanados de forma abrangente nos setores industrial e de serviços já há muito tempo. Porém, na área agrícola houve um reconhecimento tardio da necessidade de aplicação desses conhecimentos (Iida, 1998). Até mesmo os movimentos ambientalistas priorizaram por muito tempo o contexto urbano e deram pouca importância à agricultura. Hoje eles se preocupam com a contaminação do solo e das águas que assombram o vasto território nacional - tipicamente agrário (Barros, 2000).

Por mais que se tenha modernizado a produção agrícola, o trabalhador não acompanhou tal revolução e hoje sofre com o contraste entre o seu conhecimento e as adaptações tecnológicas. As condições de trabalho associadas à exposição constante de agentes contaminantes acarretam os altos índices de acidentes de trabalho. Entre eles está a contaminação pelo uso indiscriminado de agrotóxicos.

$\mathrm{O}$ aplicador desses produtos convive com a falta de informação associada à falta de assistência técnica destinada à utilização dos

1 Mestre em design, Universidade Estadual Paulista.

2 Livre docente, Universidade Estadual Paulista. 
mesmos. A grande maioria compra o produto errado, utiliza as proporções erradas e não se protege.

Nesse contexto encontra-se o rótulo da embalagem que deve conter todas as informações necessárias ao aplicador durante a tarefa. Sabe-se que as condições socioculturais interferem diretamente no entendimento da tarefa e já foi confirmado por Marangoni \& Silva (2005) que a comunicação, nesse caso, é falha. O conteúdo é muito abrangente e técnico para o público consumidor. Ainda assim, quando há dúvidas o trabalhador procura consultar o rótulo e a bula do produto.

Sendo esse insumo tão necessário à atividade agrícola e algo que acarreta sérios danos ao homem, é necessário um olhar mais crítico que produza efeitos de curto prazo para a melhoria na qualidade de vida do trabalhador. É necessária uma intervenção científica multidisciplinar que envolva as esferas da cadeia produtiva agrícola, do público usuário e de uma metodologia de design ergonômico.

\section{A força do agrotóxico na agricultura brasileira e as estatísticas}

De acordo com Elias (2003), a economia globalizada tornou necessária a existência de formas mais eficazes de produção e isso alterou radicalmente as forças produtivas da agropecuária. Desse modo, ampliou-se o investimento em pesquisa tecnológica e uma das principais aplicações foi na produção de insumos artificiais fabricados industrialmente que são capazes de suprir as deficiências do solo, prevenir as doenças das plantas, combater as pragas das plantações e aumentar o rendimento por hectare. São, portanto, capazes de responder melhor às novas formas de produção, distribuição e consumo. Com isso, a participação dos fertilizantes, defensivos, antibióticos e insumos químicos em geral no custeio da produção marcam o processo de modernização agrária.

O primeiro agrotóxico a ser sintetizado foi o dicloro difenil tricloro etano (DDT) em 1873 ou 1874 por Othmar Zeidler. Posterior- 
mente Paul Miller - pesquisador suíço - descobriu suas propriedades inseticidas (Zambrone, 1986). Após a Segunda Guerra Mundial a indústria química teve grande desenvolvimento e com ela os inseticidas sintéticos. Os anos 1960 marcam a emancipação mais intensiva desse crescimento, que se estendeu continuamente, afetando todos os níveis de produção.

Os índices que apontam o crescimento da quantidade de agrotóxicos e fertilizantes utilizada pelos produtores são superiores aos registrados pelo crescimento da própria produção agrícola, constituindose aqui uma das principais distorções da modernização agropecuária brasileira (Elias, 2003). É o que também afirma Cerqueira (2005): o relatório das Nações Unidas sobre a agricultura e alimentação mostra que o Brasil é o terceiro maior consumidor de agrotóxicos do mundo. Existem cerca de 15.000 formulações para quantrocentos agrotóxicos diferentes, sendo que cerca de oito mil formulações encontram-se licenciadas no país (Couto, 2006).

A aplicação de agrotóxicos também é excessiva. O Brasil está entre os países que mais exageram na aplicação de pesticidas nas lavouras, principalmente na horticultura, na qual se utilizam até dez mil litros de calda (mistura de agrotóxico e água para pulverização) por hectare (Caíres; Castro, 2002). Segundo Brasil (2005) e Pádua (2006), especificando apenas o mercado de herbicidas, as vendas saltaram entre 1990 e 1997 de $R$ \$ 1 bilhão para $R$ \$2,18 bilhões. Chegou-se a ter um crescimento de 540\% em vinte anos, enquanto a área plantada cresceu apenas $76 \%$. O desequilíbrio aparece com mais clareza quando comparamos o aumento desse consumo com o aumento da produtividade e a ocorrência de ervas infestantes. Aqui se confirma, portanto, a disparidade entre consumo e necessidade.

\section{Herbicidas - definição e princípios ativos}

Segundo a Associação Nacional de Defesa Vegetal (Andef, 2006), sem o uso dos produtos fitossanitários a produção e a qualidade dos 
alimentos seria drasticamente afetada, além dos riscos de gerar falta de alimentos e de promover alta nos preços.

O conceito de agrotóxico pode ser encontrado na Lei Federal $n^{\circ}$. 7802, de 11 de julho de 1989, Decreto ${ }^{\circ}$ 98816, no seu artigo 2, inciso I, que o define como "produto químico/biológico destinado ao uso nos setores agrícolas (produção, armazenamento e beneficiamento), em pastagens, na proteção de florestas e em ambientes urbanos com a finalidade de preservar a ação de seres vivos considerados nocivos".

Os agrotóxicos dividem-se pela finalidade de aplicação podendo ser herbicidas, fungicidas, acaricidas ou inseticidas, entre outros. Destacam-se aqui os herbicidas. Segundo a Organização Pan-Americana da Saúde da Organização Mundial da Saúde - órgão da Opas (1997) - herbicidas são agrotóxicos que combatem ervas daninhas. Nas últimas duas décadas, esse grupo tem tido uma utilização crescente na agricultura. Entre os diversos ingredientes estão os à base de glifosato - princípio ativo mais conhecido e que acarreta em uma série de displicências em seu manuseio pela falsa sensação de não ser prejudicial à saúde.

\section{Avaliação toxicológica dos herbicidas no organismo}

O risco de intoxicação com agrotóxicos está diretamente associado ao grau de exposição a que o usuário se submete durante a tarefa (Alves Filho \& Garcia, 2005). A contaminação humana por agrotóxicos pode ocorrer de forma direta ou indireta. A primeira ocorre devido à exposição direta que os operários das indústrias fabricantes dessas substâncias mantêm. A forma indireta resulta da exposição do conjunto de populações (humana, animal e vegetal) aos praguicidas, seja por causa de acidentes, seja pela contaminação do ambiente por resíduos industriais ou em consequência de aplicações pouco criteriosas dessas substâncias (Zambrone, 1986).

Segundo Alves Filho \& Garcia (2002), os agrotóxicos podem entrar no organismo pelas vias dérmica (pele), respiratória (por ina- 
lação) e via oral (quando ingerido). Por consequência, a intoxicação é caracterizada como aguda - quando os efeitos aparecem logo após a exposição - ou crônica - quando os efeitos aparecem depois de semanas, meses ou anos de exposição frequente. Para Alves Filho \& Garcia (2005), são diversos os fatores que interferem na exposição potencial de pessoas ou de outros organismos e elementos do meio ambiente: quantidades aplicadas, formulação e concentração, métodos e equipamentos de aplicação, tempo e frequência de aplicação, métodos de trabalho, medidas de segurança, proteção e higiene adotadas, condições ambientais (vento, temperatura, umidade etc.) e comportamento da substância no ambiente onde está sendo lançada, entre outros.

Segundo a Opas/OMS (1997) e Zambrone (1986), os agrotóxicos podem ser classificados conforme os princípios ativos e pelo grau de toxicidade que apresentam. No Brasil, a classificação toxicológica está a cargo do Ministério da Saúde. Essa classificação é representada no rótulo da embalagem com sinalização colorida, conforme a faixa em que se enquadra o produto (conforme ilustrado na tabela 26).

Ao analisar-se apenas os herbicidas nota-se que a maioria presente no mercado se classifica como "pouco tóxico" (classe IV), como é o caso dos herbicidas à base de glifosato. Porém, esta característica não isenta o produto de sérios danos à saúde quando há longa exposição aos seus componentes.

Tabela 26. Sinalização de cor nos rótulos de agrotóxico de acordo com a classe toxicológica

\begin{tabular}{l|l|l|l|l}
\hline \multicolumn{1}{c|}{ Classe do produto } & \multicolumn{1}{|c|}{ Grau de toxidade } & \multicolumn{2}{|c}{ Cor da faixa no rótulo } \\
\hline Classe I & Extremamente tóxico & vermelho & & \\
\hline Classe II & Altamente tóxico & amarelo & & \\
\hline Classe III & Medianamente tóxico & azul & & \\
\hline Classe IV & Pouco tóxico & verde & & \\
\hline
\end{tabular}

Segundo Cunha e Machado (2004), os sintomas de intoxicação podem ser percebidos rapidamente, algumas horas após a exposição constante. Para as exposições mais moderadas, os sintomas aparecem lentamente e são subjetivos e vagos, tais como dor de cabeça, 
fraqueza, mal-estar, dor de estômago e sonolência, entre outros. Já na intoxicação crônica, após meses ou anos de exposição, acarretam-se danos irreversíveis, do tipo paralisias e neoplasias e até morte.

As intoxicações do trabalhador vêm aumentando em proporções desastrosas. Os herbicidas que aparentemente são mais inofensivos por pertencerem em sua maioria à classe toxicológica IV (tarja verde) também oferecem riscos à sua saúde. Um recente estudo da Unicamp determinou que $61 \%$ das intoxicações por agrotóxicos no Brasil, entre 1996 e 2000, são devido às manipulações com glifosato (Görgen \& Guterres, 2003). Estudos mostraram claramente que o glifosato é absorvido pela membrana gastrointestinal, mesmo que lentamente, e que fica retido nos tecidos. Porém, é rapidamente eliminado se houver pausa de utilização ou contato, por isso está classificado como pouco tóxico (classe IV) na categoria toxicológica. Já na classificação ecotoxicológica, o glifosato pertence à classe III, considerado altamente tóxico para microorganismos do solo (Caires \& Castro, 2002).

Segundo o Centro de Vigilância Epidemiológica Prof. Alexandre Vranjac, do governo do estado de São Paulo (CVE, 2006), foi notificado óbito por utilização de glifosato dentro do estado no período de 1998 a 2005. Chamou a atenção na pesquisa o registro de óbito pelo fato de o produto ser considerado de baixa toxicidade.

Portanto, fica evidente que o uso de agrotóxicos no Brasil é abusivo e os altos índices de intoxicação preocupam os setores públicos. E nesse contexto observa-se a merecida atenção aos herbicidas com ativo glifosato, tido como herbicidas leves, mas que oferecem riscos potenciais aos aplicadores de agrotóxico.

\section{A Lei Federal $n^{\circ} 7802$ e a Norma Regulamentadora 31}

Para que o homem não sofra com os efeitos danosos advindos da utilização de agrotóxicos existem diretrizes jurídicas que descrevem a pesquisa, a experimentação, a produção, a embalagem e rotulagem, 
o transporte, o armazenamento, a comercialização, a propaganda comercial, a utilização, a importação, a exportação, o destino final dos resíduos e embalagens, o registro, a classificação, o controle, a inspeção e a fiscalização de agrotóxicos, seus componentes e afins, e dá outras providências (Lex, 1989). O objetivo é evitar a utilização abusiva e errônea, bem como assegurar o direito de todos ao meio ambiente equilibrado e à sadia qualidade de vida.

Segundo Garcia et al. (2005), a necessidade de instrumentos legais para o controle de substâncias perigosas é indiscutível. Para a manipulação com substâncias químicas empregadas para o controle de pragas e doenças da agricultura existe a chamada Lei dos Agrotóxicos, promulgada em 1989 (Lei n 7.802/89), que tem especial relevância.

Porém, por mais que existam diretrizes na forma da lei para as questões que envolvem o agrotóxico, sabe-se que eles são vendidos em abundância no Brasil e utilizados de forma abusiva. Muitas vezes o produto é vendido sem o receituário agronômico e o produtor (ou trabalhador) acaba contando apenas com as informações advindas das lojas de produtos agropecuários. Isso resulta em uma utilização errônea e abusiva desses produtos. Grande parte disso é o que origina os acidentes de trabalho e as concomitantes intoxicações nos usuários. As especificações sobre a rotulagem são complexas e, segundo Garcia et al. (idem), também são insuficientes sob o ponto de vista dos aspectos toxicológicos. Consta na Lei n ${ }^{\circ} 7.802$ que o rótulo deve conter as seguintes informações: descrição técnica do produto, instruções de utilização e informações relativas aos perigos potenciais dos produtos à saúde e ao meio ambiente.

Os demais tópicos a serem abordados e/ou informações complementares podem ser redigidos em uma bula (ou folheto) complementar. A Lei n 7.802 também descreve que tanto no rótulo quanto na bula devem constar, obrigatoriamente, os símbolos de perigo, nome do produto, precauções e instruções de primeiros-socorros e o nome e endereço do fabricante (e importador, quando houver). Quanto às características de layout não existem muitas restrições (como tamanho de letra, diagramação etc.). Observa-se apenas a obrigatoriedade 
de símbolos de perigo e frases de advertência, sendo que os textos e símbolos devem ser claramente visíveis, facilmente legíveis e compreensíveis em condições normais e por pessoas comuns. Resta saber se o usuário - aplicador de agrotóxico - lê tais informações antes e durante a tarefa e se o rótulo cumpre a sua obrigação de transmitir a informação de perigo e segurança do produto de forma adequada.

Segundo a Norma Regulamentadora de Segurança e Saúde no Trabalho na Agricultura - NR 31 (Brasil, 2005), o trabalhador tem o direito a receber instruções em matéria de segurança e saúde, bem como orientação e treinamento. É vedada a manipulação de quaisquer agrotóxicos, adjuvantes e produtos afins, em desacordo com a receita e as indicações do rótulo e bula. $\mathrm{O}$ empregador rural ou equiparado deve disponibilizar a todos os trabalhadores as informações necessárias para complementar as informações do rótulo do produto e contribuir para o repertório de informações quanto ao uso de agrotóxicos no estabelecimento. Esta última regra é especialmente importante no caso dos trabalhadores não alfabetizados. A norma é dirigida para pessoas que se expõem direta ou indiretamente aos produtos agrotóxicos. Fica proibida a sua manipulação por menores de 18 anos, gestantes e maiores de sessenta anos.

Como pode ser observado, o rótulo e a bula que contêm as informações dos agrotóxicos possuem importância relevante para a execução da tarefa de forma segura, embora contenham grande volume de informação e exijam do leitor conhecimento técnico prévio.

\section{Problemas encontrados na manipulação dos agrotóxicos e nos rótulos}

Segundo Macedo (2002), pesquisas demonstraram que o produtor não está preparado para o uso correto de agrotóxicos. A maioria ignora os efeitos nocivos dos produtos (ao próprio agricultor e ao meio ambiente), não usa equipamentos de proteção e desrespeita o prazo de carência para a venda da produção agrícola ao consumidor final do produto. Um exemplo disso foi relatado empiricamente pela observa- 
ção in loco de uma região com produtores que utilizam estufa. O local de trabalho onde era realizada a manipulação de agrotóxicos mostrouse bastante incorreto por ser totalmente aberto, armazenando os produtos de forma irregular e próximo a um leito de rio (figura 35).

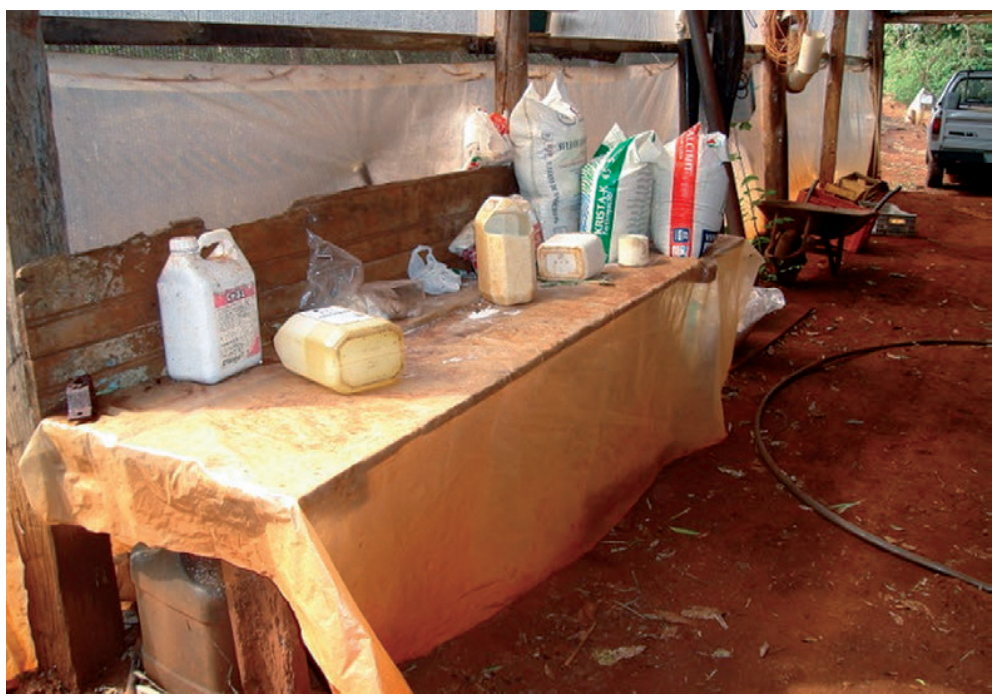

Figura 35. Local de trabalho para manipulação, mistura e armazenamento de agrotóxicos.

Outros dados relatados pela pesquisa empírica apontam que o trabalhador e o produtor se queixam de não ter assistência e os produtos são facilmente vendidos sem receituário - sendo que a bula geralmente não acompanha o produto ou acaba se perdendo durante a tarefa e a armazenagem. Os usuários reconhecem, também, que não conhecem as leis vigentes, não leem as informações da embalagem com frequência e não utilizam devidamente os Equipamentos de Proteção Individual (EPIs) por conta do calor no interior da estufa e do desconforto.

Até aqui se pode concluir que a informação dos rótulos das embalagens acaba sendo ineficiente para a execução da tarefa e que a linguagem do conteúdo não é apropriada para o público a que se destina. Ainda, comparando-se os rótulos de agrotóxicos com outros 
insumos químicos (fertilizantes, adubos e hormônios) utilizados na produção, vê-se que os agrotóxicos são mais econômicos em termos de elementos estético-funcionais e mais excessivos em conteúdo textual. Como agravante, quando comparados entre si os agrotóxicos de mesma classe toxicológica contêm idêntico padrão visual (figura 36), fato este que proporciona um grande perigo de confusão na identificação do produto.

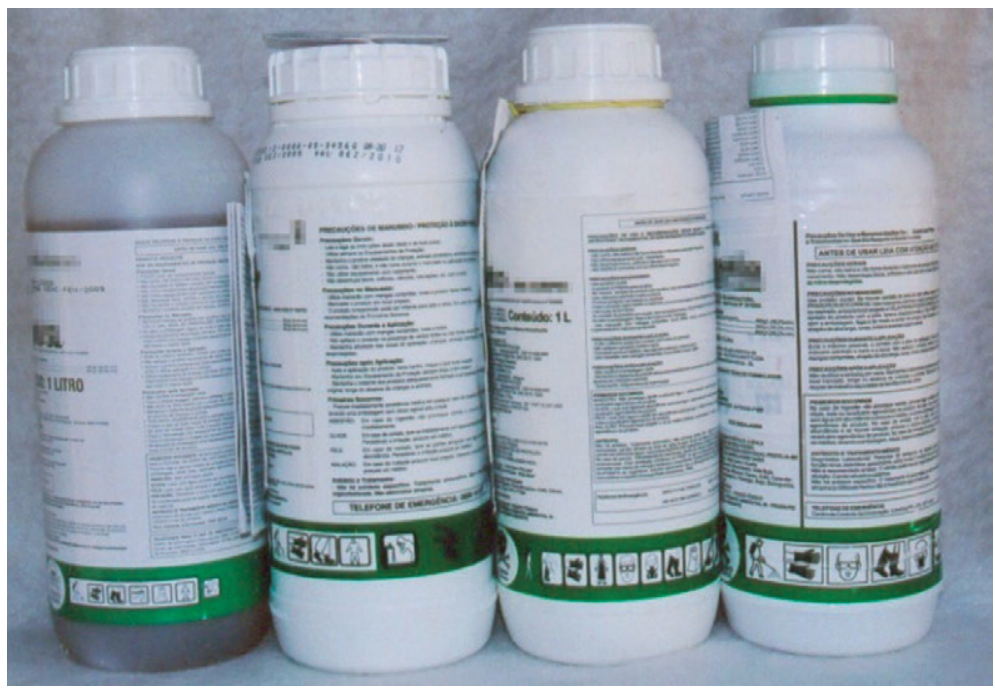

Figura 36. Exemplo de repetição do padrão visual entre embalagens.

Marangoni \& Silva (2005) descrevem a sinalização inadequada dos rótulos sob o ponto de vista do design. Foi realizado um levantamento sobre a compreensão dos pictogramas dos rótulos de embalagens de agrotóxico na região de Araçatuba (SP) e constatou-se que o usuário não compreendeu de maneira suficiente o significado dos símbolos. Afirmam também que o grau de escolaridade está intrinsecamente relacionado com o entendimento da informação e, consequentemente, com a operação. Conclui-se, portanto, que transmissão da mensagem não está sendo satisfatória de acordo com o público usuário. 
Considerando o exposto acima, o problema de usabilidade e entendimento da informação dos rótulos é evidente. O conteúdo prescrito pela Lei $n^{\circ} 7.802$ e pela Norma Regulamentadora 31 torna-se complexo, o que exige preparação técnica para a tarefa. Confirma-se, portanto, a necessidade de uma reavaliação dos modelos de rótulo de agrotóxico adotados como padrão com enfoque especial para os herbicidas de tarja verde, que têm tido suas vendas aumentadas juntamente com o aumento do índice de intoxicação.

\section{Considerações sobre design e ergonomia em projetos gráficos}

Segundo Munari (1997), todos os aspectos da comunicação visual têm como ponto comum a objetividade. É necessário que a imagem utilizada seja legível por e para todos os indivíduos da mesma maneira. Se a mensagem utilizada não for objetiva, poderá acarretar a perda da comunicação visual e até mesmo causar confusão. Para haver comunicação visual é preciso haver três elementos distintos, que são o emissor, o receptor e a mensagem. Na perfeita relação entre esses componentes leva-se em consideração o nível cultural do público a que a mensagem é dirigida e suas condições fisiológicas e sensoriais.

Os "itens" visuais que compõem a comunicação visual (ponto, linha, forma, textura, escala/proporção, dimensão e movimento) possibilitam a elaboração de mensagens para todos os níveis de alfabetismo visual por meio da relação de harmonia e contraste. A mensagem é resultado do design gráfico a partir da construção de códigos linguísticos (textos, letras, números) e códigos icônicos (figuras e imagens). O ordenamento estético-funcional desses elementos textuais e não-textuais é que compõem a representação gráfica comunicacional.

Segundo Baxter (2001), quando se fala de um produto atrativo, raramente se refere ao seu som, cheiro ou tato. A percepção humana é amplamente dominada pela visão e, quando se fala no estilo do rótulo, refere-se ao seu estilo visual, pois o sentido visual é predominante sobre os demais. O campo da intensidade de percepções e impressões 
dos sentidos pertence certamente à vivência artística, que constitui a base da criatividade.

A regra mais forte para a percepção visual possui suas bases na Gestalt, teoria formulada na década de 1920 por psicólogos alemães (Gomes Filho, 2000). O ser humano tem uma grande habilidade para descobrir simetrias em formas complexas, em formas naturais com simetria incompleta e até em objetos que tenham a simetria distorcida. De acordo com os psicólogos gestaltistas, possuímos ainda a capacidade para detectar padrões irregulares, baseando-nos em princípios de proximidade, similaridade e continuidade.

Relacionado a isso está a ergonomia, que vem complementar a validação da ideia, por meio das propriedades perceptivas de um objeto e de fatores cognitivos. A programação visual associada à ergonomia permite auxiliar a comunicação visual quanto ao ajuste do sistema e o conforto visual, propiciando máxima eficiência de transmissão da informação. Portanto, projetos de design gráfico associados a requisitos ergonômicos denotam uma eficiente comunicação e, portanto, a boa interface na relação usuário/tarefa, contribuindo de forma significativa para o desempenho da operação.

A embalagem tem a função de comunicar ao consumidor. No conjunto da embalagem enfoca-se o rótulo que fornece detalhes do produto. Tratando-se especificamente dos rótulos de risco, a importância do tratamento dos elementos visuais torna-se ainda mais relevante. A sua finalidade é facilitar o reconhecimento do produto à distância pela aparência geral dos símbolos, permitir a identificação rápida dos perigos que apresentam e promover a identificação dos cuidados observados no manuseio e estiva.

Com base nessas informações, pode-se dizer que os modelos atuais usados em rótulos de agrotóxicos possuem apenas informação prática, sendo difícil notar elementos visuais que sinalizem as advertências de perigo por um equilíbrio da forma. As questões relativas aos rótulos de risco parecem não ser aplicadas, o que dificulta para o usuário interpretar a mensagem e localizar com urgência uma informação de perigo. Logo, uma abordagem de design ergonômico necessariamente deve ser realizada. 


\section{Pressupostos teóricos e hipóteses}

Até aqui se pode dizer que o trabalhador está exposto a um alto grau de periculosidade e contaminação, relatados por desastrosas estatísticas. Os herbicidas, especificamente os à base de glifosato, que aparentemente não oferecem riscos por serem considerados pouco tóxicos, também compõem o panorama de utilização abusiva e inconsequente.

As leis e regulamentações que abordam o assunto não são aplicadas com o devido rigor e o usuário, o trabalhador agrícola, é o maior prejudicado. Entre outras coisas, lhe são cobradas a informação extensa, específica e técnica da execução da tarefa com o uso de agrotóxicos. Os rótulos das embalagens - que fazem a interface direta com o usuário - poderiam ser mais bem trabalhados sem descumprir as diretrizes legais. O resultado é que o padrão utilizado para a configuração dos rótulos atuais não é suficiente para a devida transmissão da informação. O usuário acaba sendo vítima desse mercado tão próspero que se aproveita das suas fragilidades sociais e econômicas.

Constitui-se assim um grave contexto de problemas de saúde pública, demandando intervenção em diversas esferas, entre elas a do designe da ergonomia para propiciar o desenvolvimento de novas configurações mais seguras e eficientes (sob o ponto de vista da comunicação) nas embalagens de agrotóxicos. O problema é evidente e parte da solução está (ou pode estar) ao alcance de uma interferência de design ergonômico.

Pressupõe-se que a reconfiguração dos rótulos de embalagem de agrotóxicos poderia aumentar o desempenho da comunicação e, com isso, a melhoria da tarefa. Nesse sentido, a contribuição científica não somente é necessária para aprimorar o conhecimento da tarefa, mas adquire fundamental importância por tratar-se de um setor com público tão carente e com índice demasiado elevado de acidentes do trabalho no Brasil.

A hipótese é que os atuais rótulos de herbicida poderiam ser melhorados com a aplicação de uma metodologia de design ergonômico para o planejamento visual gráfico, uma vez que os atuais rótulos de embalagem de agrotóxico não estão transmitindo a mensagem de forma eficiente por terem excessivo conteúdo e planejamento visual gráfico descoordenado para o público-alvo. 


\section{Metodologia}

Como metodologia foi realizada uma grande pesquisa bibliográfica, pesquisa empírica, realização de um projeto de rótulo e pesquisa de campo. O objeto de estudo escolhido para este capítulo foi o rótulo das embalagens de agrotóxico herbicida de um litro e de ingrediente ativo glifosato.

Sujeitos/amostra: A amostra abrange sessenta indivíduos dos sexos feminino e masculino, trabalhadores rurais aplicadores de agrotóxico (especificamente os das pequenas propriedades de hortaliças em estufa) e que exercem trabalho familiar dentro das regiões de Bauru e Ourinhos, ambos do estado de São Paulo, Brasil.

Procedimento: Após uma análise realizada com quatro rótulos de herbicidas encontrados no mercado, os mais consumidos na região de estudo, foram relatados os principais problemas de diagramação. A partir disso, desenvolveu-se um novo rótulo de herbicida utilizando os conceitos de design ergonômico. A pesquisa preliminar constatou pouca variação de configuração dos rótulos existentes. Por essa razão foi escolhido um único modelo (o de pior desempenho na avaliação) para os testes com o objetivo de compará-lo ao novo rótulo.

Coleta de dados e instrumentos: Esse experimento foi realizado em campo, por uma amostragem estratificada. A coleta de dados deu-se por uma entrevista padronizada. Para a avaliação foram aplicados três questionários (protocolos), nos quais foram analisadas três variáveis, baseadas na metodologia de Wilkinson et al. (1997):

- Protocolo 1: Tempo de localização da informação.

- Protocolo 2: Compreensão do conteúdo.

- Protocolo 3: Usabilidade percebida pelo usuário.

No Protocolo 1 (variável 1) é medido o tempo que se leva para identificar um tópico específico dos rótulos, os primeiros-socorros. Essa é uma medição indireta da qualidade da diagramação, ou seja, da organização visual da informação no rótulo, que permitiu a comparação entre os dois objetos. No Protocolo 2 (variável 2) é medida a compreensão da informação que foi quantificada por meio da arguição dos usuários sobre atitudes e procedimentos que eles tomariam após a leitura do 
rótulo e classificadas como certas ou erradas. Aqui foi observada a legibilidade associada aos fatores culturais. O Protocolo 3 (variável 3) é o registro do grau de satisfação do usuário em relação aos rótulos e foi quantificada seguindo uma escala de zero (péssimo) a dez (ótimo).

Os instrumentos utilizados para a execução desta pesquisa foram: material impresso e didático, cronômetro e softwares gráficos e estatísticos.

Análise dos dados: Após a coleta, os dados foram tabulados e analisados de forma a confrontar a proposta inicial e as hipóteses.

\section{Desenvolvimento da proposta de rótulo de embalagem herbicida}

As etapas propostas para a metodologia de um projeto visual gráfico ergonômico estão abaixo representadas, baseando-se em Munari (1997) e Moraes \& Frisoni (2001).

- A nálisedo usuário: revelou agrandediversidadeantropométrica e de biótipos, sendo que o indivíduo apresenta altos índices de carência de recursos, possui baixo grau de escolaridade e distância geográfica de assistência médica, técnica e social.

- Análisedatarefaprescrita: deumamaneirageral, otrabalho de aplicação de agrotóxicos caracteriza-se como de longa jornada diária e semanal com ausência de intervalos para descanso, tampouco férias. Apresenta caráter cíclico e sazonal no qual o sistema é aberto e em contato com meio contaminante. Existe uma ordem criteriosa e complexa de atividades a serem realizadas com o rótulo antes, durante e depois da aplicação de herbicida. Essas medidas envolvem leitura constante das informações, higiene, manutenção dos equipamentos, armazenamento e respeito aos períodos de intervalo de aplicação do produto.

- A nálisedas quatro embalagens referenciais: os critérios deavaliação foram cor, tipologia, ilustrações, orientação da leitura, diagramação, legibilidade e a conformidade com a Lei n ${ }^{\circ} 7.802$ e a Norma Regulamentadora 31 (NR-31) de segurança no trabalho. Como resultado dessa avaliação pôde-se concluir que os 
rótulos analisados estão, na maior parte dos requisitos legais, em conformidade com a lei. Porém, apresentam problemas ergonômicos e com planejamento visual gráfico insuficiente. Os textos apresentam pouco contraste, fazendo com que a leitura se torne monótona e confusa. Os pictogramas aparecem separados dos elementos textuais (na borda do rótulo) com fundo verde numa sequência linear de aproximadamente 18 desenhos com tamanhos variados. Por apresentar instruções de emergência, o texto deveria estar bem sinalizado e com conteúdo mais claro. Quanto à legibilidade pode-se dizer que o rótulo oferece difícil localização das partes e dificuldade para a percepção visual. Não foram explorados com eficiência elementos como cores, proporção e tipos de letras. Quanto ao tamanho da letra, o resultado é ainda pior, a uma distância de $35 \mathrm{~cm}$ entre o usuário e o objeto, o texto torna-se ilegível exigindo do usuário maior tempo e esforço para a leitura.

- Requisitos deprojeto: estabeleceu-sea partir dessaanáliseque é preciso haver sinalização entre os diferentes tópicos/assuntos do rótulo para facilitar a identificação em caso de emergência. Os elementos textuais devem oferecer clareza e limpeza visual para facilitar a percepção e acuidade visual. Deve haver o maior emprego possível de cor, já que o texto é extenso e cansativo. A diagramação deve ter contraste e harmonia com diferentes tamanhos de letra para destacar a importância e hierarquia de assuntos. A informação deve seguir a NR-31, mas de maneira clara para o entendimento de todos os níveis de compreensão.

- Processo criativo e elaboração do novo rótulo: baseou-seem Löbach (2000) para as etapas de solução de problemas. Essas etapas foram subdivididas em quatro fases denominadas análise do problema, geração de alternativas, avaliação das alternativas e realização da solução. As características do produto redesenhado são apresentadas na tabela 27.

Para a orientação/sentido de leitura do rótulo, preservou-se a divisão de três colunas, estabelecidas para hierarquizar os três temas diferentes abordados (informações da marca e da classe do produto, instruções de manuseio e proteção à saúde humana e cuidados relativos à proteção do meio ambiente, figura 37). 
Tabela 27. Características gráficas do layout.

\begin{tabular}{l|l}
\hline Formato de impressão: & $285 \mathrm{X} 157 \mathrm{~mm}$ \\
\hline Superfície do material impresso: & Papel revestido \\
\hline $\begin{array}{l}\text { Tamanho da "mancha" (área de } \\
\text { grafismo): }\end{array}$ & 275 x $150 \mathrm{~mm}$ \\
\hline Cores utilizadas: & Preto, verde especial e amarelo especial \\
\hline Processo de impressão: & Flexografia \\
\hline Tipologia: & Arial, Arial Black e Berlin sans FB Demi \\
\hline Tamanho de letra & $6,6.5,7,10,12,32$ \\
\hline Recursos gráficos: & $\begin{array}{l}\text { Esboços manuais, computação gráfica } \\
\text { (software Corel Draw) e impressão. }\end{array}$ \\
\hline Diagramação: & $\begin{array}{l}\text { Composta de texto, imagem e destaques para } \\
\text { os tópicos, negrito no texto e textos coloridos. }\end{array}$ \\
\hline
\end{tabular}
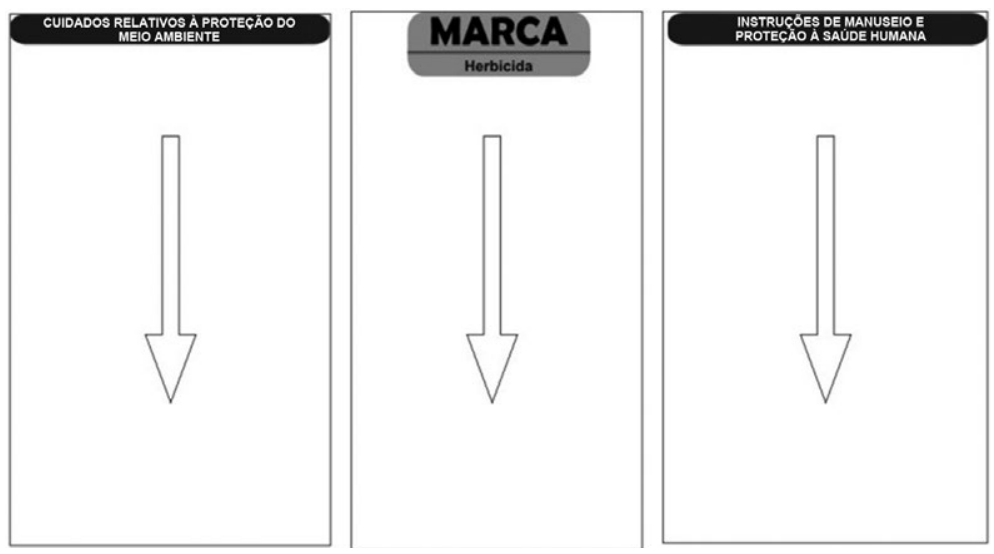

Figura 37. Sentido de leitura para a divisão de colunas do rótulo.

Dentro das colunas foram acrescentadas subdivisões, referentes ao mesmo tema, para melhorar a localização do texto, principalmente quanto aos aspectos de emergência. Foram utilizadas soluções de diagramação para melhorar a legibilidade por meio de cores, símbolos e espaço entre "manchas" (blocos de texto ou imagem), bem como diferentes tamanhos de letra (figura 38). Quanto à orientação dos pictogramas de perigo, os mesmos foram retirados da borda inferior e colocados com o texto para facilitar a sinalização de determinado conteúdo informativo. 

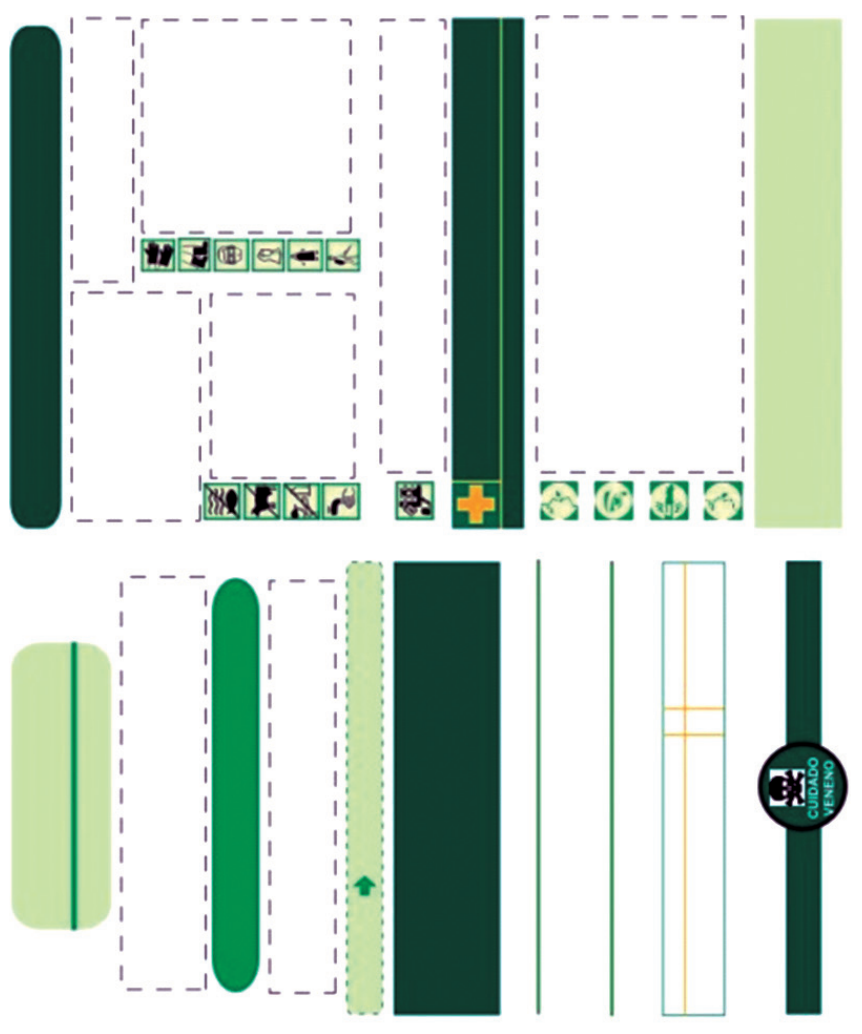

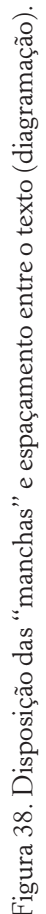
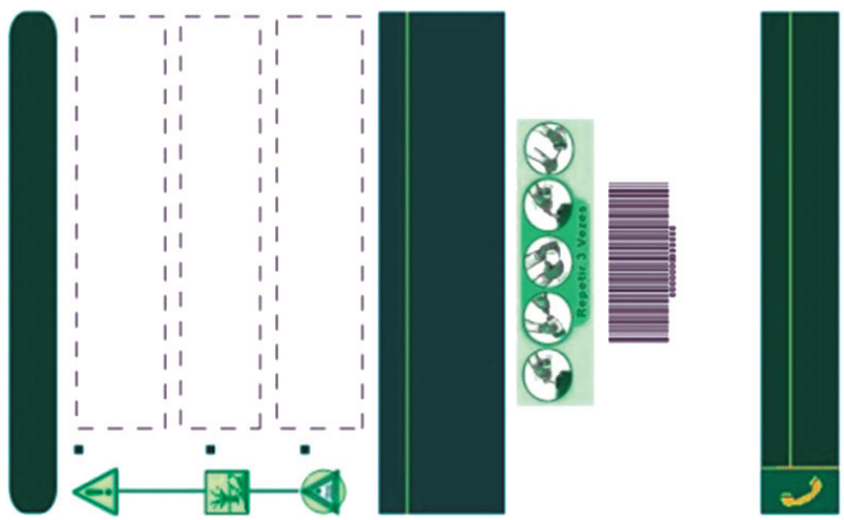
Foi elaborada uma edição do texto pela necessidade que havia de diminuir grandes volumes de texto e reduzir o conteúdo técnico. Também foi feito um estudo de tamanho de letra para que o modelo proposto ficasse em conformidade com a Lei $n^{0} 7.802$, ou seja, visível por qualquer pessoa e em uma situação qualquer.

Foram inseridos alguns itens até então desprezados nos rótulos comerciais:

- a identificação do produto como herbicida (figura 39);

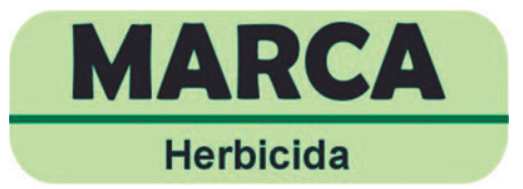

Figura 39. Inserção da categoria do produto para fácil visualização e identificação.

- a diluição máxima e mínima permitida para o produto (figura 40), supondo-se que, na ausência da bula, as principais medidas estariam disponíveis para consulta;

\section{CONTEÚDO: 1 litro}

Diluição: de 5 a $40 \mathrm{ml}$ para 100 c de água (Ver Bula)

Figura 40. Indicação de diluição máxima e mínima permitida para o produto.

- desenho ilustrando o processo de tríplice lavagem (figura 41).

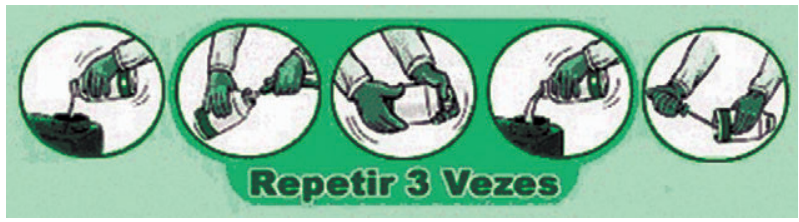

Figura 41. Ilustração explicativa sobre a tríplice lavagem.

Da união de todos esses critérios originou-se o novo rótulo, criado em tamanho natural e que está demonstrado abaixo em escala reduzida (figura 42): 

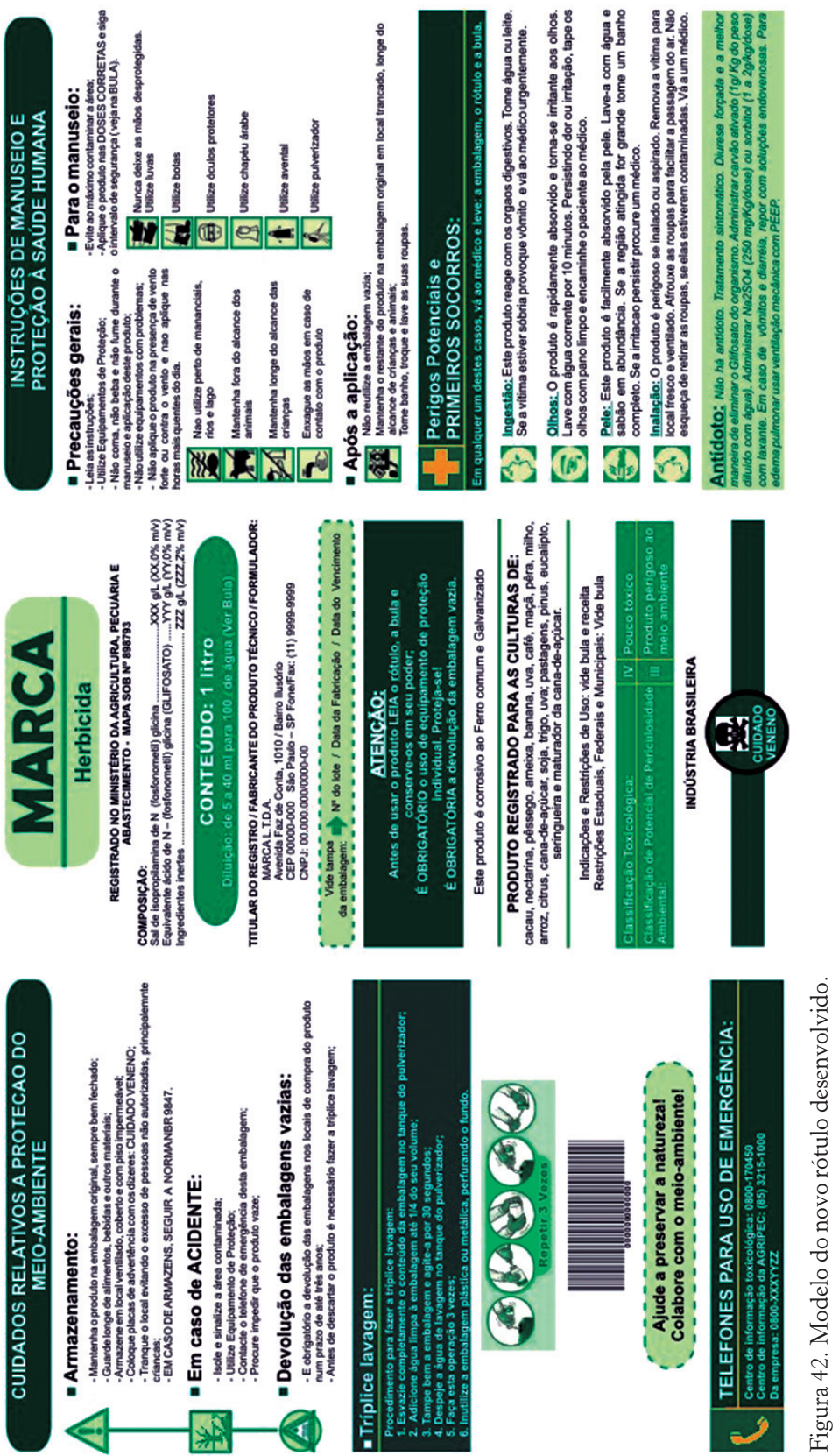
A comparação visual das duas embalagens oferece diferenças significativas (figura 43).
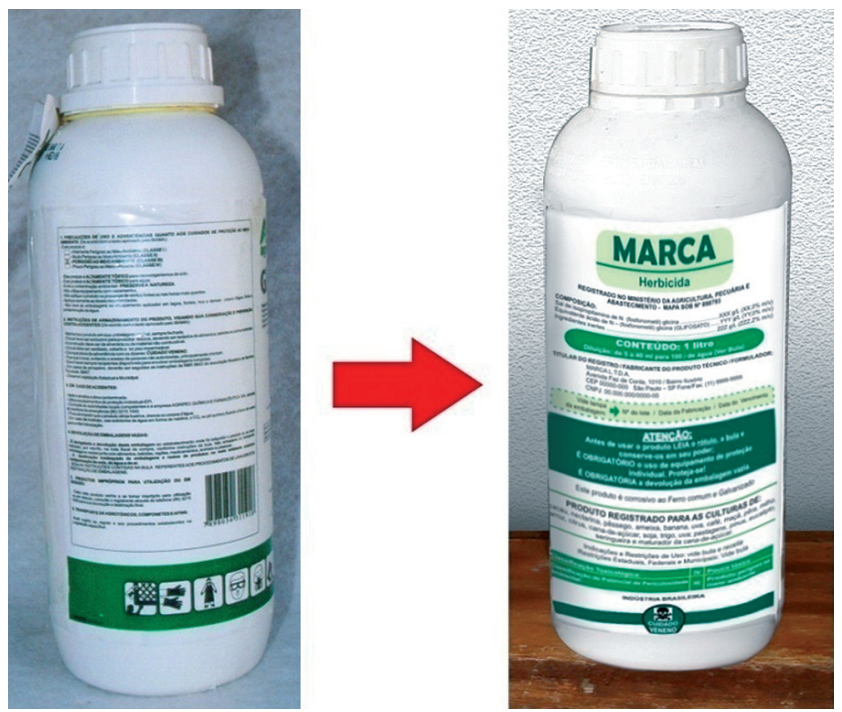

Figura 43. Apresentação do novo modelo contraposto à embalagem usada para comparação na pesquisa.

\section{Resultados e discussão}

Para o teste realizado em campo diferenciou-se a nomenclatura das duas embalagens selecionadas para comparação como embalagem 1 (embalagem comercial selecionada como de pior desempenho entre as quatro analisadas) e embalagem 2 (projeto de rótulo desenvolvido). O resultado das entrevistas para cada protocolo está descrito a seguir.

- Protocolo 1 - Localização da informação: Do total de entrevistados, cinquenta eram do sexo masculino $(83,34 \%)$ e dez eram do sexo feminino (16,66\%). Predominou a faixa etária de pessoas entre 50 e 59 anos. Observa-se a ocorrência de pessoas acima de sessenta anos trabalhando, faixa etária não permitida para tal atividade (figura 44). 


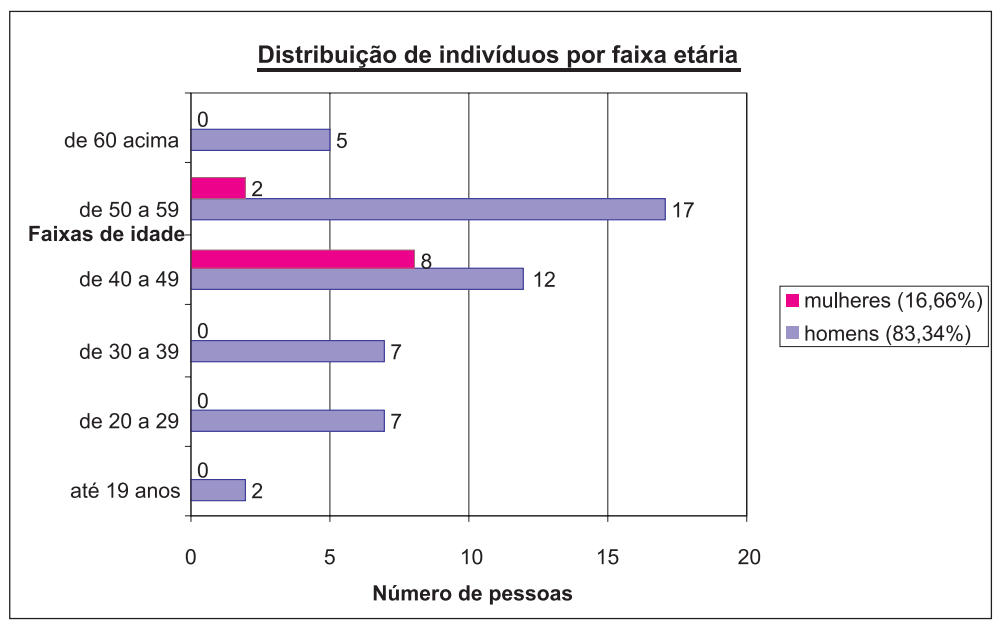

Figura 44. Distribuição de faixa etária dos entrevistados.

Em relação ao tempo cronometrado para localização do tópico escolhido para avaliação, observou-se que a embalagem 2 apresentou o melhor desempenho com o menor tempo registrado $(35,32$ segundos). Os índices da mediana (22 e 17 segundos) e desvio padrão (76,16 e 59,99 segundos) demonstram a grande variação entre o primeiro e o último índices, cronometrados para cada indivíduo (tabela 28).

Tabela 28. Relação estatística do tempo cronometrado (em segundos).

\begin{tabular}{l|c|c|c}
\hline & Média aritmética & Desvio padrão & Mediana \\
\hline Tempo embalagem 1 & $59,40 \mathrm{~s}$ & $76,16 \mathrm{~s}$ & $22 \mathrm{~s}$ \\
\hline Tempo embalagem 2 & $35,32 \mathrm{~s}$ & $56,99 \mathrm{~s}$ & $17 \mathrm{~s}$ \\
\hline
\end{tabular}

- Protocolo 2 - Compreensão do texto: pediu-se para os indivíduos lerem a informação após a sua localização. Os resultados indicam que a maioria não conseguiu ler e entender as instruções da embalagem 1 (figura 45). 


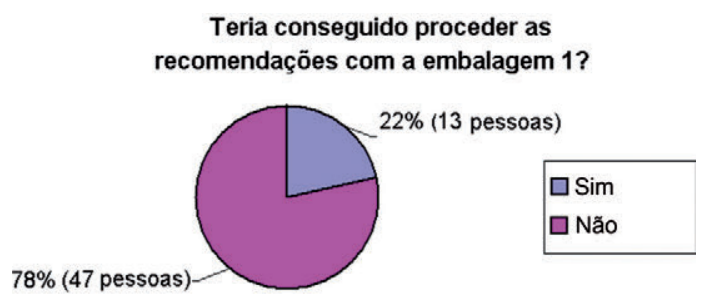

Figura 45. Porcentagem das pessoas que entenderiam os procedimentos apenas com a embalagem 1.

As respostas da entrevista também apontaram que a embalagem 2 é mais fácil de visualizar e facilita a compreensão do conteúdo informativo.

- Protocolo 3 - Usabilidade percebida pelo usuário: Nessa parte da entrevista foram coletadas informações que apontassem a opinião do usuário acerca da manipulação com o produto, suas experiências, sugestões e críticas. Os resultados mostraram que os entrevistados acham que há excesso de informação nos rótulos convencionais, que as letras são muito pequenas e que eles se sentem desestimulados à leitura. A maioria (90\%) relatou, também, que considera as informações das embalagens convencionais ineficientes para orientação numa situação de emergência. Houve relatos de indivíduos intoxicados (33\% dos entrevistados!). Setenta e oito por cento (78\%) desconhecem os perigos e disseram que não saberiam como proceder numa situação de urgência apenas com a embalagem 1. Por último foi perguntado aos entrevistados que nota eles dariam às duas embalagens, numa escala de zero a dez. Os resultados foram: a nota dada para a embalagem 1 (embalagem comercial) foi de média 5 e a nota da embalagem 2 (nova) foi de 9 a 10, ou seja, quase o dobro. Esses dados mostram exatamente qual foi o desempenho das duas embalagens ao longo da entrevista e o papel desempenhado pela aplicação do design ergonômico. Faz-se valer, portanto, a tentativa de melhoria no projeto visual gráfico e o retorno positivo do usuário. Essas modificações são importantes e devem ser concretizadas. 


\section{Conclusão}

Ao fim deste capítulo pode-se concluir que as hipóteses foram verificadas e são válidas para as pressuposições. O rótulo pode perfeitamente ser melhorado, tanto no design gráfico quanto na usabilidade, sem maiores esforços e sem fugir das diretrizes legais.

Afirma-se, portanto, que uma simples modificação por meio do design ergonômico em rótulos de embalagens de agrotóxicos facilita a visibilidade, a compreensão e o manuseio, segundo foi relatado pela opinião do público usuário. O depoimento dos trabalhadores mostrou que com os rótulos convencionais há uma desmotivação para ler os procedimentos, graças ao excessivo conteúdo informativo e ao tamanho de letra. No entanto, quando a leitura torna-se fácil e agradável, o usuário mobiliza-se positivamente a aprender.

A diagramação associada à edição de texto torna-se uma ferramenta essencial para elevar a comunicação de determinado veículo. Isso confere maior credibilidade ao fabricante e dá maior segurança ao usuário da embalagem. Além disso, os pictogramas possuem força extraordinária de transcender a mensagem, principalmente quando o grau de alfabetismo é variável e existem condições de perigo a serem ressaltadas.

Percebe-se que há necessidade de acoplar muitos dados informativos na embalagem e os fabricantes se utilizam da bula para suprir tal necessidade, o que é totalmente compreensível. Deve-se, no entanto, tomar bastante cuidado ao selecionar as informações mais importantes para a bula, pois o agricultor as desconhece e acaba contando com o ensinamento e a assessoria das lojas de produtos agropecuários que muitas vezes não estão preparadas para interpretar o conteúdo técnico ou não o fazem de maneira ética.

Além desses agravantes, também se deve levar em conta que as condições de iluminação e insalubridade reforçam a dificuldade de enxergar o rótulo e que, numa situação de urgência, a família inteira do agricultor (ou outro funcionário qualquer) deve ter acesso ao conteúdo informativo de forma clara, concisa e objetiva. Numa situação de urgência, muitas vezes, o marido é socorrido pela mulher ou por seus filhos. 
Não se tem a pretensão de dizer que o modelo proposto resolveu definitivamente todos os problemas, mas, com o público avaliado da grande região de Bauru/Ourinhos, ele teve um desempenho de leitura extremamente favorável. É importante que haja outros projetos voltados para esse público e que aborde o manuseio com agrotóxicos. Muitas são as variáveis que tornam esse trabalho tão insalubre e, para piorar, o usuário está isolado geograficamente de assistência hospitalar e de informação.

Algumas recomendações podem ser feitas como requisitos de projetos futuros de layout de rótulos para esse e outros produtos semelhantes:

- Projeto com uma edição de texto pensada no público usuário, facilitando a linguagem e ressaltando os itens de segurança.

- Layout que utilize recursos de cor, desenho, textos grandes e que aproveite o máximo possível o espaço de impressão sem se tornar cansativo, que respeite os aspectos do design ergonômico e da gestalt do objeto. Afinal, o design dá a forma e concretiza ideias, a ergonomia dá respaldo científico e ambas resultam em um projeto que resolve problemas.

Confirmou-se, portanto, que os rótulos atuais não estão sendo suficientes para a devida transmissão da informação. Uma simples melhoria pode ser realizada nesse âmbito e tantos outros, sendo que a área carece de implementação científica. Para que tais mudanças sejam concretizadas, fica a cargo das entidades envolvidas, das universidades e da sociedade cobrar melhorias para essa população que movimenta o principal setor produtivo do país e que vem sofrendo demasiadamente pelo descaso da população urbana e dos fabricantes de agrotóxico. Por menor que seja a contribuição, ela se torna válida.

\section{Referências bibliográficas}

ALVES FILHO, J. P. A., GARCIA, E. Prevenção de acidentes no uso de agrotóxicos. (Cartilha do Trabalhador). São Paulo: Fundacentro, 2002. 15p. ANDEF (Associação Nacional de Defesa Vegetal). Por que precisamos de produtos fitossanitários? Seção Agricultura. Disponível em: <http:// www.andef.com.br/2003/agri01.asp>. Acesso em 26 ago. 2006. 
BARROS, A. T. de. A SBPC e a pesquisa científica sobre agricultura e meio ambiente (1972-92). Cadernos de Ciência E Tecnologia. v.17, n.2, maio/ ago. 2000.

BAXTER, M. Projeto de produto: guia prático para o desenvolvimento de novos produtos. São Paulo: Edgard Blücher, 2001.

BRASIL. Lei nº 7.802, de 11 de julho de 1989. Lex: Dispõe sobre a pesquisa, a experimentação, a produção, a embalagem e rotulagem, o transporte, o armazenamento, a comercialização, a propaganda comercial, a utilização, a importação, a exportação, o destino final dos resíduos e embalagens, o registro, a classificação, o controle, a inspeção e a fiscalização de agrotóxicos, seus 86 componentes e afins, e dá outras providências. Diário Oficial da República Federativa do Brasil, Brasília, 13 jul. 1989.

BRASIL. Norma Regulamentadora de Segurança e Saúde no Trabalho na Agricultura, Pecuária, Sivicultura, exploração Florestal e Aquicultura - NR 31. Portaria nº 86, de 3 mar. 2005. Diário Oficial da União, 4 mar. 2005.

CAIRES, S. M. de; CASTRO, J. G. D. Levantamento dos agrotóxicos usados por produtores rurais do município de Alta Floresta - Mato Grosso. Revista de Biologia e Ciências da Terra. Universidade Estadual da Paraíba, Campina Grande, v.2, n.1, 2 sem. 2002.

CVE. Centro de Vigilância Epidemiológica Prof. AlexandrinoVranjac. Governo do estado de São Paulo. Intoxicação por Agrotóxico: Série Histórica. Disponível em: <http://cve.saude.sp.br/htm/doma/agro_cml9805. htm>. Acesso em 23 ago. 2006.

CERQUEIRA, A. Resíduos na produção da mandioca ainda prejudicam meio ambiente. Serviço de Apoio às Micro e Pequenas Empresas (Sebrae). Alagoas, abr. 2005. Disponível em:< http://www.al.sebrae.com.br/ conexao/VisualizarConteudo.asp? CodConteudoConexao $=1056 \&$ Co dpasta $=149>$. Acesso em 23 ago. 2006.

COUTO, J. L. V. do. Riscos na aplicação de agrotóxicos. Universidade Federal Rural do Rio de Janeiro (UFRRJ). Seção de Segurança do trabalho na área rural. Seropédica, 2006. Disponível em: <http://www.ufrrj. $\mathrm{br} /$ institutos/it/de/acidentes/agrotx.htm>. Acesso em 23 ago. 2006.

CUNHA, F. G. da; MACHADO, G. J. Estudos de geoquímica ambiental e o impacto na saúde pública no município de São Gonçalo do Piauí, estado do Piauí. Programa Nacional de Pesquisa em Geoquímica Ambiental e Geologia Médica (PGAGEM). Serviço Geológico do Brasil (CPRM). Brasil: Depat, 2004. 
ELIAS, D. Globalização e agricultura: a região de Ribeirão Preto/SP.São Paulo: Edusp, 2003.

GOMES FILHO, J. Gestalt do objeto: sistema de leitura visual da forma. São Paulo: Escrituras, 2000.

GARCIA, E. G. G., BUSSACOS, M. A., FISCHER, F. M. Impacto da legislação no registro de agrotóxicos de maior toxicidade no Brasil. Revista de Saúde Pública. São Paulo, v.39, n.5, out. 2005. ISSN 0034-8910.

GARCIA, E., ALVES FILHO, J. P. A. Aspectos de prevenção e controle de acidentes no trabalho com agrotóxicos. (Apostila). São Paulo: Fundacentro, 2005. 52p.

GÖRGEN, S., GUTERRES, E. Efeitos nocivos do glifosato. Revista Consciência Net. Porto Alegre, out. 2003. Disponível em: http://www. consciencia.net/2003/10/19/glifosato.html. Acesso em 23 out. 2006.

IIDA, I. Ergonomia: projeto e produção. São Paulo: Edgard Blücher, 1998.

LÖBACH, B. Design industrial: bases para a configuração dos produtos industriais. São Paulo: Edgard Blücher, 2000.

MACEDO, J. A. B. de. Introdução à química ambiental: química \& meio ambiente \& sociedade. 1.ed. Juiz de Fora: Jorge Macedo, 2002, p.487.

MARANGONI, J. C., SILVA, J. C. P. da. Análise de um sistema de informação visual pictórico - embalagens de agrotóxicos. Educação Gráfica. Bauru: Universidade Estadual Paulista, Número Especial, jun.2005.

MORAES, A. de; FRISONI, B. C. Ergodesign: produtos e processos. Rio de Janeiro: 2AB, 2001.

MUNARI, B. Design e comunicação visual. Tradução Daniel Santana. São Paulo: Martins Fontes, 1997.

OPAS - Organização Pan-Americana da Saúde; OMS - Organização Mundial da Saúde. Ministério da Saúde. Manual de vigilância da saúde de populações expostas a agrotóxicos. Brasília: Secretaria de Vigilância Sanitária. Departamento Técnico-Normativo. Divisão de Meio Ambiente a Ecologia Humana, 1997.

PÁDUA, J. A. A formação da agricultura brasileira: uma herança predatória. Temas em debate. EBAPE/Fundação Getúlio Vargas. Rio de Janeiro, 2006. Disponível em:<http://www.ebape.fgv.br/cids/NOVO\%20 DEBATE\%20AgricultP\%C3\%A1dua.html>. Acesso em 23 ago. 2006.

WILKINSON, R. L., CARY, J. W., BARR, N. F., REYNOLDS, J. Comprehension of pesticide safety information: effects of pictorial and textual warnings. International journal of pest management. 1997, 43(3) 239-45.

ZAMBRONE, F .A. D. Perigosa família. Rio de Janeiro: Sociedade Brasileira para o Progresso da Ciência, n.4, v.22, jan./ fev.1986. 



\title{
9 \\ RÓTULOS E BULAS DE AGROTÓXICOS: PARÂMETROS DE LEGIBILIDADE TIPOGRÁFICA
}

\author{
Maria Gabriela Nunes Yamashita ${ }^{1}$ \\ João Eduardo Guarnetti dos Santos ${ }^{2}$
}

\section{Introdução}

A agricultura concentra grande parte das atividades mais penosas: além de o agricultor submeter-se diariamente ao trabalho com máquinas inseguras e desconfortáveis, ainda se expõe aos riscos advindos do manejo de agrotóxicos. Segundo a OPAS (1997), ocorrem no mundo cerca de três milhões de casos de intoxicação por agrotóxicos, gerando um total de 220 mil mortes. No Brasil, os números calculados aproximam-se das 297 mil intoxicações. Como fator agravante, o Brasil aparece no mercado mundial como o terceiro maior consumidor de agrotóxicos, movimentando em torno de US\$ 3,9 bilhões em 2006. A produção de soja concentra $50 \%$ de todo o agrotóxico comercializado no país, que atualmente é o segundo maior produtor desse grão e o único, dentre os grandes produtores, com condições de aumentar a área cultivada.

A tarefa de aplicar o agrotóxico exige do trabalhador um conhecimento aprofundado sobre o produto, seu modo seguro de aplicação e os riscos à saúde do trabalhador e ao meio ambiente. Portanto, bulas e rótulos têm um papel de vital importância, devendo transmitir ao

1 Mestre em design, Universidade Estadual Paulista.

2 Livre-docente, Universidade Estadual Paulista. 
aplicador de agrotóxicos todas as informações necessárias para o uso correto dos produtos, tais como uso de equipamentos de proteção individual (EPI) e procedimentos em caso de intoxicação.

Entretanto, o número elevado de casos de intoxicação revela um problema: ou as informações em rótulos e bulas de agrotóxicos não são lidas ou não são compreendidas pelos agricultores. A legislação federal de agrotóxicos e afins determina diversas exigências e apresenta modelos de rótulo e bula que devem ser utilizados na criação de qualquer impresso dessa natureza. Entretanto, em uma análise superficial de rótulos e de bulas, percebe-se que os padrões estipulados não são cumpridos. Além disso, as informações contidas nesses impressos são demasiadamente técnicas e desconsideram a cultura e linguagem próprias do homem do campo, dificultando a transmissão das informações necessárias.

\section{Objetivos}

O presente capítulo visa identificar os maiores problemas relativos à leitura e ao entendimento de informações contidas em rótulos e bulas de agrotóxicos, coletando dados sobre a leitura e compreensão das informações escritas e pictóricas e verificando o cumprimento ou não do que dispõe a legislação federal de agrotóxicos sobre a rotulagem desses produtos.

Pretende-se obter diretrizes para este capítulo por meio de pesquisa de campo realizada com agricultores que cultivam soja na região do distrito de Warta, município de Londrina, estado do Paraná. De acordo com os problemas indicados por eles, pretende-se analisar rótulos e bulas de agrotóxicos, observando problemas relacionados à legibilidade e compreensão dos textos e pictogramas apresentados, além de verificar o cumprimento das exigências da legislação federal de agrotóxicos e afins em tais rótulos.

Com isso, pretende-se fornecer embasamento para futuros trabalhos que visem aperfeiçoar tais impressos com a intenção de torná-los mais legíveis e fáceis de serem compreendidos. 


\section{Revisão bibliográfica}

Os agrotóxicos são:

produtos e agentes de processos físicos, químicos ou biológicos, destinados ao uso nos setores de produção, no armazenamento e beneficiamento de produtos agrícolas, nas pastagens, na proteção de florestas, nativas ou plantadas, e de outros ecossistemas e de ambientes urbanos, hídricos e industriais, cuja finalidade seja alterar a composição da flora ou da fauna, a fim de preservá-las da ação danosa de seres vivos considerados nocivos, bem como as substâncias e produtos empregados como desfolhantes, dessecantes, estimuladores e inibidores de crescimento. (Decreto ${ }^{\circ} 4.074$, de 4 de janeiro de 2.002)

Segundo Luna et al. (2006), apesar de certas substâncias, como enxofre e arsênico, já serem utilizadas com o intuito de controlar insetos e pragas em plantações de gregos e romanos por volta do século VIII a.C., foi somente a partir do século XX que os primeiros agrotóxicos passaram a ser comercialmente produzidos. Ainda assim, a disseminação de tais produtos só ocorreu a partir da Segunda Guerra Mundial, com a descoberta de dois poderosos produtos: o DDT e do Sharadam.

Os agrotóxicos podem ser classificados, segundo Peres et al. (2003), de acordo com a praga que controlam (sua função), segundo o grupo químico ao qual pertencem e de acordo com os efeitos à saúde humana e ao ambiente. Segundo sua função, os agrotóxicos são classificados de forma simplificada em herbicidas (combatem ervas indesejadas), inseticidas (combatem insetos), fungicidas (combatem fungos), desfolhantes (eliminam folhas indesejadas), fumigantes (combatem bactérias do solo), raticidas (combatem ratos e demais roedores), moluscocidas (combatem moluscos), nematicidas (combatem nematoides) e acaricidas (combatem ácaros). Quanto ao seu grau de toxicidade, os agrotóxicos são classificados em quatro categorias, sendo atribuída uma cor distinta para cada uma delas (tabela 29). 
Tabela 29. Classificação dos agrotóxicos quanto ao risco à saúde. Fonte: IMA (1999 apud Santos, 2003).

\begin{tabular}{|c|c|c|c|}
\hline CLASSIFICAÇÃo & COR DA FAIXA & $\begin{array}{l}\text { DOSAGEM LETAL } \\
50\end{array}$ & $\begin{array}{l}\text { DOSE CAPAZ DE } \\
\text { MATAR UM ADULTO }\end{array}$ \\
\hline $\begin{array}{l}\text { Classe I: extremamente } \\
\text { tóxico }\end{array}$ & Vermelha & $\begin{array}{l}5 \mathrm{mg} / \mathrm{kg} \text { de peso } \\
\text { corpóreo }\end{array}$ & $\begin{array}{l}1 \text { pitada/ } \\
\text { algumas gotas }\end{array}$ \\
\hline $\begin{array}{l}\text { Classe II: } \\
\text { tóxico }\end{array}$ & Amarela & $\begin{array}{ll}5-50 \mathrm{mg} / \mathrm{kg} & \mathrm{de} \\
\text { peso corpóreo } & \\
\end{array}$ & $\begin{array}{l}\text { Algumas gotas/ } \\
1 \text { colher de chá }\end{array}$ \\
\hline $\begin{array}{l}\text { Classe III: } \\
\text { medianamente tóxico }\end{array}$ & Azul & $\begin{array}{l}50-500 \mathrm{mg} / \mathrm{kg} \\
\text { peso corpóreo }\end{array}$ & $\begin{array}{l}1 \text { colher de chá/ } \\
2 \text { colheres de sopa }\end{array}$ \\
\hline Classe IV: pouco tóxico & Verde & $\begin{array}{l}500-5000 \mathrm{mg} / \mathrm{kg} \\
\text { de peso corpóreo }\end{array}$ & $\begin{array}{l}2 \text { colheres de sopa/ } \\
1 \text { copo }\end{array}$ \\
\hline
\end{tabular}

Os agrotóxicos ainda recebem uma classificação de acordo com sua periculosidade ambiental, que vai de "pouco" até "altamente perigoso" (tabela 30).

Tabela 30. Classificação de periculosidade ambiental dos agrotóxicos. Fonte: IMA (idem).

\begin{tabular}{ll}
\hline Classe & Nivel de perigo ao ambiente \\
\hline Classe I & Altamente perigoso \\
Classe II & Muito perigoso \\
Classe III & Perigoso \\
Classe IV & Pouco perigoso \\
\hline
\end{tabular}

\section{Consumo de agrotóxicos}

A comercialização dos agrotóxicos e sua utilização foram amparadas pelo discurso da indústria agroquímica: "somente a produção intensiva conseguirá matar a fome de uma população que cresce geometricamente e ela só é possível com o uso de agrotóxicos. (Andef apud Bueno, 2004). No Brasil, o uso de agrotóxicos começou a se intensificar a partir da década de 1960, devido em grande parte ao Plano Nacional de Desenvolvimento, que obrigava todo agricultor que buscasse financiamento a comprar, com o crédito rural, determinada cota de agrotóxico. Isso, aliado à propaganda $e$ ao discurso da indústria química, fez do Brasil um dos maiores consumidores mundiais de agrotóxicos.

De acordo com Santos (2003), a indústria agroquímica faturou, em 2001, US\$ 30 bilhões no mundo. No Brasil, em 2000, já havia faturado cerca de US\$3 bilhões. O consumo de agrotóxicos aumentou de forma tão acentuada que elevou o Brasil à posição de terceiro 
maior consumidor mundial desses produtos. A venda de agrotóxicos está relacionada, segundo Santos (2003), a um número reduzido de culturas. Em 1997, cinco culturas concentravam 65\% de todo agrotóxico comercializado no Brasil: soja (33,3\%), cana-de-açúcar $(11,1 \%)$, milho (7,6\%), café $(7,2 \%)$ e cítricos (6,3\%). Já em 2004 , segundo dados do Sindag, $50 \%$ de todo agrotóxico comercializado era destinado à produção de soja.

Dentre os agrotóxicos mais utilizados no país, destacam-se os herbicidas e inseticidas, como mostra a tabela 31.

Tabela 31. Vendas de agrotóxicos por classe, 2002. Fonte: Sindag.

\begin{tabular}{lcc}
\hline Classe de produto & Vendas (US\$ milhões) & \% \\
\hline Herbicidas & 988 & 51 \\
Inseticidas & 468 & 24 \\
Fungicidas & 360 & 18 \\
Acaricidas & 72 & 4 \\
Outros & 64 & 3 \\
\hline
\end{tabular}

\section{Consequências do uso de agrotóxicos para a saúde do trabalhador}

Quando os agrotóxicos começaram a ser utilizados no Brasil, eram comumente denominados defensivos agrícolas. Na simplicidade do campo, também eram conhecidos como "remédios para plantas". Para Peres et al. (2003), tais termos enfatizam apenas as "qualidades" do produto e escondem seus efeitos negativos ao meio ambiente e à saúde humana. Segundo Vagner e Figueira (2004), a primeira denúncia dos danos causados pelo uso desordenado de agrotóxicos surgiu só por volta da década de 1960, com a publicação do livro Silent spring (primavera silenciosa), de Rachel Carson, cujos dados levaram à proibição do uso de determinados agrotóxicos em diversos países a partir da década de 1970.

Atualmente, sabe-se que os efeitos dos agrotóxicos não se restringem ao trabalhador rural e podem permanecer no ambiente até mesmo por décadas. Para Martine \& Garcia (1987), o uso de agrotóxicos tem aumentado o número de pragas existentes ao eliminar 
inimigos naturais dessas pragas, além de envenenar insetos úteis como abelhas e polinizadores. Além disso, estudos realizados pela Anvisa entre 2001 e 2002, com vegetais destinados ao consumo humano, mostraram índices de contaminação acima do permitido em cerca de $80 \%$ das amostras analisadas.

Os danos à saúde do homem podem se manifestar de duas maneiras: como intoxicação aguda ou crônica. Na intoxicação aguda os sintomas surgem rapidamente, geralmente em até 24 horas após a exposição curta porém excessiva a produtos extrema ou altamente tóxicos (tarjas vermelha e amarela, respectivamente) e são, em geral, bem nítidos. Entre os sintomas mais comuns encontram-se espasmos musculares, náuseas, vômitos, dificuldades respiratórias e desmaios.

Já a intoxicação crônica manifesta-se tardiamente, meses ou anos após a exposição pequena ou moderada a agrotóxicos, geralmente a vários deles, e quase sempre acarreta danos irreversíveis, como neoplasias ou paralisias. É o tipo de intoxicação mais difícil de ser diagnosticada por não ter sintomas bem definidos, que se confundem facilmente com os de outras doenças.

\section{Equipamentos de proteção individual (EPI)}

É de fundamental importância que o trabalhador rural conheça os EPIs e os utilize, como forma de evitar as intoxicações por agrotóxicos. Tais equipamentos têm a função de impedir o contato do corpo com o agrotóxico, protegendo as chamadas vias de exposição. Os EPIs devem ser utilizados de acordo com o tipo de agrotóxico utilizado, sendo que cada produto tem a indicação de quais equipamentos são necessários para sua aplicação. Daí também a importância de ler os rótulos e bulas. Os principais EPIs, de acordo com a Andav (2001), são:

a) luvas: devem ser impermeáveis e têm a função de proteger as mãos, partes do corpo que mais têm contato com o agrotóxico aplicado;

b) máscaras ou respiradores: servem para evitar a inalação de partículas tóxicas, névoas e vapores orgânicos; 
c) viseira facial: têm a função de proteger olhos e rosto de possíveis respingos de agrotóxico durante o manuseio ou aplicação;

d) jaleco e calça hidrorrepelentes: são indicados para proteger o corpo de respingos de agrotóxico, mas não de jatos dirigidos de veneno;

e) boné árabe/touca árabe: protege o couro cabeludo e o pescoço de respingos, devendo ser fabricados em tecidos hidrorrepelentes;

f) capuz ou touca: tem a mesma função do boné árabe (deve ser confeccionado em não-tecido ou em tecido hidrorrepelente, sendo geralmente peça integrante de macacões ou jalecos);

g) avental: serve para aumentar a proteção durante o preparo da calda ou de eventuais vazamentos de equipamentos de aplicação costal (deve ser confeccionado em material resistente a solventes orgânicos);

h) botas: protegem os pés do contato com o agrotóxico (devem ser impermeáveis, resistentes a solventes orgânicos e, preferencialmente, de cano longo).

\section{Informações em rótulos e bulas de agrotóxicos}

Segundo Mont'Alvão (2002), o Código de Defesa do Consumidor estabelece como obrigação do fornecedor de produtos possivelmente nocivos ou perigosos informar sobre sua periculosidade ao consumidor de maneira ostensiva. No caso específico dos agrotóxicos, sua embalagem e rotulagem são regulamentadas pelo Decreto-Lei $\mathrm{n}^{\circ} 4074$, de 4 de janeiro de 2002, que determina certos requisitos que devem ser atendidos, de modo a propiciar segurança e alertar o usuário desses produtos sobre os riscos inerentes ao manejo desses produtos químicos.

Segundo o Decreto, rótulos e bulas de agrotóxicos devem conter, entre outras informações, a procedência do produto, grau de toxicidade, forma de utilização, recomendações para que a bula seja lida antes da aplicação do agrotóxico, frases de advertência e símbolos 
de perigo padronizados de acordo com sua classe toxicológica e instruções para o caso de acidentes. A figura 46 ilustra o modo como o rótulo deve ser dividido e como as informações devem ser dispostas.

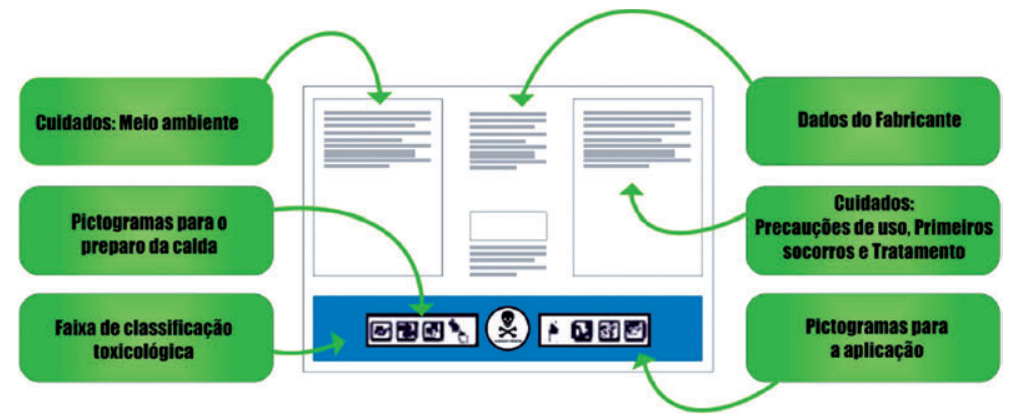

Figura 46. Divisão do rótulo em três colunas e disposição das informações segundo critérios da legislação federal de agrotóxicos. Fonte: Andef.

Os pictogramas a constarem nos rótulos devem ser internacionalmente aceitos, e têm a finalidade de facilitar a comunicação com o aplicador dos produtos, além de informar o público não-alfabetizado.

\section{Percepção do risco}

Peres et al. (2003) afirmam que os agricultores têm, ainda hoje, uma percepção distorcida sobre os riscos inerentes aos agrotóxicos. Para eles, os agrotóxicos são "remédios" ou "defensores" de suas lavouras, o que faz com que seus riscos acabem sendo minimizados ou mesmo ignorados pelos trabalhadores rurais.

Além disso, o uso contínuo e prolongado de agrotóxicos criou uma condição de familiaridade com o agricultor. Como os sintomas de intoxicação nem sempre são muito claros ou imediatos, o trabalhador acostumou-se a vê-los apenas como consequências normais da aplicação desses produtos. A familiaridade, como cita Matias (2002), traz desrespeito, ou seja, faz com que o trabalhador não se previna nem se proteja adequadamente. Outro fato citado pelo autor é que, 
de modo geral, as pessoas acreditam que correm menos riscos que as demais, ou seja, que suas ações são sempre mais cautelosas que as de outras pessoas.

Observando o número elevado de casos de intoxicação, concluise que ou os agricultores não se protegem adequadamente durante a aplicação de agrotóxicos ou não os utilizam de maneira correta. $\mathrm{O}$ fato de esses trabalhadores não compreenderem os riscos aos quais se expõem ao aplicar tais produtos demonstra que as advertências nos rótulos e bulas de agrotóxicos não têm eficácia.

Uma das causas da ineficácia das advertências pode ser, de acordo com Mont'Alvão (2002), sua veiculação de maneira evasiva. Para Matias (2002), a eficiência da advertência depende do modo como ela enfatiza as consequências ruins que podem ocorrer ao indivíduo caso ele desconsidere e deixe de seguir as precauções indicadas. Para tanto, o programador visual deve ter uma imagem clara de público-alvo.

No caso específico do trabalhador rural, suas características são bastante definidas e distintas das do homem urbano. Para Bordenave (1983) existe uma "incomunicação" entre os moradores da zona rural, causada sobretudo pelas condições sociais, pelas altas taxas de analfabetismo ou baixo nível de instrução, assim como a longa e exaustiva jornada de trabalho que atrapalha as visitas e reuniões entre vizinhos. Entretanto, como ressaltam Peres et al. (2005), não se deve menosprezar os saberes do homem do campo, julgando sua inteligência pela sua habilidade para a leitura ou pelo domínio da linguagem formal.

\section{Leitura e compreensão das informações: legibilidade do texto impresso}

Para que as informações nos rótulos e bulas de agrotóxicos sejam compreendidas, elas devem ser, antes de tudo, legíveis. Um texto difícil de ser lido é também difícil de ser compreendido, pois, segundo Iida (2005), o esforço do leitor para distinguir as palavras o atrapalha em organizar as ideias do texto. 
O processo de percepção do texto impresso pode ser descrito, segundo Heitlinger (2007), por dois temos: legibilidade (percepção visual) e readability (compreensão intelectual do texto). O primeiro termo refere-se à visibilidade, nitidez e reconhecimento dos caracteres do texto, enquanto o segundo termo refere-se à interpretação do texto, ou seja, a aquisição intelectual do texto por aquele que o lê. Além de fatores como iluminação e contraste entre o texto e a página (figura versus fundo), características próprias dos elementos tipográficos (como os caracteres numéricos e letras utilizados) influem em sua legibilidade. Assim, de acordo com Gruszynski (2000), características como desenho e tamanho da fonte, alinhamento de parágrafos e extensão da linha interferem diretamente na legibilidade do texto.

É consenso entre diversos autores que o uso de serifas facilita a leitura de textos contínuos. Para Heitlinger (2007), as serifas ajudam a agrupar as letras das palavras, fazendo o texto parecer contínuo para o leitor. Fontes mais simples também facilitam a leitura, enquanto as rebuscadas necessitam de maior tempo para serem lidas.

Com exceção dos leitores pouco experientes, costuma-se ler os textos pelo formato das palavras, e não letra por letra. Assim, Dul \& Weerdmeester (1995) afirmam ser preferível o uso de letras em caixa-baixa (minúsculas) do que em caixa-alta, pois os caracteres com ascendentes (b, d, f, h, l, t) e os com descendentes (q, g, j, p, y) se destacam e facilitam a identificação da imagem da palavra. Letras maiúsculas devem ficar restritas para nomes, abreviações e títulos, já que retardam a leitura.

O corpo, ou seja, altura da fonte utilizada, deve estar de acordo com a distância de leitura do texto. Sanders \& McCormick (1993) recomendam para materiais impressos em geral os tamanhos de fontes comumente utilizados em jornais e revistas, ou seja, algo entre 9 e $11 \mathrm{pt}$ (calculados pelos autores de 2,3 a 2,8 $\mathrm{mm}$ ).

O espaçamento entre as linhas também tem grande influência na legibilidade do texto: linhas mais longas exigem maior espaçamento entre si. De forma geral, esse espaçamento deve ser de, no mínimo, $1 / 30$ do comprimento da linha. Isso evita que a visão humana embaralhe as linhas, confundido-as. 
A divisão do texto em parágrafos facilita a leitura, segundo Iida (2005), pois evita a formação de grandes blocos de texto que se assemelham a um padrão de listras, o que poderia causar desconforto ao leitor. Para o autor, os textos justificados devem ser evitados. No caso de manuais ou bulas, quando o leitor procura informações rápidas e diretas para resolver determinadas dúvidas, o autor recomenda o uso de textos estruturados, organizados em tópicos e com subtítulos. Esse tipo de texto facilita e agiliza a consulta pelos usuários.

\section{Informações visuais: pictogramas}

"Em uma qualificação literal, o pictograma constitui-se de uma imagem ou conjunto de imagens integrantes de uma escrita sintética" (Ribeiro, 1993). Como observa Iida (2005), a grande vantagem da utilização de pictogramas é que eles superam as barreiras impostas pela linguagem escrita, podendo ser compreendidos por pessoas nãoalfabetizadas e por estrangeiros, desde que respeitadas determinadas características culturais de cada país.

Entretanto, segundo Sanders \& McCormick (1993), o uso de pictogramas só é preferido se retratar fielmente de forma visual o que pretendia. Em caso de dúvida, ainda é melhor utilizar a linguagem escrita. No caso do uso de pictogramas para o público rural, deve-se atentar para determinadas características próprias desse público. É necessário que as mensagens sejam adequadas ao seu repertório visual, já que alguns códigos pictóricos normais para o homem urbano são estranhos ao homem do campo.

Bordenave (1983) destaca certas características próprias da percepção do homem do campo, algumas relacionadas a populações com baixo grau de escolaridade:

a) Grau de detalhe: traços em excesso ou em falta diminuem a compreensão da figura.

b) Figuras descarnadas: figuras descarnadas não diminuem a compreensão e identificação da figura apresentada. 
c) Familiaridade: a presença de objetos familiares ao agricultor facilita a identificação da figura, devendo-se considerar, portanto, as diferenças culturais e regionais: para certas regiões, por exemplo, o paiol de arameé mais comum que o de madeira.

d) Interpretação literal: Bordenave (1983) afirma que o agricultor tende a interpretar literalmente o que vê, tendo certa dificuldade para perceber o sentido figurativo de certas imagens.

e) Tratamentos imaginativos: a humanização ou personificação de objetos ou animais pode gerar confusões no público rural, sendo preferível utilizar imagens mais realistas.

f) Tamanho real versus magnificação: a modificação ou aumento do tamanho de um objeto ou animal conhecido pelo agricultor pode confundi-lo.

g) Leitura da perspectiva: geralmente aprende-se a decodificar a perspectiva ainda na infância, dentro das escolas. Portanto, indivíduos não-alfabetizados podem ter dificuldade em ver os planos e compreender as diferenças de tamanho próprias da representação da perspectiva.

h) Quadro individual versus série: a apresentação de informações em sequência de imagens aumenta a compreensão.

Analisando esses fatores apresentados por Bordenave (1983), percebe-se que a comunicação para o público rural necessita de maior cautela e um profundo conhecimento das características culturais e dos costumes regionais da população à qual se destina.

\section{Material e métodos}

\section{Material}

Para a análise dos rótulos e bulas, foi elaborada uma tabela de verificação contendo todas as exigências dos anexos VIII e IX do Decreto Lei $\mathrm{n}^{\circ} 4074$ de 4 de janeiro de 2002 que dispõem sobre a rotulagem de agrotóxicos e conteúdo das bulas. Também foi criada uma tabela 
de avaliação das características tipográficas e da legibilidade dos rótulos e bulas, segundo dados obtidos no levantamento bibliográfico.

Para a pesquisa de campo foi elaborado um questionário com perguntas pertinentes à utilização de agrotóxicos, visando identificar problemas na compreensão e na leitura das informações contidas nos rótulos e bulas.

\section{Métodos}

\section{Análise dos rótulos e bulas de agrotóxicos}

De modo a avaliar o cumprimento da legislação vigente, foram estudados rótulos de algumas embalagens de agrotóxicos utilizados na cultura da soja, sendo observados todos os critérios exigidos nos anexos VIII e IX do Decreto-Lei n ${ }^{\circ} 4074$ de 4 de janeiro de 2002, entre eles a distribuição das informações no rótulo e sua divisão em colunas, e o tamanho dos pictogramas e dimensões da faixa da classificação toxicológica. Assim, foram analisados os rótulos dos seguintes produtos: Roundup, da Monsanto; Galgotrin e Metafós da Milenia Agro Ciências; Podium, Attach, Folicur e Nativo, todos da Bayer Cropscience.

Já as bulas avaliadas foram as dos agrotóxicos: Assist, da Basf; Roundup, da Monsanto; Nativo e Podium, da Bayer Cropscience; Metafós, da Milenia Agro Ciências.

Foram criadas e aplicadas duas tabelas: uma para avaliar todas as características constantes no Decreto-Lei n 4074 , e outra para verificar a legibilidade dos caracteres tipográficos e textos constantes em rótulos e bulas de agrotóxicos.

\section{Pesquisa de campo}

Para avaliar a compreensão e leitura das informações contidas em rótulos e bulas de agrotóxicos foi aplicado um questionário formulado essencialmente com perguntas abertas, que possibilitavam que o 
entrevistado se expressasse livremente. Foi utilizada uma linguagem simples, permitindo uma maior aproximação do público entrevistado e evitando possíveis problemas de compreensão.

Além dessas questões, foram apresentados 16 pictogramas, em cor preta sobre fundo branco, em dimensões de $2 \times 2$ centímetros, ou seja, maior que o tamanho em que tais elementos são apresentados nos rótulos de agrotóxicos.

Como amostra para a pesquisa, foram selecionados agricultores do distrito de Warta, município de Londrina, estado do Paraná. O desenvolvimento dessa região ocorreu devido à cafeicultura, sendo que o município de Londrina chegou a ser um dos maiores produtores mundiais de café. Atualmente, a população local dedica-se ao cultivo de trigo, milho e principalmente soja. A população do distrito de Warta é de cerca de 1.500 pessoas: 930 na área urbana (64\%) e 570 na zona rural (38\%).

Como o presente trabalho propõe-se a avaliar problemas na compreensão e leitura de rótulos e bulas de agrotóxicos, somente a população rural, que tem contato com tais produtos, foi estudada. Dessa forma, partiu-se de um universo de 570 pessoas, moradores da zona rural do distrito de Warta, do qual foi extraída uma amostra de cerca de $5 \%$, ou seja, trinta entrevistados.

A condição para a escolha dos entrevistados, além de residirem no distrito, era que cultivassem soja com a utilização de agrotóxicos. Não era necessário que o entrevistado aplicasse pessoalmente o agrotóxico, mas sim que conhecesse os agrotóxicos utilizados e fosse trabalhador rural.

\section{Resultados}

\section{Resultados das análises de rótulos e bulas}

Dentre os sete rótulos analisados, três não apresentavam os pictogramas exigidos. Dentre estes últimos, um não continha a faixa de classificação toxicológica, que havia sido substituída, provavelmente 
por questões estéticas, por uma linha da cor correspondente à classe toxicológica à qual o produto pertencia, contornando todo o texto do rótulo. Nos outros dois rótulos, a classificação toxicológica descrita no rótulo não correspondia à cor apresentada, ou seja, a cor estava correta, mas o produto era descrito como sendo de uma classe de menor toxicidade (figura 47).

\section{CUIDADO VENENO MEDIANAMENTE TÓXICO CUIDADO VENENO
MEDIANAMENTE TÓXICO}

Figura 47. Rótulo sem pictogramas e com classificação toxicológica incorreta.

Em todos os demais rótulos analisados, os pictogramas tinham altura menor que $50 \%$ da altura da faixa de classificação toxicológica. Em três desses rótulos, as faixas de classificação toxicológica eram maiores do que o exigido no modelo apresentado pela legislação federal de agrotóxicos. Dessa forma, os pictogramas teriam a proporção adequada se comparados à altura do rótulo, porém seriam desproporcionais à altura da faixa de classificação.

Outro problema encontrado em quatro dos rótulos analisados foi quanto ao diâmetro do círculo do pictograma que representa a frase: "cuidado veneno". O círculo deveria ter diâmetro de tamanho igual à altura da faixa de classificação toxicológica, mas nesses três rótulos analisados ele é apresentado menor do que deveria ser (figura 48).

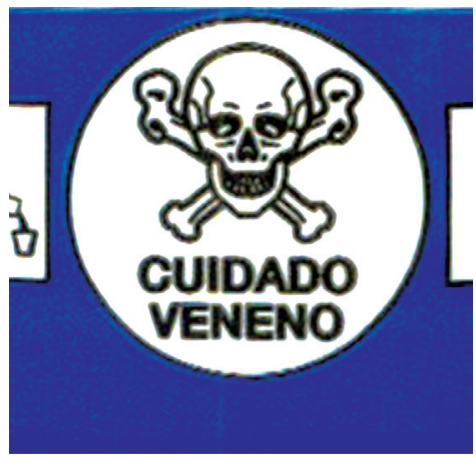

Figura 48. Círculo com diâmetro menor que a altura da faixa azul de classificação toxicológica. 
Em dois dos rótulos analisados, os dizeres "cuidado veneno", que deveriam estar posicionados dentro do círculo com o desenho de uma caveira com duas tíbias cruzadas, estavam fora do mesmo (figura 49).

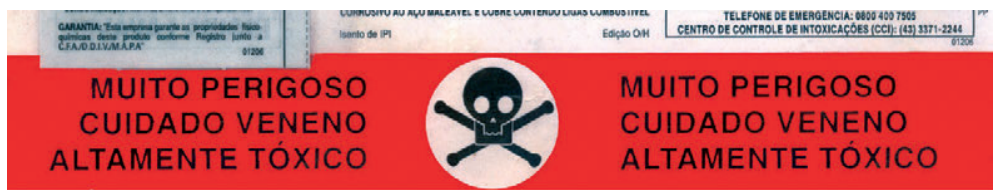

Figura 49. Texto "cuidado veneno" fora do círculo com o desenho de uma caveira com duas tíbias cruzadas.

Quanto às características tipográficas e à legibilidade dos textos em rótulos e bulas, todos os impressos analisados apresentavam fontes em tamanho menor que o indicado. Além disso, frequentemente eram utilizadas fontes sem serifa para textos contínuos, além de frases inteiras grafadas em caixa-alta, o que dificulta a leitura do texto, tornando-a mais lenta.

No aspecto do cumprimento das exigências da legislação federal de agrotóxicos, os problemas encontrados nas bulas foram a falta de informações, como o método de desativação (não constava em quatro das cinco bulas analisadas), efeitos adversos (faltou em duas das bulas), mecanismos de ação e absorção, efeitos agudos e crônicos e informações em caso de acidente no transporte (que faltaram todas numa mesma bula analisada).

Os maiores problemas nesses impressos concentraram-se na legibilidade dos textos e na distribuição das informações, sendo que informações diversas eram agrupadas, quando o desejável seria que fossem agrupadas apenas as informações semelhantes, como forma de facilitar a consulta da bula pelo leitor.

\section{Resultado da pesquisa de campo}

Dentre os agricultores entrevistados, $97 \%$ eram do sexo masculino, o que pode ser compreendido pelo fato de tarefas como aplicar 
ou mesmo lidar com agrotóxicos serem tidas como atividades masculinas. Dos entrevistados, $27 \%$ tinham entre 51 e sessenta anos, 26\% tinham entre 31 e 40 anos e $17 \%$ tinham entre 41 e 50 anos. Cerca de $50 \%$ dos entrevistados estavam na faixa etária compreendida entre 20 e 49 anos, que, de acordo com o Sinitox, abrange o maior número de casos de intoxicação.

Observou-se que dentre os entrevistados, $41 \%$ não tinham concluído o ensino fundamental, 17\% tinham ensino médio completo, $20 \%$ tinham terceiro grau completo e $3 \%$ não eram alfabetizados.

Os agrotóxicos mais citados pelos agricultores foram os herbicidas (37\%), seguidos dos inseticidas (33\%) e fungicidas (20\%). Tais dados obtidos reforçam os números fornecidos pelo Sindag, que colocam os herbicidas como a categoria mais comercializada no país em 2002.

Dentre os produtos mais citados, apesar dos da classe toxicológica III serem os mais utilizados, a divisão entre tais classes foi bastante equilibrada: $47 \%$ eram das classes I e II (extremamente tóxico e altamente tóxico, respectivamente), que são as que agrupam os produtos que oferecem maior perigo à saúde do trabalhador, e 53\% eram das classes III e IV (medianamente tóxico e pouco tóxico, respectivamente), como mostra a figura 50 .

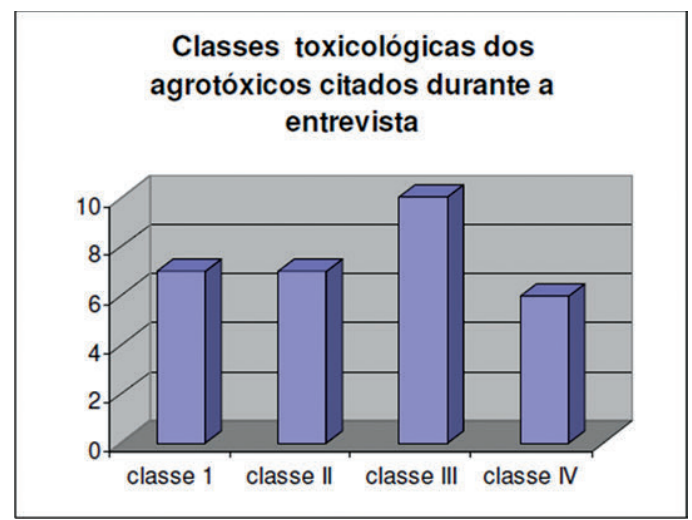

Figura 50. Classes toxicológicas dos agrotóxicos citados pelos entrevistados como sendo os mais utilizados. 
Quando questionados sobre a frequência de leitura de rótulos e bulas, a maioria dos entrevistados declarou ler frequentemente ambos os impressos (47\% e 43\%, respectivamente). Apenas $13 \%$ afirmaram nunca ler os rótulos e $17 \%$ disseram nunca ler as bulas. Contudo, o fato de o entrevistado afirmar ler não significa que ele compreenda as informações contidas nesses impressos. Trabalhos semelhantes realizados com agricultores apontaram que, apesar de eles afirmarem compreender as informações nos rótulos, poucos realmente conseguiam identificar termos apresentados nesses impressos.

Dos entrevistados, $57 \%$ afirmaram não encontrar problemas na leitura de rótulos e bulas. Dentre os $43 \%$ restantes, as dificuldades mais citadas foram as seguintes (em ordem decrescente): o tamanho muito reduzido das fontes utilizadas nos textos, o nível técnico dos mesmos (citado pelos agricultores como muito complicado), a complexidade das figuras (muito difíceis de serem compreendidas) e seu tamanho reduzido. É interessante lembrar que a porcentagem de indivíduos, entre os entrevistados com mais de cinquenta anos, corresponde a quase $45 \%$. Certamente a idade é um fator que interfere na acuidade visual, prejudicando a leitura de informações em pequenas dimensões.

Quando questionados sobre as classes toxicológicas, 83\% dos entrevistados afirmaram conhecer a classificação toxicológica e as cores correspondentes a cada classe. Contudo, menos da metade dos entrevistados (43\%) foi capaz de acertar a sequência completa de cores, como mostra a figura 51 .

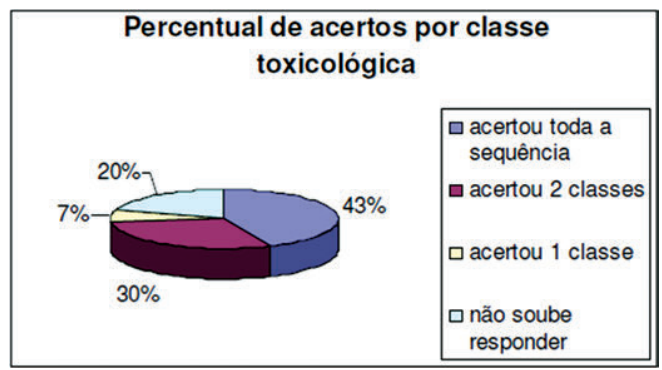

Figura 51. Percentual de acertos por classe toxicológica. 
Para avaliação dos pictogramas, foram apresentados 16 pictogramas a cada entrevistado, pedindo que ele identificasse todos os pictogramas cujo significado soubesse. Os pictogramas apresentados são os mostrados na figura 52 .

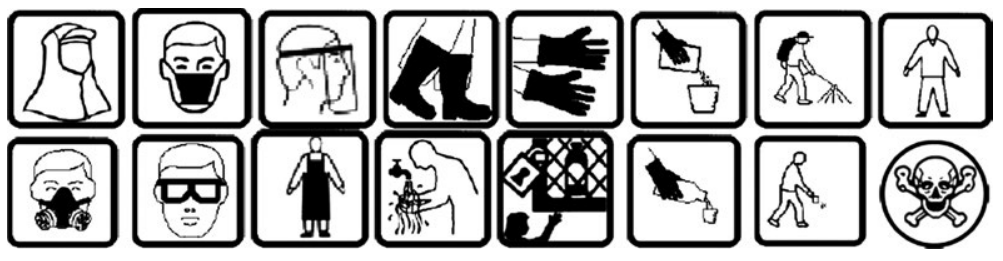

Figura 52. Pictogramas apresentados aos entrevistados.

$\mathrm{Na}$ ordem em que aparecem na figura, da esquerda para a direita, seus significados são: uso de boné árabe, respirador, viseira facial, botas, luvas, manuseio de formulações sólidas, aplicação de formulações líquidas, macacão impermeável, respirador com filtros, óculos de proteção, avental impermeável, lave-se após aplicar agrotóxico, mantenha trancado e fora do alcance de crianças, manuseio de formulações líquidas, aplicação de formulações sólidas, cuidado veneno.

Dentre esses, os pictogramas da figura 53 apresentaram baixos índices de compreensão pelos entrevistados.

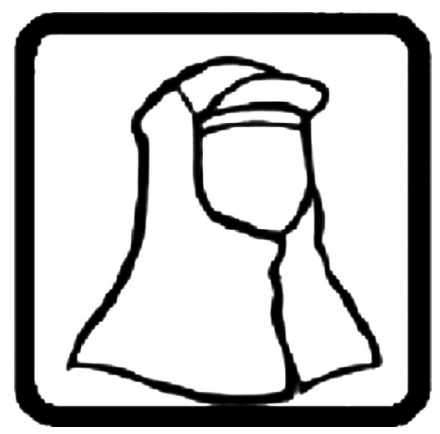

Figura 53. Boné árabe. 
O pictograma representado na figura 53 indica a necessidade de uso de boné árabe. Não foi corretamente identificado por 34\% dos entrevistados. Além disso, o nome correto desse EPI foi lembrado apenas por $10 \%$ dos entrevistados, sendo que outros $10 \%$ souberam indicar a função correta do EPI, mas não seu nome.

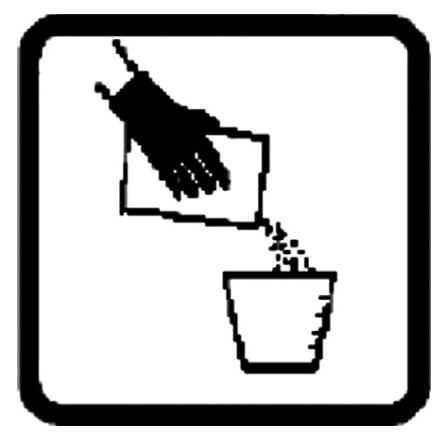

Figura 54. Manuseio de formulações sólidas.

O pictograma representado na figura 54 demonstra o modo de manuseio de formulações sólidas. Dos entrevistados, 23\% não soube dizer seu significado.

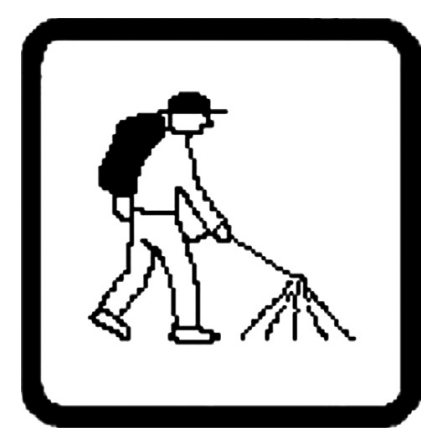

Figura 55. Aplicação de formulações líquidas.

A figura 55 designa o modo de aplicação de formulações líquidas. Esse pictograma foi identificado por menos da metade dos entrevistados (41\%), mesmo representando um equipamento bastante familiar 
aos agricultores (a bomba costal). Alguns entrevistados entenderam a figura de forma oposta, entendendo-a como se representasse um trabalhador aplicando veneno sem proteção.

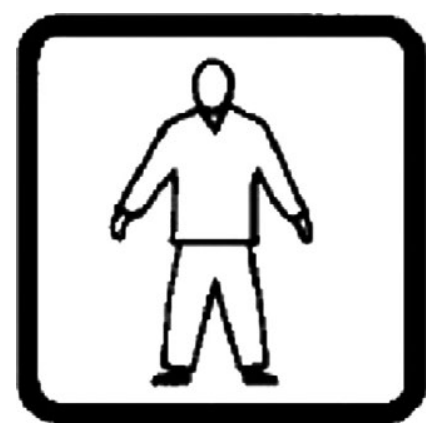

Figura 56. Macacão impermeável.

A figura 56 indica a necessidade de uso de macacão impermeável. Dos entrevistados, 41\% não souberam defini-lo e outros $16 \%$ definiram-no de maneira errada.

A figura 57 foi identificada pela maioria dos entrevistados apenas como "lave as mãos". O pictograma não esclarece a ação esperada, e a imagem da torneira corrobora isso. Se a ação correta é "tomar banho", provavelmente a imagem de um chuveiro seria mais indicada.

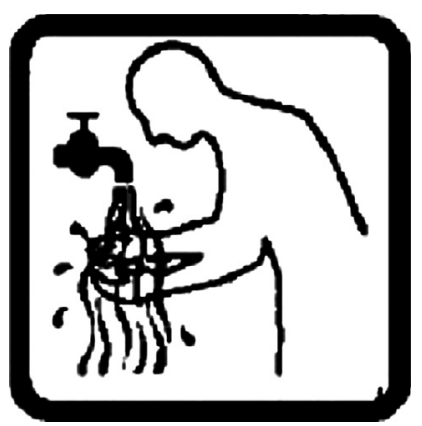

Figura 57. Lave-se após o uso de agrotóxicos. 


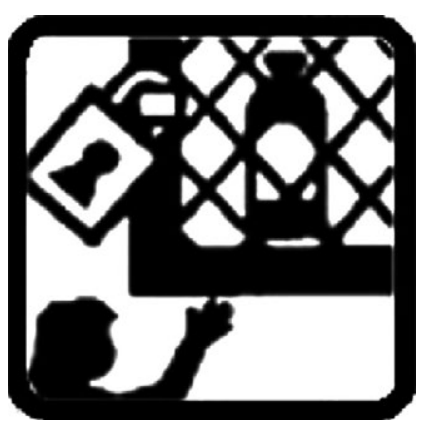

Figura 58. Mantenha em local trancado e fora do alcance de crianças.

Grande parte dos entrevistados não percebeu a imagem da criança representada na parte inferior esquerda da figura 58 , que foi percebida por apenas $27 \%$ deles. Nenhum entrevistado definiu de maneira integral esse pictograma: ou entenderam-no como guardar fora do alcance de crianças, ou apenas como guardar o agrotóxico em local seguro/trancado.

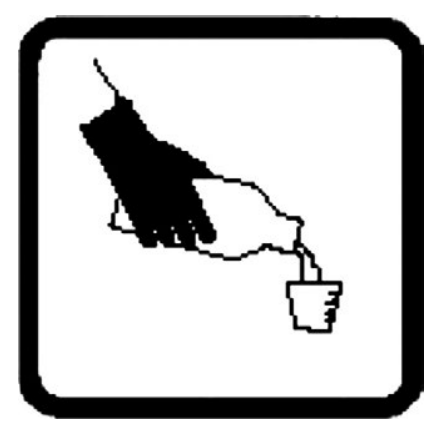

Figura 59. Manuseio de formulações líquidas.

O pictograma representado na figura 59 foi corretamente identificado por apenas $7 \%$ dos agricultores entrevistados. Outros 20\% não souberam responder e todos os demais deram definições erradas para a figura. 


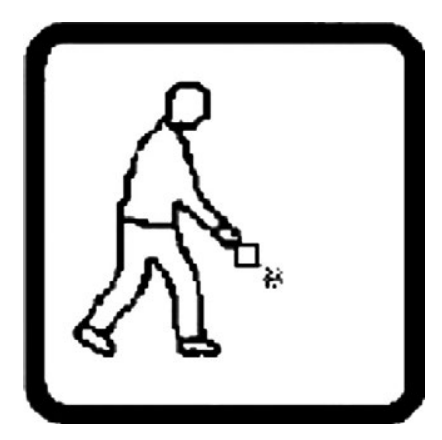

Figura 60. Aplicação de formulações sólidas.

O pictograma representado na figura 60 foi o que obteve menor índice de compreensão, sendo que $82 \%$ dos entrevistados não souberam identificá-lo. Os 12\% restantes identificaram-no de maneira incorreta.

\section{Conclusão e recomendações}

De acordo com os dados obtidos na pesquisa de campo, no levantamento bibliográfico e na análise de rótulos e bulas de agrotóxicos, conclui-se que apesar de a maioria dos agricultores entrevistados ler os rótulos e bulas de agrotóxicos, a compreensão desses impressos ainda é problemática. O uso de cores na classificação toxicológica é ineficaz, sendo que certas classes são comumente confundidas entre si. As dimensões dos pictogramas e das fontes dos textos dificultam sua visualização e são apontadas pelos entrevistados como os maiores problemas nos rótulos e bulas. Além disso, metade dos pictogramas analisados mostrou-se ineficaz, sendo interpretados de maneira errônea pela maioria dos agricultores pesquisados.

A tendência à interpretação literal, característica dos agricultores com menor grau de instrução, interferiu na compreensão de determinados pictogramas, fazendo com que parte dos entrevistados não percebesse o significado real de certos pictogramas. 
Observou-se que o grau de escolaridade interfere diretamente na compreensão das informações, tanto escritas como visuais. Os textos, termos e pictogramas apresentados foram mais facilmente entendidos e definidos por indivíduos com mais anos de estudo.

Quanto à avaliação gráfica dos rótulos e bulas, todos os impressos analisados apresentaram fonte em corpo menor que o recomendado, além do uso excessivo de caixa-alta, gerando problemas na leitura do texto e da imagem da palavra. A minimização dos riscos inerentes ao manuseio de agrotóxicos e o desconhecimento de informações importantes, como a classificação toxicológica dos produtos, tornam o agricultor vulnerável e propenso a danos à sua saúde e ao meio ambiente.

Percebe-se, portanto, que as informações em rótulos e bulas de agrotóxicos ainda são ineficazes para seu público. Ignoram características físicas, culturais e os saberes do agricultor, de forma que ou a comunicação com ele não se estabelece, ou torna-se ineficiente. Dessa maneira, conclui-se que diversos itens nos rótulos e bulas de agrotóxicos devem ser modificados, como forma de garantir a leitura e a compreensão dos mesmos e, consequentemente, possibilitar uma maior segurança no manejo desses produtos.

\section{Referências bibliográficas}

ANDAV.Associação Nacional dos Distribuidores de Defensivos Agrícolas eVeterinários. Manual do uso correto e seguro de produtos fitossanitários/ agrotóxicos. 2001. Disponível em: http://www.andav.com.br/. Acesso em: 24 jan. 2006.

BORDENAVE, J. E. D. O que é comunicação rural. São Paulo: Brasiliense, 1983. 104p. (Primeiros Passos)

BRASIL. Decreto-Lei ${ }^{\circ} 4074$, de 4 de janeiro de 2002. Regulamenta a Lei ${ }^{\circ}$ 7.802, de 11 de julho de 1989, que dispõe sobre a pesquisa, a experimentação, a produção, a embalagem e rotulagem, o transporte, o armazenamento, a comercialização, a propaganda comercial, a utilização, a importação, a exportação, o destino final dos resíduos e embalagens, o registro, a classificação, o controle, a inspeção e a fiscalização de agro- 
tóxicos, seus componentes e afins, e dá outras providências. Disponível em: http://www.sindag.com.br. Acesso em: mar. 2007.

BUENO, W. C. Veneno no prato, açúcar na pauta: a comunicação a serviço do lobby dos agrotóxicos. Conferência Brasileira de Comunicação e Saúde-2004, IV, 2004. Disponível em: http://www.scielosp.org. Acesso em: set. 2006.

DUL, J., WEERDMEESTER, B. Ergonomia prática. São Paulo: Edgard Blücher, 1995.

GRUSZYNSKI, A. C. Do invisível ao ilegível. Rio de Janeiro: 2AB, 2000. 116p.

HEITLINGER, P. Legibilidade do texto impresso. Cadernos de Tipografia n.3, 2007. Disponível em: http://tipografos.net/cadernos/cadernos-3. pdf. Acesso em: 15 nov. 2007.

IIDA, I. Ergonomia: projeto e produção. 2.ed. São Paulo: Edgard Blücher, 2005.

LUNA, A. J., SALES, L. T., SILVA, R. F. Agrotóxicos: responsabilidade de todos (uma abordagem da questão dentro do paradigma do desenvolvimento sustentável). Disponível em: www.prt6.mpt.gov.br/forum/ downloads/Artigo1_Adeilson.doc. Acesso em: maio 2006.

MARTINE, G., GARCIA, R. C. Os impactos sociais da modernização agrícola. São Paulo: Caetés, 1987.

MATIAS, N. T. Sinalização de segurança: efetividade e credibilidade das fontes de informação. Avisos, advertências e projeto de sinalização. Rio de Janeiro: 2AB, 2002. p.75-111.

MONT'ALVÃO, C. Design de advertência para embalagens. 2.ed. Rio de Janeiro: 2AB, 2002. 48p.

PERES, F., MOREIRA, J. C., DUNOIS, G. S. É veneno ou é remédio? Agrotóxicos, saúde e ambiente. Rio de Janeiro: Fiocruz, 2003.

PERES, F. et al. Desafios ao estudo da contaminação humana e ambiental por agrotóxicos. Ciência e Saúde Coletiva. v.10, Rio de Janeiro, 2005. Disponível em: http://www.scielo.br/scielo. Acesso em: out. 2006.

RIBEIRO, M. Planejamento visual gráfico. 3.ed. Brasília: Linha, 1993. p.47-79.

SANDERS, M. S., McCORMICK, E. J. Human factors in engineering and design. 7a.ed. Nova Iorque: McGraw-Hill, 1993. Educação GráficaEdição Especial 200864

SANTOS, J. E. G. Agrotóxicos: segurança das operações desenvolvidas por trabalhadores rurais e aplicadores na realização do controle fitossanitário 
das culturas de café (coffea arabica), laranja (citrus máxima (burn) merril), abacaxi (ananás comosus l. Merril), tomate (licopersicum esculentum mill) e cana-de-açúcar (sacharum officinarum) no centro-oeste paulista. Bauru, 2003. Tese (Livre-docência) - Faculdade de Engenharia de Bauru, Universidade Estadual Paulista.

VAGNER, A. B., FIGUEIRA, A. V. O. Segurança ambiental. Biotecnologia e meio-ambiente. Viçosa: UFV, 2004. 


\title{
10 \\ ANÁLISE ERGONÔMICA DO COLETE À PROVA DE BALAS PARA ATIVIDADES POLICIAIS
}

\author{
Iracilde Clara Vasconcelos ${ }^{1}$ \\ Luiz Gonzaga Campos Porto ${ }^{2}$
}

\section{Introdução}

\section{Justificativa}

Os representantes da ordem constituída, incluindo os policiais, não recebem mais o respeito de épocas passadas, em que a simples presença do policial fardado acalmava os ânimos e garantia a ordem pública. Hoje, o cenário é muito diferente, estamos vivendo em um período de perda ou quase inexistência de referências essenciais que evidenciem um equilíbrio na convivência social.

Esse estado de desequilíbrio e desordem pública em que a sociedade e a polícia se encontram tem situado a violência no cerne da vida cotidiana, ocupando destaque nos jornais e programas televisivos especiais, gerando um profundo sentimento de insegurança (Chesnais, 1996), situação em que, invariavelmente, o policial não passa incólume em um enfrentamento armado, tendo, muitas vezes, que se expor a perder a vida em conflitos armados, caracterizando o alto risco epidemiológico dessa atividade (Santos, 1997).

1 Mestre em design, Universidade Estadual Paulista.

2 Livre-docente, Universidade Estadual Paulista. 
Essa composição de insegurança, uma psicose coletiva que atinge diretamente os profissionais de segurança pública, necessita de ações que objetivem romper esse círculo vicioso, considerando que violência gera o medo, mas o medo também gera violência. Segundo Fraga (2005), pouca atenção tem se dado à saúde ocupacional do profissional de segurança pública, especialmente aos policiais militares, embora a temática - saúde do trabalhador - tenha destaque nas diversas áreas que englobam Gestão de Segurança e Saúde Ocupacional. Estudos quanto à segurança pública geralmente dão ênfase aos aspectos técnicos da profissão, com pouca importância quanto à segurança do trabalho, quadro diferente em relação a países como França e Estados Unidos, onde, exemplarmente, se verifica a presença constante de pesquisadores e especialistas universitários voltados para a produção de soluções na área de segurança (Martins, 2007).

O desempenho do papel de profissional de segurança pública ocorre num ambiente violento, de riscos e tensões, levando os profissionais de segurança pública a receber uma sobrecarga emocional, fatigante e desconfortável, em situações adversas e estressantes. Com o aumento da criminalidade, até mesmo nas pequenas cidades, os confrontos diretos com criminosos têm-se tornado frequentes, devendo o Estado priorizar investimentos em equipamentos de segurança. Entre tantos, destacamos equipamentos de proteção individual, de interesse específico, neste capítulo, o colete à prova de balas, que passou a ser difundido no Brasil a partir da segunda metade da década de 1980. Embora não haja dúvidas em relação a sua eficácia, ele é alvo de frequentes reclamações em relação ao desconforto, excesso de peso, calor, e outros argumentos facilmente derrubados pela proteção que ele oferece.

O progresso tecnológico, um processo inexorável, vem contribuindo para aliviar o trabalho físico do homem com o crescente aumento da produtividade e qualidade dos produtos e serviços, provocando gradativamente o deslocamento da atividade humana para tarefas que as máquinas serão capazes de realizar.

Embora a evolução tecnológica aplicada à atividade policial seja primordial no combate à criminalidade, nesse setor o profissional 
executante operacional não foi nem será dispensado; ao contrário, deve-se investir substancialmente no aumento do contingente e em suas condições de trabalho.

No estado de São Paulo atuam hoje cerca de 130 mil policiais civis e militares. É evidente que, dentro desse contingente, tem aumentado a quantidade de mortos e feridos por armas de fogo ou cortantes, muitas vezes porque os policiais não estão equipados com elementos de segurança que possam protegê-los, como, por exemplo, os coletes à prova de balas, equipamento imprescindível aos profissionais de segurança, expostos pelas condições de trabalho a disparos de armas de fogo, facadas ou golpes. Desde 6 de dezembro de 2006, a Portaria 191 do Ministério do Trabalho e Emprego (MTE) regulamentou o colete à prova de balas como um Equipamento de Proteção Individual (EPI).

Com a nova regulamentação da legislação trabalhista, até 2011, todos os trabalhadores da segurança pública deverão obrigatoriamente possuir e estar treinados para o uso de coletes à prova de balas para protegerem-se dos riscos de sua profissão. Os coletes deverão ser de uso individual, por uma questão de higiene, e levando em consideração a compleição física de cada usuário e a durabilidade do produto.

\section{Objetivos}

Sabe-se, por meio de trabalhos científicos com abordagens metodológicas multidisciplinares, que o desempenho das atividades policiais apresenta maior tendência para as experiências de sofrimento, de fadiga e de estresse. Nesse contexto, vê-se que no desempenho da atividade policial, os profissionais, além de desenvolverem suas atividades em condições de sobrecarga física e mental, usam equipamentos de proteção individual que são objetos de reclamações pelo excessivo desconforto, agravado pela fadiga e estresse, características peculiares à atividade e, ainda, intensificado pelas altas temperaturas tropicais, além da zona de conforto térmico, caracterizando fatores que influenciam no seu desempenho, ocupando, portanto, um lugar de destaque (Iida, 2005). 
Procurou-se entender e demonstrar os possíveis problemas existentes no uso de equipamentos de proteção individual dos profissionais de segurança pública no desempenho da sua função por uma abordagem ergonômica, estudando, à luz dessa concepção, os coletes à prova de balas, relacionando as queixas frequentes em relação ao conforto e usabilidade por parte desses profissionais, identificando os problemas referentes ao uso, visando atender à necessidade do usuário, seu conforto, sem desconsiderar os parâmetros de segurança, de fundamental importância, peculiar à atividade policial, exaltando parâmetros ergonômicos em projetos de produtos, técnicas operacionais para controle e prevenção de acidentes e doenças ocupacionais; enfim, implantando e consolidando conceitos de segurança do trabalho na atividade policial.

\section{Revisão da literatura}

\section{Atividade policial}

A atividade policial é caracterizada pela diversidade de ações executadas durante as situações com as quais ela tem de lidar, tanto que seu papel é até confundido, colocando o policial a conviver durante sua jornada de trabalho com muitos imprevistos e perigos, submetendo seu corpo a condições fatigantes. Além disso, não possui horário fixo de trabalho, concorrendo a variadas escalas de serviço, diurnas ou noturnas, sem diferença para finais de semana ou feriados.

O trabalho policial é solicitado a toda e qualquer ocorrência, seja por iniciativa própria, seja por solicitação ou determinação superior (Monjardet, 2002). E, em função de suas atividades, do meio ambiente em que se encontra e das condições organizacionais que são impostas a essa atividade, são solicitados do corpo do policial diferentes sistemas, aparelhos e órgãos. Segundo Piva (2005) e Bayler (2001), o policial, ao entrar para a corporação, oferece seu corpo à instituição, que o profissionaliza, podendo culminar na disposição em ofertar a própria vida numa missão policial e, ainda, invariavelmente, 
o submete ao cansaço e à fadiga e ao consequente aparecimento de doenças ou agravamento de outras preexistentes.

No policiamento, os processos de locomoção mais utilizados são o motorizado e a pé e, eventualmente, montado, aéreo e em embarcações. Entretanto, em todas as situações, o policial expõe seu corpo a situações desfavoráveis, trabalha em terrenos irregulares, cubículos, temperaturas anormais, em tráfego intenso, enfim, em inúmeras situações que, invariavelmente, exigem do policial rapidez, percepção, prudência, observação, memória, concentração e precisão física e psicológica (Velho, 1994; Silveira, 1997 apud Rodriguez-Añez, 2003).

Simões cita que a atividade policial é praticada

sob iluminação deficitária (originando desconforto visual e dificuldade de atuação), como também atua no tráfego intenso de veículos e/ou pedestres, submetendo-se à ruídos constantes (o que causa interferência direta nas suas atividades cognitivas, além de fisiologicamente causar o aumento da produção dos hormônios que são considerados "hormônios de estresse", taquicardia, alterações no sono - mesmo horas após ao contato com o ruído, desconforto, exasperação, indisposição, ansiedade e depressão) e a produtos químicos (inspirando fumaças, gases e vapores tóxicos, exigindo a capacidade máxima do pulmão para oxigenar o sangue). (2003)

Além disso, o policial pode sofrer agressões físicas, ataques por objetos cortantes e perfurantes (projétil de arma de fogo) e, sobre todos os aspectos, os incidentes em tiroteio com armas de fogo são reconhecidos como os mais traumatizantes para o policial.

E ainda, o policial, durante sua jornada de trabalho, carrega vários equipamentos que, em geral, são: arma de porte, algemas, rádio HT, cassetete e bolsa com bloco de infrações, que pesam em torno de 2,10 kg. Além disso, o peso dos coletes balísticos varia em torno de 1,6 kg a 2,6 kg os masculinos e 1,1 kg a 1,8 kg os femininos, o que dependendo da condição física do policial pode ser um fator limitante para o bom desempenho de suas atividades, e assim colaborar para o aparecimento de sinais de cansaço, dores nos membros inferiores e nas costas (Simões, 2003). 
Esse meio laboral exige do policial o máximo de sua coordenação motora e dos seus músculos, com movimentos rápidos, ágeis e precisos em ações como correr, pular, puxar, carregar pesos, levantar ou caminhar rapidamente.

Em pesquisa específica sobre Qualidade de Vida no Trabalho de Policiais Militares da Região Metropolitana do Recife, Asfora (2004) constatou que $60 \%$ dos policiais entrevistados consideram o estresse do dia a dia elevado ou excessivo. A mesma autora aborda que níveis muito altos de estresse podem causar problemas mentais e psicológicos, doenças ou predisposições a doenças.

Estudando-se os policiais como trabalhadores, observa-se a falta de atenção específica à sua saúde, assim como aos demais profissionais do setor-serviço (Souza \& Minayo, 2005). Reis (2006) considerou que as regras de Medicina e Segurança do Trabalho não atendem, com a devida profundidade, à realidade dos serviços da Polícia Militar e, em relação às Normas Regulamentadoras, o autor colabora, sugerindo a implantação de normas específicas para a atividade policial, já que, pelo seu estudo, ele conclui sobre a necessidade de regras apropriadas que deem ênfase à aplicação de mecanismos capazes de aliviar e minimizar principalmente os efeitos do estresse, além de outros fatores psíquicos decorrentes do contato intensivo com mazelas humanas e, também, pelo confronto armado, muitas vezes tirando a vida de outro ser humano.

\section{Ergonomia e design ergonômico}

Por tudo, o autor enfatiza a aplicação de princípios de ergonomia e, abordando a relação entre saúde ocupacional e produtividade, conclui que essa ligação

incorpora elementos que consideram o elemento humano como o principal fator que torna possível a produção de serviços. Assim, pensar em eficiência das organizações policiais implica em atentar para as condições de preservação da saúde e de prevenção contra a perda da saúde dos policiais. (idem) 
Contudo, o gerenciamento da saúde ocupacional do policial militar com ações focadas que ponderem os fatores de riscos advindos da atividade policial, além de reverter em seu bem-estar, reverte em expressivas melhoras nas consequências individuais e organizacionais, abrangendo grande importância do interesse público, pois, para o cumprimento do dever junto à sociedade, o policial depende de sua saúde de forma intrínseca, ao velar pela paz social.

Considerando que a contribuição ergonômica não se limita à análise das situações conhecidas e à exposição de recomendações visando apontar modificações dos meios de trabalho (ergonomia de correção), enfatiza-se que essa disciplina também tem fundamental importância na fase inicial de projeto do produto e dos meios de trabalho, fundamentando-se no conhecimento sobre o homem, na atividade de trabalho que será desenvolvida, e em situações hipotéticas, buscando-se a análise da situação de referência (ergonomia de concepção). Portanto, a contribuição ergonômica, nas várias etapas da fase inicial do projeto do produto, da máquina ou do ambiente, poderá propor, além de novos produtos, novos meios de trabalho, prevenindo problemas futuros e, ainda, intervir na melhoria do ambiente de trabalho (Iida, 2005), proporcionando ao usuário prazer, bem-estar, relaxamento e conforto, visando atender a esses quesitos e usuários mais exigentes, mercados mais competitivos, exigências normativas mais rigorosas. Além disso, inovações tecnológicas mais frequentes apresentam o denominado design ergonômico definido como "a aplicação do conhecimento ergonômico no projeto de dispositivos tecnológicos, com o objetivo de alcançar produtos e sistemas seguros, confortáveis, eficientes, efetivos e aceitáveis" (Paschoarelli, 2003).

Para atender a essa demanda tão presente neste início de século, deve-se considerar no desenvolvimento de projeto de produto aspectos de usabilidade, conforto, desempenho e segurança. Segundo Paschoarelli \& Silva (2006), o design ergonômico possui alternativas metodológicas criadas para melhorar o desenvolvimento dos produtos por meio da análise da interação entre o homem e os produtos ou dispositivos tecnológicos, e o desenvolvimento de procedimentos metodológicos de avaliação e análise do produto deve apresentar uma abordagem científica que atenda aos aspectos ergonômicos e, assim, 
considere as capacidades e as limitações do ser humano, e nesse processo agregue aos produtos propriedades que garantam máxima segurança, funcionalidade e usabilidade.

Os mesmos autores contribuem complementando que o design ergonômico deve fundamentar-se em abordagens epidemiológicas, abrangendo conhecimentos fisiológicos, perceptivos e psicológicos na interface homem versus tecnologia, em um processo trans e multidisciplinar e, dessa forma, analisar e revelar os problemas ergonômicos, tendo-se como finalidade principal melhorar a qualidade de vida.

Nesse sentido, este capítulo propõe a análise ergonômica em produtos já existentes, como os coletes à prova de balas que foram criados desde os primórdios da história e desenvolvidos ao longo de sua existência sem critérios ergonômicos e de usabilidade. Porém, podem ser aprimorados e redesenhados, valendo-se de pesquisas que verifiquem o nível de adequação do produto ao usuário e, servindose desses, aplicar os resultados em indicativos que tenham valores objetivos para melhorar o produto, adequando-o ao usuário e atendendo a suas necessidades e características sem, contudo, perder em segurança, tendo em vista que a inadequação dessa interface gera estresse e frustração (Fowler, 2003).

Nesse contexto, o método para a análise ergonômica pode apresentar vários aspectos que podem se valer da criatividade do designer, considerando-se aspectos de conforto que incluem ajuste, mobilidade e aceitabilidade térmica, e ainda aspectos psicológicos, com ênfase em uma visão holística da interação do homem com o produto que, além da adequação das características e limitações físico-humanas, também considere seu estilo de vida, seus sonhos, valores, gostos e desejos.

\section{Colete à prova de balas}

Basicamente, um colete à prova de balas é constituído de uma capa externa feita de duas camadas de tecido comum, como o terbrim, que acondiciona os dois painéis balísticos, um frontal e outro dorsal, estes constituídos de diversas camadas de tecido balístico, que são revestidos por uma capa (figura 61). 


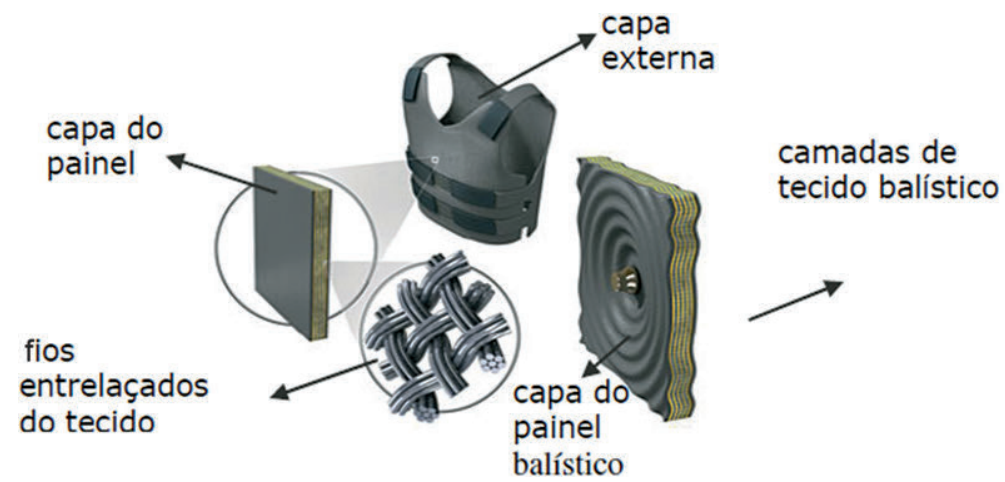

Figura 61. Partes componentes do colete balístico. Fonte: Revista mundo estranho.

Para a confecção do painel balístico são sobrepostas camadas sucessivas de tecido balístico em número suficiente para garantir o nível de proteção do colete, o que geralmente varia entre 15 e 35 camadas, e, apesar da resistência do tecido balístico, este pode ser trabalhado com tesouras e máquinas de costura industriais comuns (figura 62).

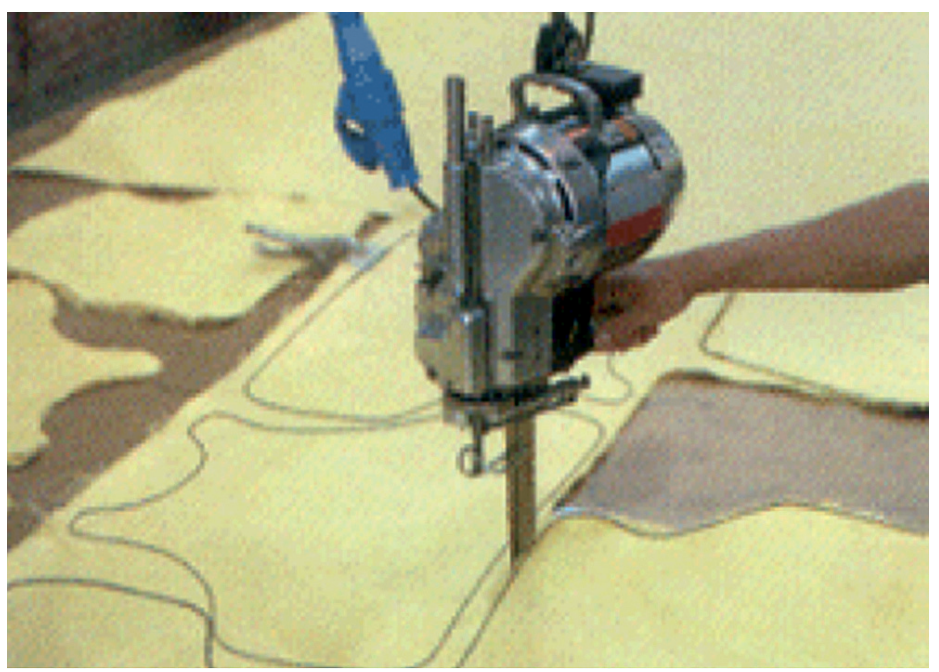

Figura 62. Camadas de material balístico sobrepostas sendo cortadas com máquina de costura industrial. Fonte: CBC. 
Esses painéis são cortados nos moldes definidos (figuras 62 e 63) e costurados nas extremidades para permanecerem em camadas sobrepostas, formando um painel que é revestido de uma capa nãoremovível de duas camadas de tecido. Para que o painel balístico não seja molhado, usa-se o nylon, um tecido impermeável que o protege do contato com a umidade e/ou chuva e do suor do corpo do usuário e, para tanto, as bordas devem apresentar arremates que garantam a estanquidade, impedindo a entrada de água pelos pontos da costura em caso de submersão (figuras 64 e 65):
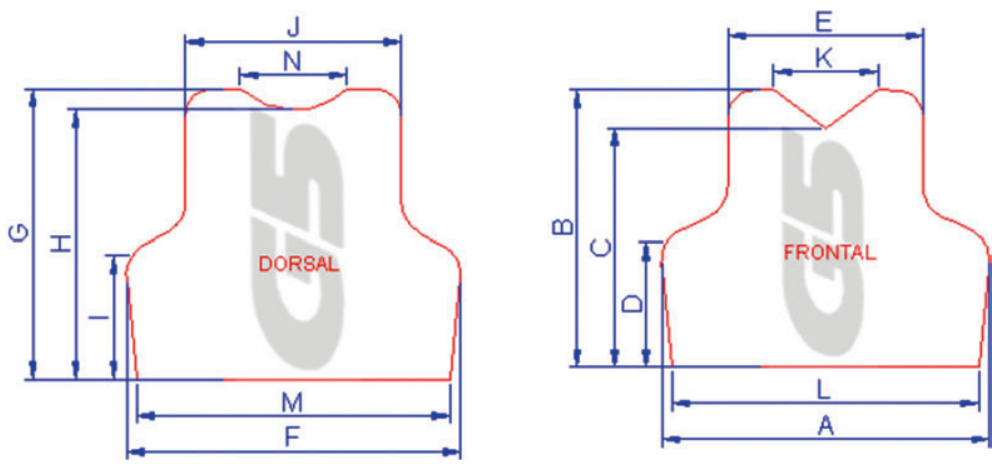

Figura 63. Moldes dos coletes. Fonte: site G5.

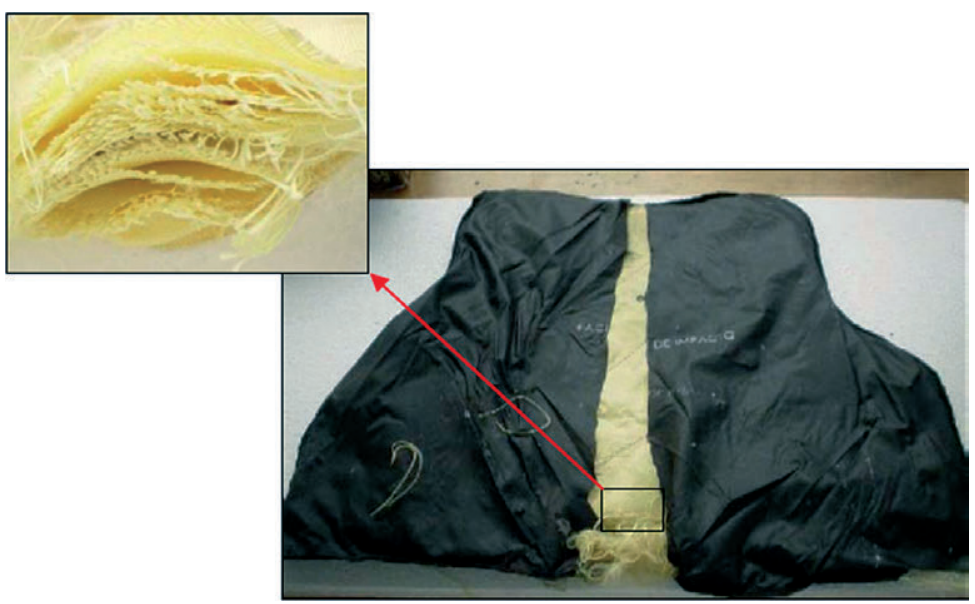

Figura 64. Detalhes do tecido balístico em camadas sobrepostas, formando o painel. 


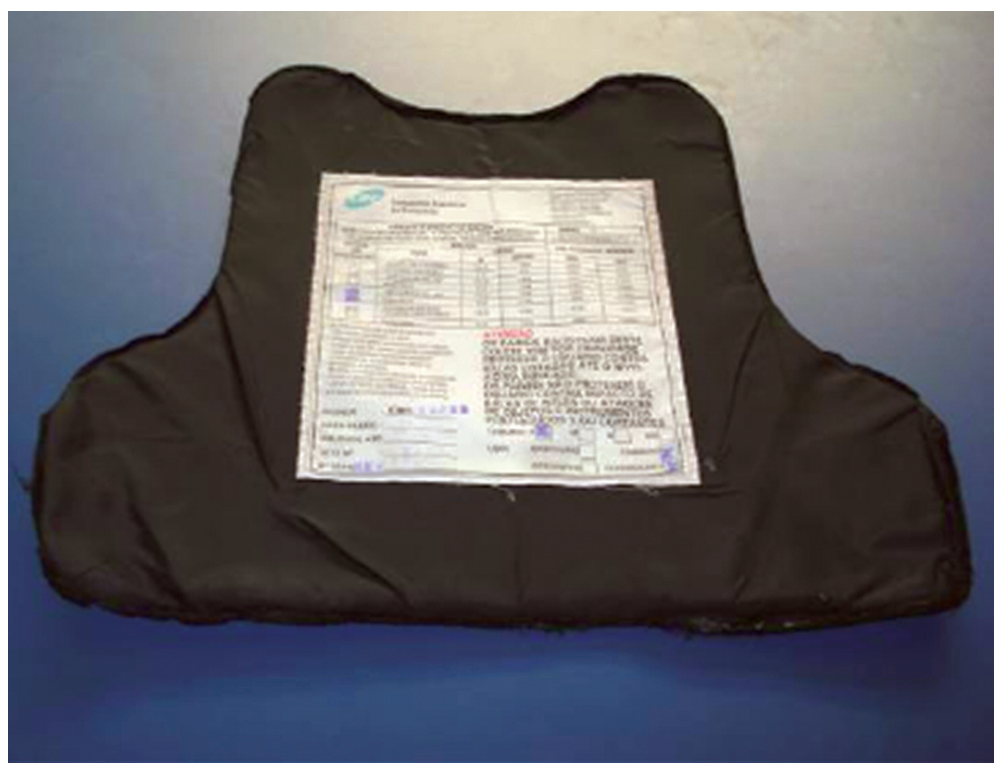

Figura 65. Capa interna do painel balístico, com a etiqueta de informações técnicas.

Em atendimento à Norma National Institute of Justice (NIJ), o painel balístico e a capa externa devem possuir uma etiqueta com informações no idioma português, de forma legível e indelével, em cor contrastante com o nome, logotipo ou outra identificação do fabricante; uso masculino ou feminino; modelo; tamanho PP, M, G ou GG; nível de proteção e certificado de conformidade com a Norma NIJ Standard 0101.04; número de série; data de fabricação; data de validade da proteção balística; munições que suporta (calibre, velocidade, peso e características do projétil); instruções de uso e conservação dos painéis balísticos.

A capa externa frontal e dorsal geralmente é confeccionada em tecido de alta tenacidade, um misto de algodão e poliéster em forma de envelopes com fechamento em velcro, na qual são introduzidos os painéis de proteção balística frontal e dorsal. Possui regulagem nas laterais e nos ombros, com tiras do mesmo tecido e revestidas com velcro (figuras 66 a 69). 


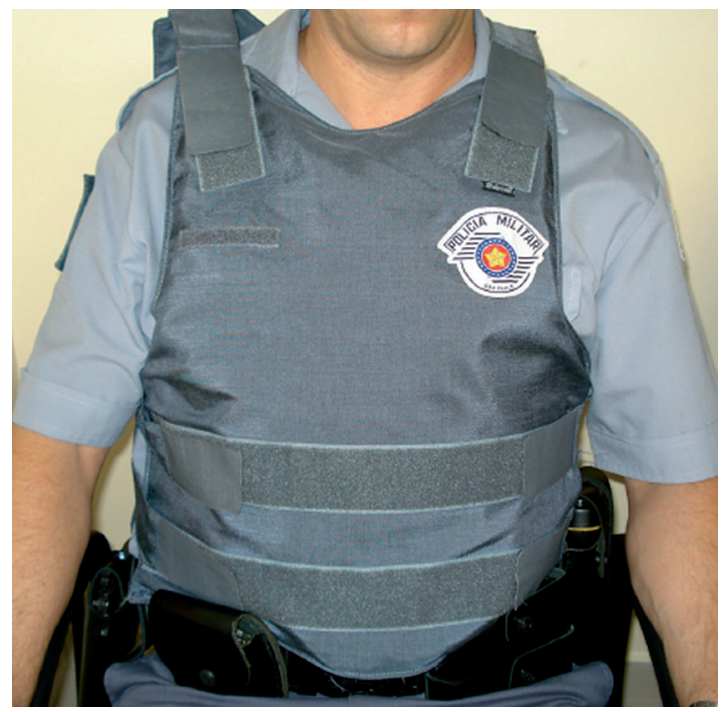

Figura 66. Capa externa frontal.

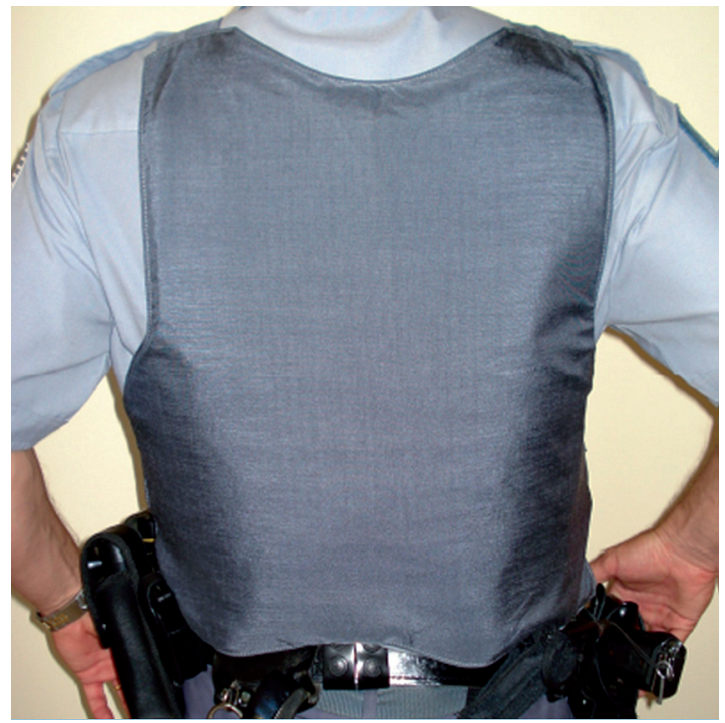

Figura 67. Capa externa dorsal. 


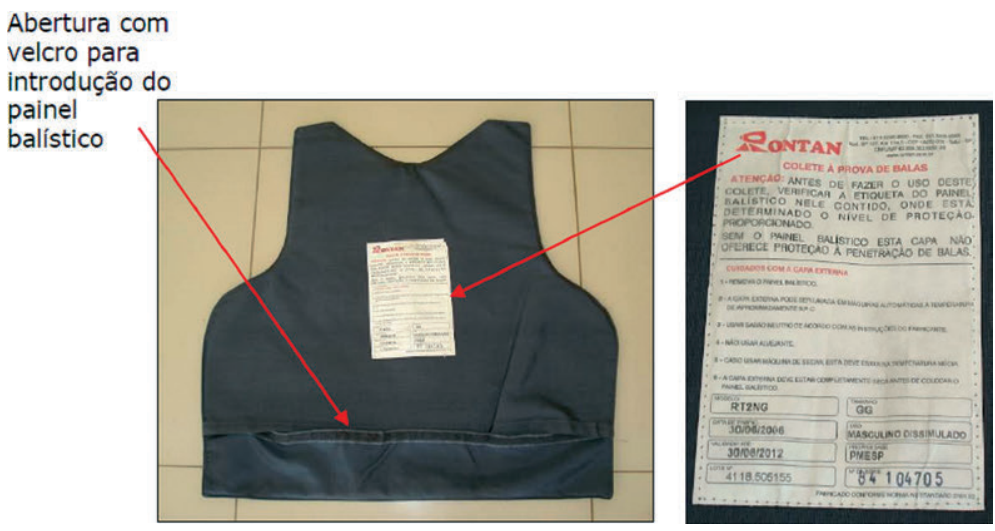

Figura 68. Capa externa do painel balístico frontal e detalhe da etiqueta.

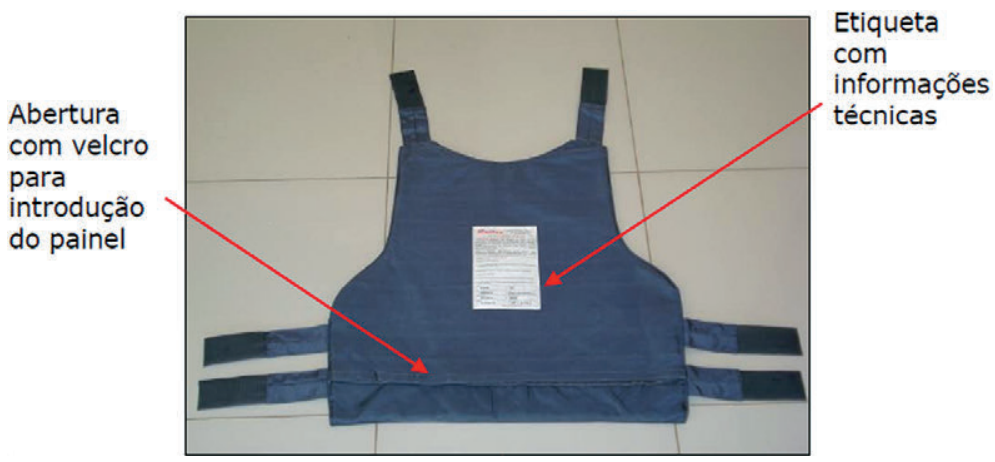

Figura 69. Capa externa do painel balístico dorsal.

\section{Metodologia}

Para realização da pesquisa foi elaborado um questionário com 11 perguntas que abordava os aspectos de conforto e usabilidade dos coletes à prova de balas, para que os entrevistados manifestassem sua opinião quanto aos seguintes aspectos: conforto, grau de conforto em relação ao peso, etiqueta com informações, abertura com velcro para introdução do painel balístico, grau de conforto em relação ao calor 
durante o uso, adequação dos tamanhos PP, P, M, Ge GG às medidas corporais do usuário, satisfação em relação às medidas dos coletes, partes do colete nas quais as medidas são desconfortáveis, adequação do modelo utilizado para a atividade policial e sugestões, diagnóstico de problema de saúde causado pelo uso do colete, se o desconforto do colete prejudica a atividade policial, nível de resistência do policial quanto ao uso contínuo, se o uso do colete contribui para sentir-se fatigado no final do turno de trabalho.

Iida (2005), em congruência com outros autores, afirma que o "sentimento" quanto ao conforto, usabilidade e fadiga em relação a um produto deve ser manifestado pelo usuário. Levando isso em conta, para este capítulo utilizamos medidas subjetivas que representassem variáveis categorizadas nominais (sim e não) e ordinais em escalas de satisfação (como excelente, bom, regular, ruim e péssimo), que melhor indicassem o grau de conforto do produto pesquisado em relação ao peso, calor, medidas, modelo e adequação à atividade, entre outros aspectos. Portanto, no questionário o policial pode traduzir seu "sentimento", quantificando o nível de conforto e usabilidade do equipamento e suas interrelações com o nível de fadiga.

A população $(\mathrm{N}=761)$ compreendeu os policiais militares do quadro da Secretaria de Segurança Pública do estado de São Paulo, que realizam o policiamento ostensivo e preventivo na área de abrangência do $4^{\circ} \mathrm{BPM} / \mathrm{I}$, sendo 65 do sexo feminino e 696 do sexo masculino. Todos continuamente durante o turno de trabalho utilizam o colete à prova de balas de nível II, modelo dissimulado, de painel balístico confeccionado com camadas de tecidos de fios de aramida, de polietileno e da combinação dos dois.

\section{Resultados e considerações finais}

Os resultados apontaram que mesmo que os entrevistados considerem o modelo adequado para a atividade policial, sugeriram que as medidas dos coletes sejam redimensionadas, principalmente na altura frontal, decote e cavas, sendo consenso que o colete apresente 
um modelo mais confortável, menos quente e mais leve. Uma fração de $20 \%$ dos policiais apontou seu uso como causa determinante de problemas de saúde, entretanto, deve-se considerá-la, para que este evento seja anulado na totalidade. Para as policiais, a insatisfação em relação ao conforto, ao peso e à medida do busto é maior quando comparada aos homens. Porém, nas demais avaliações não se observam diferenças significativas entre os dois sexos.

Considerando a opinião do usuário, conclui-se que o design desse EPI deve ser repensado. Em relação aos resultados da pesquisa sobre o colete à prova de bala enfatiza-se que seu uso parece influenciar no desempenho da atividade policial por causar desconforto, ser pesado, oferecer sofrível conforto térmico e por contribuir para que o policial apresente fadiga no final de turno de trabalho, em detrimento de sua saúde e segurança e de sua qualidade de vida, refletindo diretamente na sociedade que experimenta seus serviços.

Em relação ao peso do colete, as queixas não foram tão incisivas, o que pode ser atribuído ao conhecimento e conscientização, por parte dos policiais, quanto à importância do número de camadas para obter-se a devida proteção contra o impacto de projéteis e com o menor trauma possível no ponto de choque.

Conclui-se que os objetivos foram alcançados por meio da metodologia aplicada, pois as interferências indesejáveis na qualidade de um produto quanto ao conforto podem ser diminuídas ou exterminada, por intermédio de uma abordagem ergonômica com a participação do usuário e pela inferência de sua opinião, sua vivência, suas queixas quanto ao conforto, usabilidade e fadiga em relação ao produto, estabelecendo a ergonomia como elemento favorável para a concepção de produtos confortáveis e prazerosos, propiciando, assim, mudanças positivas no cenário policial por intermédio de princípios ergonômicos, dando importância a essa profissão.

Visando às futuras intervenções no design do colete à prova de balas, os resultados aqui obtidos devem ser considerados desde a concepção do produto, evitando inadequações por meio da aplicação de princípios ergonômicos e de usabilidade, como garantia de um produto mais confortável e usuários mais satisfeitos, contribuindo 
de forma efetiva para a segurança de trabalho e qualidade de vida do policial.

Como recomendação para trabalhos futuros sugere-se a realização de um levantamento antropométrico do efetivo da PMESP para a adequação de medidas e de molde do colete que melhor se aproxime do perfil de seus usuários e atenda a seus anseios, oferecendo maior conforto e usabilidade, sem perdas em relação à segurança de proteção.

Finalizando, considera-se que este estudo, por ser o primeiro no Brasil a investigar os aspectos ergonômicos do colete balístico, seja um referencial de dados para posteriores pesquisas com essa população. Recomenda-se acompanhar a implantação de sugestões ergonômicas, além de investigar os efeitos das possíveis mudanças ocorridas, nas quais outros fatores, associados à condição de trabalho e conhecimento do ser humano policial, possam ser analisados dentro do contexto ergonômico, implantando e consolidando conceitos de segurança do trabalho na atividade policial, agregando valor a esse profissional.

\section{Referencias bibliográficas}

ABRAHÃO, J. R. R. Coletes à prova de balas. Revista Magnum. São Paulo, n.12, ano II, 1988.

ARAÚJO, T., SARMENTO, J. Do que é feito um colete à prova de balas? Revista mundo estranho, abr 2007. Disponível em: http:/ / mundoestranho.abril.com.br/extra/materia_223649.shtml Acesso em: 30 jun 2007.

ASFORA, S. C. Qualidade de vida no trabalho de policiais militares da região metropolitana do Recife. Recife, 2004. 187p. Dissertação (Mestrado)Curso de Ciências, Universidade Federal de Pernambuco.

BAYLEY, D. H. Padrões de policiamento. 2.ed. São Paulo: Edusp, 2001.

BRASIL. Ministério da Defesa. Portaria n 18 D Log. 19 de dezembro de 2006, contém Normas Reguladoras da Avaliação Técnica, Fabricação, Aquisição, Importação e Destruição de Coletes à Prova de Balas. Disponível em <http://www.sindespdf. com.br/2006/legislacao/Portaria\%2018\%20D\%20Log\%2019\%20dez\%2006\%20-\%20COLETES.pdf> Acesso em: 23 jun.2007. 
BRASIL. Ministério do Trabalho e Emprego. Normas Regulamentadoras: contém disposições gerais sobre segurança e medicina no trabalho. Brasília: [s.d.]. Disponível em: <http://www.mte.gov.br/legislacao/ normas_regulamentadoras/default.asp> Acesso em: 20 jun 2007.

CHESNAIS, J. Artigo traduzido por Luiz Gonzaga de Freitas. Revista a força policial. São Paulo, n.9, jan./mar. 1996

FOWLER, J. The evaluation and testing of two ballistic vests: a comparison of comfort. Florida, 2003. Dissertação (Mestrado) - Curso de Ciências, Department Of Textiles And Consumer Sciences, College Of Human Sciences The Florida State University.

FRAGA, C. K. A Polícia Militar Ferida: da violência visível à invisibilidade da violência nos acidentes em serviço. Porto Alegre, 2005. 187p. Tese (Doutorado) - Curso de Serviço Social, Universidade Católica do Rio Grande do Sul.

GRANDJEAN, E. Manual de ergonomia: Adaptando o trabalho ao homem. 4.ed. Porto Alegre: Bookman, 1998.

HARRIS, T. Como funciona o colete à prova de balas. 2001. Disponível em: $<$ http://ciencia.hsw.com.br/colete-a-prova-debalas. htm $>$ Acesso em: $1^{\circ}$ jul. 2007).

IIDA, I. Ergonomia: projeto e produção. 2.ed. São Paulo: Edgard Blücher, 2005.

IMPRENSA OFICIAL. Anteprojeto de lei $n^{\circ}$ 305, São Paulo, SP, v.115, n.93, 19 mai. 2005. Disponível em: <http://www.imprensaoficial.com. br>. Acesso em: 25 jun. 2005.

MARTINS, S. B. O conforto no vestuário: uma interpretação da ergonomia. Metodologia para avaliação de usabilidade e conforto no vestuário. Florianópolis, 2005.140p. Tese (Doutorado) - Engenharia de Produção, Universidade Federal de Santa Catarina.

MINAYO, M. C. S., SOUZA, E. R. Missão investigar: entre o ideal e a realidade de ser policial. Rio de Janeiro: Garamond. 2003.

MONJARDET, D. O que faz a polícia. Polícia e Sociedade. Núcleo de Estudos da Violência da Universidade de São Paulo. São Paulo: Edusp, n.10, 2002.

NATIONAL INSTITUTE OF JUSTICE. (November 2000). Ballistic resistance of personal body armor, NIJ standard-0101.04. Disponível em < http://www.nlectc.org/pdffiles/0101.04RevA.pdf> Acesso em: 23 abr. 2006.

PASCHOARELLI, L. C. Usabilidade aplicada ao design ergonômico de transdutores de ultrassonografia: uma proposta metodológica para ava- 
liação e análise do produto. São Carlos, 2003. 142p. Tese (Doutorado) - Curso de Engenharia de Produção, Universidade Federal de São Carlos, 2003.

PASCHOARELLI, L. C., SILVA, J. C. P. da. Metodologias de design ergonômico: uma análise a partir da revisão de suas similaridades e divergências na ação projetual. In: $7^{\circ}$ Congresso Brasileiro de Pesquisa e Desenvolvimento em Design. Anais... Curitiba, 2006. 1 CD-ROM.

PIVA, L. Trabalho e Sofrimento Psíquico: um estudo de caso com policiais militares. Assis, 2005. 126p. Dissertação (Mestrado) - Curso de Psicologia, Departamento de Faculdade de Ciências e Letras de Assis, Unesp.

REIS, G. P. dos. A engenharia de produção aplicada às organizações de serviços em segurança pública: um estudo exploratório. Rio de Janeiro: 2006. Disponível em: <http://www.comunidadesegura.org/files/active/0/ Gilberto_Protasio_Engenharia_de_Produ\%C3\%A7\%C3\%A3o.pdf $>$ Acesso em: 22 jun 2007.

RODRIGUEZ-AÑEZ, C. R. Sistema de avaliação para a promoção e gestão do estilo de vida saudável e da aptidão física relacionada à saúde de policiais militares. Florianópolis, 2003. 143p. Tese (Doutorado) Engenharia de Produção, Universidade Federal de Santa Catarina.

SANTOS, J. V. T. dos. A arma e a flor: formação da organização policial, consenso e violência. Tempo Social - Revista de Sociologia da USP. São Paulo, v.9, n.1, 1997.

SIMÕES, M. C. Formulação de um repositor hidroeletrolítico para o trabalho físico ostensivo de policiais militares, adaptado as variações climáticas de Florianópolis. Florianópolis, 2003. 271p. Tese (Doutorado) - Engenharia de Produção, Universidade Federal de Santa Catarina.

SOUZA, E. R.,; MINAYO, M. C. S. Policial, risco como profissão: morbimortalidade vinculada ao trabalho. Ciência saúde coletiva. [online]. out./dez. 2005, v.10, n.4, p.917-28. Disponível em: http://www.scielo. $\mathrm{br} /$ scielo.php? $\mathrm{script}=$ sci_arttext\&pid=S1413-81232005000400015\&ln $\mathrm{g}=\mathrm{en} \& \mathrm{nrm}=$ iso $>$. ISSN 1413-8123. Acesso em: 12 nov.2005. 


\title{
11 \\ DESIGN ERGONÔMICO: \\ ANÁLISE DO CONFORTO E DESCONFORTO DOS CALÇADOS COM SALTO ALTO
}

\author{
Eunice Lopez Valente ${ }^{1}$ \\ Luis Carlos Paschoarelli ${ }^{2}$
}

\section{Introdução}

Os calçados (ou sapatos) são complementos essenciais no modo de vida humano, uma vez que têm por princípio a proteção da Extremidade dos Membros Inferiores (EMI). Além desse aspecto funcional, esses produtos tornaram-se fundamentais no que refere à moda. Por esses motivos, os calçados femininos são atualmente disponibilizados numa grande diversidade de formas e modelos e produzidos numa grande variedade de materiais, técnicas de confecção, acabamentos e cores, entre outros.

Sendo um produto de interface com o pé humano, os calçados femininos devem ser projetados a partir de parâmetros ergonômicos, com destaque para os aspectos perceptivos das usuárias. A ergonomia, em seus princípios metodológicos, pode contribuir no estudo dessa interface, fornecendo parâmetros científicos para o design ergonômico desse produto.

1 Mestre em design, Universidade Tuiuti do Paraná.

2 Pós-doutorado em ergonomia, Universidade Estadual Paulista. 


\section{Revisão bibliográfica}

\section{Moda e calçados femininos}

O conceito de moda surgiu em meados do século XIV e está diretamente relacionado a vestimentas, embora Jones (2005) afirme que moda é uma forma especializada de ornamentar o corpo, fazendo crer que todo elemento usado no corpo de forma decorativa pode ser compreendido como produto da moda. Conforme Rech (2002), a moda compreende mudanças socioecológicas, psicológicas e estéticas relacionadas à arquitetura, artes visuais, música, religião, política, literatura, decoração e vestuário. Segundo Montemezzo (2003), os produtos destinados ao consumo, como o vestuário, denotam mudanças nos aspectos sociais, econômicos, ambientais e mercadológicos.

Para a moda, os calçados representam um ícone da transformação, pois os modelos podem evidenciar tanto passado quanto futuro. Os materiais utilizados para a confecção seguem a tendência de moda atual, bem como modelos, alturas e formatos de salto.

A variabilidade de modelos e exemplos de calçados femininos pode revelar uma atração indefinível por um par de sapatos, fazendo aflorar fantasias pessoais. A sedução pela altura de um salto pode conduzir a uma atração especial. E esse desejo não tem nada a ver com a necessidade, pois a excitação está em colocar o pé em um par novo, que provoca o encantamento e o charme, sensações que o calçado velho não mais pode provocar. Nesse sentido, O’Keefe afirma que "o tédio resulta da familiaridade e, quando um sapato começa a ficar confortável e feito ao pé, perde sua qualidade de talismã” (1996, p.15).

De acordo com Puls (2003), o desenvolvimento de calçados e a inovação caminham lado a lado com a criatividade e com a percepção, que é um reflexo da evolução do tempo. Atualmente, é natural que a preocupação com o produto da moda, o calçado, esteja ligada às condições econômicas e aos hábitos dos indivíduos, muito mais que as propostas dos designers em oferecer novos estilos. Assim, a cultura determina como será a produção dos calçados e o seu uso, como no caso dos calçados femininos de salto alto, que seguem as regras da 
moda e, muitas vezes, entram em conflito com questões relacionadas ao conforto dos pés das usuárias.

\section{Calçados femininos e salto alto}

Particularmente quando se referem a calçados femininos, as mulheres geralmente se dividem em dois grupos - aquelas que aceitam e utilizam saltos e aquelas que os rejeitam. Saltos altos nos calçados femininos estão associados ao gênero, status, sensibilidade feminina e moda. Muitas mulheres consideram-nos desconfortáveis, e algumas feministas tendem a interpretá-los como símbolos de submissão feminina. De modo simultâneo, profissionais da área da saúde alertam sobre os acidentes que os saltos altos podem provocar e deformações nos pés, torção nos tornozelos e problemas nas costas. Porém, apesar desses avisos, os calçados de saltos altos ficam cada vez mais populares.

De acordo com O'Keefe, "as mulheres podem 'enfiar' uns chinelos, 'calçar' uns tênis ou 'pôr' uns sapatos mais confortáveis, mas 'vestemse' de saltos altos” (1996, p.72). Portanto, esse público, mesmo não querendo que os pés fiquem doloridos, é dominado pelo fascínio dos saltos altos que impele à aceitação, se não à adoração dos mesmos. Um calçado de salto alto pode tornar uma mulher mais ou menos poderosa, pois, apesar do desconforto percebido, ela pode sentir satisfação.

Quando uma mulher está "vestida" de saltos altos, é forçada a ter uma postura diferenciada, pois seu centro de gravidade é deslocado para a frente. A parte inferior das costas se arqueia, a coluna e as pernas parecem se alongar, e o peito projeta-se para a frente. A panturrilha e os tornozelos parecem mais bem torneados e a curvatura inferior dos pés parece querer sair dos calçados.

Assim, mesmo sem se mover, a mulher calçando saltos altos transforma seu corpo, parecendo mais alta e mais magra. Os saltos altos conferem aos calçados características que fazem com que eles sejam conhecidos por sua forma e altura. Eles são um tipo de ornamento que pode ser anexado a uma grande variedade de diferentes calçados sapatilhas, sandálias, mules, botas e até tênis. Associam-se à sensação 
e percepção femininas, sendo percebidos não somente como o mais sexy tipo de calçado, mas também como o mais formal, em moda, e o mais prestigiado - razões pelas quais as mulheres podem gostar dele.

Algumas mulheres decidiram há muito tempo que o conforto é seu interesse principal. Em muitos lugares, os calçados confortáveis são uma parte do estilo casual. Obviamente, nem todos os calçados de salto alto são desconfortáveis, por isso as sapatilhas confortáveis com salto médio são muito procuradas pelas mulheres. O consenso, porém, é que os calçados com salto raso são os mais confortáveis. Consequentemente, os saltos altos trazem a ideia implícita de que o conforto não é a única consideração, pois, sob certas circunstâncias, o glamour vem a ser mais importante. Inversamente, quando saltos rasos ou médios estão na moda, os saltos altos parecem excessivos.

\section{Problemas fisiológicos decorrentes do uso de calçados femininos}

Do ponto de vista anatômico, a EMI humana é constituída pelo denominado "pé", o qual foi se caracterizando (na evolução humana) como elemento e sistema de apoio e equilíbrio (neste último caso, associado às demais regiões anatômicas do corpo humano) do corpo sobre o solo, mantendo-o ereto, além de ser a peça fundamental do processo de locomoção humana.

Segundo Pericé (1986), sua forma e sua estrutura interna atuam como um suporte ou pedestal para o corpo e, ao mesmo tempo, como um sistema de alavancas que o impulsionam durante o ato de caminhar, correr, saltar, e como elemento amortecedor dos impactos que recebe do solo. É talvez um dos mecanismos vitais do corpo humano mais negligenciado, mas, ainda assim, capaz de cumprir sua tarefa, mesmo sob as mais adversas condições e pressões, graças à sua estrutura perfeita.

De acordo com Carrasco (1995), o apoio do pé pode ser caracterizado por três classes: normais ou neutros, cuja impressão na superfície de apoio demonstra uma ligação entre o antepé e o calcanhar; côncavo, 
ou arcado/supinado, cujo arco pode ser tão acentuado que na sua impressão pode não ocorrer a ligação entre o antepé e o calcanhar; e chato, ou também denominado de pronador excessivo, caracterizado por apenas um pequeno arco impresso, tocando praticamente todo o chão, com a sola plana. O pé chato é o que mais sofre com calçados, pois, muitas vezes, estes não são desenvolvidos para esse tipo de pé.

Outro problema anatômico comumente observado no pé humano é o joanete (ou Hallux Valgus), caracterizado por um desvio lateral do grande artelho, causado pela contínua pressão exercida sobre o grande artelho lateralmente em calçados estreitos e bicudos. $\mathrm{O}$ joanete é caracterizado como uma patologia que, muitas vezes, exige intervenção ortopédica ou cirúrgica. Saltos altos também favorecem o desenvolvimento dessa deformidade, pois o antepé é forçado para a ponta frontal estreita do calçado, provocando uma deformação ou acréscimo de osso e o aumento da angulação da articulação do dedão.

Observa-se, assim, que as EMIs apresentam particularidades físicas e fisiológicas que devem ser compreendidas na observação dos parâmetros para o design ergonômico de calçados femininos. No entanto, esses fatores não são determinantes para compreender como se dá, plenamente, a relação entre as usuárias e os calçados, exigindose analisar também os aspectos perceptivos desse uso.

\section{Percepção da usabilidade de calçados femininos}

A usabilidade de calçados é um fator decisivo no projeto desse produto, uma vez que se faz uso do mesmo em grande parte do dia (para as pessoas que realizam atividades ocupacionais pelo menos um terço do dia). Além disso, por ser muitas vezes considerado exclusivamente um elemento da moda, ele precisa apresentar características ergonômicas intrínsecas, independentemente da variabilidade de tipos e modelos.

Alguns importantes estudos envolvendo a ergonomia e o design de calçados já foram desenvolvidos no Brasil (Monteiro, 2000; Van der Linden, 2004). Entretanto, entre os vários aspectos que ainda mere- 
cem atenção específica na relação do design ergonômico de calçados destacam-se a influência do salto alto na usabilidade, principalmente em calçados femininos, e a adequação antropométrica.

Estudos na área clínica, biomecânica e ergonômica têm demonstrado a influência do salto alto em calçados. Segundo Carrasco (1995), conforme se aumenta a altura do salto, altera-se a distribuição da pressão corporal nos pés e o equilíbrio, prejudicando a segurança do caminhar. Quando o pé se apoia no chão sem salto nenhum, o calcanhar suporta uma carga de $57 \%$ do corpo e a região metatarsiana $43 \%$. Com o salto de $2 \mathrm{~cm}$, há um equilíbrio de $50 \%$ do peso do corpo na parte anterior do pé e na parte posterior, no calcanhar. Com o salto de $4 \mathrm{~cm}$, o calcanhar suporta $43 \%$ do peso do corpo e o metatarso $57 \%$. Com um salto de $6 \mathrm{~cm}, 75 \%$ do peso do corpo ficará sobre a região metatarsiana e $25 \%$ sobre o calcanhar. Com um salto de $10 \mathrm{~cm}$ ou maior, praticamente toda a carga é suportada pela região anterior do pé. Eé essa a região mais afetada do pé feminino dentro de um calçado de salto alto. Kerrigan, Lelas \& Karvosky (2001) realizaram um estudo sobre calçados femininos em sujeitos com osteoartrite de joelho, avaliando a influência do salto alto na torção do joelho, e constataram que usuárias de salto alto apresentaram aumento na possibilidade da torção, principalmente na região patelo-femural e medial do joelho, região anatômica típica de mudanças degenerativas de articulações.

Outro estudo de Kerrigan, Johansson \& Bryant (2005) avaliou se mulheres utilizando calçados com saltos de apenas $38 \mathrm{~mm}$ de altura apresentavam probabilidade de torção na articulação do joelho. Mesmo nesse caso, foi constatado um aumento significativo nas torções de joelho, o que é relevante para o desenvolvimento e progressão da osteoartrite dessa articulação. Portanto, o salto pode ser considerado um problema grave, principalmente para mulheres portadoras de osteoartrite do joelho.

Quanto à relação entre altura do salto e distribuição de pressão plantar, força de impacto e percepção de conforto, Yung-Hui \& Wei-Hsien (2004) realizaram um estudo com dez mulheres saudáveis, utilizando calçados com saltos de $10 \mathrm{~mm}, 51 \mathrm{~mm}$ e $76 \mathrm{~mm}$. Os resultados indicaram que o aumento da altura do salto tem correlação 
com o aumento da força de impacto e da percepção de desconforto durante a caminhada. Eles observaram também que um apoio de calcanhar para calçados de salto alto reduz a pressão no calcanhar e o impacto de força; um suporte de arco inserido na palmilha reduz a pressão média no antepé; e o uso de ambos os sistemas colabora no conforto percebido durante o uso.

Outro estudo que compara diferentes alturas de salto foi desenvolvido por Lee, Jeong \& Freivaldsb (2001) utilizando três alturas (zero, $45 \mathrm{~mm}$ e $80 \mathrm{~mm}$ ) com mulheres paradas, em pé e andando. Quatro principais efeitos biomecânicos foram observados: com o aumento do salto, a flexão do ângulo do tronco diminui significativamente. Já a análise eletromiográfica da região da tíbia anterior e da lombar bem como o movimento vertical do centro do corpo aumentou significativamente enquanto caminhavam com calçados de salto alto.

Manfio (2003) identificou as alterações das características cinemáticas e da força vertical durante a marcha descalça e com calçados de diferentes alturas de salto. A amostra caracterizou-se por sujeitos que calçavam exclusivamente a numeração 35 (sistema francês) e usavam calçados de salto alto frequentemente. A marcha foi avaliada em cinco diferentes alturas de salto: zero, $5 \mathrm{~mm}, 25 \mathrm{~mm}, 55 \mathrm{~mm}$ e $85 \mathrm{~mm}$. Observou-se que as maiores alterações cinemáticas foram encontradas entre a situação descalça, calçado sem salto e calçado de salto com $85 \mathrm{~mm}$. Segundo a autora, tais alterações devem ser consideradas no design e na fabricação do calçado de salto, proporcionando assim maior conforto.

A relação entre fadiga muscular e estabilidade do pé durante a marcha com salto alto foi avaliada por Gefen et al. (2001) por meio da análise da pressão plantar e da eletromiografia (EMG). A estabilidade médio-lateral do pé foi caracterizada medindo-se desvios médio-laterais no centro de pressão e correlacionando esses dados com a fadiga nos músculos da panturrilha. Usuárias habituais de calçados de salto alto demonstraram um desequilíbrio dos músculos da perna em condições de fadiga, situação que é correlacionada com uma anormal substituição lateral do centro de pressão com o pé no chão e pé com calçado. 
Speksnijder et al. (2004) estudaram a pressão do pé, medida em dez mulheres saudáveis, enquanto caminhavam com calçados de salto alto $(59,1 \mathrm{~mm})$ e salto baixo $(19,5 \mathrm{~mm})$. O pé foi dividido em sete regiões. Para cada região os seguintes parâmetros foram calculados: o pico de pressão (PP), tempo de pressão integral (TPI), força máxima (FM), tempo de força integral (TFI), tempo de contato (TC) e área de contato (AC). Em saltos altos, a carga foi reduzida no médio pé, e sob o calcanhar a AC e FM caíram significativamente. Caminhar com calçados de salto alto causou um aumento no pico de pressão de 30\% no antepé central em comparação com saltos baixos, com os quais o TPI aumentou para 48\%. No médio antepé esses parâmetros aumentaram em $34 \%$ e $47 \%$ respectivamente. Um aumento de salto alto mostra a correlação de PP para TPI no médio antepé e para PP no antepé central.

Apesar de a maioria dos estudos revisados até então apresentarem resultados que condenam o uso de salto elevado, um estudo desenvolvido por Potério Filho (2003) afirma que esse tipo de salto proporciona maior contração muscular, o que aumenta em até 30\% a eficiência do bombeamento do sangue. Esse movimento muscular das pernas atua sobre as veias e faz com que o sangue retorne para o coração com maior pressão, não permitindo a sua volta por ação das válvulas. Assim, enquanto a pessoa anda, ocorrerá o bombeamento, e a pressão nas veias das pernas permanece muito baixa, diminuindo a chance de aparecer qualquer edema (infiltração de líquido semelhante ao soro sanguíneo).

\section{Percepção de desconforto/conforto em calçados}

A maioria das abordagens do design ergonômico depende da percepção de uso por parte dos usuários de um determinado produto, e essa percepção é decorrente de alguns critérios de avaliação. De acordo com Paschoarelli (2003), os principais critérios utilizados na avaliação de um produto são o desconforto (critério negativo) e o conforto (critério positivo). Segundo Ferreira (1999), o desconforto 
é definido pela "falta de conforto", ou o contrário de conforto, mas, para Iida (2005), o conforto não apresenta uma definição precisa, e depende da área de estudo em que é aplicado. Do ponto de vista operacional, a primeira definição de conforto foi proposta em um estudo de Hertzberg, que afirmou ser o conforto a "ausência de desconforto" (Lueder, 1983). Já para Noyes (2001), conforto é um estado mental que ocorre na ausência de desconforto, e a única maneira de avaliá-lo é por meio da declaração do indivíduo sobre o quão confortável ele se sente. A partir dessa proposição, Jordan (2000) afirma que os produtos percebidos como confortáveis são aqueles que proporcionam sensações prazerosas a seus usuários.

Ao considerar o conforto a partir do uso de calçados, pode-se argumentar que calçado confortável é aquele que não expõe os pés a enfermidades ou deformações, mas isso só não garante a caracterização e a definição desse conceito. O conforto pode ser definido de várias maneiras, por ser uma variável qualitativa. Iida (2005) define-o como "uma qualidade ergonômica do produto", e esse é um atributo valorizado pelo usuário. Van der Linden \& Guimarães (2004), após coleta de expressões e definições, propuseram a definição de conforto como "uma sensação prazerosa de bem-estar físico e psicológico. O conforto é, também, uma condição de bem-estar com ausência de dor, desconforto e estresse, definida a partir de uma sensação de desconforto". De acordo com Slater (1985), o conforto apresenta uma natureza multidimensional, resultante de três dimensões: física, fisiológica e psicológica.

Os aspectos físicos correspondem à interação com o ambiente e seus efeitos nas dimensões fisiológica e psicológica. Assim, enquanto os aspectos fisiológicos do conforto estão relacionados ao funcionamento do corpo humano, envolvendo ações de regulação involuntárias, os aspectos psicológicos referem-se ao conforto mental e estão associados a questões como autoimagem, identidade e individualidade.

Além da falta de consenso quanto à definição de "conforto", também não existe uma condição objetiva e precisa para se mensurar o conforto, tornando necessário o uso de averiguações para se saber o quão confortável o indivíduo se sente em relação a determinado 
produto (Sanders \& McCormick, 1993). Segundo Borg, a utilização de métodos para avaliar subjetivamente tarefas e usos de objetos tornou-se um procedimento comum em abordagens ergonômicas, uma vez que as cargas de atividades "são estudadas não somente com métodos fisiológicos, mas também com estimativas de percepção" (2000, p.81), sendo seus resultados um "importante sinal de uma carga real ou objetiva" (idem, p.82). Em estudos sobre avaliação de conforto, Drury \& Cury (1982) citam o uso de escalas que avaliam o eixo conforto/desconforto. Eles utilizam escalas binárias (comfortable/uncomfortable), com um ponto médio entre os dois conceitos extremos (uncomfortable/medium/comfortable) e avaliação com sete pontos, indicando conforto no ponto máximo.

Van der Linden (2004) afirma que, admitindo-se o eixo conforto/desconforto com o ponto intermediário indicando um estado de indiferença (nem conforto, nem desconforto), deve-ser proceder à avaliação do conforto ou desconforto considerando toda a sua dimensão. Assim, respostas como "pouco confortável” não indicam um estado de desconforto.

De acordo com Iida (2005), as avaliações subjetivas devem considerar medidas de "sentimento" ou "percepção", já que dependem do julgamento e repertório individuais dos avaliados. Assim, devem ser utilizadas para tal fim as escalas de percepção. No sentido de não serem definidas as variáveis em que as pessoas se baseiam para determinar o conforto, Iida indica que uma avaliação subjetiva deve ser utilizada quando se pretende avaliar se um produto é confortável ou não. Deve observar-se ainda que "a importância da aparência e a atitude diante de riscos em geral são determinantes no processo de avaliação do conforto e do risco no uso de calçados" (Van der Linden, 2004).

\section{Objetivos}

Os objetivos deste capítulo foram avaliar a percepção de desconforto/conforto em usuárias de calçados de salto alto e analisar os resultados diante dos princípios do design ergonômico. 


\section{Materiais e métodos}

\section{Aspectos éticos}

Para a coleta de dados, aplicou-se um Termo de Consentimento Livre e Esclarecido (TCLE), baseado nos princípios do Conselho Nacional de Saúde, através da Resolução 196/96 - CNS; e da Norma ERG-BR 1002, do Código de Deontologia do Ergonomista Certificado (Associação Brasileira de Ergonomia, 2003).

\section{Sujeitos}

Participaram do estudo 244 mulheres universitárias adultas, com idade média de 20,90 anos (d. p. 2,52 anos; amplitude 18-30 anos), todas residentes em Curitiba e região metropolitana (PR). Além disso, tais indivíduos apresentam peso médio de $56,57 \mathrm{~kg}$ (d. p. 7,72 kg); e estatura média de 1,65 m (d. p. 0,06 m), sendo que tais variáveis foram obtidas de forma nominal.

\section{Materiais}

Para a coleta dos dados pessoais e perceptivos, utilizou-se um protocolo de identificação e coleta de dados (PICD) caracterizado por dez questões de múltipla escolha, relatando sobre o tamanho, desconforto/conforto e expressão de individualidade de calçados; uso, desconforto/altura e tempo/altura de salto de calçado. Além disso, foi disponibilizado um mapa dos pés (esquerdo e direito) a fim de possibilitar o registro de regiões de desconforto pelas usuárias e um diagrama do corpo humano, baseado no diagrama de desconforto de Corlett \& Manenica (1980), permitindo a indicação de regiões de desconforto quando do uso de calçados de salto maior que $4 \mathrm{~cm}$. 


\section{Procedimentos}

A preparação dos protocolos exigiu a realização de pré-testes. A coleta de dados deu-se no campus de uma universidade na cidade de Curitiba (PR). Após esclarecimento, houve a entrega do TCLE, o qual foi devidamente lido, aceito, preenchido e assinado. Na sequência, houve a distribuição do PICD àquelas usuárias que assinaram o TCLE e após o preenchimento houve o recolhimento dos mesmos e os dados foram revisados e submetidos à tabulação.

\section{Resultados}

A percepção da diferença de tamanho entre os calçados para os pés direito e esquerdo pelos sujeitos abordados, em porcentagem, é apresentada na figura 70 .

Observa-se que pouco mais da metade $(54,51 \%)$ dos sujeitos não percebe diferenças entre os calçados para os pés direito e esquerdo; aproximadamente $14 \%$ percebem diferenças sendo maior o esquerdo que o direito ou maior o direito que o esquerdo, e 17,21\% percebem que esse aspecto é indiferente, pois varia de acordo com o modelo.

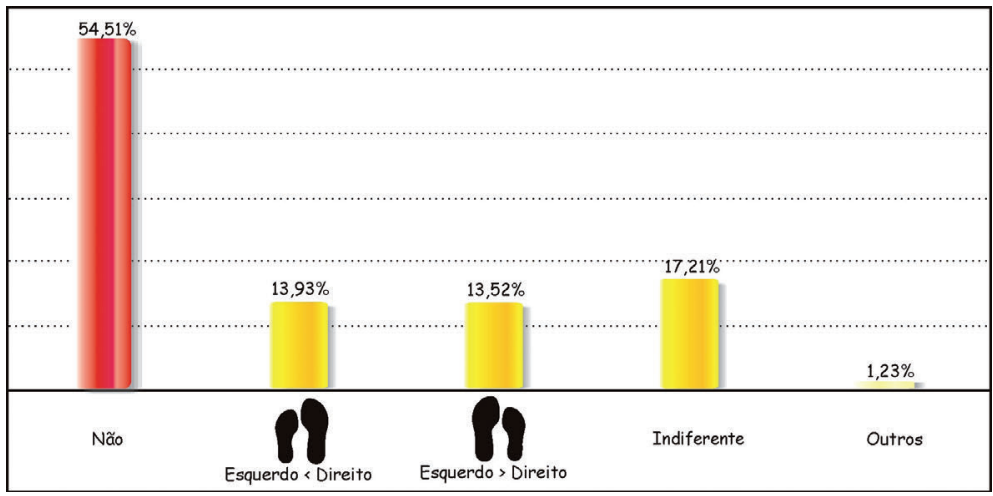

Figura 70. Porcentagem do número de sujeitos que percebem algum tipo de desconforto nos pés em consequência da percepção de diferença de tamanho de calçados para pés direito e esquerdo. 
A percepção de diferenças entre os calçados dos pés direito e esquerdo pode variar de acordo com diferentes modelos (figura 71). Observa-se que os modelos com maior porcentagem de indicação de percepção de diferenças de tamanho entre os pés direito e esquerdo são a bota de salto alto e bico fino (46,85\%), o escarpim (45,05\%) e os tênis $(36,94 \%)$.

Quanto à percepção de desconforto nos pés em consequência da percepção de diferença de tamanho de calçado entre os pés direito e esquerdo, observou-se que aproximadamente $28 \%$ dos sujeitos não percebem diferença e mais da metade percebe diferença, particularmente quando a percepção refere-se a um calçado menor (figura 72).

Nesse caso, ao perceber a diferença de tamanho entre os calçados para os pés direito e esquerdo enquanto experimentam o mesmo durante a compra, aproximadamente $60 \%$ dos sujeitos compram o calçado com maior numeração (figura 73).

Quanto à individualidade e o próprio sentimento, observou-se que os calçados que mais expressam essas condições são o tênis $(57,79 \%)$, a bota plataforma $(34,43 \%)$ e o escarpim (32,38\%), seguidos de outros (figura 74). Quanto à sensação de alívio (facilidade) e relaxamento (redução de constrangimentos físicos e psicológicos) durante as principais atividades diárias (figura 75), observou-se que os modelos calçados que mais expressam essas condições são o tênis $(85,25 \%)$, a rasteirinha $(40,16 \%)$ e a bota plataforma $(36,07 \%)$, seguidos de outros. Já quanto à sensação de aborrecimento, desprazer ou desconforto em usar calçado durante as principais atividades diárias (figura 76), observou-se que os modelos que mais expressam essas condições são a sandália de salto alto $(48,36 \%)$, a bota de salto alto e bico fino $(44,67 \%)$ e o escarpim (36,89\%), seguidos de outros.

Quanto à frequência de uso de calçados de salto alto, aproximadamente $44 \%$ utilizam-no ocasionalmente, $40 \%$ frequentemente e 16\% diariamente (figura 77).

Já quanto à relação entre altura do salto e a percepção de desconforto, observou-se que os maiores índices são para os saltos com $10 \mathrm{~cm}$ de altura ou mais, ou aproximadamente $64 \%$ dos sujeitos (figura 78). E quanto ao tempo decorrido de uso de calçado de salto até a percepção de desconforto, a maioria (43,03\%) indicou mais de duas horas (figura 79). 


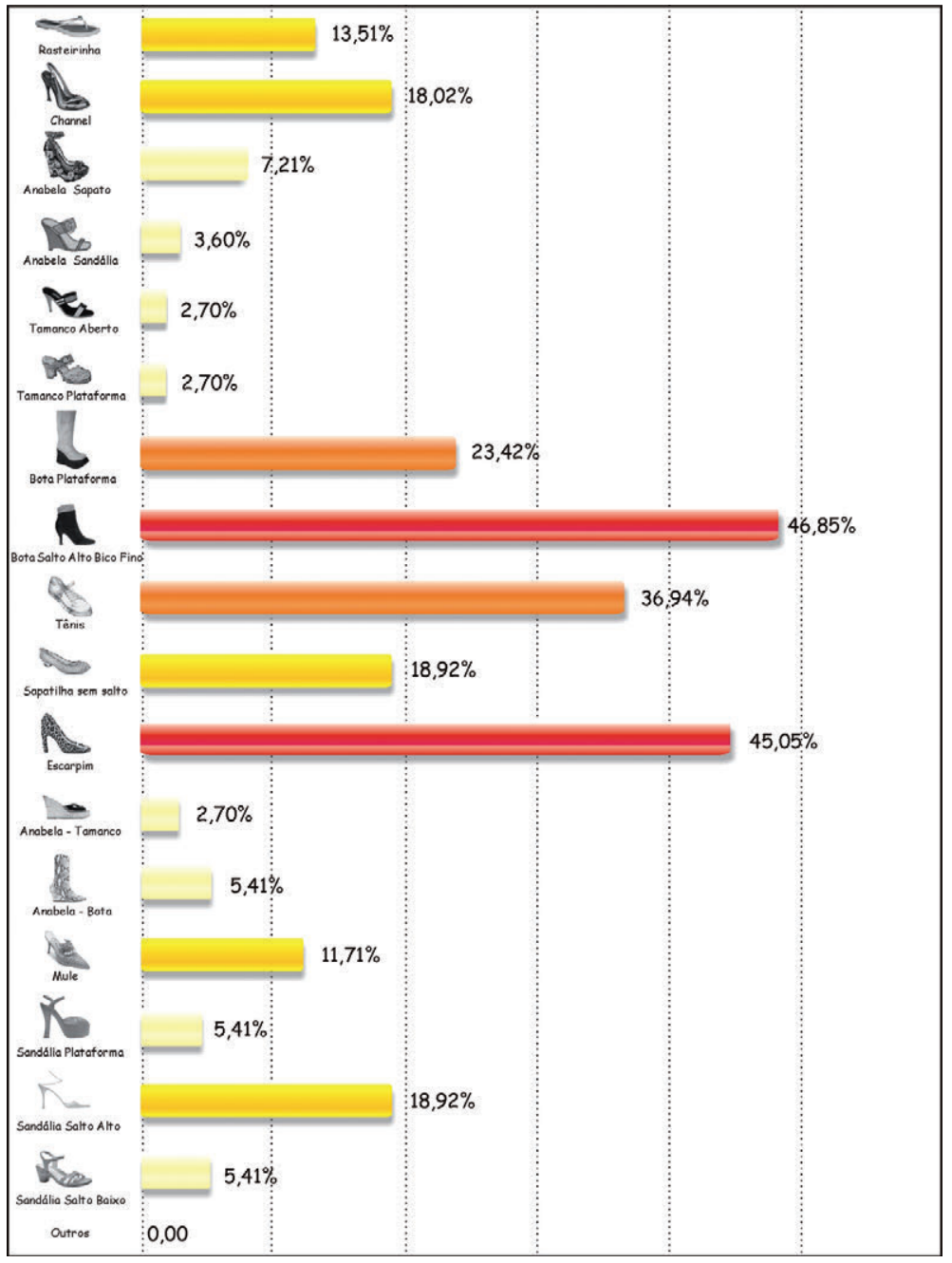

Figura 71. A percepção de diferenças varia de acordo com diferentes modelos. 


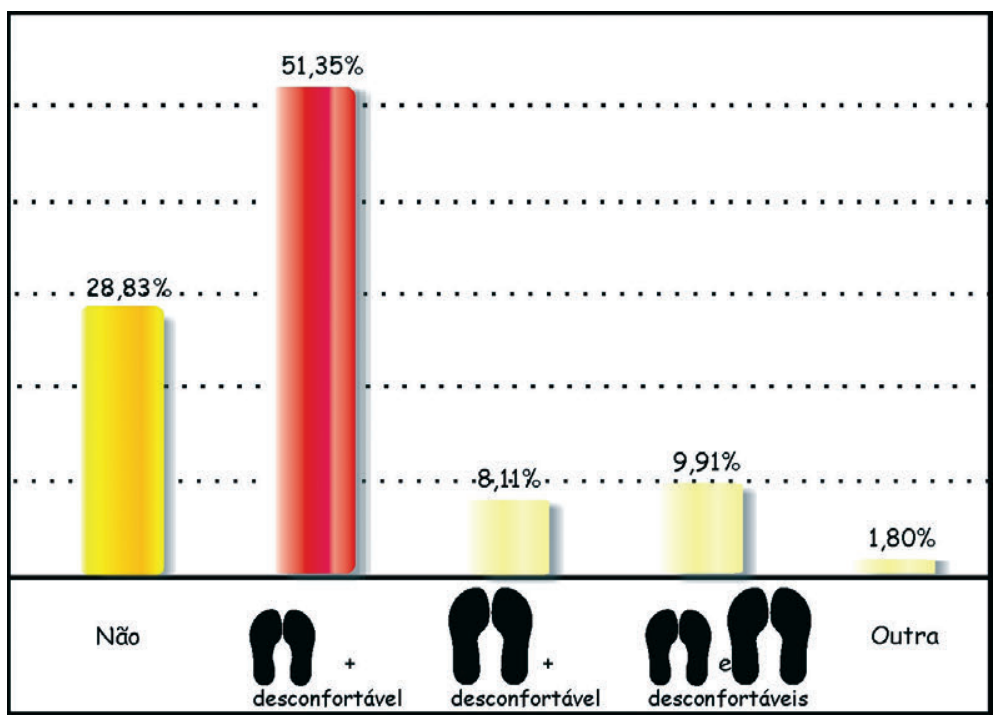

Figura 72. Porcentagem do número de sujeitos que percebem algum tipo de desconforto nos pés devido ao tamanho de calçados menores e maiores.

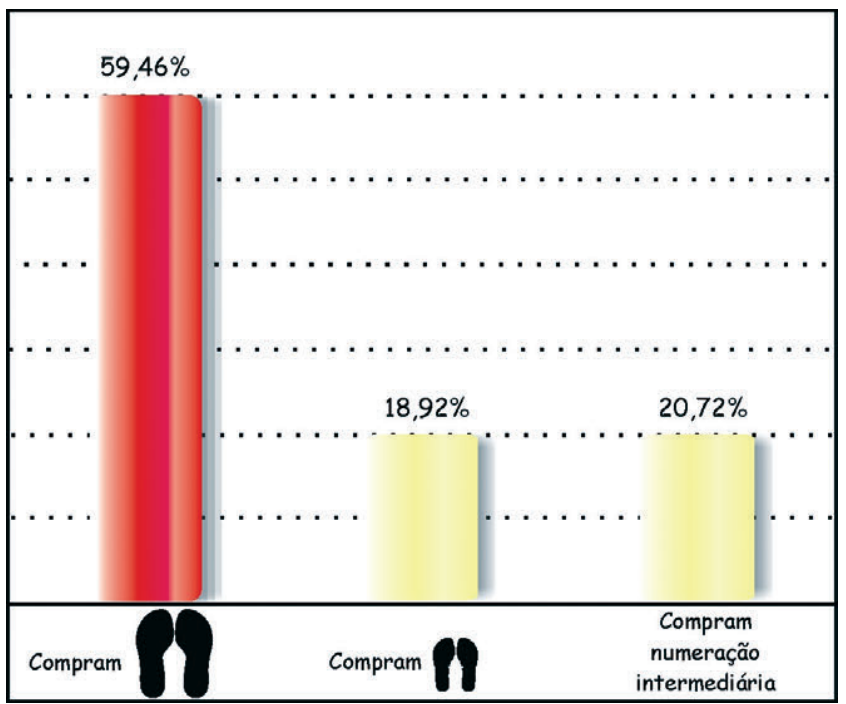

Figura 73. Porcentagem do número de sujeitos que percebem diferença de tamanhos para pé direito e pé esquerdo, durante a compra. 


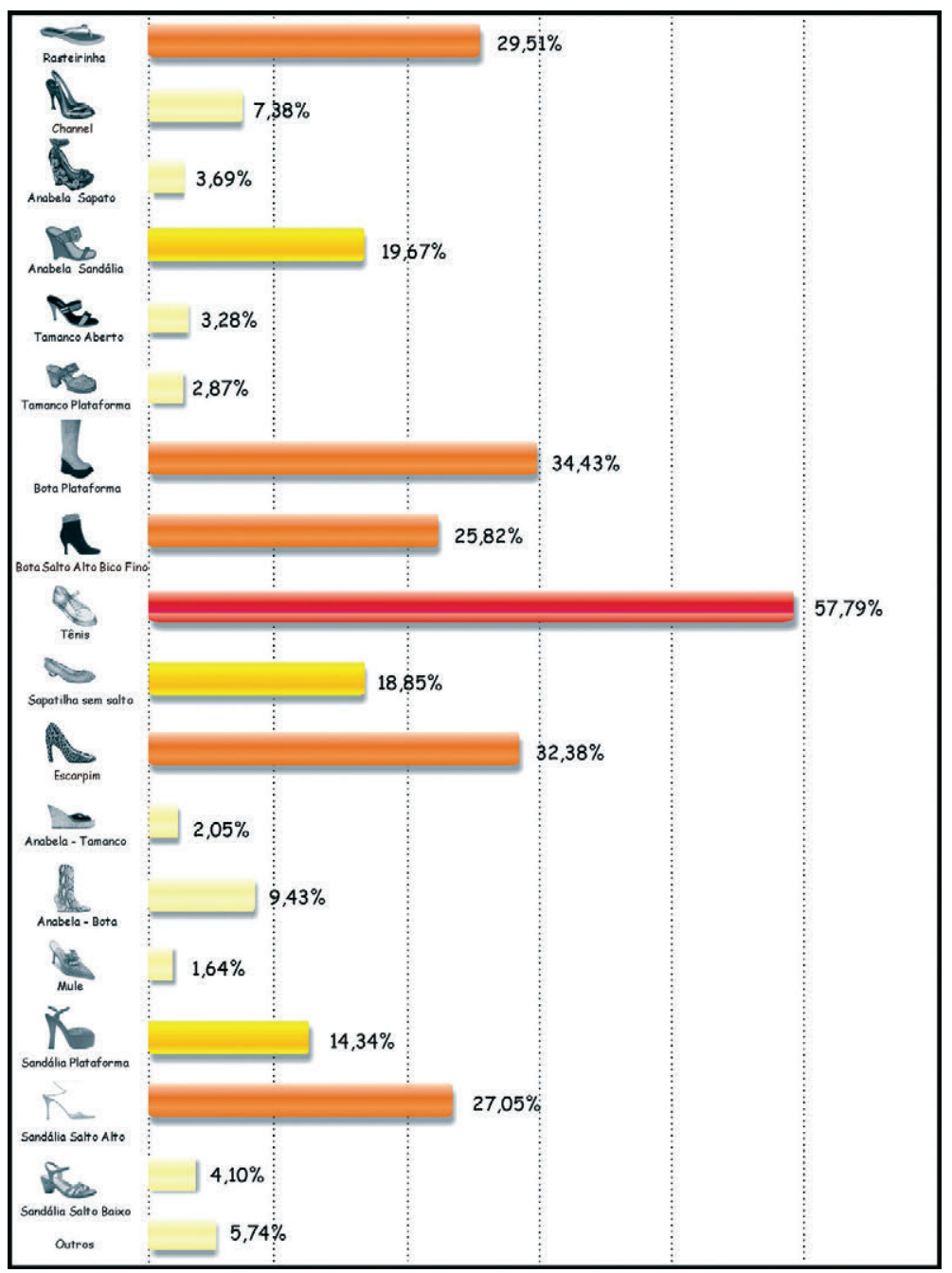

Figura 74. Porcentagem do número de modelos que expressam a individualidade e o próprio sentimento das entrevistadas. 


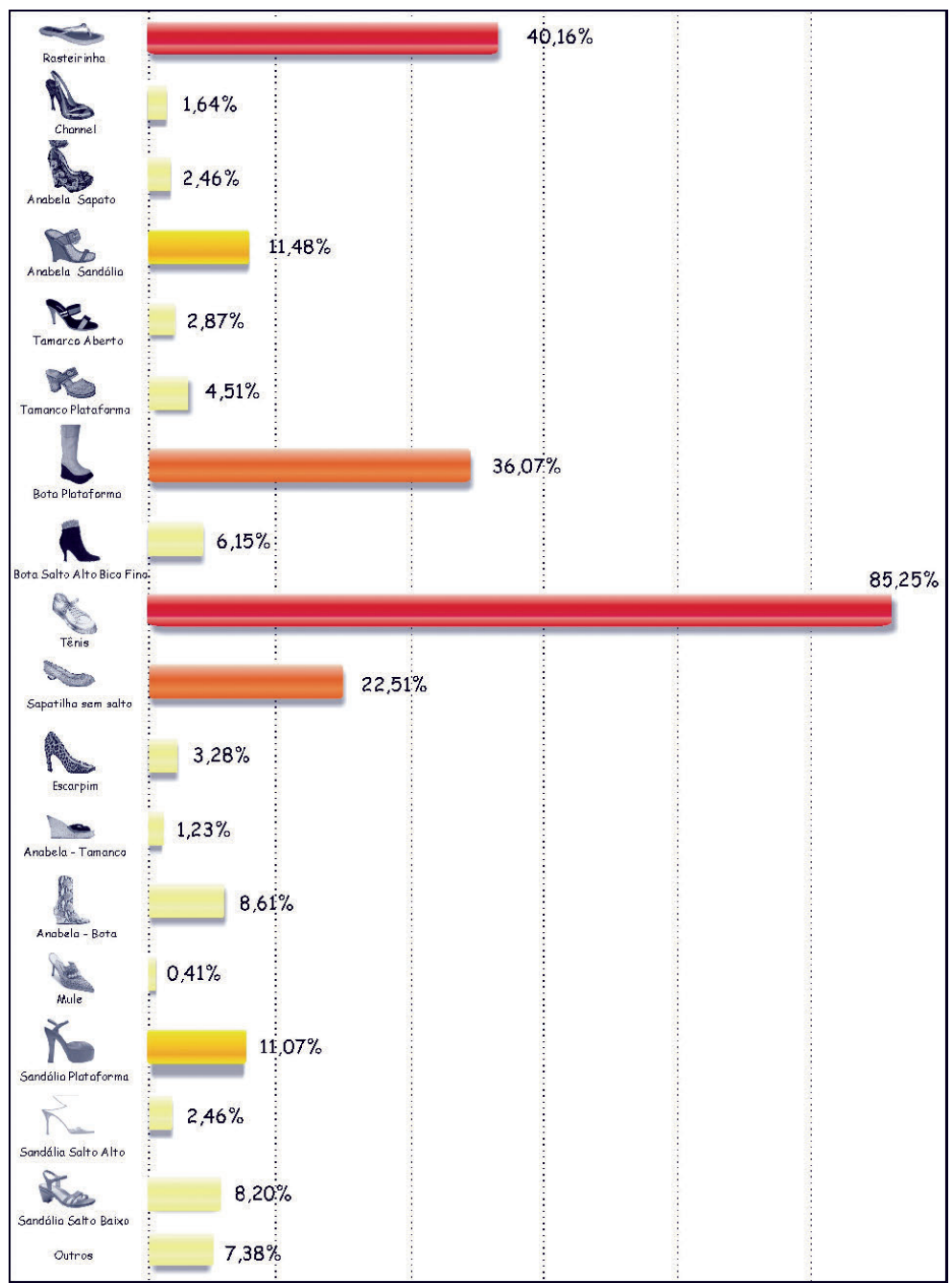

Figura 75. Porcentagem do número de modelos que expressam alívio e relaxamento das entrevistadas. 


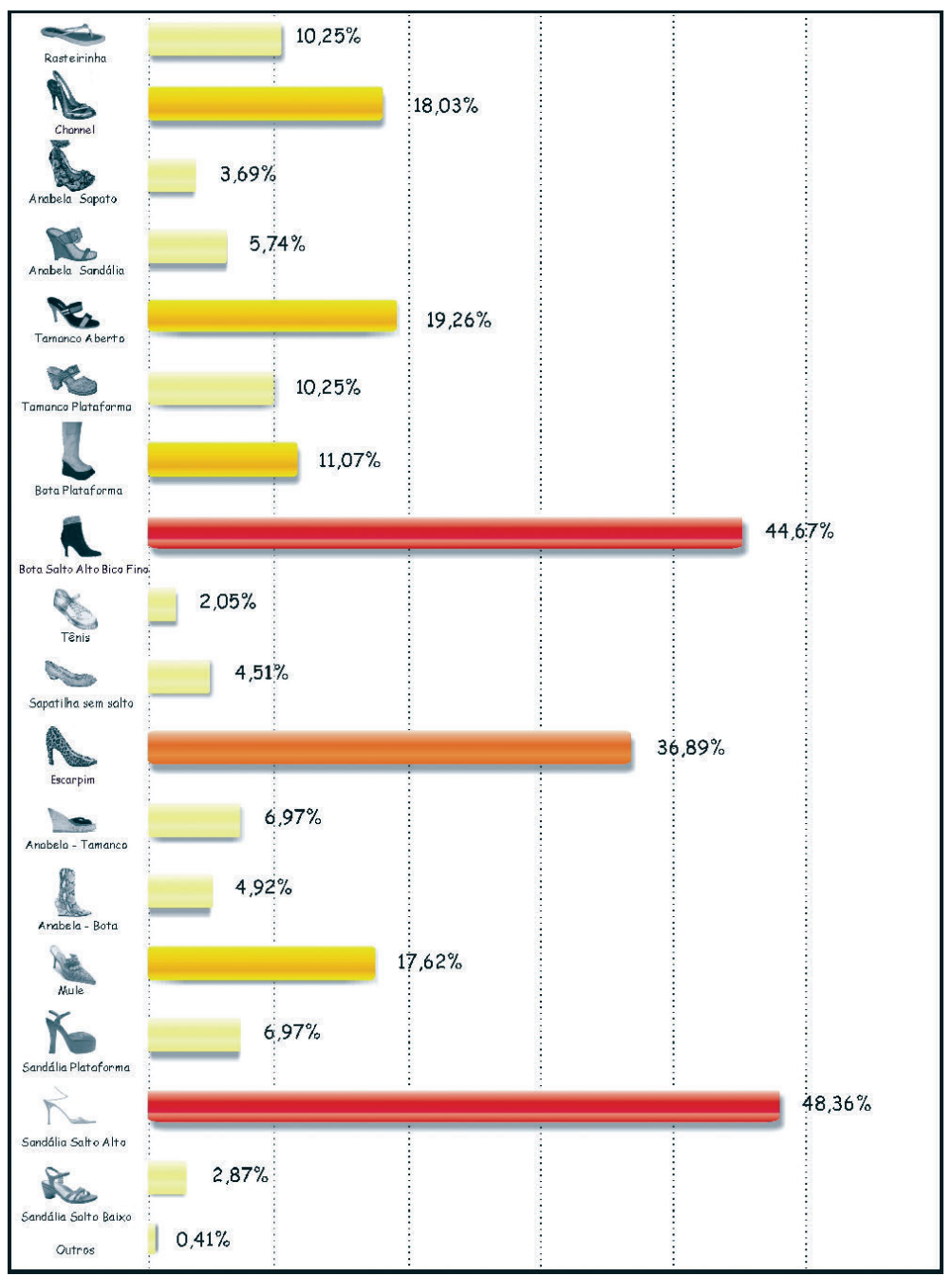

Figura 76. Porcentagem do número de modelos que expressam maior aborrecimento, desprazer ou desconforto das entrevistadas. 


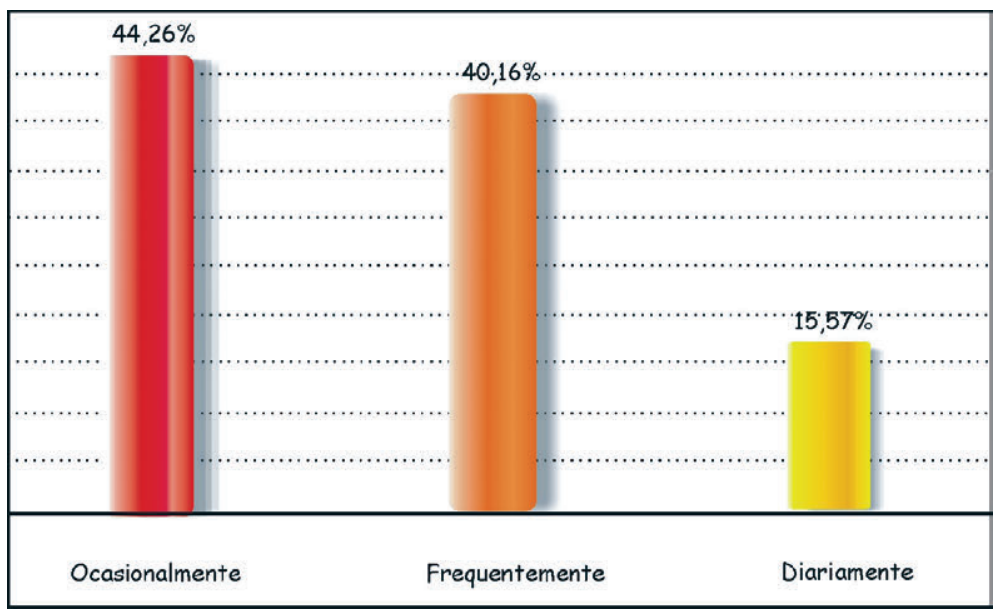

Figura 77. Porcentagem da frequência com que os sujeitos usam salto alto.

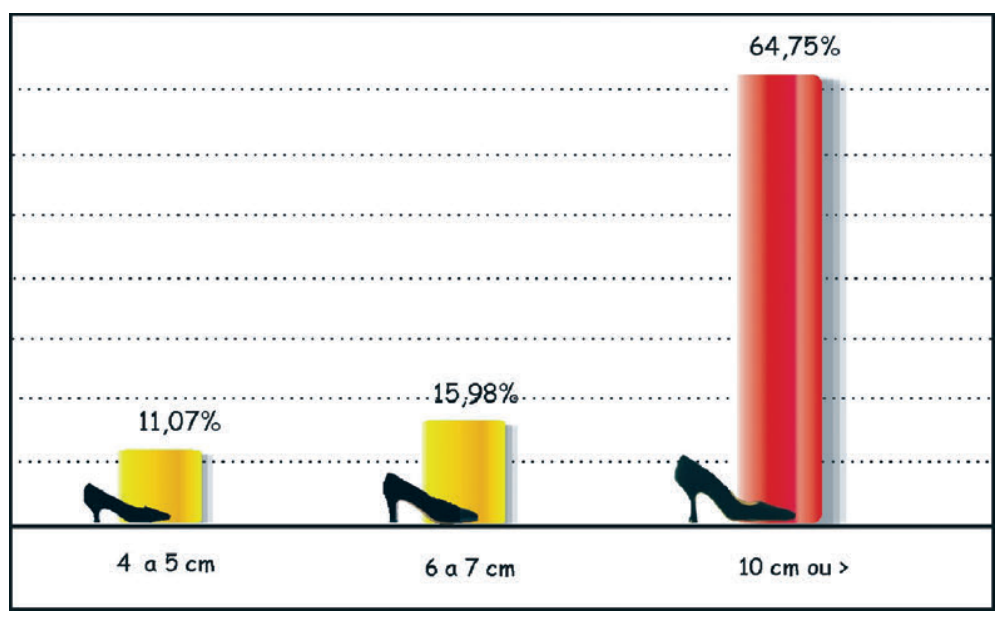

Figura 78. Porcentagem da relação entre altura do salto e percepção de desconforto. 


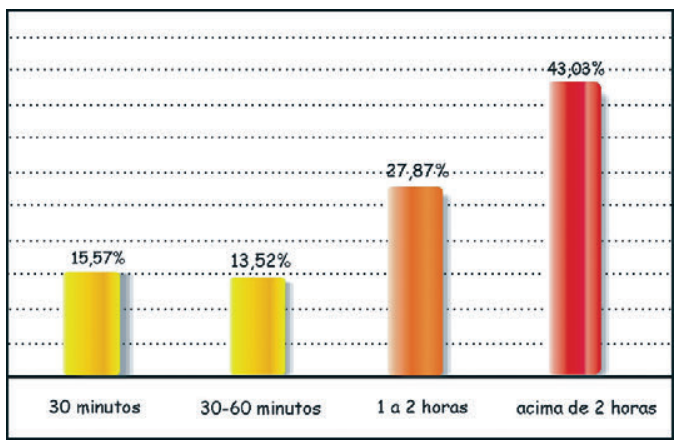

Figura 79. Porcentagem da relação do tempo de uso do salto alto e a percepção de desconforto.

Já quanto à percepção de desconforto nas regiões do corpo humano indicadas pelas usuárias de calçados com salto alto, destacam-se a região lombar (nas costas), com $42 \%$, e a região logo abaixo dos joelhos, na perna direita, com 44\%, e na perna esquerda, com $42 \%$ (figura 80 ).

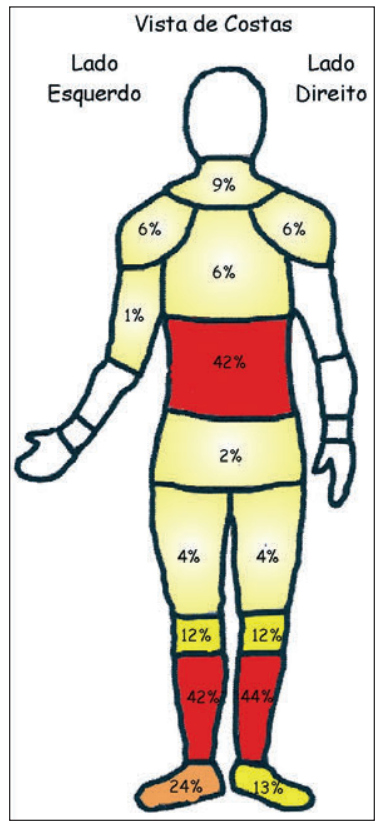

Figura 80. Regiões do corpo humano em que há maior percepção de desconforto. Fonte: Adaptado de Corlett \& Manenica (1980). 


\section{Discussão e considerações finais}

O design ergonômico, associado a outras áreas do conhecimento, busca compreender a relação entre usuários e dispositivos tecnológicos de um sistema, com o objetivo de melhorar os parâmetros projetuais e, consequentemente, a usabilidade de produtos. Dentre os produtos de uso imprescindível para as atividades cotidianas contemporâneas, e que ainda foram pouco estudados quanto à sua interface com os usuários, destacam-se os calçados.

Os calçados são produtos cujas funções relacionam-se à proteção das EMIs e à associação de valor estético ao vestuário de um determinado grupo de indivíduos. Se específicos para a população feminina, a função estética parece sobressair-se à função de proteção, e isto é amplificado quando o calçado feminino apresenta salto alto. O pé é uma estrutura especial do corpo humano, responsável pelo apoio corporal e mecanismo da marcha, sendo muitas vezes comprometido por algumas patologias diretamente relacionadas com o uso de calçados. Observa-se, também, que a evolução histórica desse produto caracteriza-se por uma alternância morfológica, ora atendendo aos aspectos de usabilidade e ora atendendo aos aspectos da moda. Estudos biomecânicos indicam que o calçado de salto alto pode causar problemas fisiológicos.

Após a aplicação dos procedimentos metodológicos e análise dos resultados, pode-se ponderar que a percepção das usuárias é um fator preponderante para o conhecimento do nível de usabilidade do produto que, associado ao conhecimento fisiológico e biomecânico das EMIs, pode contribuir expressivamente para o design ergonômico de calçados femininos.

Nesse sentido, avaliou-se neste capítulo a percepção das usuárias quanto à diferença de tamanho entre os calçados para o pé direito e esquerdo, verificando-se que essa diferença é observada por aproximadamente um terço das usuárias. Essa diferença é mais percebida quando do uso da bota de salto alto e bico fino, escarpim e tênis, os quais se caracterizam por serem "fechados", o que pode estar influenciando essa percepção. Também se constatou que a 
percepção de desconforto é maior se o tamanho do calçado é menor que o pé, o que reitera as condições descritas anteriormente, se os calçados forem fechados. Esses índices parecem influenciar a opção pela compra de calçados um número maior, quando há a percepção de diferença entre os pés direito e esquerdo.

Quanto à expressão de individualidade, verifica-se que o tênis é o mais indicado, seguido da bota plataforma e do escarpim. Nota-se também que, com relação à percepção de alívio e relaxamento, o tênis é o mais indicado. Isso ocorre em função do tipo de sujeitos pesquisados, um grupo de usuárias jovens (18 a trinta anos), universitárias, que fazem uso do tênis para a sua principal atividade diária: o estudo.

A indicação de percepção de desconforto é maior para a sandália de salto alto e a bota de salto alto e bico fino. Observa-se também que a percepção de desconforto apresenta uma relação com o tamanho do salto (figura 78) e com o tempo de uso (figura 79). Nesse sentido, pode-se afirmar que esses resultados indicam que os calçados de salto alto influenciam expressivamente a percepção de desconforto por parte desse grupo de usuárias. Esse resultado é corroborado por alguns estudos biomecânicos que indicam que o uso de calçados com salto alto pode gerar distúrbios físicos e fisiológicos (Ressio, 1999; Kerrigan et al., 2001; Gefen et al., 2002; Lee et al., 2001).

Além disso, o presente capítulo informa que aproximadamente $40 \%$ do grupo de indivíduos pesquisados utilizam frequentemente calçados de salto alto. Isso indica que o uso desse tipo de calçado é bem aceito pelas usuárias, o que parece corroborar o que Monteiro \& Moraes afirmam quando dizem que "as demandas da moda e do conforto, na maioria das vezes, não parecem ser compatíveis” (2005, p.54).

Quanto à percepção de desconforto na região plantar dos pés femininos, observou-se uma maior concentração de pontos no antepé (região metatarsiana e falanges). Schmidt (1995), Carrasco (1995) e Speksnijder et al. (2004) também encontraram elevados valores de pressão nessas regiões anatômicas durante o uso de salto alto e indicam que essa condição pode causar diferentes problemas fisiológicos, comprometendo o desempenho e o conforto durante o uso do produto. 
Com relação à percepção de desconforto nas regiões do corpo humano, as usuárias indicaram a região lombar e as pernas como as mais desconfortáveis. Esse resultado corrobora estudos realizados por Lee et al. (2001), os quais apontam que os calçados com salto alto induzem a uma diminuição significativa da flexão do tronco e um aumento na tensão muscular da região da tíbia anterior e da lombar.

Por fim, pode-se concluir que se analisou uma problemática recorrente na usabilidade de calçados femininos, utilizando a metodologia disponível para o mesmo de modo satisfatório, e demonstrouse uma condição arbitrária, relacionando moda e desconforto. Isso reafirma que estudos na área do design ergonômico são necessários para a melhoria da qualidade de vida dos indivíduos.

\section{Referências bibliográficas}

ALCANTARA, E. et al. Application of product semantics to footwear design. Part I - Identification of footwear semantic space applying differential semantics. International journal of industrial ergonomics, 35, p.713-25. Valencia, Spain, 2005. Disponível em: <www.elsevier.com/ locate/ergon>. Acesso em: 15 nov. 2005.

AÑEZ, C. R. R. Antropometria na ergonomia. Disponível em: <http://www. eps. ufsc.br/ergon/revista/artigos/Antro_na_Ergo.PDF>. Acesso em: 13 maio 2006.

BORG, G. Escalas de Borg para a dor e o esforço percebido. São Paulo: Manole, 2000.

BUCKLE, P. Musculoskeletal disorders at work. Londres: Taylor \& Francis, 1987. 262p.

BÜRDEK, B. E. História, teoria e prática do design de produtos. São Paulo: Edgard Blücher, 2006.

CARRASCO, J. M. Estilismo e modelagem: técnica do calçado. Porto Alegre: Palloti, 1995.

CORLETT, E. N., MANENICA, I. The effects and measurement of working postures. Applied ergonomics, v.11, n.1, p.7-16, 1980.

DRURY, C. G., COURY, B. G. A methodology for chair evolution. Applied ergonomics. v.13, n.3, p.195-202, 1982. 
EISENHARDT, J. A. et al. Changes in temporal gait characteristics and pressure distribution for bare feet versus various heel heights. Gait $\mathcal{E}$ posture, 4, p.280-86, 1996.

FERREIRA, A. B. de H. Novo Aurélio século XXI: o dicionário da Língua Portuguesa. 3.ed. Rio de Janeiro: Nova Fronteira, 1999. 2128p.

FISCHER-MIRKIN, T. O código do vestir: os significados ocultos da roupa feminina. Rio de Janeiro: Rocco, 2001.

GARCIA, C., MIRANDA, A.P .de. Moda é comunicação: experiências, memórias, vínculos. São Paulo: Anhembi Morumbi, 2007.

GEFEN, A. et al. Analysis of muscular fatigue and foot stability during high-heeled gait. Gait E posture. 15, p.56-63, 2002. Disponível em: <www.elsevier.com/locate/gaitpost>. Acesso em: 15 nov. 2005.

GOMES FILHO, J. Ergonomia do objeto: Sistema técnico de leitura ergonômica. São Paulo: Escrituras, 2003.

Design do objeto: bases conceituais. São Paulo: Escrituras, 2006.

HUI, L., HSIEN, H. Effects of shoe inserts and heel height on foot pressure, impact force, and perceived comfort during walking. Applied ergonomics, 36, p.355-62, 2005. Disponível em: <www.elsevier.com/ locate/apergo>. Acesso em: 15 nov. 2005.

IIDA, I. Ergonomia: projeto e produção. São Paulo: Edgard Blucher, 2005.

JONES, S. J. Fashion design - manual do estilista. São Paulo: Cosac Naify, 2005.

JORDAN, P. W. Human factors for pleasure in product use. Applied ergonomics. 29 (01), p.25-33, 1998.

KERRIGAN, C., LELAS, J. L., KARVOSKY, M. E. Women's shoes and knee osteoarthritis. The Lancet, v.357, abril 7, 2001.

KERRIGAN, C. et al. Moderate-heeled shoes and knee joint torques relevant to the development and progression of knee osteoarthritis. Arch Phys Med Rehabil, v.86, p.871-75, maio 2005.

LACERDA, D. F. Medição antropométrica dos pés. Tese (Mestrado), COPPE/UFRJ, 1984.

LAVER, J. A roupa e a moda. São Paulo: Cia. das Letras, 1989.

LEE, C., JEONG, E., FREIVALDS, B.A. Biomechanical effects of wearing high-heeled shoes. International Journal of industrial ergonomics, 28 , p.321-26, 2001. Disponível em: <www.elsevier.com/locate/ergon>. Acesso em: 15 nov. 2005.

LOBÄCH, B. Design industrial - bases para a configuração dos produtos industriais. São Paulo: Edgard Blücher, 2001. 
LUEDER, R. K. Seat comfort: a review of the construct in the office environment. Human Factors, 25(06), p.701-11, 1983.

MANFIO, E. F., ÁVILA, A. O.V. Um estudo de parâmetros antropométricos do pé feminino. Disponível em: <http://ctcca.locaweb.com.br/index. php?idiomas_id $=1 \&$ menus_site_id $=29 \&$ acao $=$ conteudo\&conteudos_ $\mathrm{id}=275>$. Acesso em: 27 ago. 2005.

MANFIO, E. F. et al. Alterações na marcha descalça e com sapato de salto. In: X CONGRESSO BRASILEIRO DE BIOMECÂNICA, 2003, Ouro Preto. Anais.... Belo Horizonte: Sociedade Brasileira de Biomecânica, 2003. v.1. p.87-90.

McWHORTER, J. M. et al. The effects of walking, running, and shoe size on foot volumetrics. Physical Therapy in Sport, 4, p.87-92, 2003. Disponível em: <www.elsevier.com/locate/yptsp>. Acesso em: 15 nov. 2005.

MONTEIRO, V. A. Calçado feminino. Estudos em Design, v.8. Rio de Janeiro, abril, 2000.

MONTEIRO, V. A., MORAES, A. de. Ergonomia, design e conforto no calçado feminino. In: MORAES, A. de. Ergodesign de produto: agradabilidade, usabilidade, segurança e antropometria. Rio de Janeiro: Anamaria de Moraes, 2005. p.37-66.

MONTEMEZZO, M. C. de F. S. Diretrizes metodológicas para o projeto de produto de moda no âmbito acadêmico. Dissertação (Mestrado). Bauru: Unesp, 2003. Educação Gráfica - Edição Especial, 2008.

NEWMAN, C. Cada sapato conta uma história. National Geographic Brasil. São Paulo: Editora Abril, ano 7, n.78, set. 2006.

NOYES, J. Designing for humans. Hove (East Sussex): Psychology Press, 2001.

O'KEEFFE, L. Sapatos: uma festa de sapatos de salto, sandálias, chinelos. Nova Iorque: Workman Publishing, 1996.

OZDEN, H. et al. Stature and sex estimate using foot and shoe dimensions. Forensic Science International, 147, p.181-84, 2005. Disponível em: <www.elsevier.com/locate/forsciint>. Acesso em: 15 nov.2005.

PASCHOARELLI, L. C. Usabilidade aplicada ao design ergonômico de transdutores de ultrassonografia: uma proposta metodológica para avaliação e análise do produto. São Carlos, 2003. Tese (Doutorado)-UFSCAR. PERICE, A. V. Dez lições de patologia do pé. São Paulo: Roca, 1986. 202p. PHEASANT, S. Bodyspace: anthropometry, ergonomics and the design of work. 2.ed. Londres: Taylor \& Francis, 1996. 244p. 
PHELAN, S.T. Fads and fashions: the price women pay. Elsevier Science, 2002.

POTÉRIO FILHO, J. Pesquisa conclui que uso do salto alto é benéfico. Disponível em: <http://www.unicamp.br/unicamp/unicamp_hoje/ ju/setembro2003/ju229pg 11b.html>. Acesso em: 17 mar. 2006.

PULS, L. M. Moda e tecnologia. Florianópolis: Udesc, 2003.

RECH, S. R. Moda, por um fio de qualidade. Florianópolis: Udesc, 2002.

REICHERT, C. Estudos da antropometria do pé. Disponível em: <http:// www.abicalcados.com.br/documentos/literatura_tecnica/ANTROPOMETRIA\%20DO\%20P\%C9.doc>. Acesso em: 30 out. 2005.

ROEBUCK, J. Anthropometric methods: designing to fit the human body. Santa Monica, California: Human Factors and Ergonomics Society, 1995.

RESSIO, C. Avaliação baropodométrica da influência de saltos altos em indivíduos normais. São Paulo: 1999. Dissertação (Mestrado em Ortopedia) - Escola Paulista de Medicina, USP.

RUSSO, B., MORAES, A. de. Usabilidade x agradabilidade de produtos. In: MORAES, A. de. Ergodesign de produto: agradabilidade, usabilidade, segurança e antropometria. Rio de Janeiro: Anamaria de Moraes, 2005. p. 93-103.

SANDERS, M. S., McCORMICK, E. J. Human factors in engineering and design. Nova Iorque: McGraw Hill, 1993.

SCHMIDT, M. R. Modelagem técnica de calçados. Porto Alegre: Senai/ RS, 1995. 398p.

SEELING, C. Moda: o século dos estilistas - 1900-1999. Colônia: Könemann, 2000.

SENAI. Inspirações para o Design de Moda/Primavera-Verão 2006/2007. Caderno de inspirações para o design de moda: verão 2006/2007. Senai Cetiqt. Rio de Janeiro: Senai/DN, 2005. 64p.

SLATER, K. Human comfort. Springfield (Illinois): Charles C. Thomas, 1985.

SPEKSNIJDER, C. M. et al. The higher the heel the higher the forefootpressure in ten healthy women. Netherlands, 2004.

STEELE, V. Shoes - a lexicon of style. Nova Iorque: Rizzoli International Publications, 1998.

TILLEY, A. R. As medidas do homem e da mulher. Porto Alegre: Bookman, 2005. 
TRIOLA, M. F. Introdução à estatística. Rio de Janeiro: LTC Livros Técnicos e Científicos, 1998.

VAN der LINDEN, J. C. Um modelo descritivo da percepção de conforto e de risco em calçados femininos. Porto Alegre, 2004. Tese (Doutorado) - UFRGS.

ZARO, M. A. et al. Biomecânica e as normas brasileiras para certificação do conforto do calçado. Disponível em: <http://ctcca. locaweb.com.br/ imagens/conteudo/artigo_cient.pdf>. Acesso em: 30 out. 2005. 



\title{
12 \\ INSATISFAÇÃO E DESCONFORTO: \\ O CASO DA POLTRONA DO MOTORISTA DE ÔNIBUS URBANO
}

\author{
Roberto Carlos Barduco ${ }^{1}$ \\ Abilio Garcia dos Santos Filho ${ }^{2}$
}

\section{Introdução}

O desconforto é um indicador de risco usado para detectar possíveis problemas no corpo. Suas possíveis causas, resultando da tensão músculo-esquelética, são o tensionamento dos músculos, nervos, vasos sanguíneos, ligamentos e membranas das articulações, a compressão de alguns tecidos do corpo, fadiga muscular, déficit de circulação sanguínea e "parcialisquemia", desobstrução dos nervos ocasionando pressão e inflamações secundárias. As atividades diárias dos motoristas de ônibus urbano incluem: muitas paradas (número excessivo de movimentos repetitivos); necessidade de deslocar o banco no sentido horizontal para colocar-se e sair do assento, devido ao espaço reduzido da cabina; revestimento do assento de material sintético ocasionando desconforto devido à transpiração; disfunções humanas (problemas posturais entre outros fatores relacionados ao posto de trabalho do condutor).

Para se amenizar essas situações e projetar um posto de trabalho ideal para os motoristas, alguns conceitos devem ser considerados. Dentre

1 Mestre em design, Universidade Estadual Paulista.

2 Livre-docente, Universidade Estadual Paulista. 
eles, seguem alguns relacionados à poltrona: o assento dos motoristas deve ter ajustes verticais e horizontais, bem como apoio com ajuste para a região lombar, devido ao longo período em posição sentada; todos os controles para ajuste do assento devem ser de fácil operação; motoristas grandes e pequenos devem ser capazes de entrar e sair facilmente do seu posto de trabalho.

O presente capítulo teve como objetivo detectar os desconfortos e insatisfações dos motoristas de ônibus urbanos com a poltrona que trabalham.

\section{Metodologia}

A pesquisa foi realizada de forma descritiva: realizou-se um estudo de caso em sete empresas de ônibus urbano na cidade de São Paulo, tendo sido entrevistados 147 motoristas de ônibus. Os motoristas responderam a um questionário, com perguntas abertas. $\mathrm{O}$ objetivo foi avaliar e comparar possíveis insatisfações e desconfortos e caracterizar o perfil dos motoristas, problemas de saúde e descrever as opiniões e sugestões dos motoristas com relação à poltrona.

\section{Critério de inclusão e delimitação da população}

O critério de escolha das empresas foi identificar aquelas que fossem especificamente de ônibus urbano e que estivessem estabelecidas de forma estratégica dentro do perímetro urbano da cidade de São Paulo, permitindo linhas de itinerários diferentes, que exigissem dos motoristas as mais diversas situações de trabalho.

As empresas juntas totalizavam um quadro de funcionários equivalente a 8.000 empregados. Foram entregues duzentos questionários, sendo divididos 28 questionários por empresa, obtendo o retorno de 147 pesquisas, totalizando uma média de 21 questionários por empresa. O questionário continha perguntas abertas e foi entregue aos 
motoristas para que o levassem para casa e respondessem de forma espontânea, sem necessidade de identificação, com o propósito de obter um aproveitamento maior da pesquisa, pois o entrevistado teria mais tempo para responder solicitando, se fosse o caso, a ajuda da família. Todos os motoristas que responderam estavam em atividade no momento da pesquisa e tiveram liberdade total para a disposição das respostas.

\section{Critérios de exclusão}

\section{Exclusão dos motoristas}

Para exclusão dos motoristas, usaram-se as seguintes considerações: motoristas que não quiseram responder ao questionário proposto, motoristas que estavam afastados do serviço e motoristas que não estavam presentes no dia da entrega do questionário.

\section{Exclusão das respostas}

Para exclusão das respostas foram usados os seguintes critérios: perguntas respondidas de forma ilegível ou difíceis de interpretar, perguntas mal interpretadas pelo entrevistado e perguntas reavaliadas e desconsideradas no conteúdo da pesquisa.

\section{Instrumentos utilizados para a pesquisa}

Para caracterização da população estudada, foram feitas questões divididas em cinco grupos: questões pessoais do entrevistado, considerando tempo de descanso, idade, grau de instrução, escolaridade, altura, peso e IMC, estado civil e tempo de trabalho; questões de saúde, considerando problemas lombares e varizes; questões da poltrona, considerando sugestões de melhorias e ou reclamações, incômodo, regulagens, revestimentos, postura, encosto de cabeça, apoia-braços, 
acesso ao posto, apoio dos pés; questões sobre o cinto de segurança, considerando incômodo, usabilidade; estimativas de mudanças de marchas e aberturas de portas.

\section{Limitações do estudo}

As perguntas abertas foram para proporcionar possíveis sugestões ou queixas. A proposta foi levarem a pesquisa para casa, deixando-os livres e mais à vontade para responder, eliminando assim pressão nas decisões das respostas, pois o motorista poderia solicitar até ajuda dos familiares, considerando que por se tratar de pesquisa descritiva muitos teriam dificuldade no preenchimento.

\section{Análise dos dados estatísticos}

Os dados dos questionários, tanto as variáveis quantitativas como as qualitativas, foram organizadas em planilhas do Excel. Foram determinadas medidas representativas tais como média, desvio padrão, valores máximos, mínimos e porcentagens. Essas medidas possibilitaram comparações com resultados de pesquisas semelhantes realizadas por outros pesquisadores.

\section{Resultados e discussões}

\section{Dados respectivos à poltrona do motorista}

\section{Presença de encosto de cabeça nas poltronas}

Dos entrevistados, 94,59\% disseram que a poltrona não tem encosto de cabeça; 4,05\% disseram ter encosto de cabeça. De acordo com o Conselho Nacional de Trânsito (Contran), Resolução n¹4/98, os veículos 
automotores produzidos a partir de primeiro de janeiro de 1999 devem ser dotados com encosto de cabeça como equipamento obrigatório, em todos os assentos dos automóveis, exceto nos assentos centrais. Pode-se observar que a maioria das poltronas não apresentou esse item, apesar de ser mencionado em lei.

\section{Sugestões de melhorias da poltrona}

Quando foi perguntado aos motoristas se tinham algumas sugestões para a poltrona que utilizavam, 85,14\% (ou seja, a maioria) manifestou algum tipo de sugestão ou reclamação, mostrando então o descontentamento dos motoristas com as mesmas, e 14,19\% não apresentaram sugestões. Essa questão permite analisar a insatisfação dos motoristas. Na tabela 32 é possível verificar as sugestões de melhorias feitas pelos entrevistados em ordem decrescente. Com esses resultados, pode-se concordar com Millies (1998) em que é comum encontrar estudos que considerem os assentos dos motoristas de ônibus como "pobres", quanto à concepção e que não geram conforto, resultando em dores musculares e problemas lombares. Analisando a tarefa do motorista de ônibus, Peacock \& Karwowski (1993), Park et al. (2000) e Saporta (2000) citam a existência de quatro critérios que definem um assento confortável para o motorista: o assento deve proporcionar ao motorista total visibilidade e alcance dos controles e instrumentos; o assento tem que acomodar todos os tipos e tamanhos de motoristas independentemente do modelo; o assento deve ser confortável por longos períodos, permitindo a alternância de postura, com tecidos que não absorvam o calor e com existência de ajustes lombares; o assento deve ser uma zona de segurança para o motorista.

Sobre os ajustes das poltronas, concorda-se com Grieco et al. (1997) e Occhipint et al. (1993), que disseram que os vários ajustes da cadeira devem ser feitos de forma fácil e prática pelo usuário. Segundo Kompier (1996) e Woodson et al. (1993), os postos de trabalho dos ônibus são em sua maioria desconfortáveis, inflexíveis e expostos a todos os elementos prejudiciais à saúde dos usuários, como calor, frio, poluição, ruídos etc. 
Tabela 32. Sugestões e queixas dos motoristas.

\begin{tabular}{cll|c|c}
\hline item & \multicolumn{1}{c|}{ Tipos de sugestões } & $\mathrm{N}$ & $\%$ \\
\hline 1 & melhorar a forma de regulagem & 71 & 47,97 \\
2 & que deslizem lateralmente & 28 & $\mathbf{1 8 , 9 1}$ \\
3 & mais conforto & 27 & $\mathbf{1 8 , 2 4}$ \\
4 & melhorar o encosto & 20 & $\mathbf{1 3 , 5 2}$ \\
5 & melhorar espaço próximo à poltrona & 19 & $\mathbf{1 2 , 8 4}$ \\
6 & falta de manutenção & 15 & $\mathbf{1 0 , 1 3}$ \\
7 & com regulagens mais rápidas & 14 & 9,46 \\
8 & encosto mais alto & 12 & 8,18 \\
9 & poltronas mais macias & 10 & 6,76 \\
10 & qualidade ruim das poltronas & 9 & 6,09 \\
$\mathbf{1 1}$ & amortecedores não funcionam & 8 & 5,42 \\
12 & regulagem se danificam rapidamente & 8 & 5,41 \\
13 & poltrona balança muito & 6 & 4,06 \\
14 & poltronas iguais rodoviários & 5 & 3,38 \\
15 & melhorar o revestimento & 4 & 2,72 \\
$\mathbf{1 6}$ poltronas iguais modelos novos & 3 & 2,03 \\
\hline
\end{tabular}

\section{Presença de apoia-braços nas poltronas}

Quando questionados a respeito da presença de apoia-braços na poltrona, uma porcentagem grande dos entrevistados, 72,30\%, disse não haver necessidade dos mesmos; 22,30\% disseram querer apoio para os braços; 5,41 \% não responderam. Porém, Panero \& Zelnick, 1993, constataram que os apoia-braços desempenham a função de aliviar o peso dos braços, ajudam a levantar-se e a sentar-se e também podem ser usados como descanso para os braços.

\section{Uso de revestimento sobre a poltrona}

Dos motoristas entrevistados, 77,70\% (a maioria) reclamaram de o revestimento da poltrona provocar muita transpiração; 18,24\% disseram não apresentar problemas de transpiração com a poltrona. Para aliviar o desconforto, $64,19 \%$ dos motoristas (mais da metade) colocam algum tipo de revestimento em cima da poltrona. Os motoristas acreditam que o uso desses revestimentos, além do alívio para com o desconforto da transpiração, os auxilia em outros fatores, como proteger a roupa contra poltronas sujas nas trocas de veículos, aliviar as dores e trazer sensação de conforto, conforme demonstra a figura 81 . 
Dos revestimentos mais utilizados pelos motoristas, as preferências em ordem de prioridade são o revestimento em capa de pano, revestimentos de bolinhas de madeira e almofada, conforme a figura 82. Entende-se então que a utilização de algum revestimento faz-se pela busca do conforto. Portanto, concorda-se com Pheasant (1986) que os materiais de revestimento devem ser porosos para permitirem a ventilação e ásperos para proporcionarem estabilidade. Segundo Iida et al. (1999), em uma pesquisa realizada com cadeiras de escritórios, o revestimento foi também um dos itens mais valorizados.

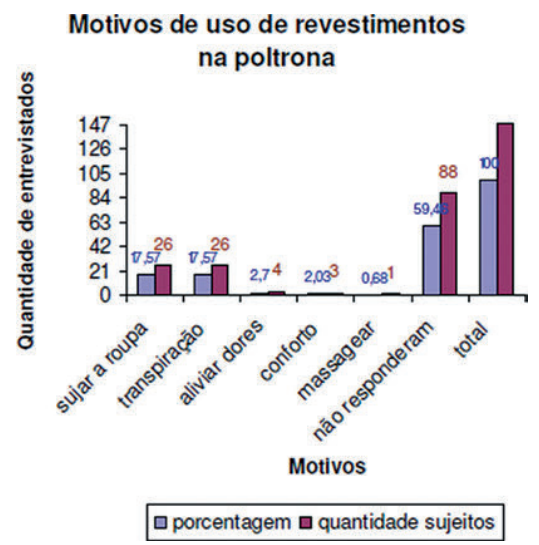

Figura 81. Motivos que levam os motoristas a usarem revestimentos sobre a poltrona.

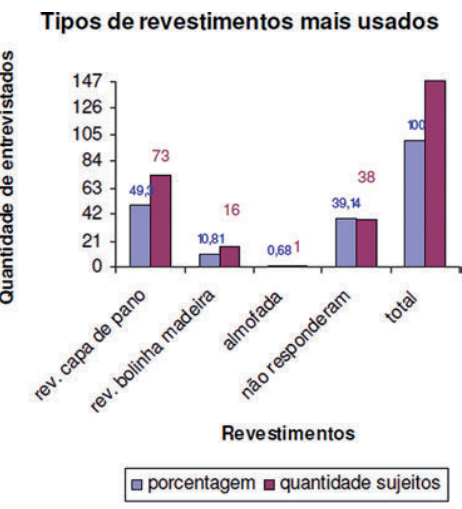

Figura 82. Gráfico demonstrativo dos tipos de revestimento mais usados pelos motoristas. 


\section{Incômodo na poltrona}

Sobre se existe algo que incomoda na poltrona, 47,97\% dos motoristas entrevistados disse não haver nada que os incomoda na poltrona; 45,95\% reclamaram que alguma parte da poltrona os incomoda. Portanto, concorda-se com Iida (1995), quando afirma que condições ambientais desfavoráveis podem tornar-se uma grande fonte de tensão na execução das tarefas em qualquer situação de trabalho. Pesquisas ergonômicas associam fatores fisiológicos, biomecânicos e de fadiga à sensação de desconforto (Zhang, 1996, Helander \& Zhang, 1997). Alguns autores têm considerado desconforto e dor como sinônimos, porém, a intensidade do desconforto tende a aumentar antes da ocorrência da dor, sugerindo que o desconforto seja mais sensível a pequenos graus de estímulos nocivos (Bates et al. 1989).

\section{Acesso ao posto do motorista}

Dos motoristas entrevistados, 52,03\% reclamaram do acesso (sentar/sair da poltrona) ser desconfortável, principalmente ao tratar-se de ônibus com motor dianteiro, enquanto $39,86 \%$ não se incomodam. Segundo Saporta (2000), o posto de trabalho do motorista de ônibus é menos importante durante o projeto que o salão dos passageiros, e ainda é comum que o projeto da cabine do motorista não seja desenvolvido sobre o seu ponto de vista, mas, sim, focando o layout para otimização das poltronas para passageiros.

Segundo Kompier (1996) e Woodson et al. (1993), os motoristas grandes e pequenos devem ser capazes de entrar e sair facilmente do seu posto de trabalho. Concordando com Panero \& Zelnick (1984), recomenda-se que, em um posto de trabalho, ao se estabelecerem as dimensões, deve-se priorizar a passagem (relação quanto à altura e largura). É determinante considerar as dimensões dos usuários de porcentagens maiores, pois são eles que terão problemas para passar e não os usuários de porcentagens menores. Quando se cruzou a altura dos entrevistados com a questão de se o ato de sentar/sair da poltrona é incômodo, constatou-se que os motoristas com até 1,56 m de altura não se queixam, mas o restante dos motoristas com alturas superiores apresentam muitas queixas, como mostra a tabela 32. 
Tabela 33. Relação faixa de altura e incômodo em sentar/sair do posto do motorista.

\begin{tabular}{|c|c|c|c|c|c|c|}
\hline \multicolumn{2}{|c|}{ 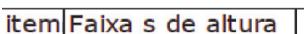 } & \multicolumn{2}{|c|}{ é incomodo } & \multicolumn{3}{|c|}{ 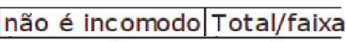 } \\
\hline & & $\mathrm{N}$ & 0 & & 3 & 3 \\
\hline 1 & de até $1,59 \mathrm{~m}$ & $\%$ & 0 & $\mathbf{F}$ & 100,00 & 100,0 \\
\hline & & $\mathrm{N}$ & 21 & & 14 & 35 \\
\hline 2 & de 1,60 até 1,69 r & $\%$ & 60,00 & $\mathbf{r}$ & 40,00 & 100,00 \\
\hline & & $\mathrm{N}$ & 46 & & 30 & 76 \\
\hline 3 & de 1,70 até $1,79 \mathrm{r}$ & $\begin{array}{l}\% \\
N\end{array}$ & $\begin{array}{c}60,53 \\
9\end{array}$ & $\boldsymbol{r}$ & $\begin{array}{c}39,47 \\
9\end{array}$ & $\begin{array}{c}100,00 \\
18\end{array}$ \\
\hline 4 & de 1,80 até $1,89 \mathrm{r}$ & $\%$ & F 50,00 & $\mathbf{P}$ & 50,00 & $\begin{array}{c}100,00 \\
4\end{array}$ \\
\hline 5 & de 1,90 até 2,00 r & $\%$ & 25,00 & $\boldsymbol{F}$ & 75,00 & 100,00 \\
\hline & Total geral & $\begin{array}{l}\mathrm{N} \\
\%\end{array}$ & $\begin{array}{c}77 \\
56,00\end{array}$ & $\boldsymbol{F}$ & $\begin{array}{c}59 \\
43,38\end{array}$ & $\begin{array}{c}136 \\
100,00\end{array}$ \\
\hline
\end{tabular}

\section{Trabalhar com os pés apoiados no chão}

Em relação a trabalhar com os pés apoiados ou não no chão, $82,43 \%$ disseram trabalhar com os pés apoiados no chão; 8,78\% disseram não trabalhar com os pés apoiados no chão. Os motoristas que alegaram não trabalhar com os pés apoiados no chão totalizaram $8,78 \%$ e, desse total, 46\% disseram ser por falta de condições do banco.

Para conforto nos membros inferiores, os pés devem estar bem apoiados sobre o solo e não deve haver compressão das coxas (Brasil, 2002). Segundo Panero \& Zelnik (1993), o desenho de um assento procurará dividir o peso do corpo que suporta nas tuberosidades isquiáticas sobre uma superfície mais extensa.

\section{Postura correta sentada}

Em relação à postura, ou seja, se os motoristas acreditam estar sentados corretamente enquanto trabalham, 58,11\% acreditam que sentam corretamente e 33,78\% não acreditam sentar na posição correta. De acordo com Iida (1990), o motorista, ao passar diversas horas na direção, não se permite muitas mudanças na postura, ficando em uma posição quase fixa no assento. A duração prolongada da tarefa produz fadiga muscular e leva à deterioração da atividade motora do organismo e ao aumento do tempo de reação. 


\section{Conclusões}

Com o presente estudo de caso, foi possível perceber a insatisfação e o desconforto dos motoristas de ônibus urbano nas empresas entrevistadas com relação à poltrona que utilizam diariamente em seu trabalho. Como prova da insatisfação, foi levantado que $85,14 \%$ dos entrevistados apresentaram uma ou mais sugestões de melhorias na poltrona; 45,95\% tinham algum tipo de reclamação a fazer; $56,76 \%$ disseram haver alguma dor que acreditavam ser por trabalharem sentados; $77,70 \%$ afirmaram que as poltronas fazem transpirar muito; 52,03\% reclamaram que o ato de sentar/ levantar da poltrona é desconfortável; $61,49 \%$ queixaram-se de que o cinto de segurançaéincômodo ou impede seus movimentos; 59,46\% acreditaram que deveria haver alguma melhoria no cinto de segurança; 64,19\% usam algum tipo de revestimento em cima da poltrona para auxiliar no conforto; $65,54 \%$ gostariam que tais revestimentos já viessem no projeto da poltrona.

Esses números revelam o descontentamento com relação ao produto. Se for considerada a árdua jornada, o estresse do trânsito congestionado, a difícil rotina com os passageiros revoltados com a superlotação, a alta temperatura do ambiente, o ruído altíssimo do motor, vibração etc., tudo isso somado com altas horas sentados em poltronas muitas vezes desconfortáveis, com as regulagens emperradas e muita transpiração, entre outros fatores, o conjunto torna a jornada do condutor uma tarefa difícil.

\section{Sugestões}

Como sugestões de melhoria no posto de trabalho do motorista de ônibus devemos prestar atenção a alguns fatores:

- poltronascommel hores regulagenseacionamentosmaisrápidos, que não emperrem com facilidade, já existentes e usadas normalmente nos ônibus rodoviários (porém, de custo mais elevado);

- revestimentos que permitam uma mel hor ventilação, absorção do suor;

- melhorias no acesso ao posto do motorista, dificultado normalmente pela presença do motor, quando se trata de motor dianteiro;

- existência deapoia-braços eapoia-cabeças nas poltronas. 


\section{Referências bibliográficas}

BRASIL. Ministério do Trabalho e Emprego. Secretaria de Inspeção do Trabalho. Nota Técnica 060/2001. Brasília, 2000.

CONTRAN - Conselho Nacional de Trânsito. Resolução no 14/98. Coordenação do Sistema Nacional de Trânsito. Inciso I, do art.12 , CTB e conforme o Decreto 2.327 da Lei 9.503 Brasília, 23 de setembro de 1998.

GRIECO, A. et al. Criteria for ergonomic evaluation of work chair. In: Work with display unities international scientific conference, 5., 1997, Tóquio. Proceedings... Tóquio: Waseda University, 1997.

HELANDER, M. G., ZHANG, L. Field studies of comfort and discomfort in sitting. Ergonomics, v.40, n.9, p.895-915, 1997.

IIDA, I. Ergonomia: projeto e produção. São Paulo: Edgard Blücher, 1995.

IIDA, I. et al. O valor do produto para os consumidores: mesas pra microcomputadores e cadeiras de digitador. Estudos em design, v.7, n.2, p.77, ago. 1999.

KOMPIER, M. A. J. Bus drivers: occupational stress and stress prevention. Geneva: International Labour Office, 1996. Disponível em: http:// www.itfglobal.org/road-transport/busalert.cfm. Acesso em: 25 de janeiro de 2006.

OCCHIPINTI, D. et al. Criteria for the ergonomic evaluation of work chairs. La Med. del Lavoro, v.84, p.274-85, 1993. Educação Gráfica Edição Especial, 2008, 174.

PANERO, J., ZELNIK, M. Las dimensiones humanas en los espacios interiores: estándares antropométricos. México: Gustavo Gili, 1993.

PARK, S.J. et al. Comfortable driving postures for Koreans. South Korea: International journal of industrial ergonomics, 2000.

PEACOCK, B., KARWOWSHI, W. Automotive ergonomics. Londres: Taylor \& Francis, 1993.

PHEASANT, S. Bodyspace: antropometry, ergonomics and design of the work. Londres: BSI Standards, 1986.

SAPORTA, H. Durable ergonomic seating for urban bus operators. Oregon: OSHA, 2000.

WOODSON, W. E., TILLMAN, B., TILLMAN, P. Human factors design handbook. 2.ed. Nova Iorque: McGraw Hill, 1993.

ZHANG, L. Identifying factors of comfort and discomfort in sitting. Human Factors, v.38, p.337-89, 1996. 


\author{
SOBRE O LIVRO \\ Formato: $14 \times 21 \mathrm{~cm}$ \\ Mancha: 23,7 x 42,5 paicas \\ Tipologia: Horley Old Style 10,5/14 \\ $1^{a}$ edição: 2009 \\ EQUIPE DE REALIZAÇÃO \\ Coordenação Geral \\ Marcos Keith Takahashi
}


CULTURA

ACADÊMICA 